\title{
Shift Verification and Validation
}

Tara Pandya, ORNL

Tom Evans, ORNL

Greg Davidson, ORNL

Seth Johnson, ORNL

Andrew Godfrey, ORNL

September 7,2016
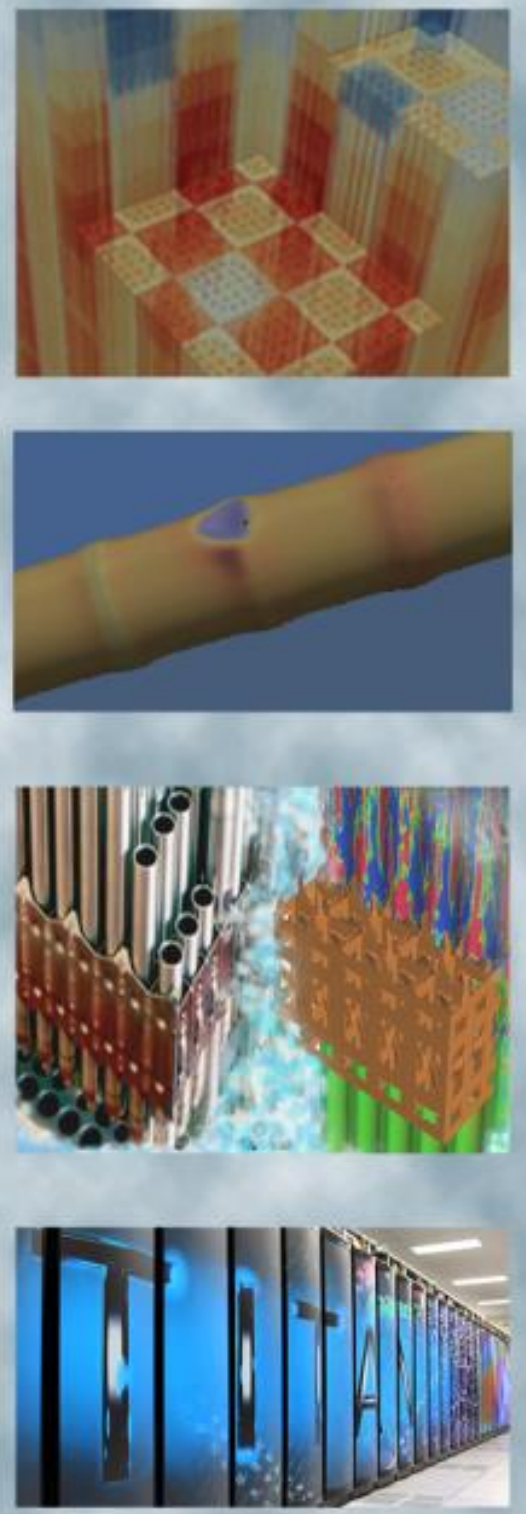

Approved for Public Release

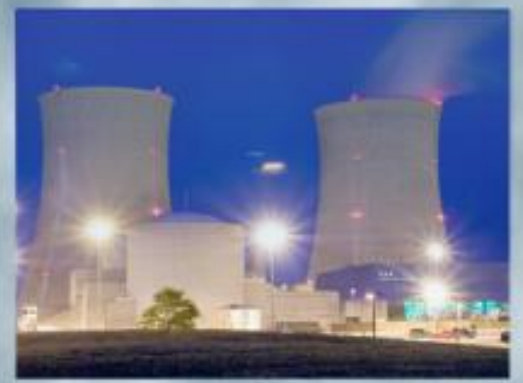




\section{DOCUMENT AVAILABILITY}

Reports produced after January 1, 1996, are generally available free via US Department of Energy (DOE) SciTech Connect.

Website http://www.osti.gov/scitech/

Reports produced before January 1, 1996, may be purchased by members of the public from the following source:

National Technical Information Service

5285 Port Royal Road

Springfield, VA 22161

Telephone 703-605-6000 (1-800-553-6847)

TDD 703-487-4639

Fax 703-605-6900

E-mail info@ntis.gov

Website http://www.ntis.gov/help/ordermethods.aspx

Reports are available to DOE employees, DOE contractors, Energy Technology Data Exchange representatives, and International Nuclear Information Sy stem representatives from the following source:

Office of Scientific and Technical Information

PO Box 62

Oak Ridge, TN 37831

Telephone 865-576-8401

Fax 865-576-5728

E-mail reports@ osti.gov

Website http://www.osti.gov/contact.html

This report was prepared as an account of work sponsored by an
agency of the United States Government. Neither the United States
Government nor any agency thereof, nor any of their employees,
makes anywarranty, express or implied, or assumes anylegal liability
or responsibility for the accuracy, completeness, or us efulness of any
information, apparatus, product, or process disclosed, or represents
that its use would not infringe privately owned rights. Reference herein
to any specific commercial product, process, or service by trade name,
trademark, manufacturer, or otherwise, does not necessarily constitu te
or imply its endorsement, recommendation, or favoring by the United
States Government or any agency thereof. The views and opinions of
authors expressed herein do not necessarily state or reflect those of
the United States Government or any agency thereof.




\section{REVISION LOG}

\begin{tabular}{|c|c|c|c|}
\hline Revision & Date & Affected Pages & \multicolumn{1}{c|}{ Revision Description } \\
\hline 0 & $10 / 21 / 2016$ & All & Initial Public Release - Unlimited \\
\hline & & & \\
\hline & & & \\
\hline & & & \\
\hline
\end{tabular}

\section{Document pages that are:}

Export Controlled ___ None

IP/Proprietary/NDA Controlled____None

Sensitive Controlled____ None

\section{Requested Distribution:}

To:

Copy: 


\section{EXECUTIVE SUMMARY}

This documentation outlines the verification and validation of Shift for the Consortium for Advanced Simulation of Light Water Reactors (CASL). Five main types of problems were used for validation: small criticality benchmark problems; full-core reactor benchmarks for light water reactors; fixed source coupled neutron-photon dosimetry benchmarks; depletion/burnup benchmarks; and full-core reactor performance benchmarks. We compared Shift results to measured data and other simulated Monte Carlo radiation transport code results and found very good agreement in a variety of comparison measures. These include prediction of critical eigenvalue, radial and axial pin power distributions, rod worth, leakage spectra, and nuclide inventories over a burn cycle. Based on this validation of Shift, we are confident in Shift to provide reference results for CASL benchmarking. 


\section{CONTENTS}

EXECUTIVE SUMMARY $\ldots \ldots \ldots \ldots \ldots \ldots \ldots \ldots \ldots \ldots \ldots$

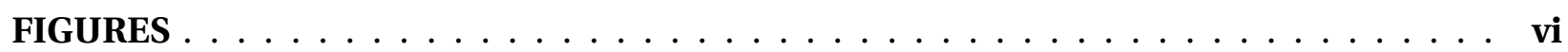

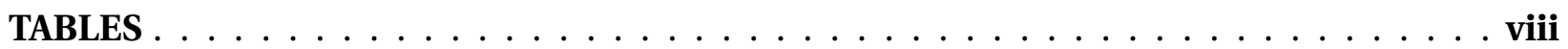

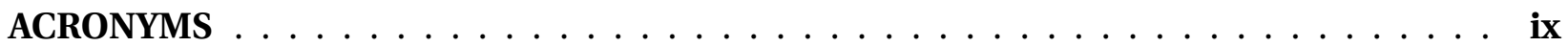

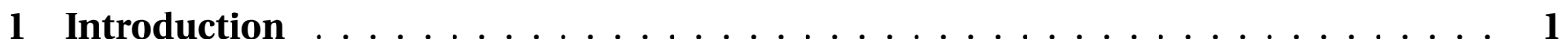

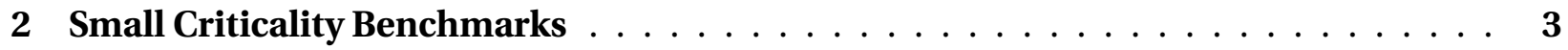

2.1 Babcock and Wilcox 1484 (BW1484) $\ldots \ldots \ldots \ldots \ldots \ldots$

2.2 Babcock and Wilcox 1810 (BW1810) $\ldots \ldots \ldots \ldots \ldots \ldots$

2.3 VENUS Critical Facility Benchmarks . . . . . . . . . . . . . . . . . 14

2.4 International Criticality Safety Benchmark Evaluation Project (ICSBEP) . . . . . 14

2.5 Benchmark on Deterministic Transport Calculations Without Spatial Homogenization $(\mathrm{C} 5 \mathrm{G} 7) \ldots \ldots \ldots \ldots \ldots \ldots$

3 Full-Core Light Water Reactor (LWR) Benchmarks $\ldots \ldots \ldots \ldots$

3.1 Westinghouse AP1000 ${ }^{\circledR}$ PWR First Core . . . . . . . . . . . . . . . 20

3.2 Watts Bar Unit 1 Initial Startup . . . . . . . . . . . . . . . . . . . . . 23

3.3 Benchmark for Evaluation and Validation of Reactor Simulations (BEAVRS) . . . . 33

3.4 KRŠKO Nuclear Power Plant . . . . . . . . . . . . . . . . . . . . 33

3.5 Surry Nuclear Power Plant: Westinghouse 3-loop PWR . . . . . . . . . . . . 33

3.6 Pincells from LWR Benchmarks . . . . . . . . . . . . . . . . . . . 34

4 Fixed Source Benchmarks $\ldots \ldots \ldots \ldots \ldots \ldots \ldots$

4.1 Leakage Spectrum Tests . . . . . . . . . . . . . . . . . . . 38

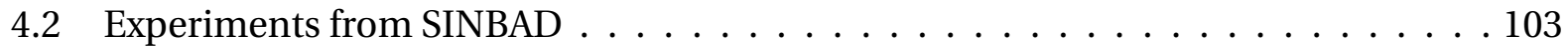

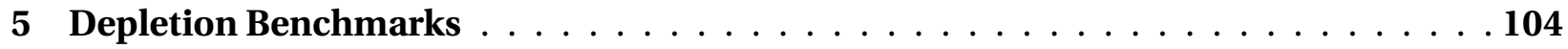

5.1 CASL Depletion Verification Test Suite . . . . . . . . . . . . . . . . . . . 104

5.2 OECD Takahama-3 $17 \times 17$ PWR Post-Irradiation Experiment (PIE) . . . . . . . . 104

5.3 ORNL High Flux Isotope Reactor (HFIR) Cycle $400 \ldots \ldots 7$

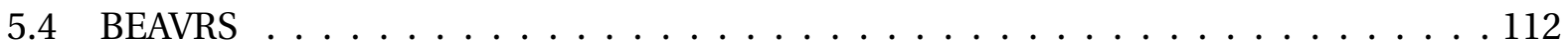

5.5 Watts Bar Unit 1 Cycle $1 \ldots \ldots \ldots \ldots$. . . . . . . . . . . . . . . . . . . . . . . . . . . . . . . . .

5.6 Westinghouse AP1000 ${ }^{\circledR}$ First Core at Hot Full Power . . . . . . . . . . . . . . . 112

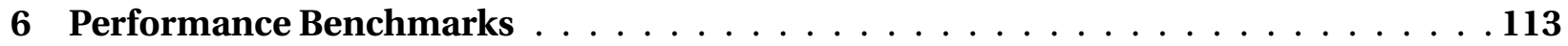

6.1 NEA MC Full-Core Reactor Power Density Performance Benchmark . . . . . . . 113

6.2 Westinghouse AP1000 ${ }^{\circledR}$ PWR Startup . . . . . . . . . . . . . . . . . 113

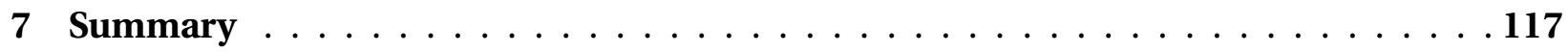




\section{FIGURES}

1 Reactivity for BW1484 cores using a $145 \mathrm{~cm}$ moderator height. . . . . . . . . . . . 4

2 Reactivity for BW1484 cores using critical moderator heights. . . . . . . . . . . . 4

3 Reactivity for BW1484 cores using supercritical moderator heights. . . . . . . . . 5

4 Reactivity calculated by Shift for BW1810 cores. . . . . . . . . . . . . . . . . . 7

5 Relative difference between Shift and benchmark in midplane pin powers for quarter assembly of BW1810 core I. . . . . . . . . . . . . . . . . 8

6 Relative difference between Shift and benchmark in midplane pin powers for quarter assembly of BW1810 core V. . . . . . . . . . . . . . . . 9

$7 \quad$ Relative difference in midplane pin powers for quarter assembly of BW1810 core XII between Shift and benchmark. . . . . . . . . . . . . . . . . . 10

8 Relative difference between Shift and benchmark in midplane pin powers for quarter assembly of BW1810 core XIV. . . . . . . . . . . . . . . . . . 11

$9 \quad$ Relative difference between Shift and benchmark in midplane pin powers for quarter assembly of BW1810 core XVIII. . . . . . . . . . . . . . . . 12

Relative difference between Shift and benchmark in midplane pin powers for quarter assembly of BW1810 core XX . . . . . . . . . . . . . . . . . 13

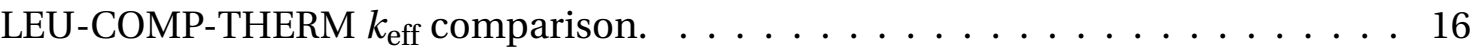

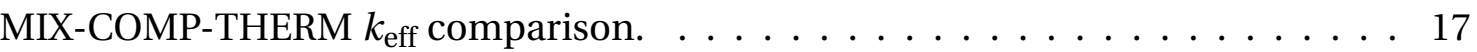

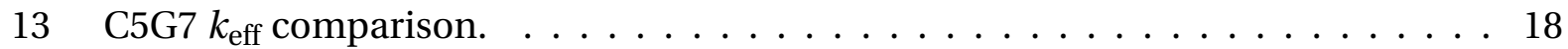

14 Rod bank locations in AP1000 ${ }^{\circledR}$ (image produced from Shift run) . . . . . . . . . . 21

15 Eigenvalues for critical configurations of WBN1 ZPPT. . . . . . . . . . . . . . 24

16 WBN1 RCCA bank worths relative error for WBN1 ZPPT. . . . . . . . . . . . 26

17 WBN1 Bank D integral rod worth comparison. . . . . . . . . . . . . . 27

18 WBN1 Bank D differential rod worth comparison. . . . . . . . . . . . . . 28

19 WBN1 axial power distribution comparison. . . . . . . . . . . . . . 29

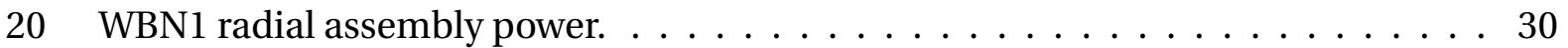

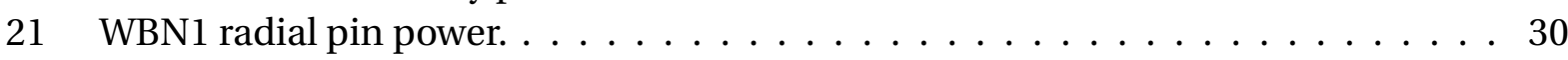

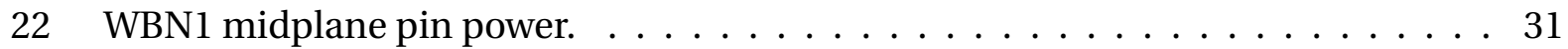

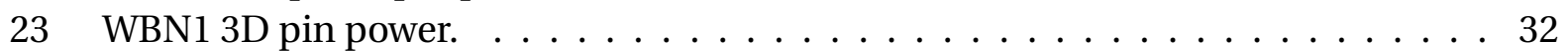

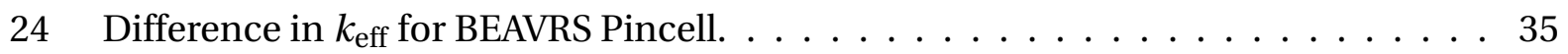

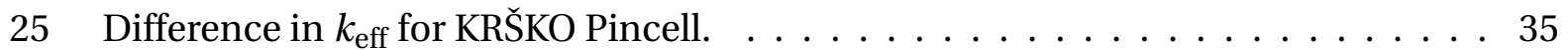

26 Difference in $k_{\text {eff for PWR21 Pincell. } \ldots \ldots \ldots \ldots \ldots} \ldots \ldots \ldots \ldots \ldots$

27 Difference in $k_{\text {eff for PWR31 Pincell. } \ldots \ldots \ldots \ldots \ldots \ldots} \ldots \ldots \ldots \ldots \ldots \ldots$

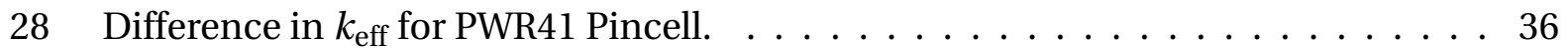

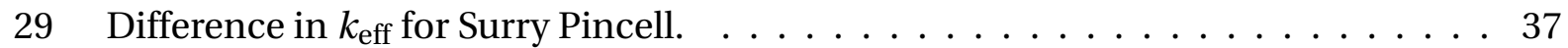

30 Calculated leakage using CE physics from ${ }^{107} \mathrm{Ag}$ spherical shell. . . . . . . . . . . 40

31 Calculated leakage using $\mathrm{MG}$ physics from ${ }^{107} \mathrm{Ag}$ spherical shell. . . . . . . . . . . 42

32 Calculated leakage using CE physics from ${ }^{27} \mathrm{Al}$ spherical shell. . . . . . . . . . . . . 44

33 Calculated leakage using MG physics from ${ }^{27} \mathrm{Al}$ spherical shell. . . . . . . . . . . 46

34 Calculated leakage using CE physics from ${ }^{10} \mathrm{~B}$ spherical shell. . . . . . . . . . . . 48

35 Calculated leakage using MG physics from ${ }^{10} \mathrm{~B}$ spherical shell. . . . . . . . . . . . . 50

36 Calculated leakage using CE physics from Carbon spherical shell. . . . . . . . . . . 52

37 Calculated leakage using MG physics from Carbon spherical shell. . . . . . . . . . 54 
38 Calculated leakage using CE physics from ${ }^{50} \mathrm{Cr}$ spherical shell. . . . . . . . . . . 56

39 Calculated leakage using MG physics from ${ }^{50} \mathrm{Cr}$ spherical shell. . . . . . . . . . . . 58

40 Calculated leakage using CE physics from ${ }^{53} \mathrm{Cr}$ spherical shell. . . . . . . . . . . 60

41 Calculated leakage using MG physics from ${ }^{53} \mathrm{Cr}$ spherical shell. . . . . . . . . . . 62

42 Calculated leakage using CE physics from ${ }^{56} \mathrm{Fe}$ spherical shell. . . . . . . . . . . . . 64

43 Calculated leakage using MG physics from ${ }^{56} \mathrm{Fe}$ spherical shell. . . . . . . . . . . 66

44 Calculated leakage using CE physics from ${ }^{155} \mathrm{Gd}$ spherical shell. . . . . . . . . . . 68

45 Calculated leakage using MG physics from ${ }^{155} \mathrm{Gd}$ spherical shell. . . . . . . . . . 70

46 Calculated leakage using CE physics from ${ }^{157} \mathrm{Gd}$ spherical shell. . . . . . . . . . 72

47 Calculated leakage using MG physics from ${ }^{157} \mathrm{Gd}$ spherical shell. . . . . . . . . . 74

48 Calculated leakage using CE physics from ${ }^{176} \mathrm{Hf}$ spherical shell. . . . . . . . . . . . 76

49 Calculated leakage using MG physics from ${ }^{176} \mathrm{Hf}$ spherical shell. . . . . . . . . . 78

50 Calculated leakage using CE physics from ${ }^{62} \mathrm{Ni}$ spherical shell. . . . . . . . . . . 80

51 Calculated leakage using MG physics from ${ }^{62} \mathrm{Ni}$ spherical shell. . . . . . . . . . . . 82

52 Calculated leakage using CE physics from ${ }^{235} \mathrm{U}$ spherical shell. . . . . . . . . . . . 84

53 Calculated leakage using MG physics from ${ }^{235} \mathrm{U}$ spherical shell. . . . . . . . . . . 86

54 Calculated leakage using CE physics from ${ }^{236} \mathrm{U}$ spherical shell. . . . . . . . . . . 88

55 Calculated leakage using MG physics from ${ }^{236} \mathrm{U}$ spherical shell. . . . . . . . . . . . 90

56 Calculated leakage using CE physics from ${ }^{238} \mathrm{U}$ spherical shell. . . . . . . . . . . . 92

57 Calculated leakage using MG physics from ${ }^{238} \mathrm{U}$ spherical shell. . . . . . . . . . . . 94

58 Calculated leakage using CE physics from ${ }^{91} \mathrm{Zr}$ spherical shell. . . . . . . . . . . . 96

59 Calculated leakage using MG physics from ${ }^{91} \mathrm{Zr}$ spherical shell. . . . . . . . . . . 98

60 Calculated leakage using CE physics from ${ }^{96} \mathrm{Zr}$ spherical shell. . . . . . . . . . . . 100

61 Calculated leakage using MG physics from ${ }^{96} \mathrm{Zr}$ spherical shell. . . . . . . . . . . 102

62 Takahama-3 PIE $k_{\text {eff }}$ comparison. . . . . . . . . . . . . . . . . . . . 105

63 Takahama-3 PIE relative percent difference in lattice-averaged atom density for select actinides. . . . . . . . . . . . . . . . . . . . . . . . 106

64 Takahama-3 PIE uranium depletion comparison. . . . . . . . . . . . . . . 106

65 Takahama-3 PIE relative percent difference in lattice-averaged atom density for select fission products. . . . . . . . . . . . . . . . . . . . . 107

66 Homogenized HFIR cycle $400 k_{\text {eff }}$ comparison. . . . . . . . . . . . . . . . 108

67 Homogenized HFIR cycle 400 actinide mass comparison. . . . . . . . . . . . . 108

68 Homogenized HFIR cycle 400 fission product mass comparison. . . . . . . . . . 109

69 Homogenized HFIR cycle $400{ }^{149} \mathrm{Sm}$ mass comparison. . . . . . . . . . . . . . . . 109

70 Detailed HFIR cycle $400 k_{\text {eff }}$ comparison. . . . . . . . . . . . . . . . . 110

71 Detailed HFIR cycle 400 actinide mass comparison. . . . . . . . . . . . . . 110

72 Detailed HFIR cycle 400 fission product mass comparison. . . . . . . . . . . . . 111

73 Detailed HFIR cycle $400{ }^{149} \mathrm{Sm}$ mass comparison. . . . . . . . . . . . . . . . 111

74 Shift strong scaling results for the NEA MC performance benchmark for reactor calculations run on Titan. . . . . . . . . . . . . . . . . . . . . 115

75 Shift strong scaling results for AP1000 ${ }^{\circledR}$ problem 1 run on Titan. . . . . . . . . . 116 


\section{TABLES}

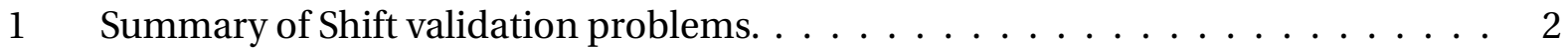

2 VALID Cases Pertaining to CASL. . . . . . . . . . . . . . . . . 14

$3 \quad$ C5G7 pin power comparisons. The numbers in parenthesis represent the relative error compared to the benchmark value. . . . . . . . . . . . . . . . . 19

4 Shift eigenvalue and benchmark comparison results for different assemblies in

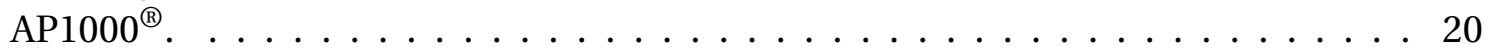

$5 \quad \mathrm{AP} 1000^{\circledR}$ eigenvalue and overall pin powers, $\triangle \mathrm{P}$, comparison to KENO-VI. . . . . . 21

6 Rod bank worth calculated using Shift compared to the benchmark for AP1000 ${ }^{\circledR}$. 22

7 Shift eigenvalue and benchmark comparison results for different assemblies in WBN1. Bank positions are shown in steps withdrawn. . . . . . . . . . . . . 25

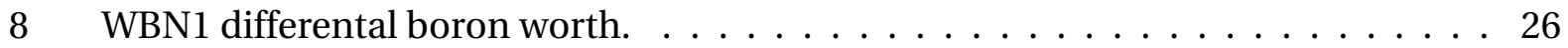

9 KRŠKO ZPPT boron endpoint criticality comparison. . . . . . . . . . . 33

10 KRŠKO ZPPT control bank reactivity worth comparison. . . . . . . . . . . . . 34

11 Takahama-3 PIE burnup lengths and number of depletion steps per burnup length.105 


\section{ACRONYMS}

$\begin{array}{ll}\text { ARO } & \text { all rods out } \\ \text { BEAVRS } & \text { Benchmark for Evaluation and Validation of Reactor Simulations } \\ \text { BOC } & \text { beginning-of-cycle } \\ \text { CASL } & \text { Consortium for Advanced Simulation of Light Water Reactors } \\ \text { CE } & \text { continuous energy } \\ \text { DBW } & \text { differential boron worth } \\ \text { HFIR } & \text { High Flux Isotope Reactor } \\ \text { HFP } & \text { hot full power } \\ \text { HPC } & \text { high performance computing } \\ \text { HZP } & \text { hot zero power } \\ \text { ICSBEP } & \text { International Criticality Safety Benchmark Experiments Project } \\ \text { LE/QI } & \text { Linear Extrapolation / Quadratic Interpolation } \\ \text { LWR } & \text { light water reactor } \\ \text { MG } & \text { multigroup } \\ \text { MOX } & \text { mixed oxide fuel } \\ \text { NEA } & \text { Nuclear Energy Agency } \\ \text { NPP } & \text { Nuclear Power Plant } \\ \text { OECD } & \text { Organisation for Economic Co-operation and Development } \\ \text { OLCF } & \text { Oak Ridge Leadership Computing Facility } \\ \text { ORNL } & \text { Oak Ridge National Laboratory } \\ \text { PCM } & \text { percent mille } \\ \text { PIE } & \text { Post-Irradiation Experiment } \\ \text { PPM } & \text { parts per million } \\ \text { PWR } & \text { pressurized water reactor } \\ \text { RCCA } & \text { rod cluster control assembly } \\ \text { RMS } & \text { root mean square } \\ \text { SCALE } & \text { Standardized Computer Analyses for Licensing Evaluation } \\ \text { SINBAD } & \text { Shielding INtegral Benchmark Archive Database } \\ \text { VALID } & \text { Verified, Archived Library of Inputs and Data } \\ \text { ZPPT } & \text { Zero Power Physics Tests } \\ & \end{array}$




\section{INTRODUCTION}

Validation of the Shift parallel Monte Carlo radiation transport code, developed at Oak Ridge National Laboratory (ORNL), has been ongoing for several years [1], [2]. The previously published Shift validation plan laid out the groundwork for the benchmarks and problems we used in this report [3]. This report gives the summary of Shift validation efforts using these problems by comparing Shift results against measured and simulated results.

Table 1 shows the details of the validation problems included in this report. In this table we present what results we compare from Shift and to what we compare these results to for each problem. We also state which frontend was used to run Shift. The two frontends used were VERA [4] and Omnibus. Both of these frontends run Shift under-the-hood but VERA is designed for reactor problems and Omnibus is a more general high-performance computing frontend.

The details of these validation and verification problems are given in the following sections: section 2 details the various small critical experiments and benchmarks; section 3 gives the verification and validation results for lattice, full core, and reactor pincell problems; section 4 presents the preliminary Shift verification and validation for small fixed source coupled neutron and photon problems and benchmarks; section 5 gives the preliminary validation of the Shift depletion capabilities as applied to an array of reactor problems; section 6 gives some parallel performance results applied to a benchmark full core reactor problem and a startup full core problem; finally, section 7 gives a summary of this verification and validation effort. 


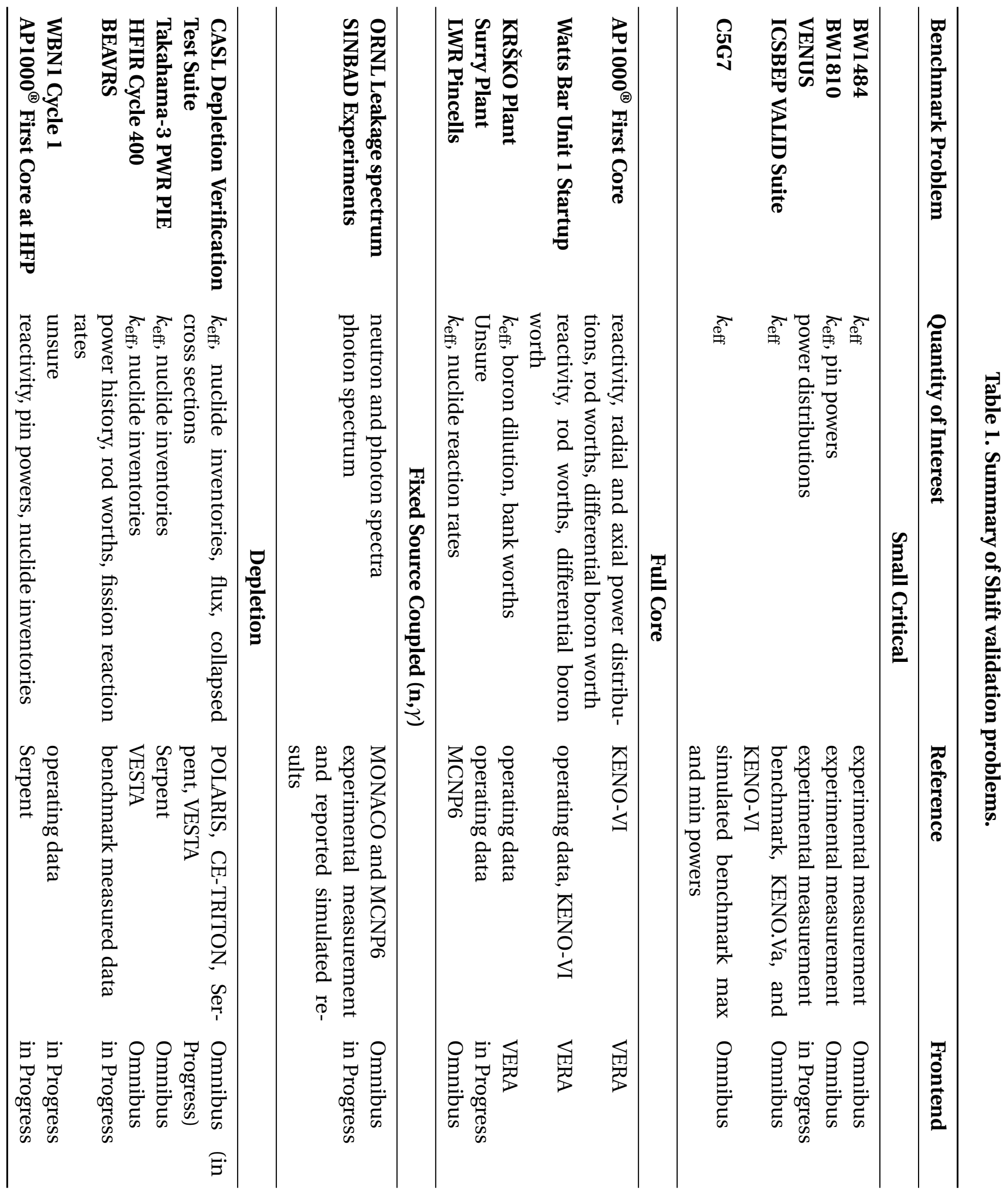




\section{SMALL CRITICALITY BENCHMARKS}

Section 2 presents the results of Shift validation using small critical benchmarks.

\subsection{BABCOCK AND WILCOX 1484 (BW1484)}

In this first section, we compare the $k_{\text {eff }}$ values calculated by Shift to the benchmark results for cores I-IX from the BW1484 experiments [5]. Full specifications for each of these cores are given in the benchmark report. Shift used ENDF B/VII.1 CE data processed using the SCALE AMPX module. For all of the cores simulated, Shift ran $1 \times 10^{6}$ particle histories per generation for 1250 generations with 250 inactive generations to ensure fission source convergence. We ensured fission source convergence in Shift by checking that the shannon entropy tally passed its statistical checks before beginning the active generations.

Three groups of core configurations were run for this validation based on the benchmark. Figure 1 shows the reactivities calculated by Shift and the experimental measurements with a fixed moderator height of $145 \mathrm{~cm}$ for cores I-IX. Reactivity was calculated according to Equation 1.

$$
\rho=\frac{(k-1) 10^{5}}{k}
$$

Figure 2 shows the reactivities calculated by Shift and the experimental measurements with varying boron concentrations and moderator heights for cores I-IX. Finally, Figure 3 shows the reactivities calculated by Shift and the experimental measurements for the supercritical configurations of cores I-IX.

Limited information in the benchmark description makes modeling these experimental configurations difficult. This includes no information about moderator density and operating pressure for each core configuration. Therefore, we consider a difference of less than $200 \mathrm{pcm}$ for calculated reactivity vs. measured reactivity to be good agreement. Most of the Shift calculated reactivities agree to within $200 \mathrm{pcm}$ of the measured reactivities. We are still investigating the large difference between Shift and the benchmark reactivities for core III and its variants and core IX. 


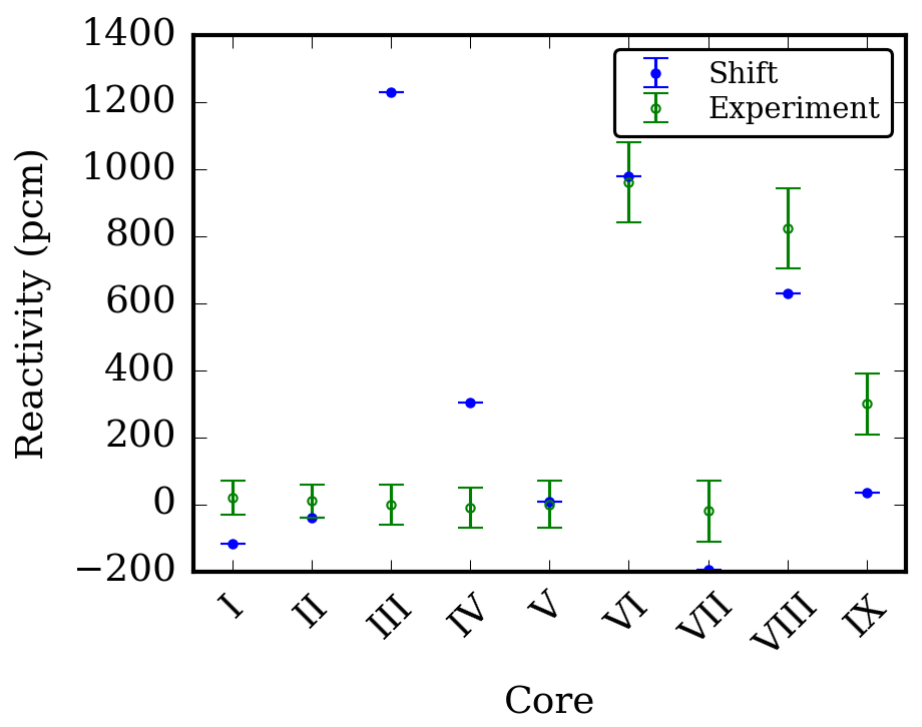

Figure 1. Reactivity for BW1484 cores using a $145 \mathrm{~cm}$ moderator height.

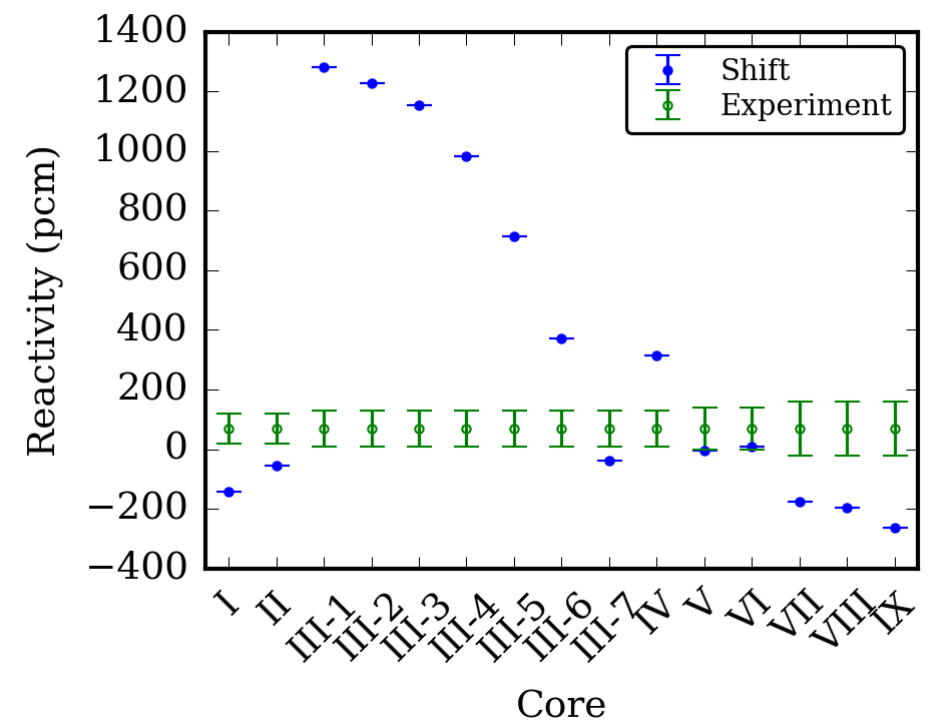

Figure 2. Reactivity for BW1484 cores using critical moderator heights. 


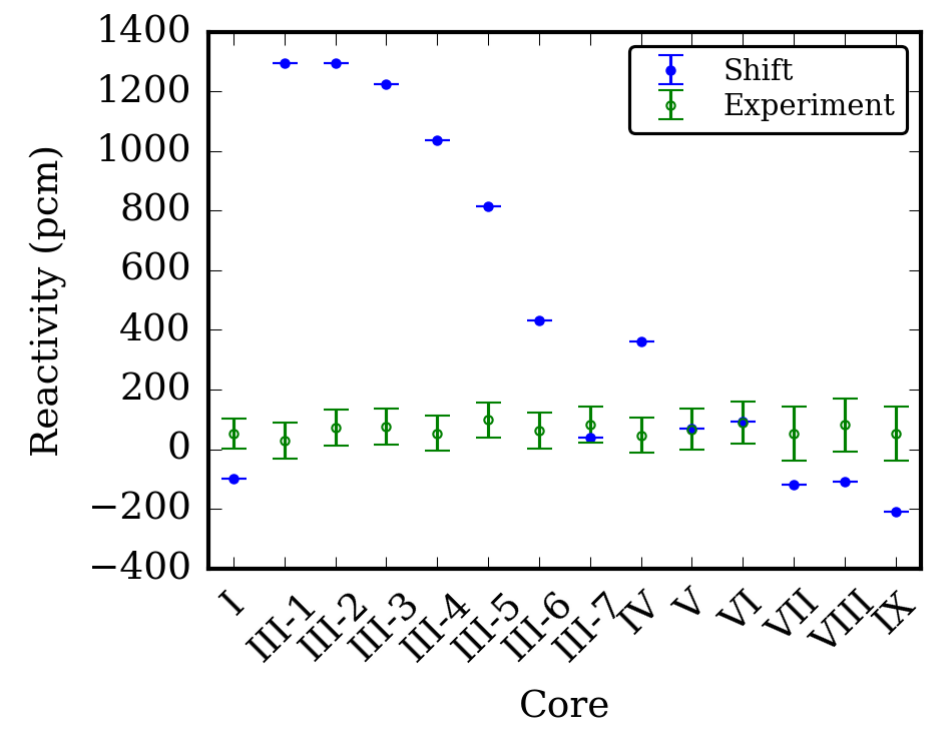

Figure 3. Reactivity for BW1484 cores using supercritical moderator heights. 


\subsection{BABCOCK AND WILCOX 1810 (BW1810)}

In this section we compare $k_{\text {eff }}$ and pin powers calculated by Shift to the benchmark results for cores I-XX, excluding core XI, for the BW1810 experiments [6]. Core XI is not simulated because it was a test core only used for ${ }^{238} \mathrm{U}$ resonance integral measurements. The full specifications for these cores are given in the benchmark report. We did not model the bottom core plate, the center grid plate, or the top grid plate in the Shift models. Shift used ENDF B/VII.1 CE data processed using the SCALE AMPX module. For all of the cores simulated, Shift ran $1 \times 10^{6}$ particle histories per generation for 1250 generations with 250 inactive generations to ensure fission source convergence. Again, we ensured fission source convergence in Shift by checking that the shannon entropy tally passed its statistical checks before beginning the active generations.

The simulated $k_{\text {eff }}$ values from Shift are compared to a $k_{\text {eff }}$ of unity, which is how these experiments were designed and run. Figure 4 shows the reactivity comparison for each simulated core. The reactivity differences over all simulated cores were $-47 \mathrm{pcm}$ (average), $-101 \mathrm{pcm}$ (minimum), and $38 \mathrm{pcm}$ (maximum), which is very good agreement for these critical configurations.

Figures 5-10 show the relative difference in pin powers between Shift and the benchmark for cores I, V, XII, XIV, XVIII, and XX. These pin powers are at the midplane of the center assembly as reported by the benchmark. We defined the relative difference as:

$$
\text { Rel. Diff. } \equiv \frac{\text { Experiment Pin Power }- \text { Shift Pin Power }}{\text { Experiment Pin Power }}
$$

Cells shown in black are either water holes, control rods, or instrument tubes. All of the RMS differences for these cores are below $1 \%$. The large maximum relative error in pin powers for cores $\mathrm{V}, \mathrm{XIV}$, and XX occurs in the pins containing gadolinium. This difference is acceptable based on the uncertainties associated with modeling these cores from the benchmark specifications. Note that the difference in pin powers, aside from these gadolinium pins, is very small, which coincides with the small RMS values because the power in these pins is a small contribution to the total power of the assembly.

From this validation, we have shown that Shift can accurately reproduce experimental data. 


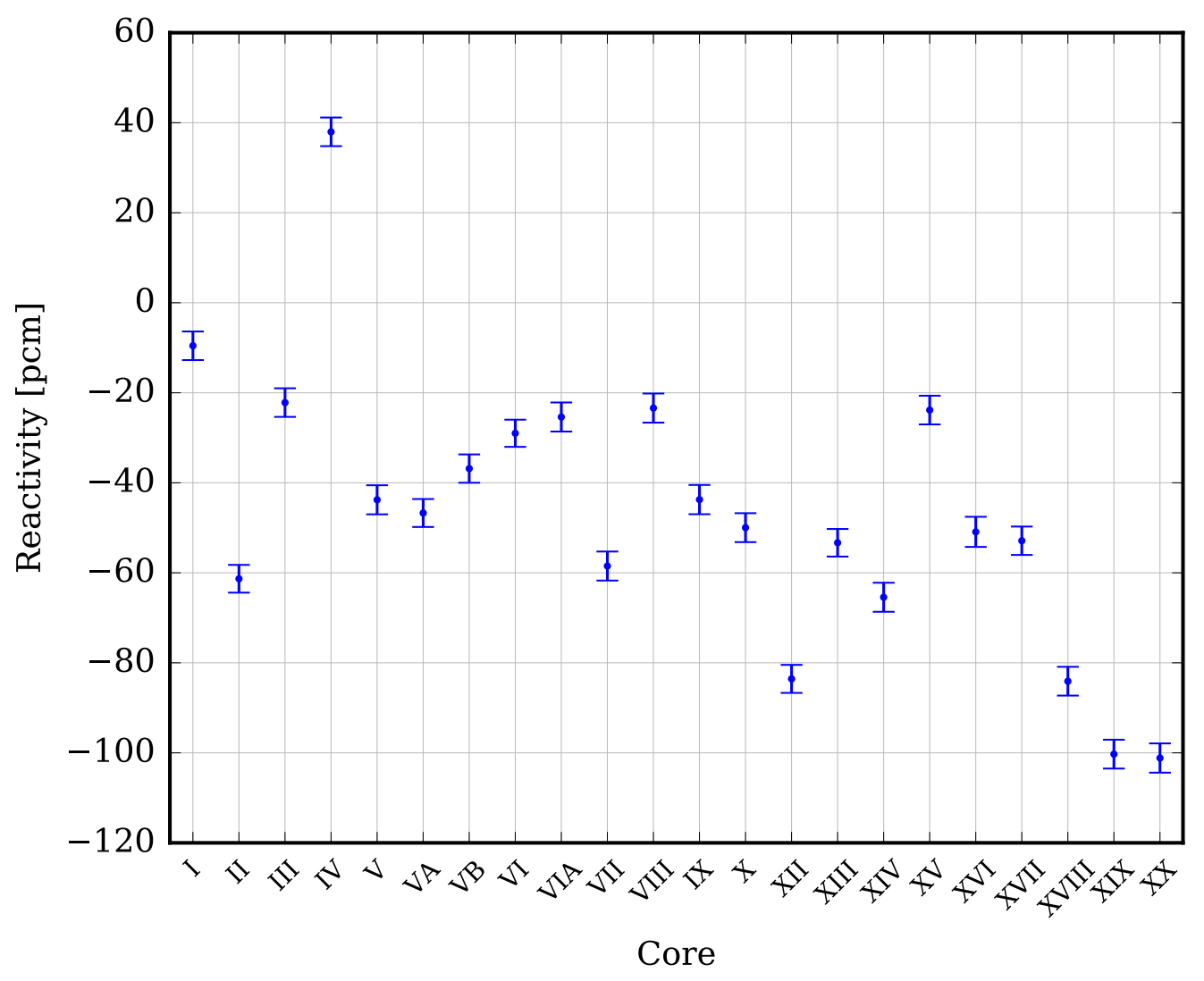

Figure 4. Reactivity calculated by Shift for BW1810 cores. 

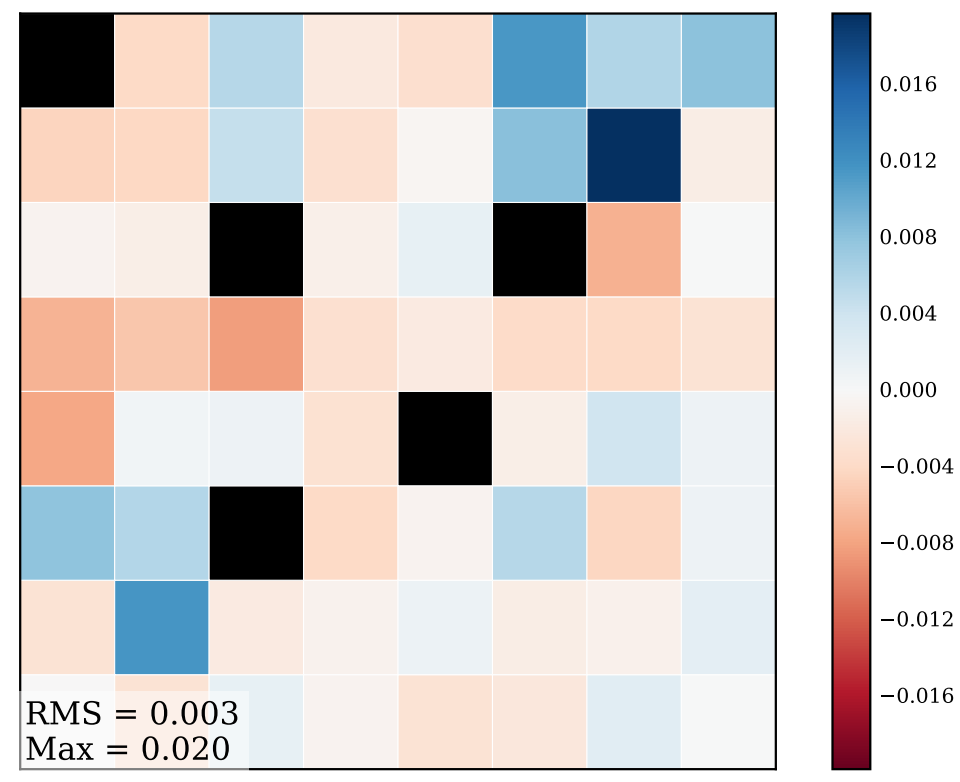

Figure 5. Relative difference between Shift and benchmark in midplane pin powers for quarter assembly of BW1810 core I. 

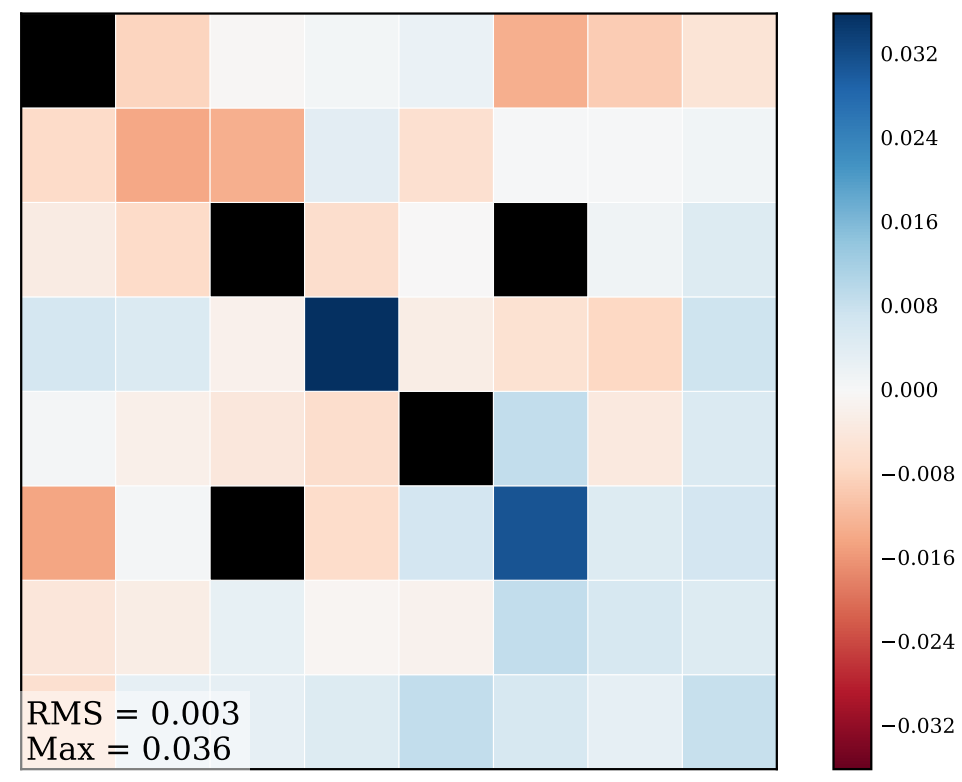

Figure 6. Relative difference between Shift and benchmark in midplane pin powers for quarter assembly of BW1810 core V. 


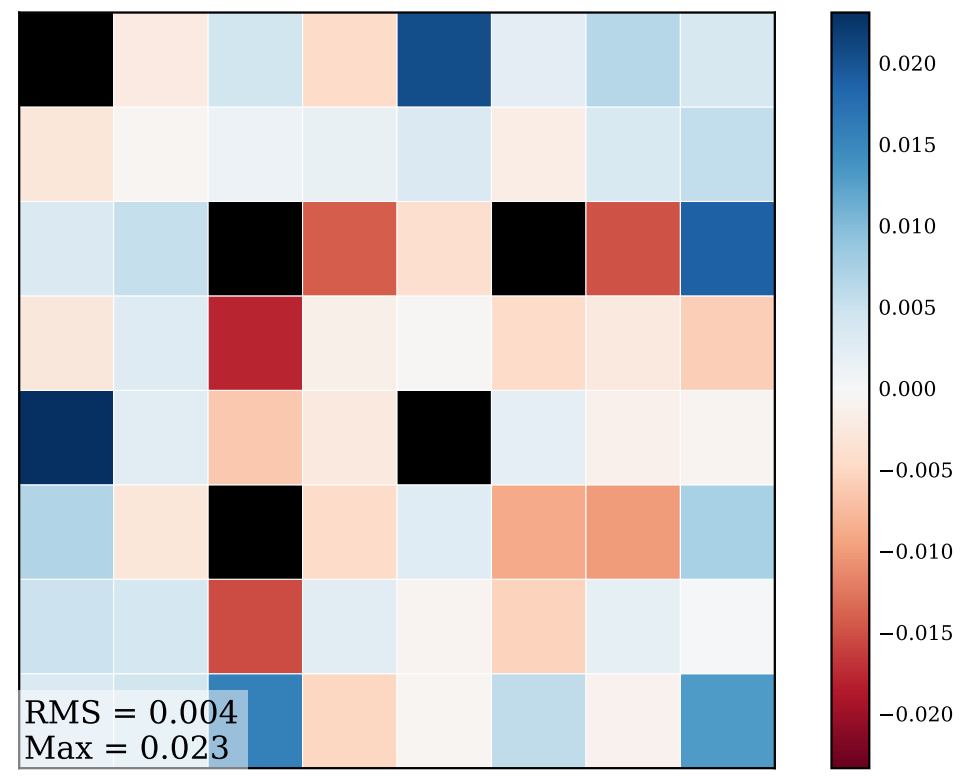

Figure 7. Relative difference in midplane pin powers for quarter assembly of BW1810 core XII between Shift and benchmark. 

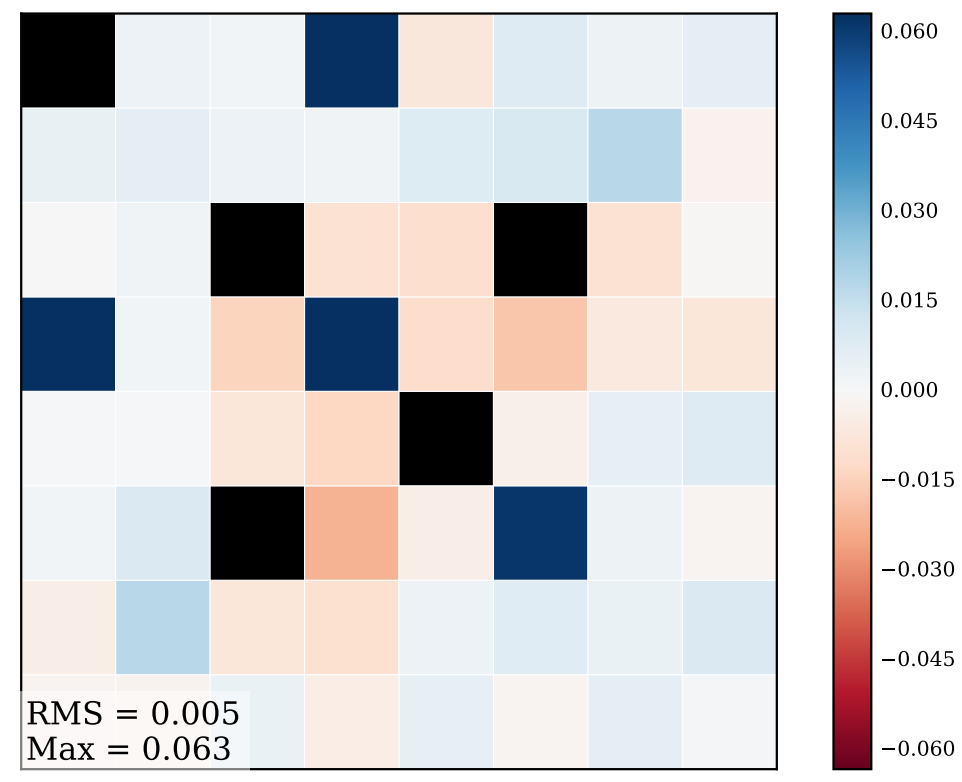

Figure 8. Relative difference between Shift and benchmark in midplane pin powers for quarter assembly of BW1810 core XIV. 

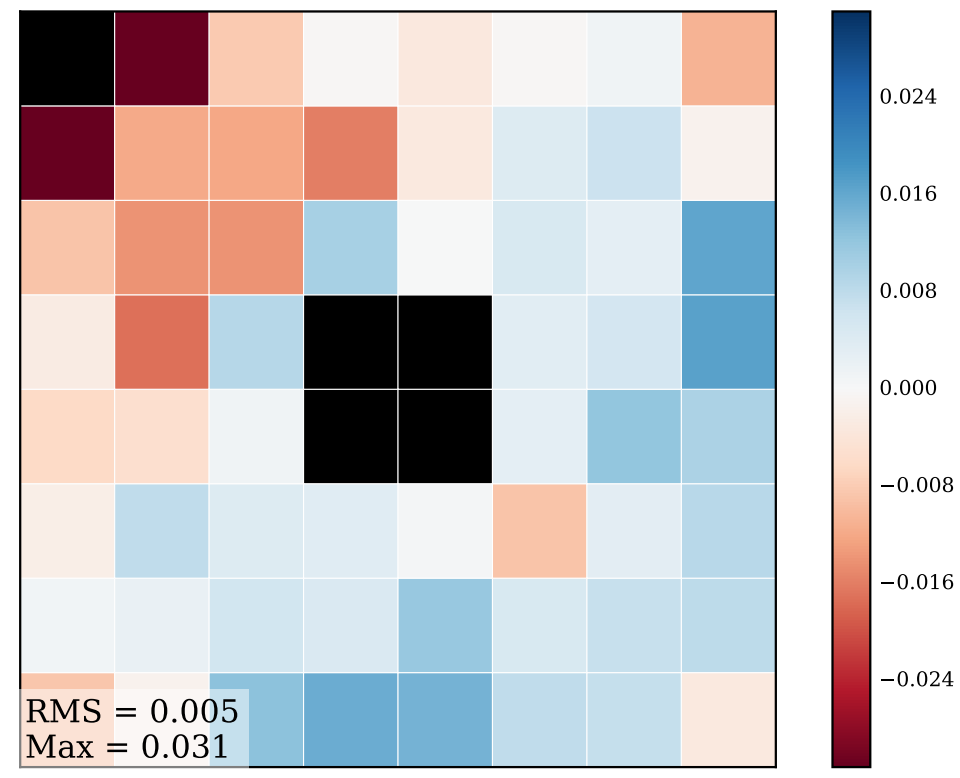

Figure 9. Relative difference between Shift and benchmark in midplane pin powers for quarter assembly of BW1810 core XVIII. 

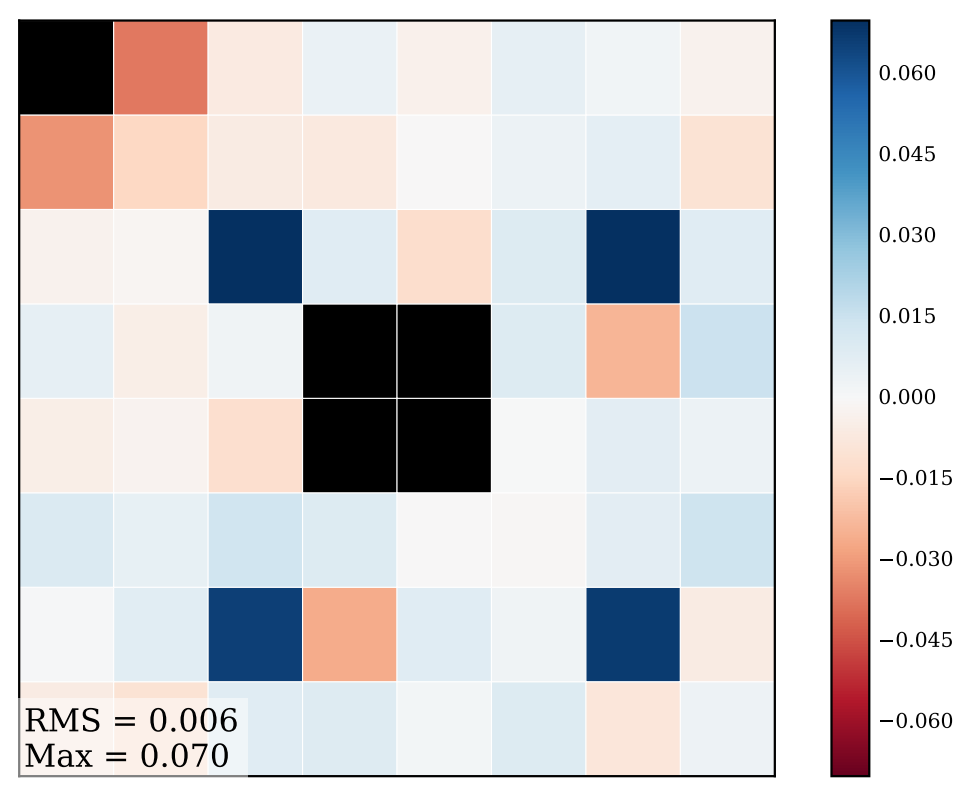

Figure 10. Relative difference between Shift and benchmark in midplane pin powers for quarter assembly of BW1810 core XX. 


\subsection{VENUS CRITICAL FACILITY BENCHMARKS}

Validation of Shift using the VENUS facility experiments is ongoing and will be reported soon.

\subsection{INTERNATIONAL CRITICALITY SAFETY BENCHMARK EVALUATION PROJECT (ICSBEP)}

As stated in the validation plan, a subset of critical benchmarks from the Validated Archived Library of Inputs and Data (VALID) suite at ORNL were run using Shift, and the results for $k_{\text {eff }}$ were compared to KENO and benchmark results [7]. The cases compared are given in Table 2 [8].

Table 2. VALID Cases Pertaining to CASL.

\begin{tabular}{c|c}
\hline Case & Instances \\
\hline LEU-COMP-THERM-001 & 8 \\
LEU-COMP-THERM-002 & 5 \\
LEU-COMP-THERM-010 & 30 \\
LEU-COMP-THERM-017 & 29 \\
LEU-COMP-THERM-042 & 7 \\
LEU-COMP-THERM-050 & 18 \\
MIX-COMP-THERM-001 & 4 \\
MIX-COMP-THERM-002 & 6 \\
MIX-COMP-THERM-004 & 11 \\
\hline
\end{tabular}

Each VALID case was run through Shift and KENO with the SCALE 252-group AMPX library and the SCALE CE library, both based on ENDF B/VII.1 data. In the following figures, MG (multigroup) and CE refer to the library used, K5 and K6 refer to KENO.Va and KENO-VI input specifications, and Experimental refers to the benchmark results. The number of case instances per figure was limited to allow for ease of presentation. Error bars shown for each point are plotted with 2 standard deviations. The error bars for Shift and KENO appear very small due to the tight convergence of these runs. Also note that some of these error bars span more than $2 \%$, which is due to the experimental measurement uncertainty.

Figure 11 shows the comparison of Shift calculated $k_{\text {eff }}$ to KENO and the benchmark for the LEU-COMP-THERM cases. All of these cases show very good agreement between these two codes and the benchmark. Figure 12 shows very good agreement in calculated $k_{\text {eff }}$ by Shift for the MIX-COMP-THERM cases to the KENO $k_{\text {eff }}$ and benchmark.

Overall, we have shown that the Shift calculation of the criticality of a system agrees very well with another Monte Carlo code and the experimental results for this set of ICSBEP benchmark problems. 


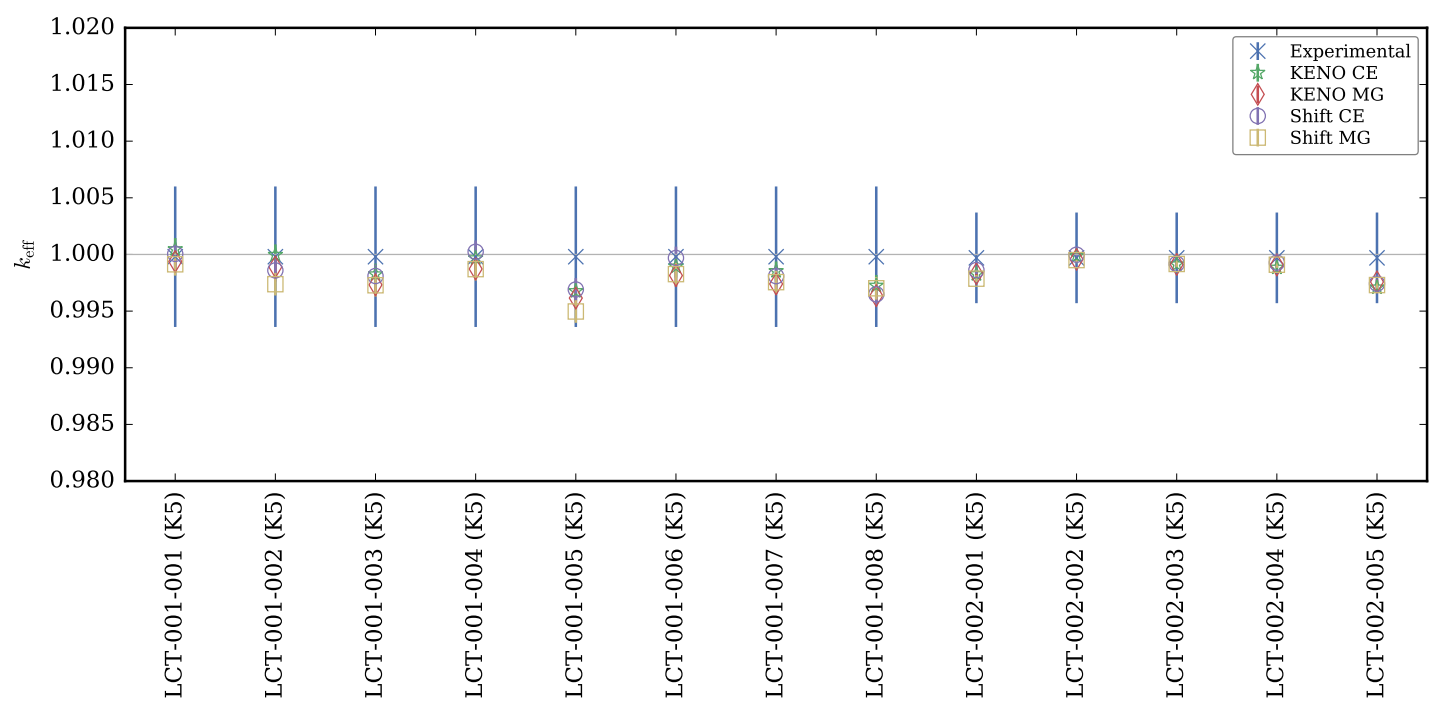

(a)

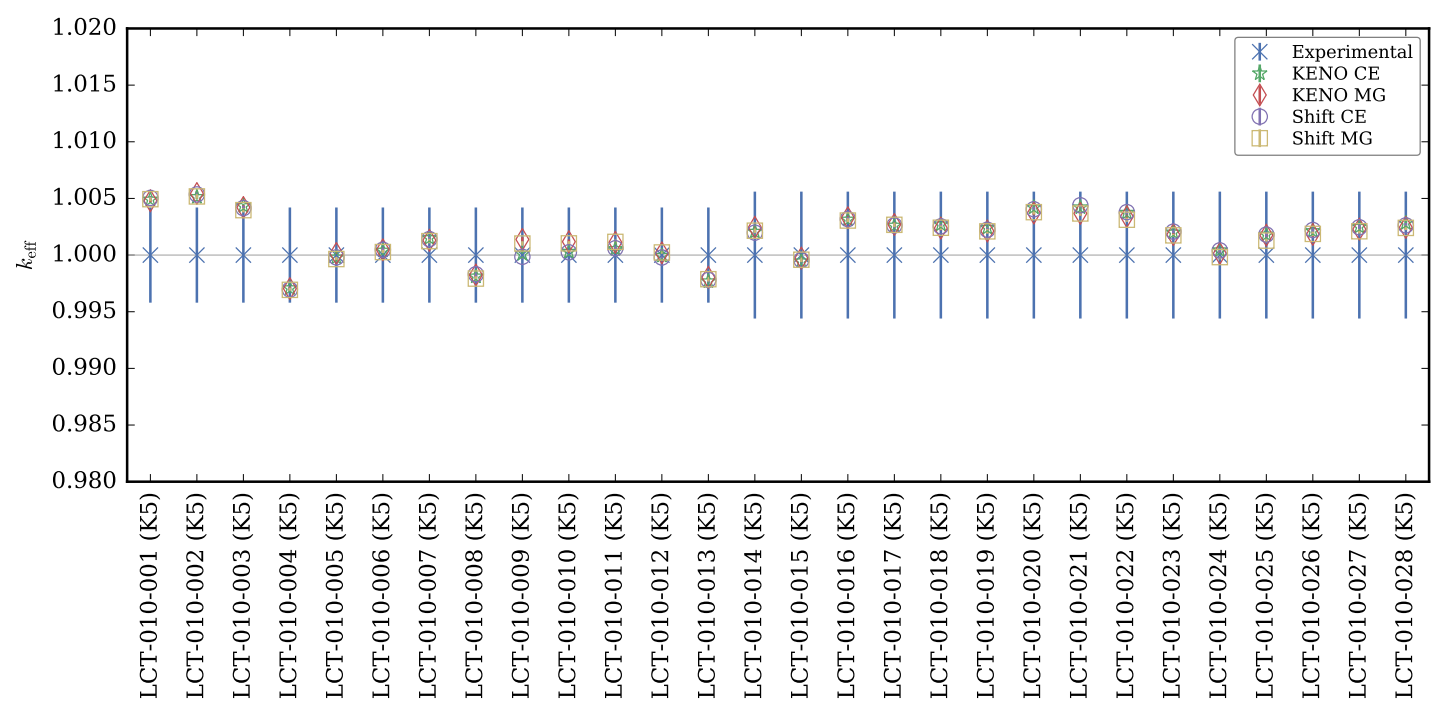

(b) 


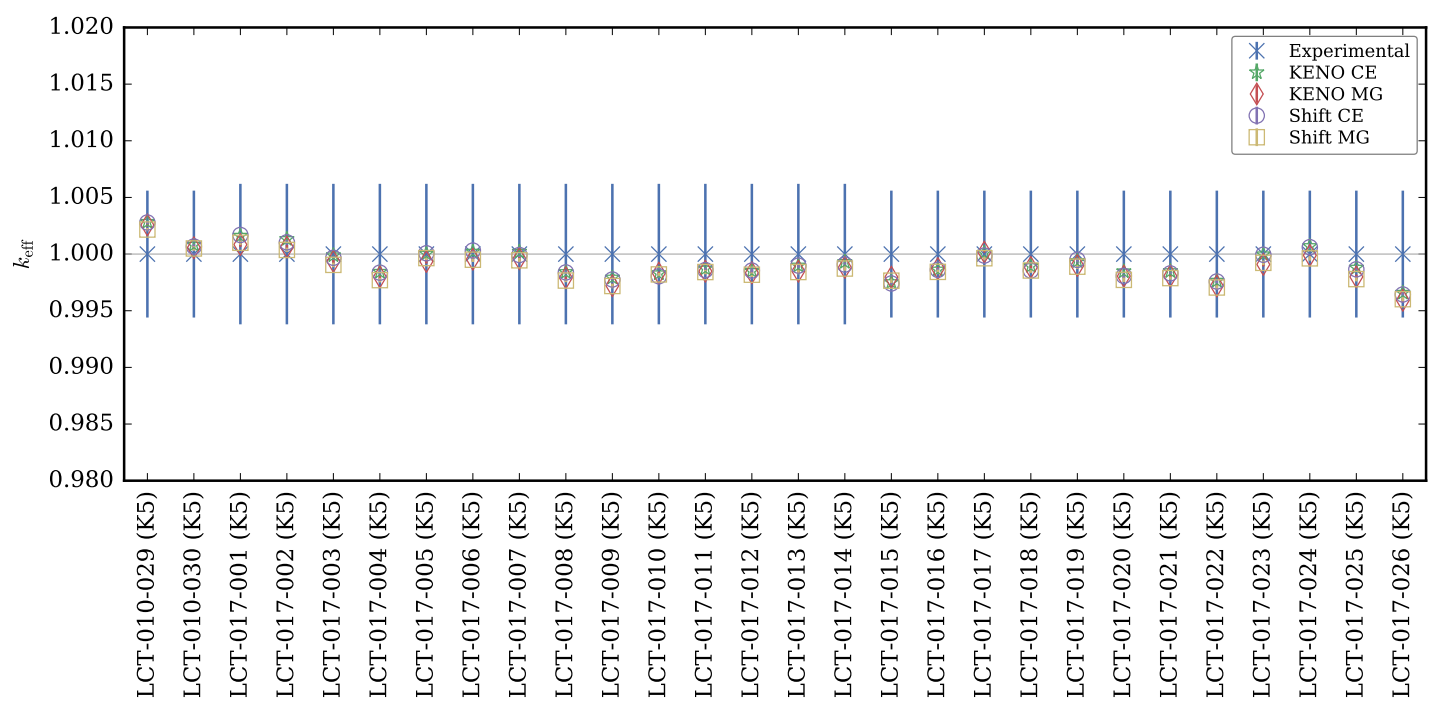

(c)

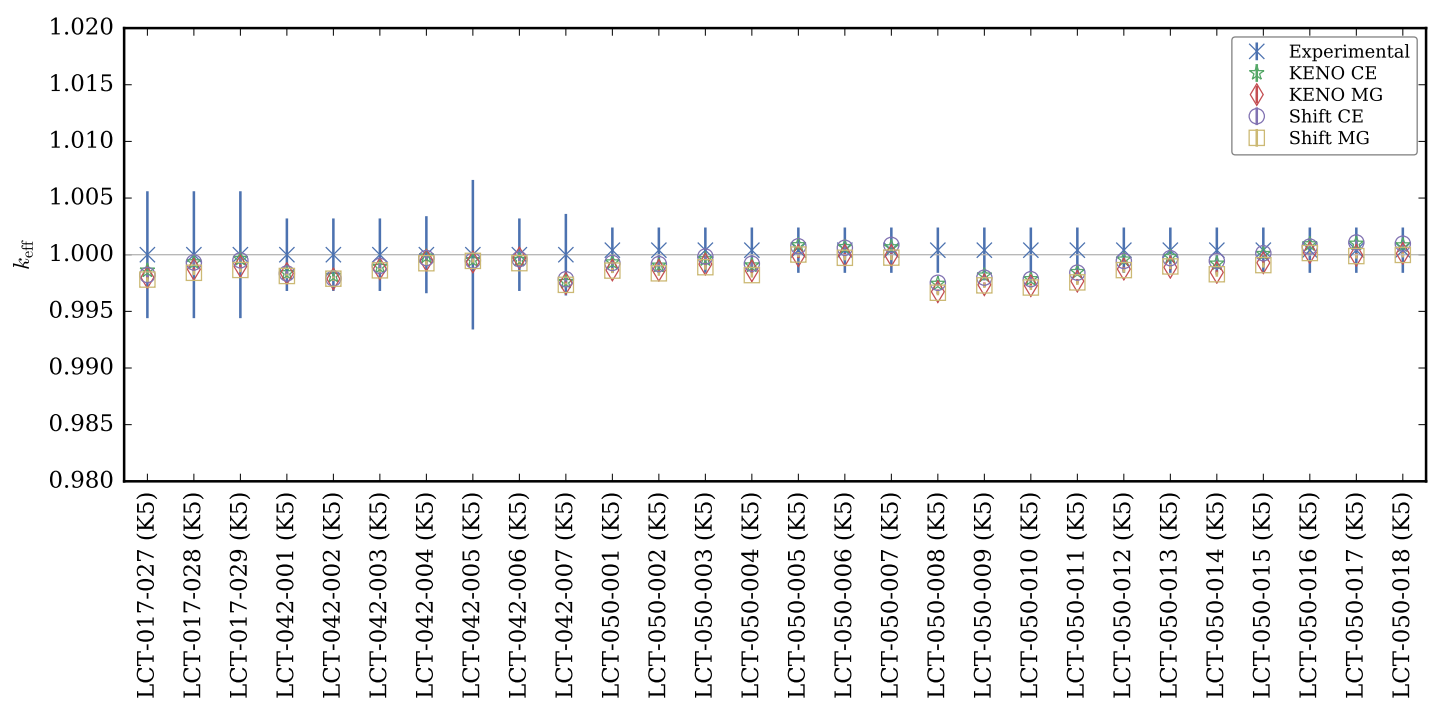

(d)

Figure 11. LEU-COMP-THERM $k_{\text {eff }}$ comparison. 


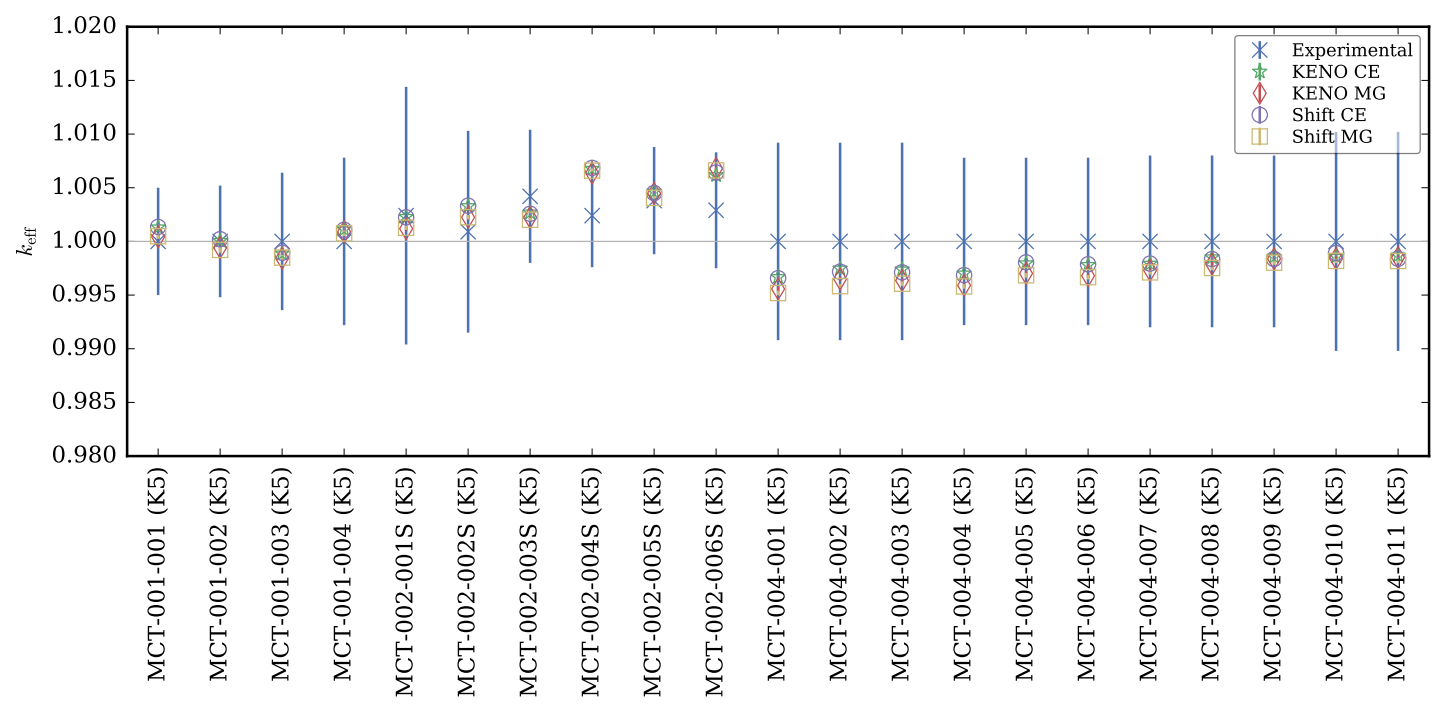

Figure 12. MIX-COMP-THERM $k_{\text {eff }}$ comparison. 


\subsection{BENCHMARK ON DETERMINISTIC TRANSPORT CALCULATIONS WITHOUT SPATIAL HOMOGENIZATION (C5G7)}

We ran the 2003 and 2005 C5G7 [9], [10] benchmark problems to verify the transport mechanics in Shift. Both of these benchmarks use a 7-group cross section set. This also provides a validation of the Shift MG capability. The core configurations and descriptions are given in the references and summarized in the Shift verification and validation (V\&V) plan [3].

Four total problems were executed in this series, all of which were executed in their threedimensional configurations: 2003 unrodded, 2005 unrodded, 2005 rodded A, and 2005 rodded B. The Shift cases were run with 1250 total generations and 250 inactive generations. The nominal number of particles per generation was set to $1 \times 10^{6}$. The comparisons with the published benchmark results for $k_{\text {eff }}$ are shown in Figure 13; the error bars shown represent 2 standard deviations. As anticipated, Shift shows excellent agreement with all cases yielding $k_{\text {eff }}$ within $12 \mathrm{pcm}$ of the published benchmark.

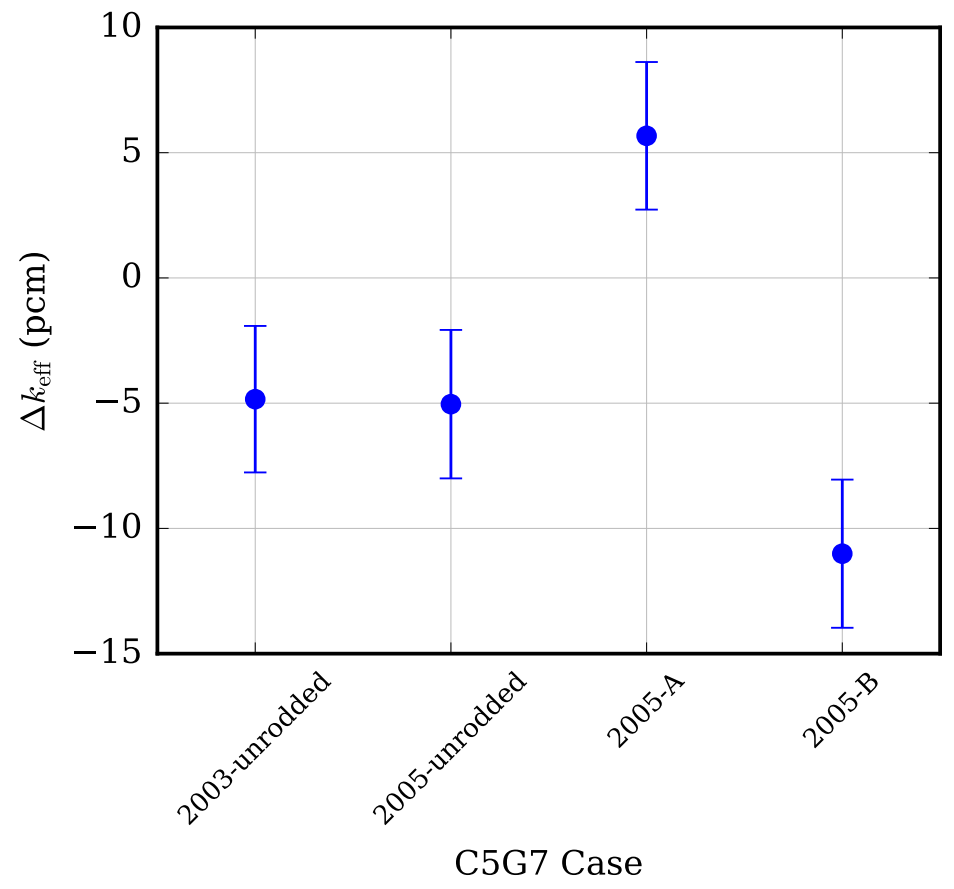

Figure 13. C5G7 $k_{\text {eff }}$ comparison.

Because we do not have access to the full benchmark results which reported pin power distributions, these are not compared here. However, we have compared the integrated assembly powers and maximum pin powers calculated by Shift to the published results. These comparisons are listed in Table 3. We see from these comparisons that Shift multigroup results are within $0.5 \%$ of the report powers which is very good agreement. 
Table 3. C5G7 pin power comparisons. The numbers in parenthesis represent the relative error compared to the benchmark value.

\begin{tabular}{lcccc}
\hline Case & Max Pin & Inner UO & Outer UO $_{2}$ & MOX \\
\hline \multirow{2}{*}{2003 unrodded } & $2.497 \pm 0.001$ & $492.768 \pm 0.014$ & $139.626 \pm 0.007$ & $211.829 \pm 0.010$ \\
& $(0.125 \%)$ & $(0.027 \%)$ & $(-0.019 \%)$ & $(-0.014 \%)$ \\
\hline \multirow{2}{*}{2005 unrodded } & $2.482 \pm 0.003$ & $491.165 \pm 0.042$ & $139.376 \pm 0.022$ & $212.736 \pm 0.032$ \\
& $(-0.035 \%)$ & $(0.007 \%)$ & $(0.018 \%)$ & $(-0.017 \%)$ \\
\hline \multirow{2}{*}{2005 rodded A } & $2.253 \pm 0.003$ & $461.312 \pm 0.041$ & $151.378 \pm 0.023$ & $221.857 \pm 0.032$ \\
& $(-0.016 \%)$ & $(-0.024 \%)$ & $(0.015 \%)$ & $(-0.071 \%)$ \\
\hline \multirow{2}{*}{ 2005 rodded B } & $1.835 \pm 0.003$ & $395.561 \pm 0.038$ & $187.402 \pm 0.027$ & $236.677 \pm 0.034$ \\
& $(-0.021 \%)$ & $(-0.041 \%)$ & $(-0.055 \%)$ & $(-0.032 \%)$ \\
\hline
\end{tabular}




\section{FULL-CORE LIGHT WATER REACTOR (LWR) BENCHMARKS}

In this section we present Shift results from full-core benchmarks and test problems. Some of these problems also consists of pincell variants taken from full-core benchmarks.

\subsection{WESTINGHOUSE AP1000 ${ }^{\circledR}$ PWR FIRST CORE}

This section presents a comparison of Shift calculations to previously published KENO-VI results [11] [12] [13] for reactivity, radial and axial power distributions, and rod worths for core physics simulations of the Westinghouse AP $10000^{\circledR}$ PWR startup core. The detailed specification for this reactor can be found in the previously published CASL report [13]. All of these results have been previously published in a journal article and are paraphrased here [1].

The Shift simulations of these various reactor configurations were performed on the Titan supercomputer [14]. Table 4 shows an eigenvalue comparison for the various AP1000 ${ }^{\circledR}$ PWR core configurations between Shift and KENO-VI. As expected, Shift results agree with those from KENO-VI with an average difference of $18 \mathrm{pcm}$ and maximum difference of $25 \mathrm{pcm}$.

\section{Table 4. Shift eigenvalue and benchmark comparison results for} different assemblies in AP1000 ${ }^{\circledR}$.

\begin{tabular}{cccc}
\hline Case ID & KENO-VI $k_{\text {eff }}$ & Shift $k_{\text {eff }}$ & Diff $(\mathrm{pcm})$ \\
\hline ARO & 1.000870 & 1.001030 & 16 \\
DBW & 1.003240 & 1.003450 & 21 \\
MA & 0.998258 & 0.998414 & 16 \\
MB & 0.998669 & 0.998909 & 24 \\
MC & 0.998956 & 0.999148 & 19 \\
MD & 0.998496 & 0.998643 & 15 \\
M1 & 0.994350 & 0.994548 & 20 \\
M2 & 0.992001 & 0.992185 & 18 \\
AO & 0.984609 & 0.984749 & 14 \\
S1 & 0.990103 & 0.990200 & 10 \\
S2 & 0.989935 & 0.990183 & 25 \\
S3 & 0.989650 & 0.989739 & 9 \\
S4 & 0.995055 & 0.995295 & 24 \\
\hline Average & & & $\mathbf{1 8}$ \\
\hline
\end{tabular}

Next, we compate the power distribution of the AP1000 ${ }^{\circledR}$ ARO problem between Shift and KENOVI. From the comparison of assembly and pin power distributions shown in Table 5, we can conclude that Shift accurately predicts integrated pin power distributions to less than a $1 \%$ error.

Finally, we compare rod bank worth calculations between Shift and KENO-VI. Figure 14 shows the location of the rod banks in a quarter of the AP $1000^{\circledR}$ core. Table 6 shows the comparison of 
Table 5. $A P 1000^{\circledR}$ eigenvalue and overall pin powers, $\Delta P$, comparison to KENO-VI.

\begin{tabular}{cccccccc}
\hline & $\begin{array}{c}k_{\text {eff }} \\
\text { Code }\end{array}$ & $\begin{array}{c}\Delta k_{\text {eff }} \\
(\mathbf{p c m}\end{array}$ & $\begin{array}{c}\text { RMS } \\
\text { Asm. } \\
(\%)\end{array}$ & $\begin{array}{c}\text { Max } \\
\text { Asm. }\end{array}$ & $\begin{array}{c}\text { RMS } \\
\text { Pin } \\
(\%)\end{array}$ & $\begin{array}{c}\text { Max } \\
\text { Pin } \\
(\%)\end{array}$ & $\begin{array}{c}\text { Hot } \\
\text { Pin } \\
(\%)\end{array}$ \\
\hline Shift & 1.00131 & 35 & 0.2 & 0.5 & 0.2 & 0.6 & -0.2 \\
\hline
\end{tabular}

the rod bank worths from Shift to CE KENO-VI. This table shows an overall RMS of $1.1 \%$ from all rod bank comparisons with the largest difference of $2.3 \%$ rod worth occurring for a bank closest to the edge of the core.

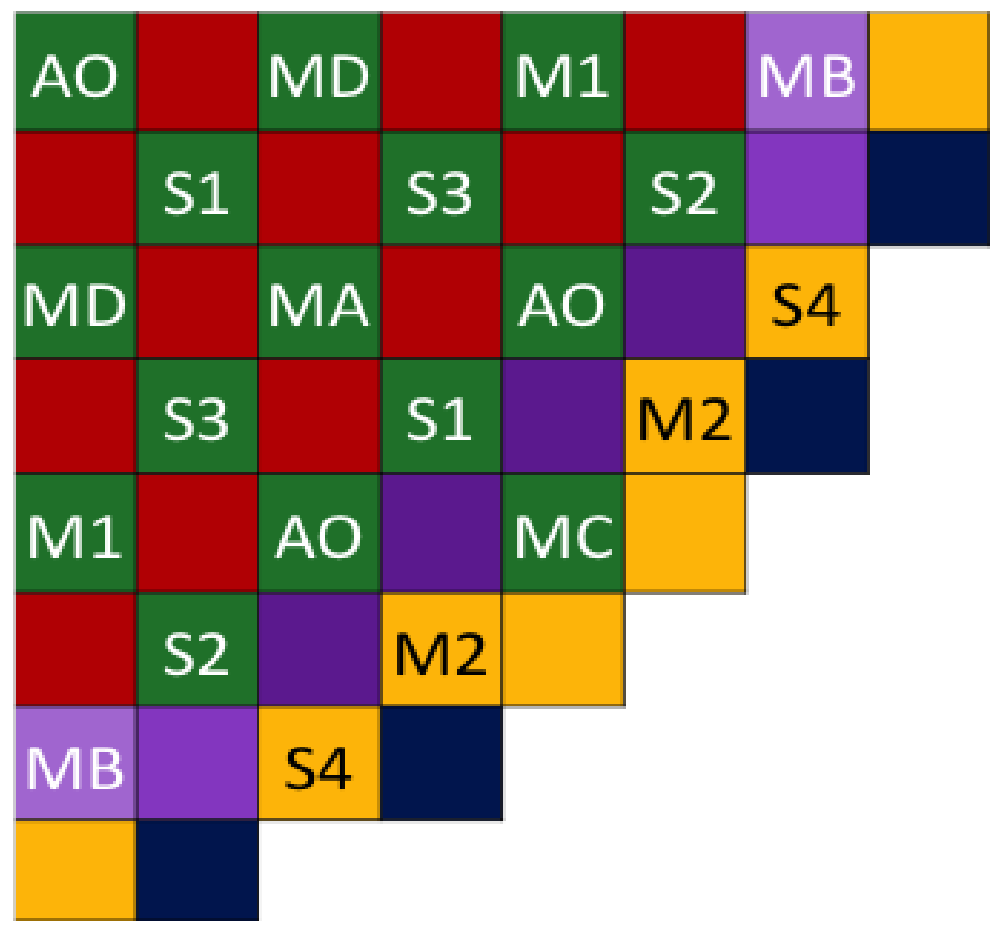

Figure 14. Rod bank locations in $\mathrm{AP} 1000^{\circledR}$ (image produced from Shift run). 
Table 6. Rod bank worth calculated using Shift compared to the benchmark for AP1000 ${ }^{\circledR}$.

\begin{tabular}{ccrrr}
\hline \multirow{2}{*}{ Rod Bank } & \multirow{2}{*}{ Material } & \multicolumn{2}{c}{ KENO-VI } & \multicolumn{2}{c}{ Shift $\Delta$ Worth } \\
\cline { 4 - 5 } & & Worth (pcm) & (pcm) & (\%) \\
\hline MA & Tungsten & 258 & 4 & 1.4 \\
MB & Tungsten & 217 & -5 & -2.3 \\
MC & Tungsten & 188 & 0 & 0.1 \\
MD & Tungsten & 234 & 5 & 2.0 \\
M1 & Ag-In-Cd & 651 & -1 & -0.2 \\
M2 & Ag-In-Cd & 887 & 1 & 0.1 \\
AO & Ag-In-Cd & 1635 & 5 & 0.3 \\
S1 & Ag-In-Cd & 1079 & 9 & 0.8 \\
S2 & Ag-In-Cd & 1096 & -7 & -0.6 \\
S3 & Ag-In-Cd & 1124 & 10 & 0.9 \\
S4 & Ag-In-Cd & 580 & 6 & 0.1 \\
\hline
\end{tabular}




\subsection{WATTS BAR UNIT 1 INITIAL STARTUP}

In this section we present the Shift results for the initial startup of the traditional Westinghouse 4-loop PWR Watts Bar Unit 1 (WBN1). We compare our Shift results to reported criticality and control rod/bank worths for the Zero Power Physics Tests (ZPPT) performed on WBN1 and results from KENO-VI [15], [16]. These problems consist of critical eigenvalue comparisons, control rod/bank worths, and differential boron worth.

For the eigenvalue comparisons, Shift was run on Titan for each of the cases shown in Table 7 using $10 \times 10^{6}$ particles histories per generation for a total of 1000 generations with 300 inactive generations. Table 7 shows very good agreement between Shift calculated $k_{\text {eff }}$ and the measured reference values.

The ten critical configurations from this table are corrected and compared in Figure 15 along with KENO-VI, Insilico, and NEXUS results. Insilico is a deterministic $\mathrm{SP}_{N}$ radiation transport code at ORNL and NEXUS is an in-house code at Westinghouse. A $-57 \mathrm{pcm}$ correction is added to account for thermal expansion to all codes, and a -39 to $-53 \mathrm{pcm}$ correction was used for the SC and SD Bank criticals and worths to account for rotational symmetry [16] to most codes except NEXUS, which already has rotational symmetry. Finally, the correction for thermal scattering at $565 \mathrm{~K}$ of $-43 \mathrm{pcm}$ was applied to all results, consistent with the KENO-VI results in [17]. The average reactivity error for Shift is $-96 \mathrm{pcm}$ when compared with the startup measurements, and 33 pcm when compared to KENO-VI.

The eight control rod bank worth calculations are provided in Figure 16. For each code, including Shift, the measured worths are inferred from the reference bank critical position using calculated shadow factors as described in [16]; to be consistent, each code was used to calculate those factors. Though the Bank A error is slightly large, it is consistent with KENO-VI.

Shift also calculated the differential boron worth (DBW) of WBN1. Table 8 shows a comparison of the DBW calculated by Shift and other codes, including MPACT which is a 2D/1D deterministic method of characteristics radiation transport code at the University of Michigan. All of these codes, including Shift, calculate a very small difference in differential boron worth to the measured value. The measurement of the Bank D worth has not been released, but we did compare the worth calculated by Shift to KENO-VI. Figures 17 and 18 show the integral and differential rod worth comparison for Bank D of WBN1 between Shift and KENO-VI. These results calculated by Shift for the integral rod worth of Bank D are within $1 \%$ of the KENO-VI calculated results. The large relative error of $6 \%$ in differential rod worth at the beginning of the insertion (the right side of Figure 18) is due to the very small worth of the rod at this point of the insertion.

Finally, power distribution comparisons between Shift and KENO-VI are shown in the following figures. For each figure, the RMS of the power distribution is included. Figures 19-23 show various power distribution comparisons between Shift and KENO-VI. Note that these comparisons are performed without incore instrumentation and with Bank D at the initial critical position of 167 steps withdrawn. Please see reference [17] for further discussion of the uncertainties in the reference distributions. The agreement is very good in all cases, with a minor in/out radial tilt 


\section{Shift Verification and Validation}

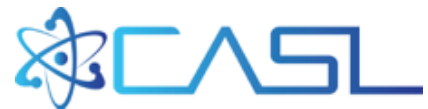

demonstrated in the full core results. Also, note that the reference solution contains additional radial core structure such as the core barrel and neutron pads, while Shift does not. This is expected to result in a small deviation in pin and assembly power in the assemblies closest to the neutron pad on the core diagonal axis.

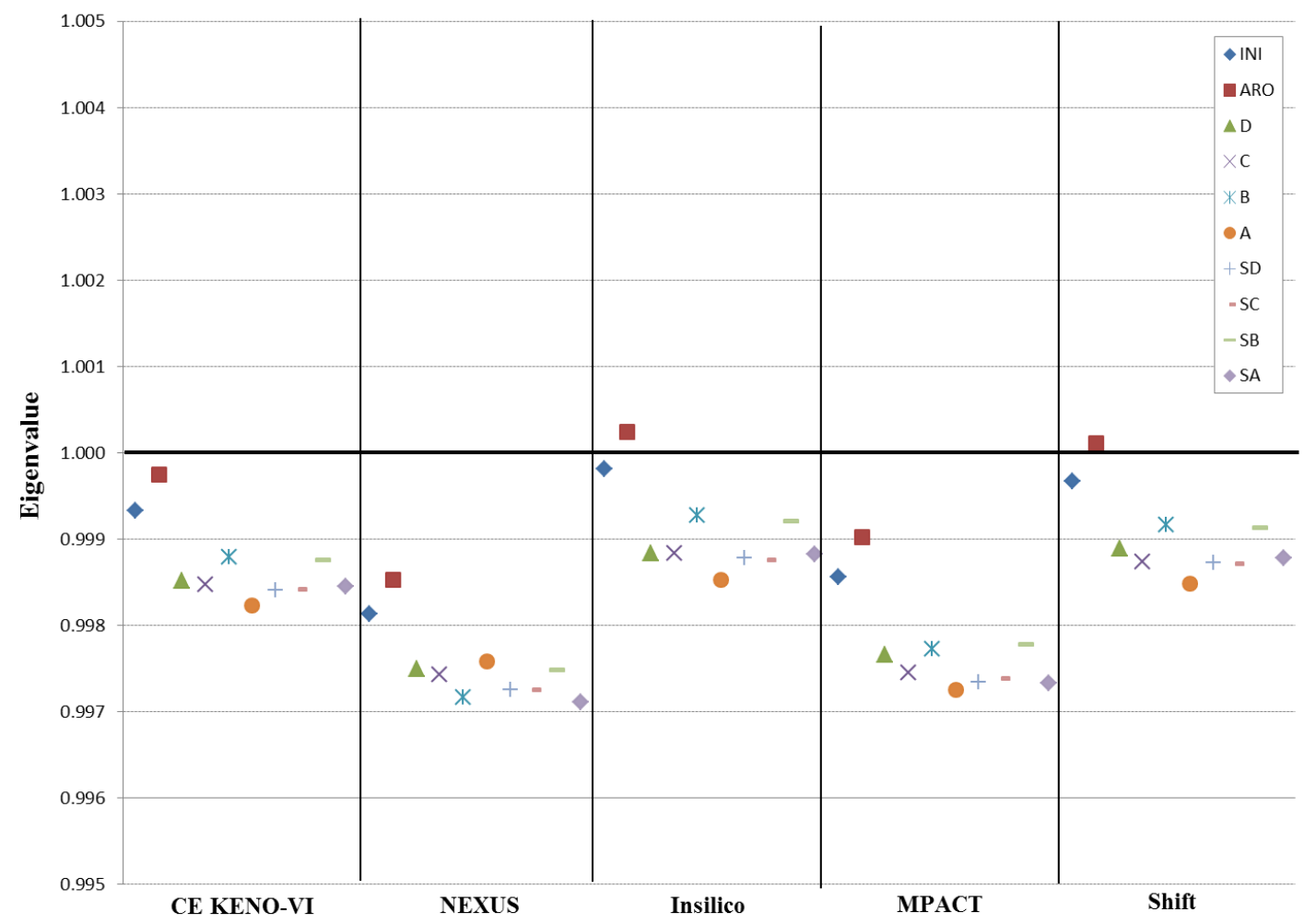

Figure 15. Eigenvalues for critical configurations of WBN1 ZPPT. 
Table 7. Shift eigenvalue and benchmark comparison results for different assemblies in WBN1. Bank positions are shown in steps withdrawn.

\begin{tabular}{|c|c|c|c|c|c|c|c|c|c|c|c|c|}
\hline Case & $\begin{array}{l}\text { Boron } \\
(\mathrm{ppm})\end{array}$ & $\begin{array}{c}\text { Temp } \\
(\mathrm{K})\end{array}$ & $\mathbf{A}$ & B & C & D & SA & SB & SC & SD & $\begin{array}{l}\text { Reference } \\
(\leq 2 \mathrm{pcm})\end{array}$ & $\begin{array}{c}k_{\text {eff }} \text { diff } \\
(\leq 6 \mathrm{pcm})\end{array}$ \\
\hline 1 & 1285 & 565 & - & - & - & 167 & - & - & - & - & 0.999899 & 34 \\
\hline 2 & 1291 & $\downarrow$ & - & - & - & - & - & - & - & - & 1.000321 & 36 \\
\hline 3 & 1170 & $\downarrow$ & 0 & - & - & 97 & - & - & - & - & 0.998797 & 26 \\
\hline 4 & $\downarrow$ & $\downarrow$ & - & 0 & - & 113 & - & - & - & - & 0.999358 & 37 \\
\hline 5 & $\downarrow$ & $\downarrow$ & - & - & 0 & 119 & - & - & - & - & 0.999039 & 27 \\
\hline 6 & $\downarrow$ & $\downarrow$ & - & - & - & 18 & - & - & - & - & 0.999084 & 37 \\
\hline 7 & $\downarrow$ & $\downarrow$ & - & - & - & 69 & 0 & - & - & - & 0.999022 & 33 \\
\hline 8 & $\downarrow$ & $\downarrow$ & - & - & - & 134 & - & 0 & - & - & 0.999324 & 37 \\
\hline 9 & $\downarrow$ & $\downarrow$ & - & - & - & 71 & - & - & 0 & - & 0.998983 & 30 \\
\hline 10 & $\downarrow$ & $\downarrow$ & - & - & - & 71 & - & - & - & 0 & 0.998976 & 32 \\
\hline 11 & $\downarrow$ & $\downarrow$ & - & - & - & - & - & - & - & - & 1.012841 & 40 \\
\hline 12 & $\downarrow$ & $\downarrow$ & 0 & - & - & - & - & - & - & - & 1.003716 & 35 \\
\hline 13 & $\downarrow$ & $\downarrow$ & - & 0 & - & - & - & - & - & - & 1.003941 & 41 \\
\hline 14 & $\downarrow$ & $\downarrow$ & - & - & 0 & - & - & - & - & - & 1.002843 & 34 \\
\hline 15 & $\downarrow$ & $\downarrow$ & - & - & - & 0 & - & - & - & - & 0.998815 & 39 \\
\hline 16 & $\downarrow$ & $\downarrow$ & - & - & - & - & 0 & - & - & - & 1.008281 & 45 \\
\hline 17 & $\downarrow$ & $\downarrow$ & - & - & - & - & - & 0 & - & - & 1.002018 & 38 \\
\hline 18 & $\downarrow$ & $\downarrow$ & - & - & - & - & - & - & 0 & - & 1.007749 & 39 \\
\hline 19 & $\downarrow$ & $\downarrow$ & - & - & - & - & - & - & - & 0 & 1.007745 & 41 \\
\hline 20 & 1291 & 560 & - & - & - & - & - & - & - & - & 1.000608 & - \\
\hline 21 & $\downarrow$ & 570 & - & - & - & - & - & - & - & - & 1.000034 & - \\
\hline 22 & 1230 & 565 & - & - & - & 0 & - & - & - & - & 0.992755 & 32 \\
\hline 23 & $\downarrow$ & $\downarrow$ & - & - & - & 23 & - & - & - & - & 0.993162 & 32 \\
\hline 24 & $\downarrow$ & $\downarrow$ & - & - & - & 46 & - & - & - & - & 0.994555 & 34 \\
\hline 25 & $\downarrow$ & $\downarrow$ & - & - & - & 69 & - & - & - & - & 0.997369 & 32 \\
\hline 26 & $\downarrow$ & $\downarrow$ & - & - & - & 92 & - & - & - & - & 1.000279 & 36 \\
\hline 27 & $\downarrow$ & $\downarrow$ & - & - & - & 115 & - & - & - & - & 1.002542 & 34 \\
\hline 28 & $\downarrow$ & $\downarrow$ & - & - & - & 138 & - & - & - & - & 1.004163 & 38 \\
\hline 29 & $\downarrow$ & $\downarrow$ & - & - & - & 161 & - & - & - & - & 1.005300 & 37 \\
\hline 30 & $\downarrow$ & $\downarrow$ & - & - & - & 184 & - & - & - & - & 1.006073 & 37 \\
\hline 31 & $\downarrow$ & $\downarrow$ & - & - & - & 207 & - & - & - & - & 1.006468 & 39 \\
\hline \multirow[t]{2}{*}{32} & $\downarrow$ & $\downarrow$ & - & - & - & - & - & - & - & - & 1.006584 & 37 \\
\hline & & & & & & & & & & & Average & 36 \\
\hline
\end{tabular}




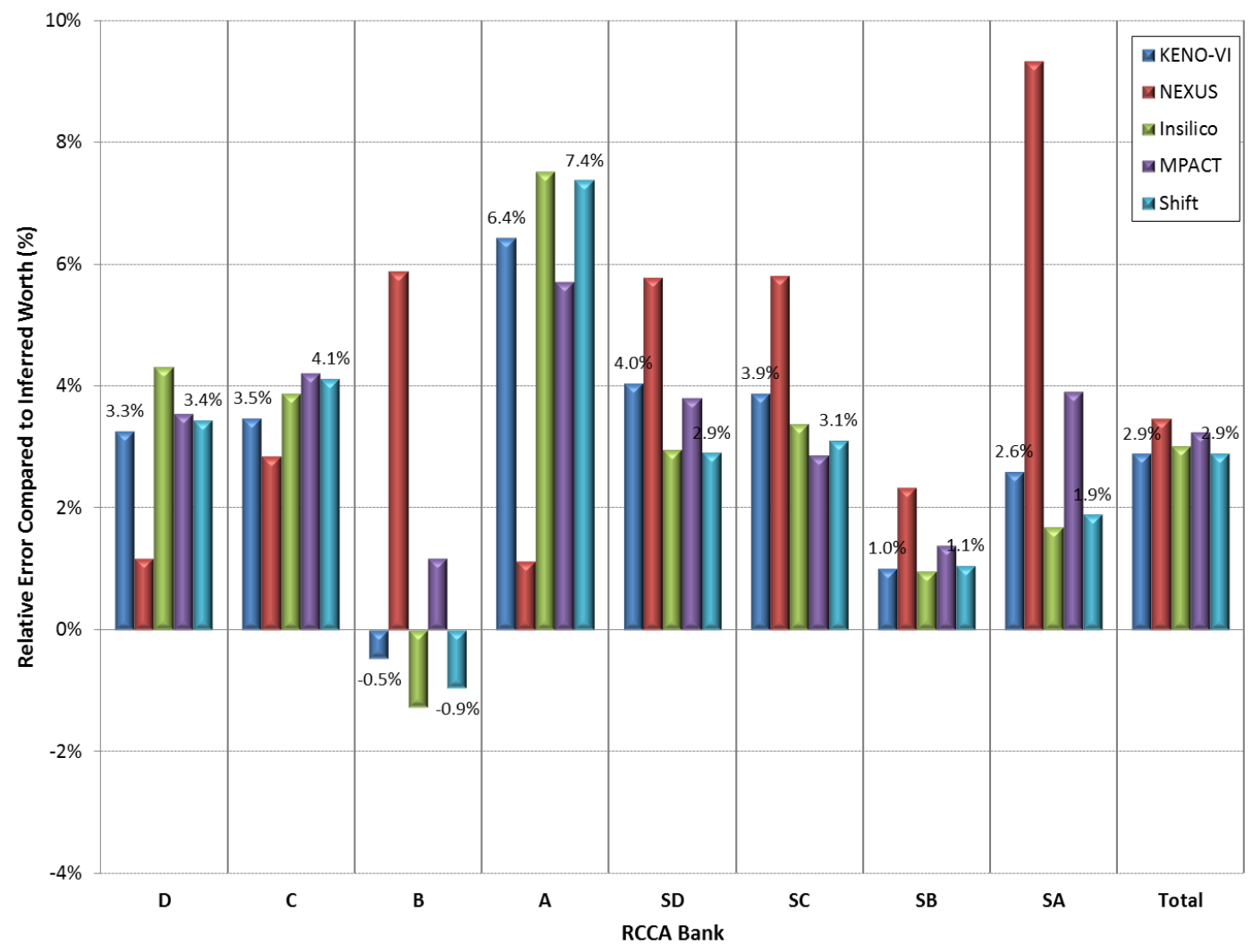

Figure 16. WBN1 RCCA bank worths relative error for WBN1 ZPPT.

Table 8. WBN1 differental boron worth.

\begin{tabular}{lcc}
\hline Code & $\begin{array}{c}\text { DBW } \\
(\mathrm{pcm} / \mathrm{ppmB})\end{array}$ & $\begin{array}{c}\text { Difference } \\
(\mathrm{pcm} / \mathrm{ppmB})\end{array}$ \\
\hline Measured & -10.77 & - \\
Shift & -10.25 & 0.52 \\
CE KENO-VI & -10.21 & 0.56 \\
NEXUS & -10.12 & 0.65 \\
Insilico & -10.16 & 0.61 \\
MPACT & -10.16 & 0.61 \\
\hline
\end{tabular}




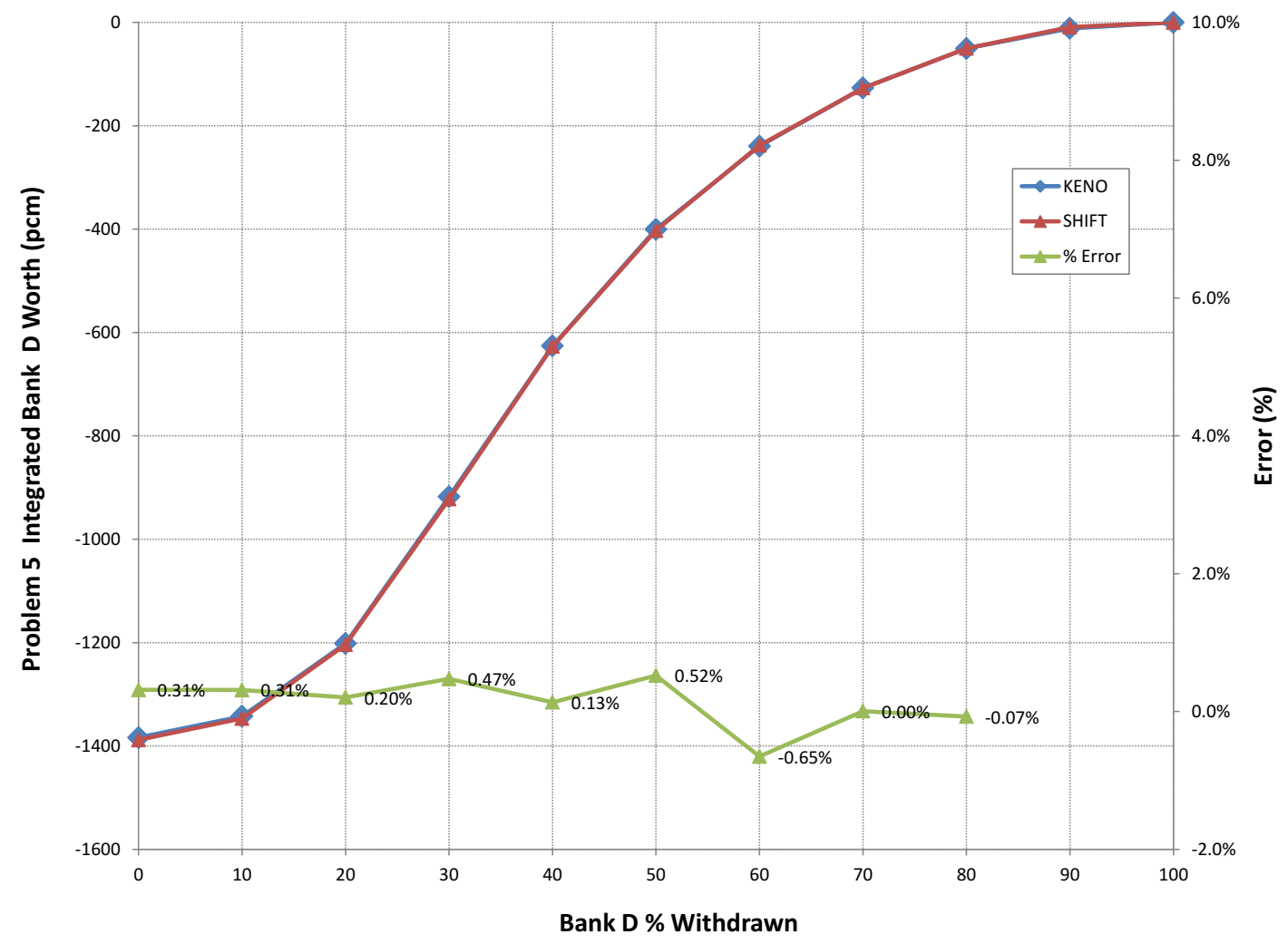

Figure 17. WBN1 Bank D integral rod worth comparison. 


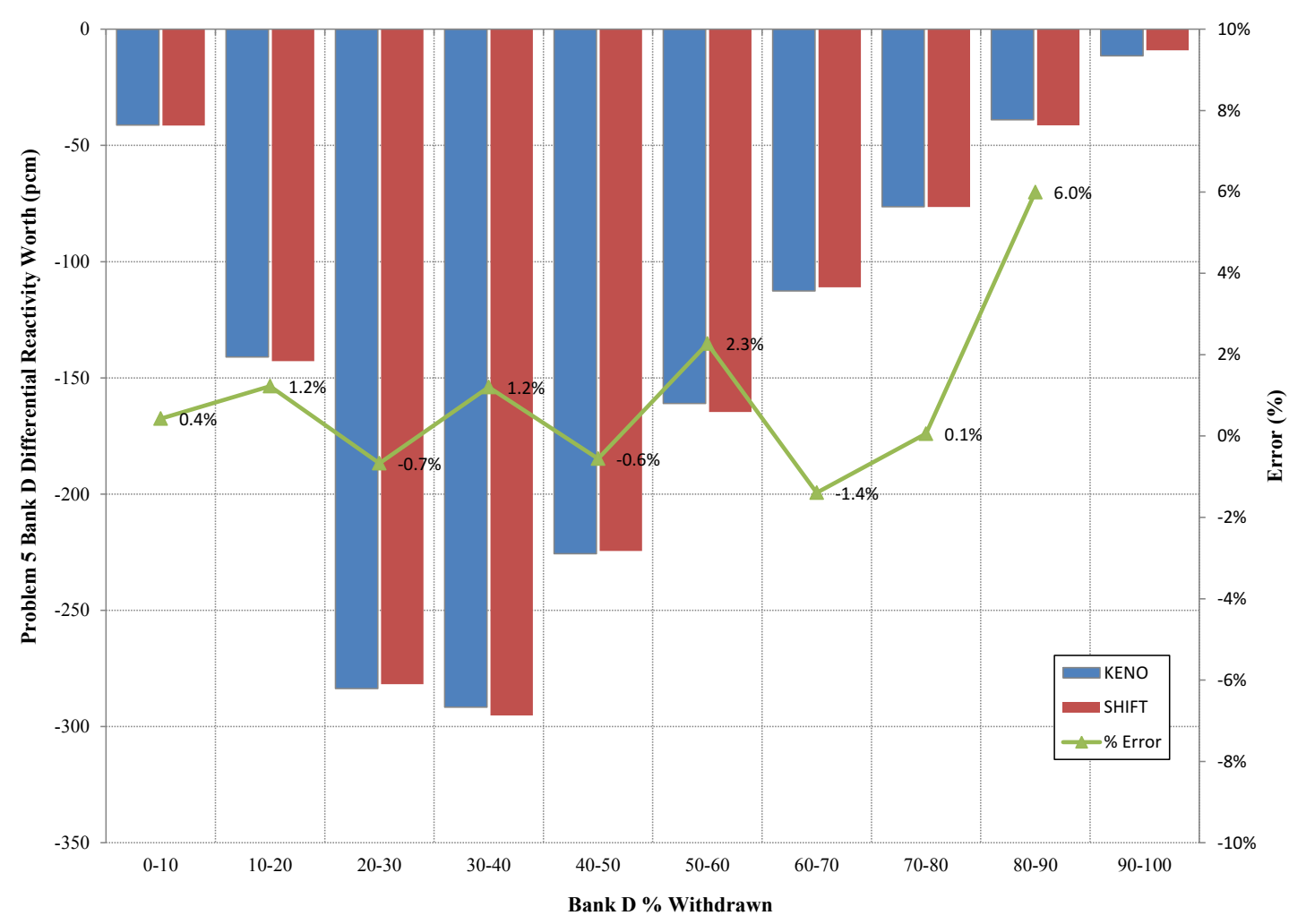

Figure 18. WBN1 Bank D differential rod worth comparison. 


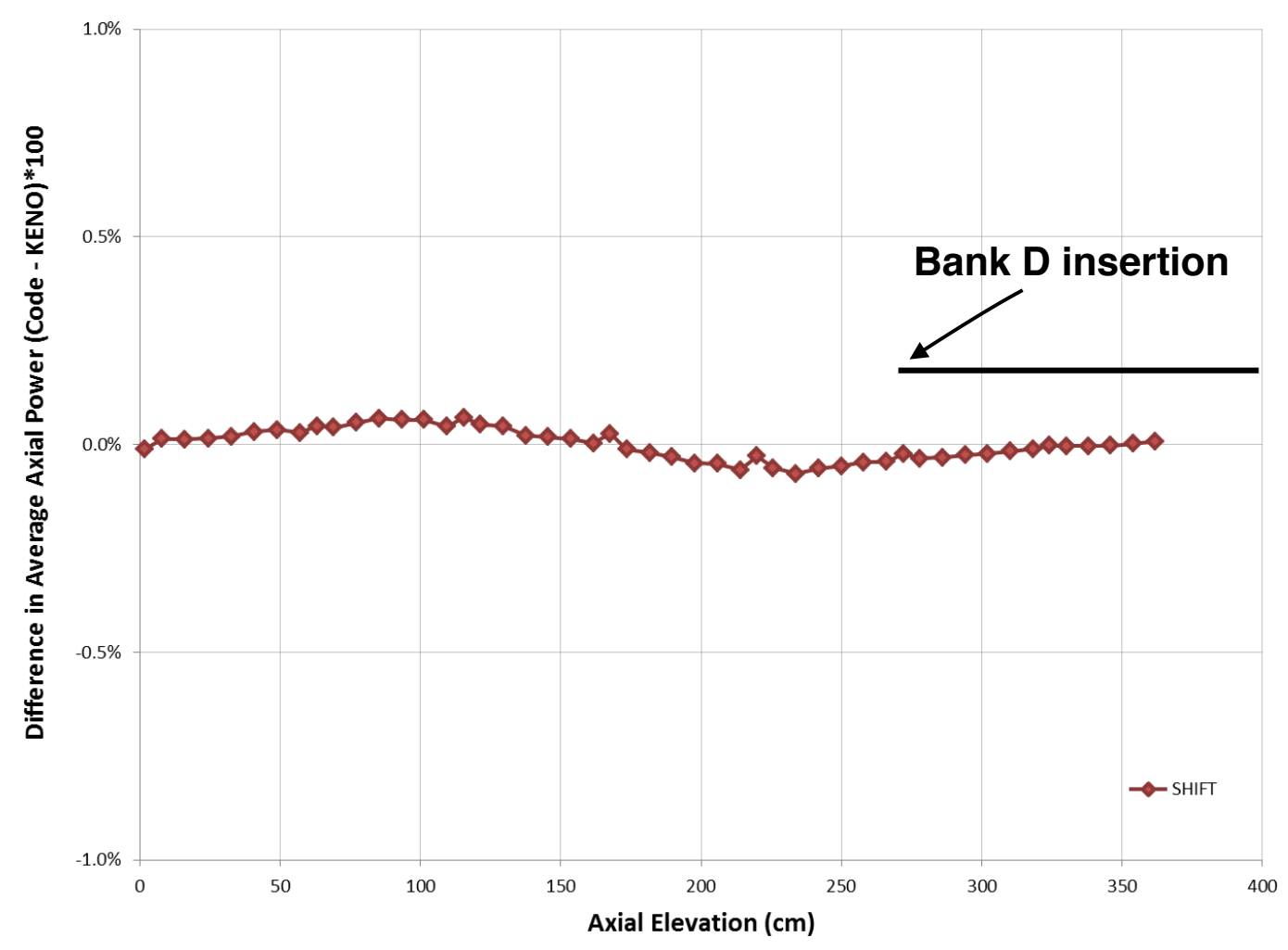

Figure 19. WBN1 axial power distribution comparison. 


\begin{tabular}{|c|c|c|c|c|c|}
\hline 0.958 & & & & & \\
\hline 0.928 & 1.006 & & & & \\
\hline 1.026 & 0.915 & 1.071 & & & \\
\hline 0.991 & 1.087 & 1.045 & 1.164 & & \\
\hline 1.069 & 1.050 & 1.176 & 1.085 & 1.234 & \\
\hline 1.050 & 1.163 & 1.152 & 1.148 & 0.893 & 0.905 \\
\hline 1.084 & 1.065 & 1.101 & 1.045 & 0.939 & 0.621 \\
\hline 0.792 & 0.905 & 0.801 & 0.655 & & \\
\hline
\end{tabular}

Max: 1.234
Avg: 1.000

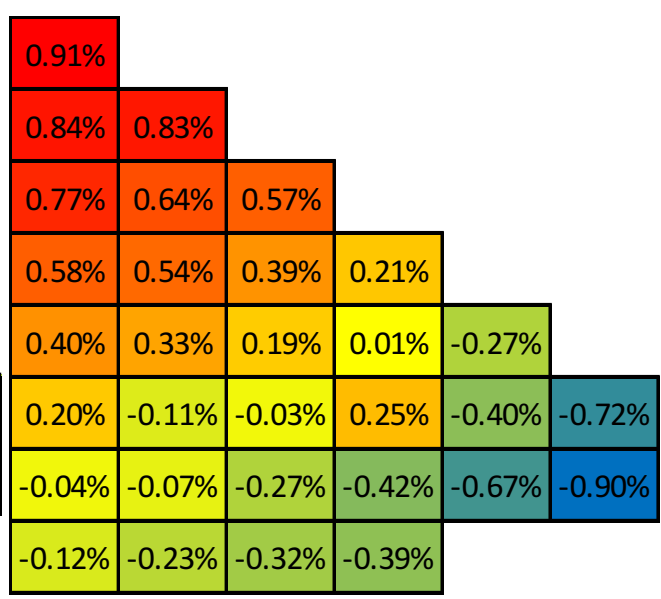

Max: $0.84 \% \quad$ Min: $-0.90 \% \quad$ RMS: $0.45 \%$

(b) Differences with KENO-VI

(a) Shift normalized power

Figure 20. WBN1 radial assembly power.

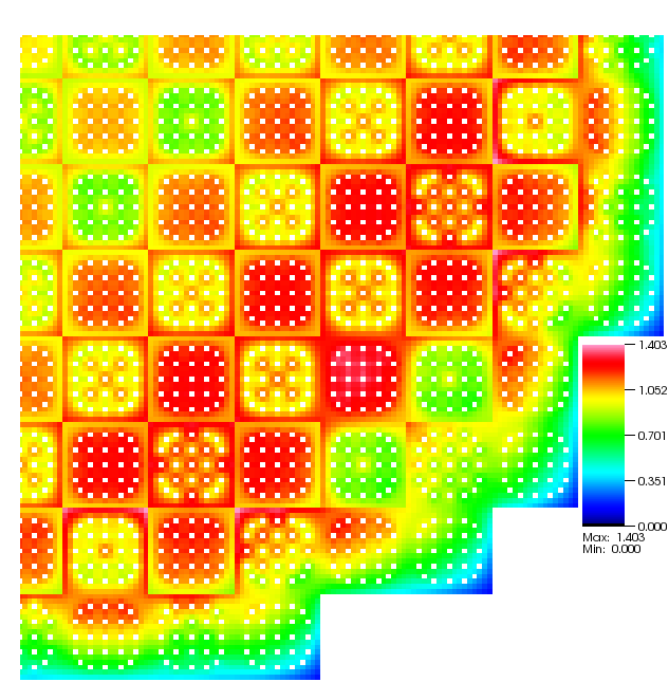

(a) Shift normalized power

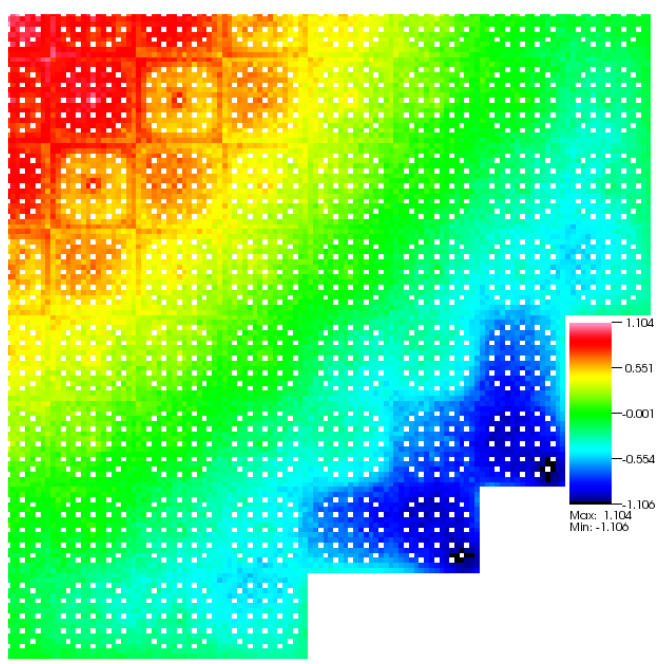

(b) Differences with KENO-VI, RMS = $0.46 \%$

Figure 21. WBN1 radial pin power. 


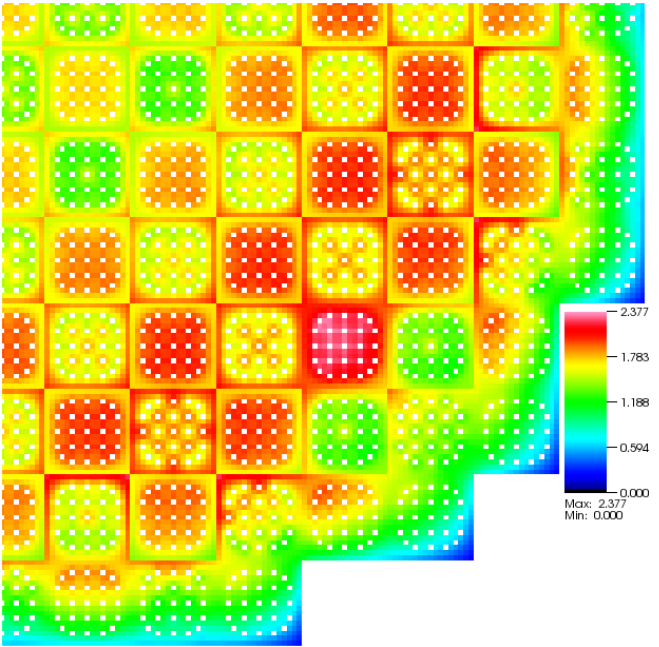

(a) Shift normalized power

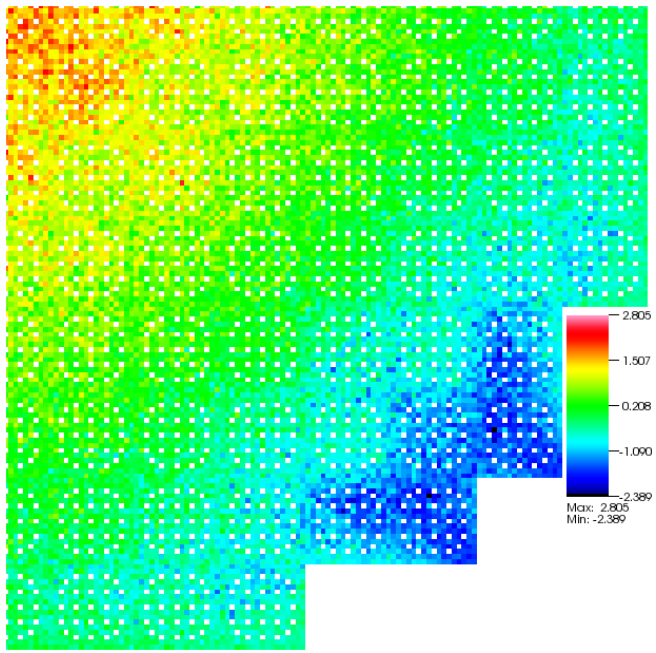

(b) Differences with KENO-VI(\%)

Figure 22. WBN1 midplane pin power. 


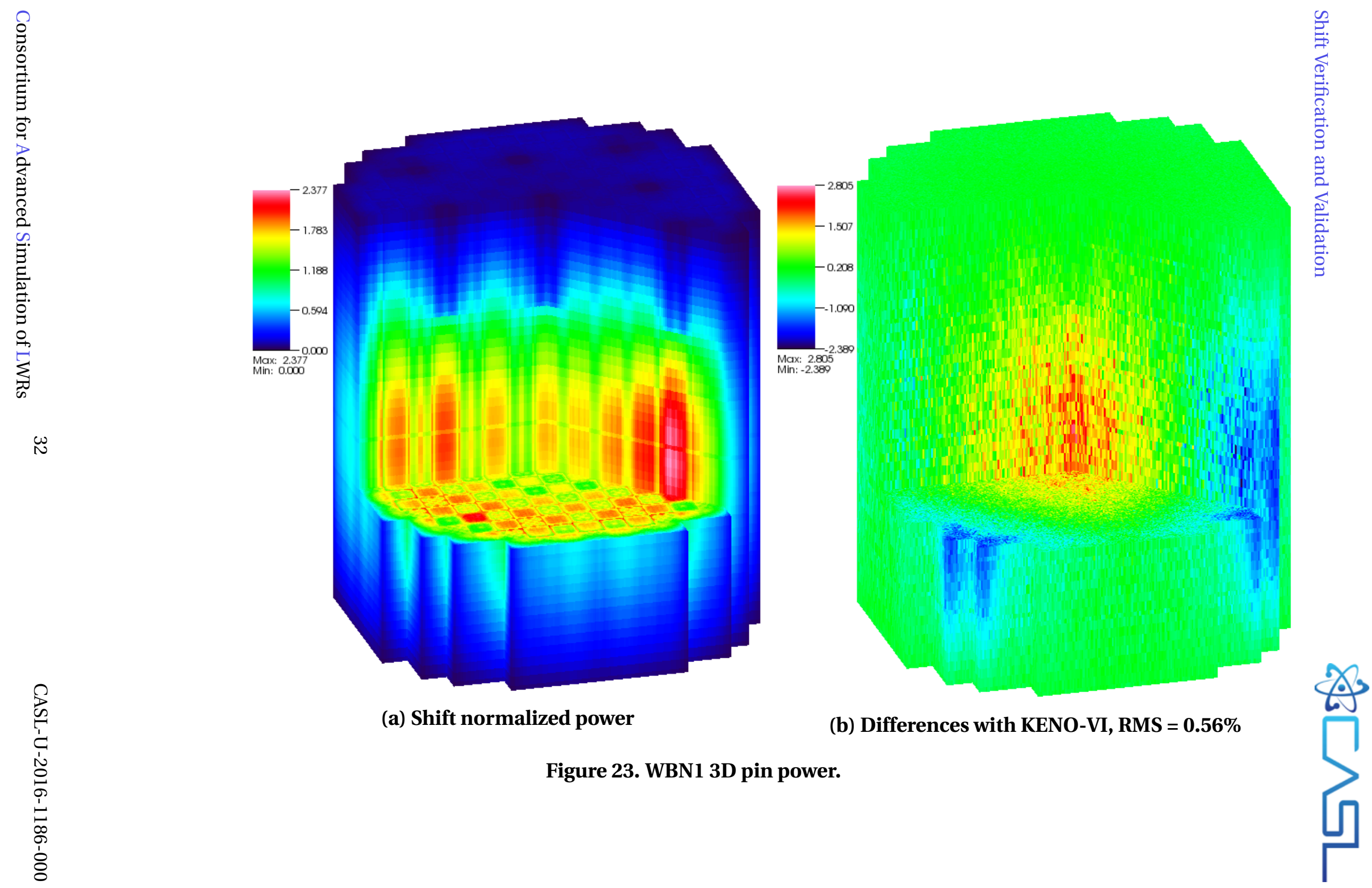




\subsection{BENCHMARK FOR EVALUATION AND VALIDATION OF REACTOR SIMULATIONS (BEAVRS)}

Shift was run using the BEAVRS benchmark and has produced results to coincide with the ZPPT cycle 1 and cycle 2 . These results are in the process of being analyzed and compared to the operating data. Results will be reported soon.

\subsection{KRŠKO NUCLEAR POWER PLANT}

This section presents initial results for validation of Shift using measured data from the KRŠKO nuclear power plant (NPP) as part of the ZPPT. These results were published previously in a conference paper; please see this paper for further details [18].

As part of the ZPPT for this reactor, the beginning-of-cycle (BOC) hot-zero-power (HZP) all-rodsout (ARO) critical boron concentration was measured; the calculated Shift boron concentration of $1451 \mathrm{ppm}$ of boron agreed to within $6 \mathrm{ppm}$ of the measured value. Note that the Shift calculation did not include the effects of thermal expansion. Table 9 shows the reactivity difference (in pcm) from criticality for each boron dilution endpoint following an RCCA bank insertion. The Shift calculated values agree within $150 \mathrm{pcm}$ of the measured values. Table 10 shows the relative difference between Shift calculated bank worths and measured worths for various banks. We see very good agreement for the Shift calculated bank worths considering that the effects of thermal expansion were not accounted for in the Shift calculation.

Table 9. KRŠKO ZPPT boron endpoint criticality comparison.

\begin{tabular}{l|rr} 
RCCA Position & $\begin{array}{r}\text { Measured Boron } \\
(\mathrm{ppm})\end{array}$ & $\begin{array}{r}\text { Shift Difference } \\
(\mathrm{pcm})\end{array}$ \\
\hline ARO & 1445 & 58 \\
D In & 1343 & 95 \\
CD In & 1192 & 147 \\
BCD In & 1108 & 96 \\
ABCD In & 905 & 41 \\
\hline Average & & $88 \pm 41$ \\
\hline
\end{tabular}

We have seen excellent agreement so far between calculated Shift results and measured data for the KRŠKO NPP. Further validation results, including power distribution comparisons and cycle 1 burnup, will be reported soon.

\subsection{SURRY NUCLEAR POWER PLANT: WESTINGHOUSE 3-LOOP PWR}

Validation of Shift using plant data from the Surry nuclear power plant is still underway as we are awaiting the operating data from the plant. 
Table 10. KRŠKO ZPPT control bank reactivity worth comparison.

\begin{tabular}{l|rr} 
RCCA Bank & $\begin{array}{r}\text { Measured Worth } \\
(\mathrm{pcm})\end{array}$ & $\begin{array}{r}\text { Shift Relative Error } \\
(\%)\end{array}$ \\
\hline D & 949 & -0.3 \\
C with D In & 1367 & 3.4 \\
B with CD In & 872 & -0.6 \\
A with BCD In & 2091 & 2.1 \\
\hline Total & 5279 & $-0.1 \pm 2.4$ \\
\hline
\end{tabular}

\subsection{PINCELLS FROM LWR BENCHMARKS}

In this section we present the Shift results for a selection of pincells from full core benchmarks and plant data as given in the MPACT report [19]. The Shift results for $k_{\text {eff }}$ are compared to the simulated results of these pincells from MCNP6 [20].

In the following figures, the error bars shown are $3 \sigma$, and the three plots on each figure correspond to three different boron concentrations in the moderator. The following cases were simulated using Shift and MCNP6 and are shown in these figures:

1. ${ }^{235} \mathrm{U}$ enrichment of $2.1 \%$,

2. hot coolant density $\left(\operatorname{den} 1=0.0743, \operatorname{den} 2=0.0705, \operatorname{den} 3=0.0658 \mathrm{~g} / \mathrm{cm}^{3}\right)$,

3. boron concentration $(B=0,600,1300 \mathrm{ppm})$,

4. hot fuel temperature $(\mathrm{T}=600,900,1200 \mathrm{~K})$, and

5. cold case (room temperature of $\mathrm{T}=293.6 \mathrm{~K}, \bmod \operatorname{den} 0=0.100335 \mathrm{~g} / \mathrm{cm}^{3} \mathrm{~m}$ ).

For all of these simulations Shift used the SCALE CE 7.1 data based on ENDF B/VII.1, and MCNP6 used the corresponding ACE libraries based on this data.

Figure 24 shows the difference in $k_{\text {eff }}$ between Shift and MCNP6 for a pincell from BEAVRS cycle 1. The maximum difference from all of these cases is approximately $100 \mathrm{pcm}$. Figure 25 shows the calculated $k_{\text {eff }}$ difference between Shift and MCNP6 for a pincell from the KRŠKO NPP. The maximum difference from all of these cases is approximately $90 \mathrm{pcm}$.

Figure 26 shows the calculated $k_{\text {eff }}$ difference between Shift and MCNP6 for a pincell from WBN1 cycle 1 called PWR21. The maximum difference from all of these cases is approximately 110 pcm. Figure 27 shows the calculated $k_{\text {eff }}$ difference between Shift and MCNP6 for a different pincell from WBN1 cycle 1 called PWR31. The maximum difference from all of these cases is approximately $90 \mathrm{pcm}$. Figure 28 shows the calculated $k_{\text {eff }}$ difference between Shift and MCNP6 
for a different pincell from WBN1 cycle 1 called PWR41. The maximum difference from all of these cases is approximately $95 \mathrm{pcm}$. Finally, Figure 27 shows the calculated $k_{\text {eff }}$ difference between Shift and MCNP6 for a pincell from the Surry NPP. The maximum difference from all of these cases is approximately $90 \mathrm{pcm}$. The trend of increasing difference with increasing temperature is most likely due to the difference in CE data between Shift and MCNP6.
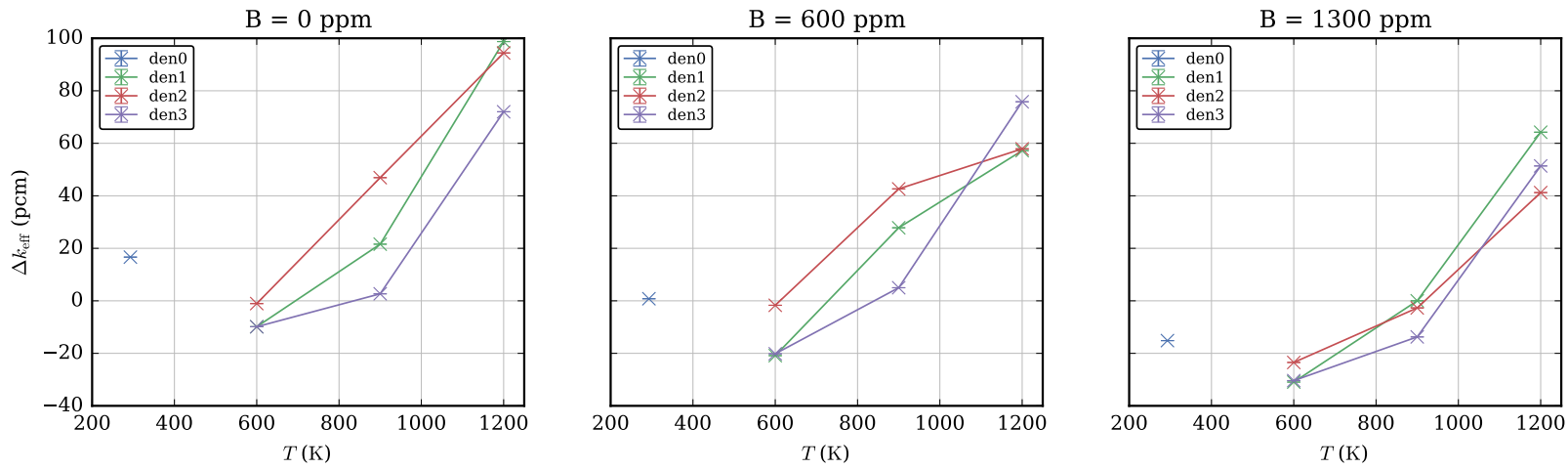

Figure 24. Difference in $k_{\text {eff }}$ for BEAVRS Pincell.
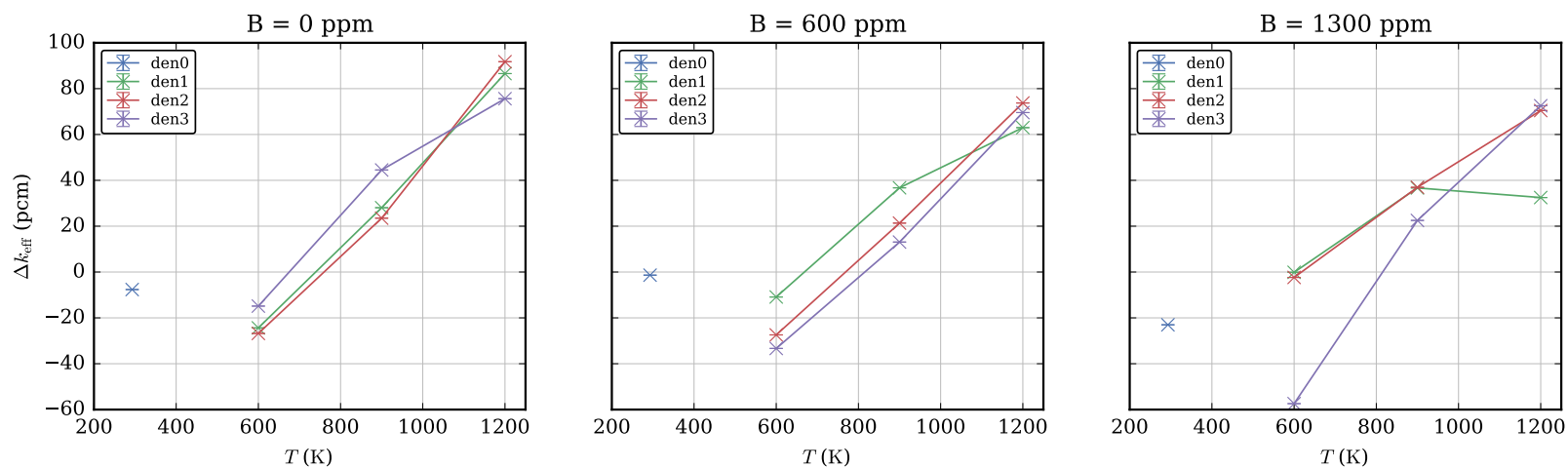

Figure 25. Difference in $k_{\text {eff }}$ for KRŠKO Pincell.

Overall, these results have shown very good agreement in the calculation of $k_{\text {eff }}$ for various pincell configurations by Shift as compared to a reference Monte Carlo radiation transport code. 

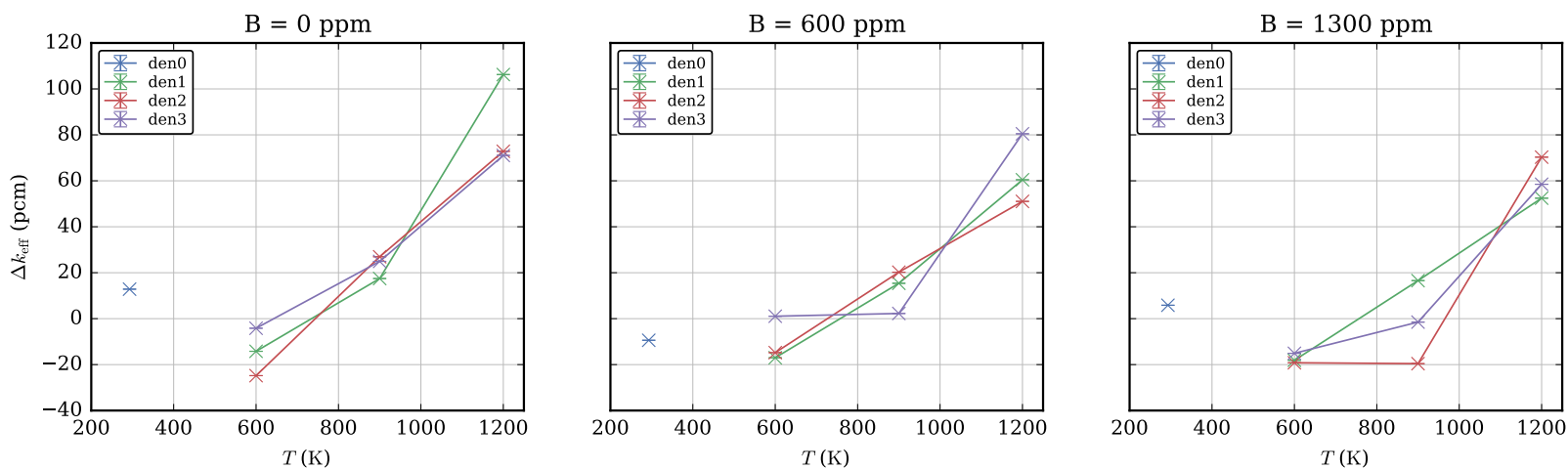

Figure 26. Difference in $k_{\text {eff }}$ for PWR21 Pincell.
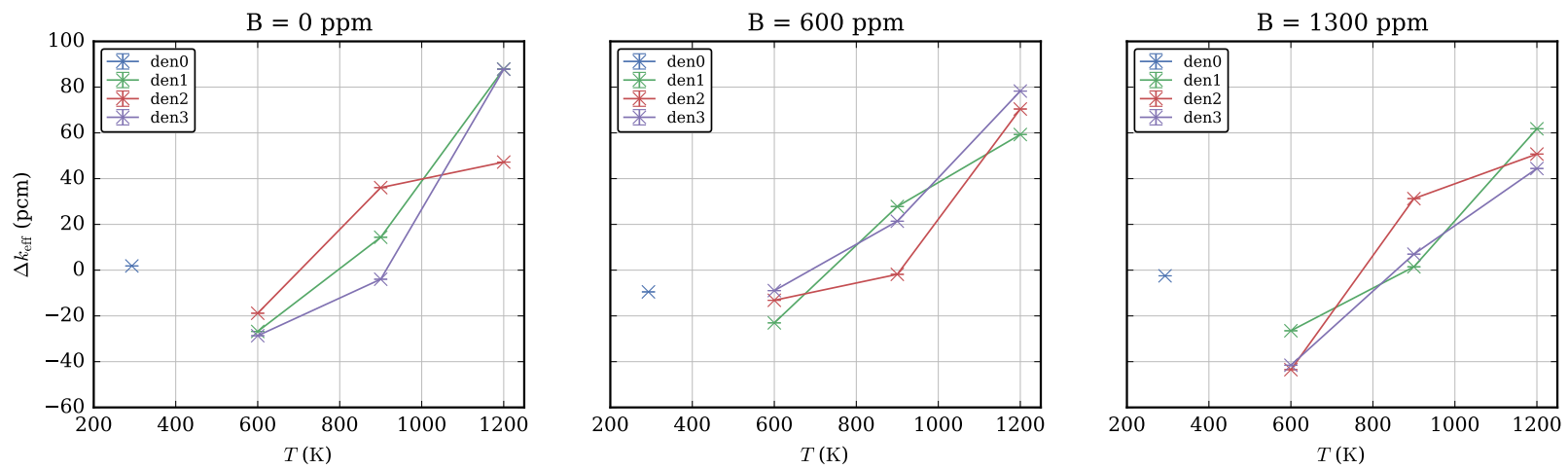

Figure 27. Difference in $k_{\text {eff }}$ for PWR31 Pincell.
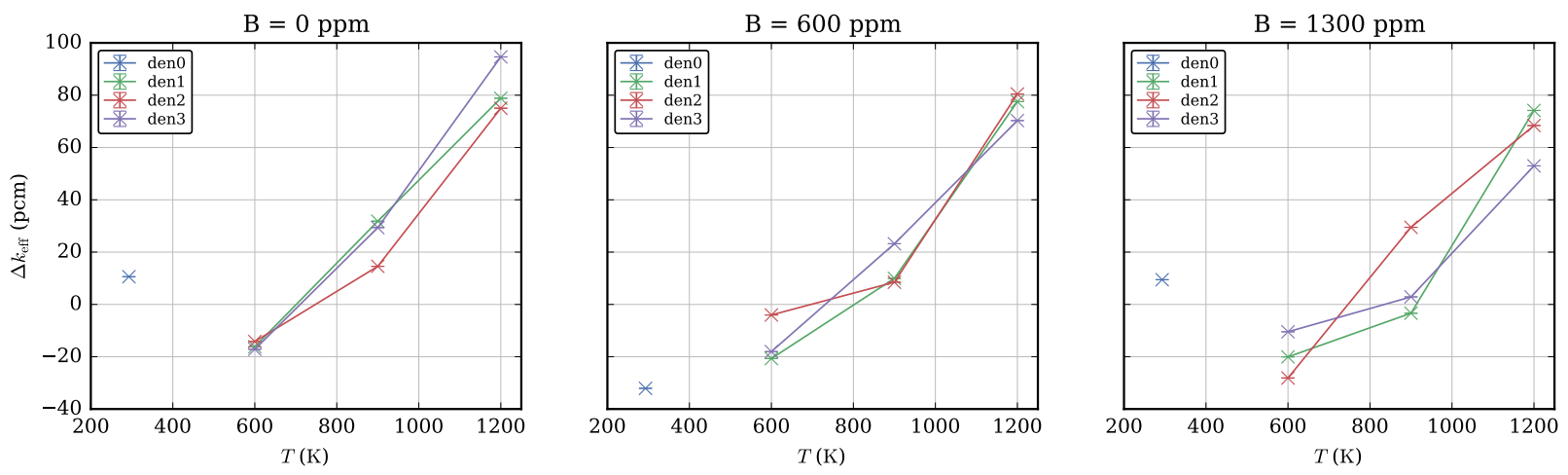

Figure 28. Difference in $k_{\text {eff }}$ for PWR41 Pincell. 

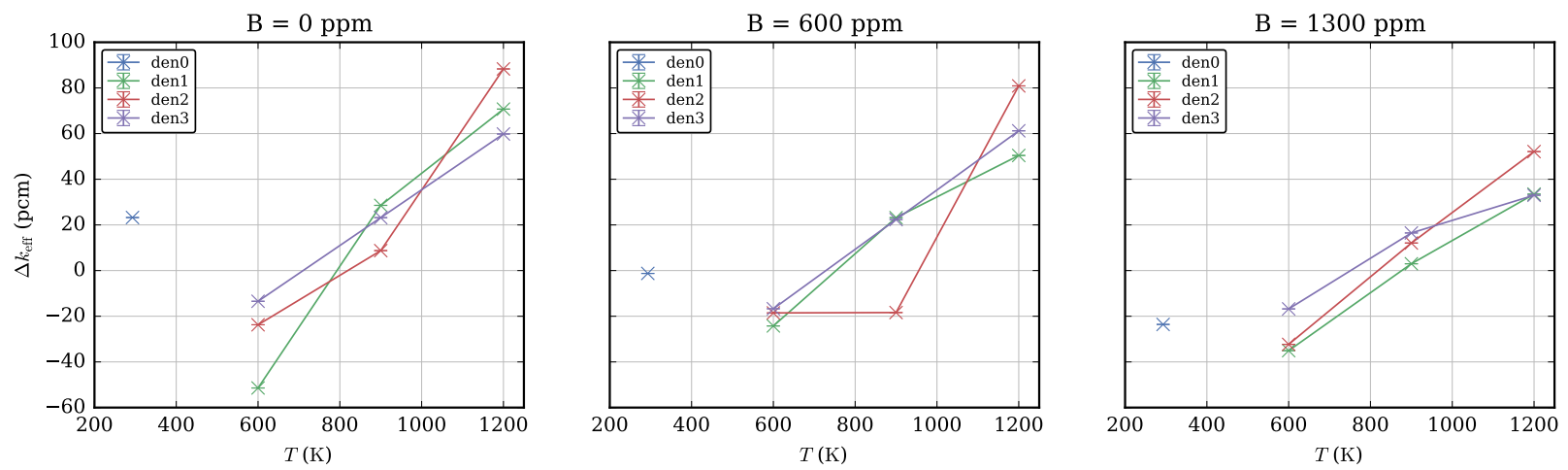

Figure 29. Difference in $k_{\text {eff }}$ for Surry Pincell. 


\section{FIXED SOURCE BENCHMARKS}

In this section we present results of Shift validation using coupled (neutron-photon) fixed source benchmarks.

\subsection{LEAKAGE SPECTRUM TESTS}

We ran a set of leakage problems consisting of a source in the center of a spherical shell of material, as outlined in the validation plan [3]. The neutron and photon spectra leaking out of the spherical shell were compared between Shift, MONACO [21], and MCNP6 [20]; all codes used ENDF B/VII.1 data libraries [22].

We ran the problems with the following set of isotopes: ${ }^{107} \mathrm{Ag},{ }^{27} \mathrm{Al}, \mathrm{C},{ }^{50} \mathrm{Cr},{ }^{53} \mathrm{Cr},{ }^{10} \mathrm{~B},{ }^{56} \mathrm{Fe},{ }^{155} \mathrm{Gd}$, ${ }^{157} \mathrm{Gd},{ }^{176} \mathrm{Hf},{ }^{62} \mathrm{Ni},{ }^{235} \mathrm{U},{ }^{236} \mathrm{U},{ }^{238} \mathrm{U},{ }^{91} \mathrm{Zr},{ }^{96} \mathrm{Zr}$. The following figures show the neutron and photon spectra from Shift, MONACO, and MCNP6 and the relative difference of these spectra compared to the Shift results. We show CE and MG physics Shift results using the SCALE CE 7.1 library and the SCALE 200 neutron and 47 photon group 7.1 library. MONACO was run using the same SCALE libraries, and MCNP6 was run only using its CE 7.1 library.

In Figures 30-61 we see very good agreement between Shift and MONACO spectra using CE and MG physics. This is expected since they are using the same data and mostly the same physics implementation. We see relatively good agreement between Shift and MCNP6 with the differences mainly attributed to the differences in the data libraries used. Note that the dips observed in these spectra plots are energies at which data is not available in the processed library so the flux is reported as zero. The shifted peak in the photon flux at low energy for ${ }^{236} \mathrm{U}$ calculated by Shift is still under investigation.

Overall, we have shown good agreement in neutron and photon leakage spectra between Shift, MONACO, and MCNP6 for a select range of nuclides. 

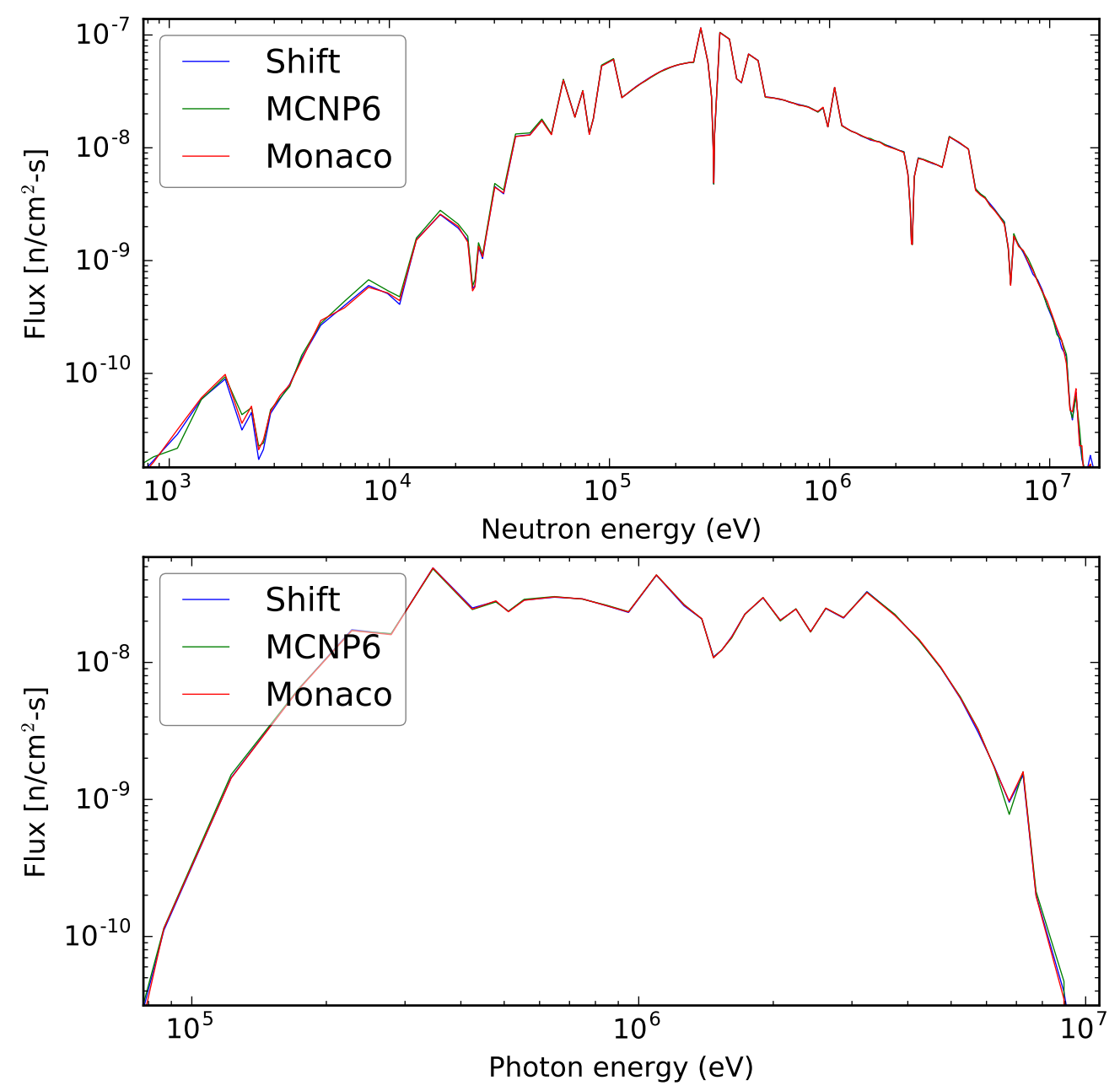

(a) Flux 

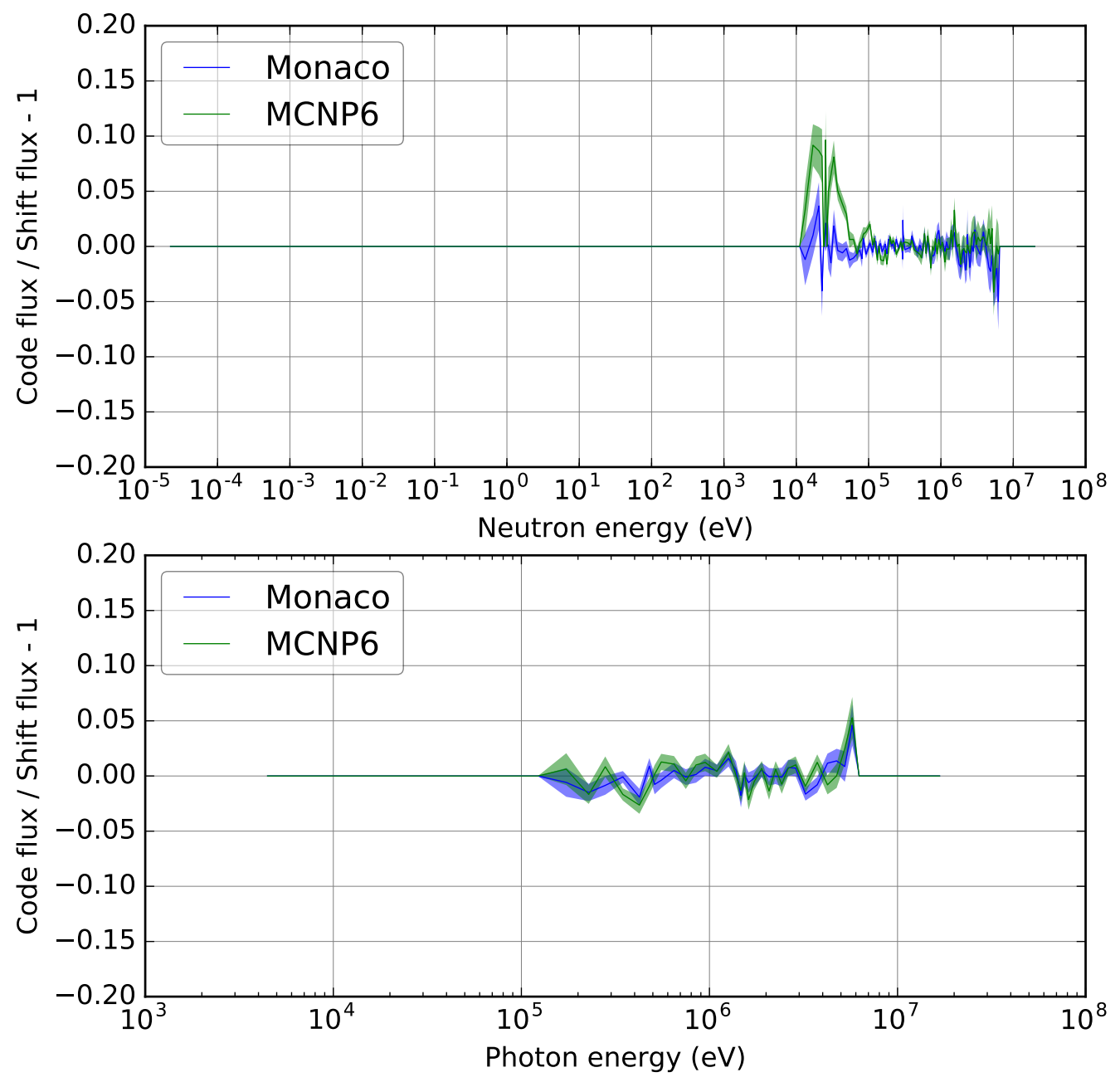

(b) Relative difference in flux

Figure 30. Calculated leakage using CE physics from ${ }^{107} \mathrm{Ag}$ spherical shell. 

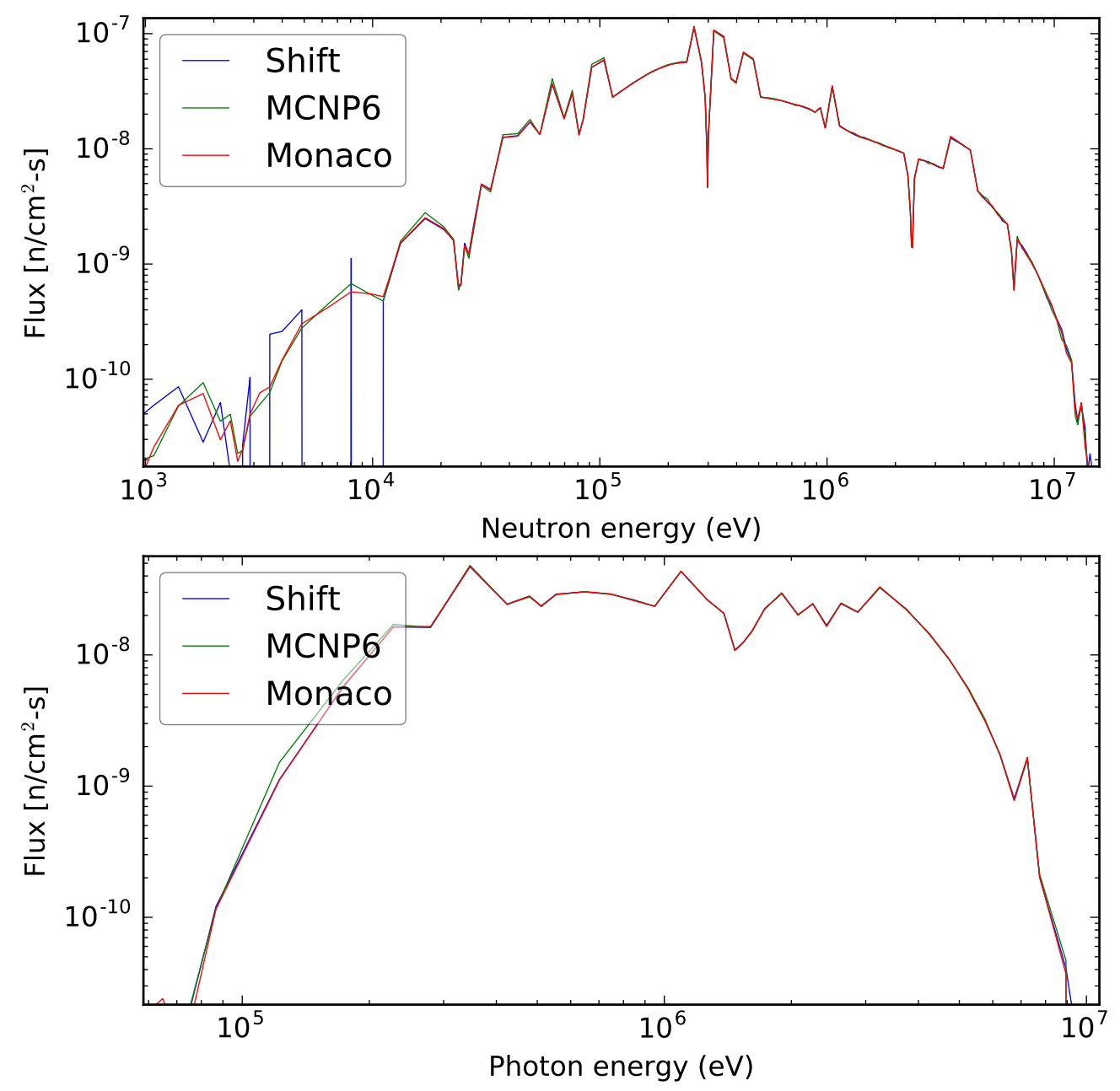

(a) Flux 

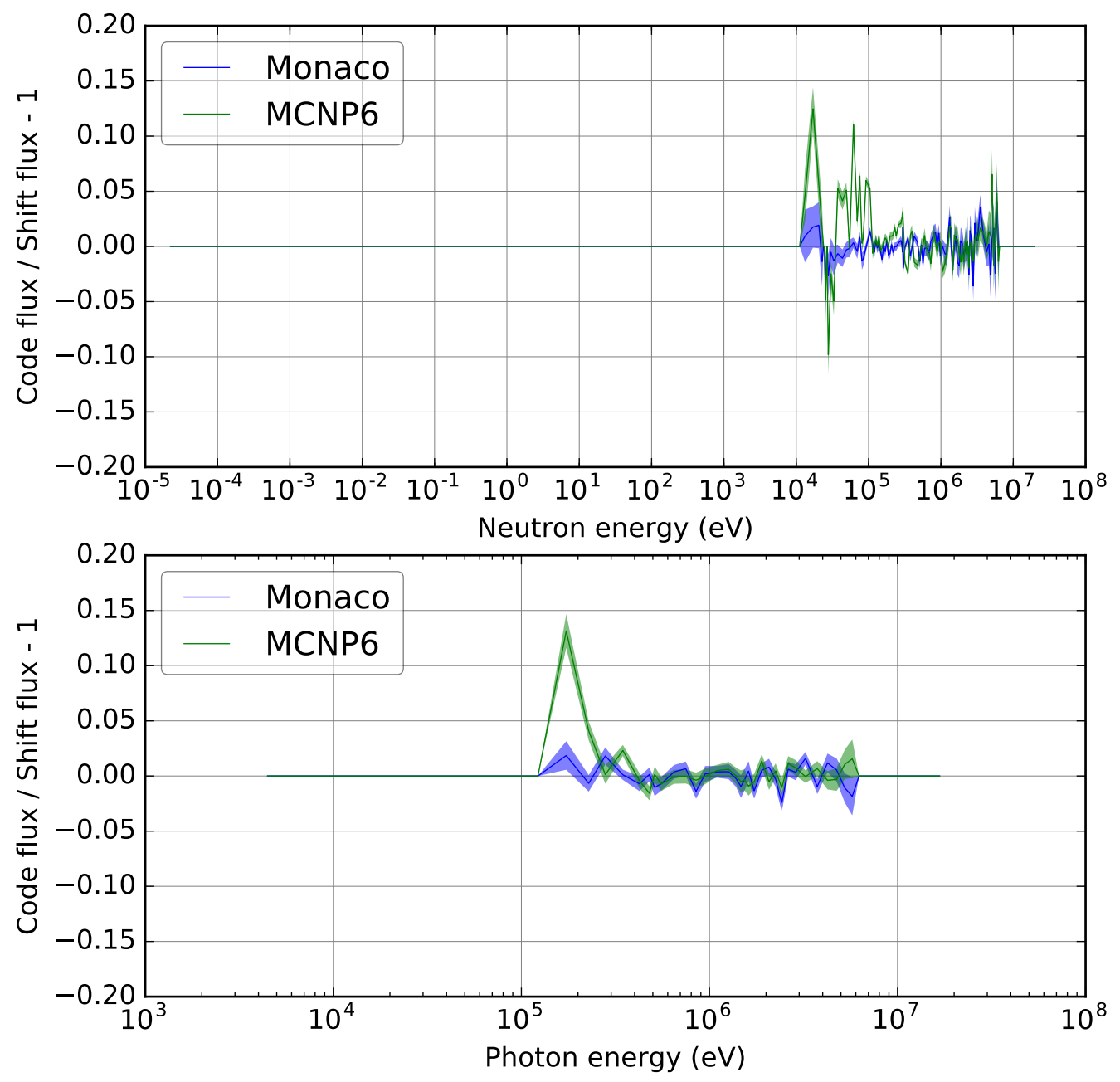

(b) Relative difference in flux

Figure 31. Calculated leakage using MG physics from ${ }^{107} \mathrm{Ag}$ spherical shell. 

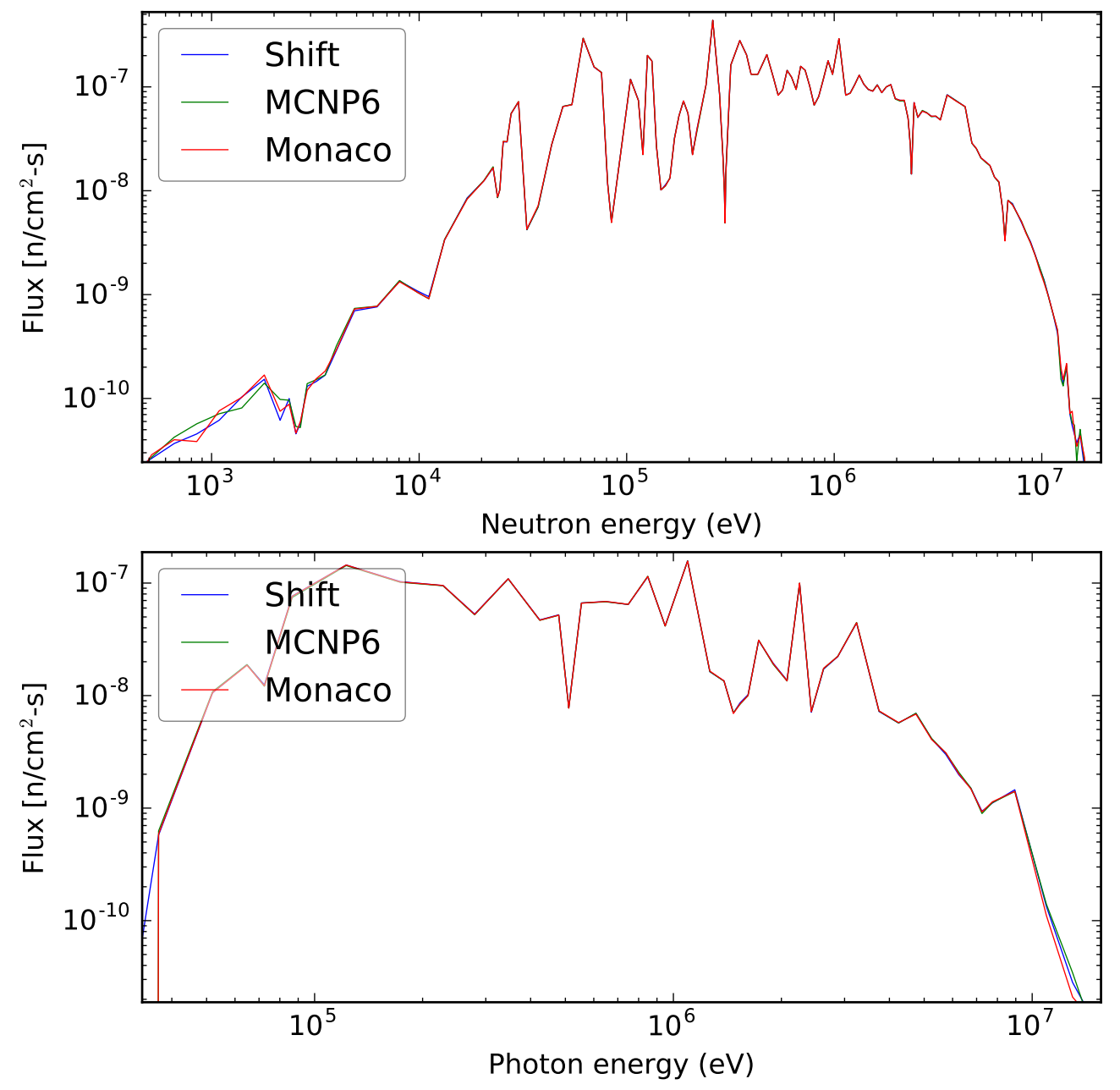

(a) Flux 

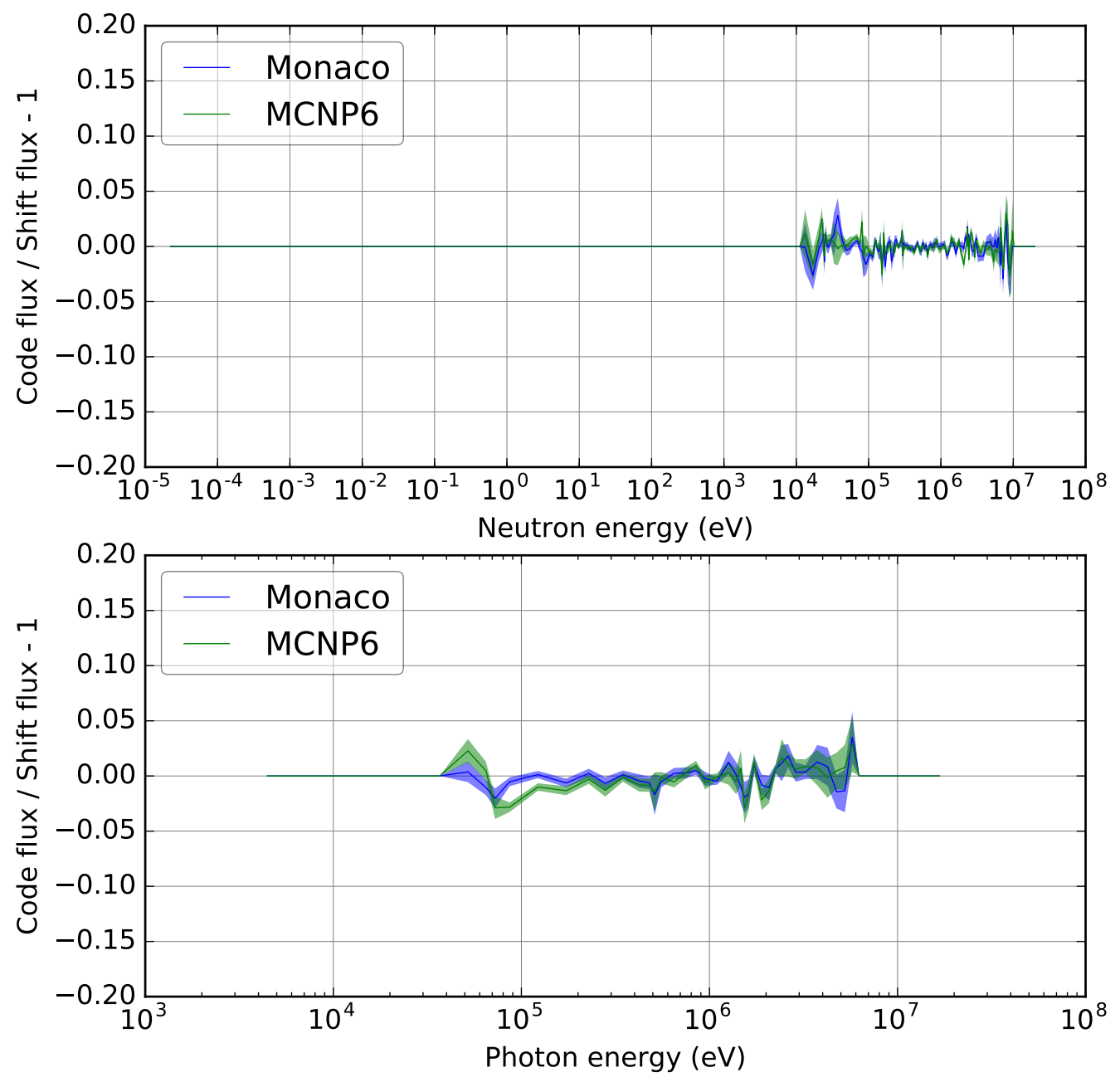

(b) Relative difference in flux

Figure 32. Calculated leakage using CE physics from ${ }^{27} \mathrm{Al}$ spherical shell. 

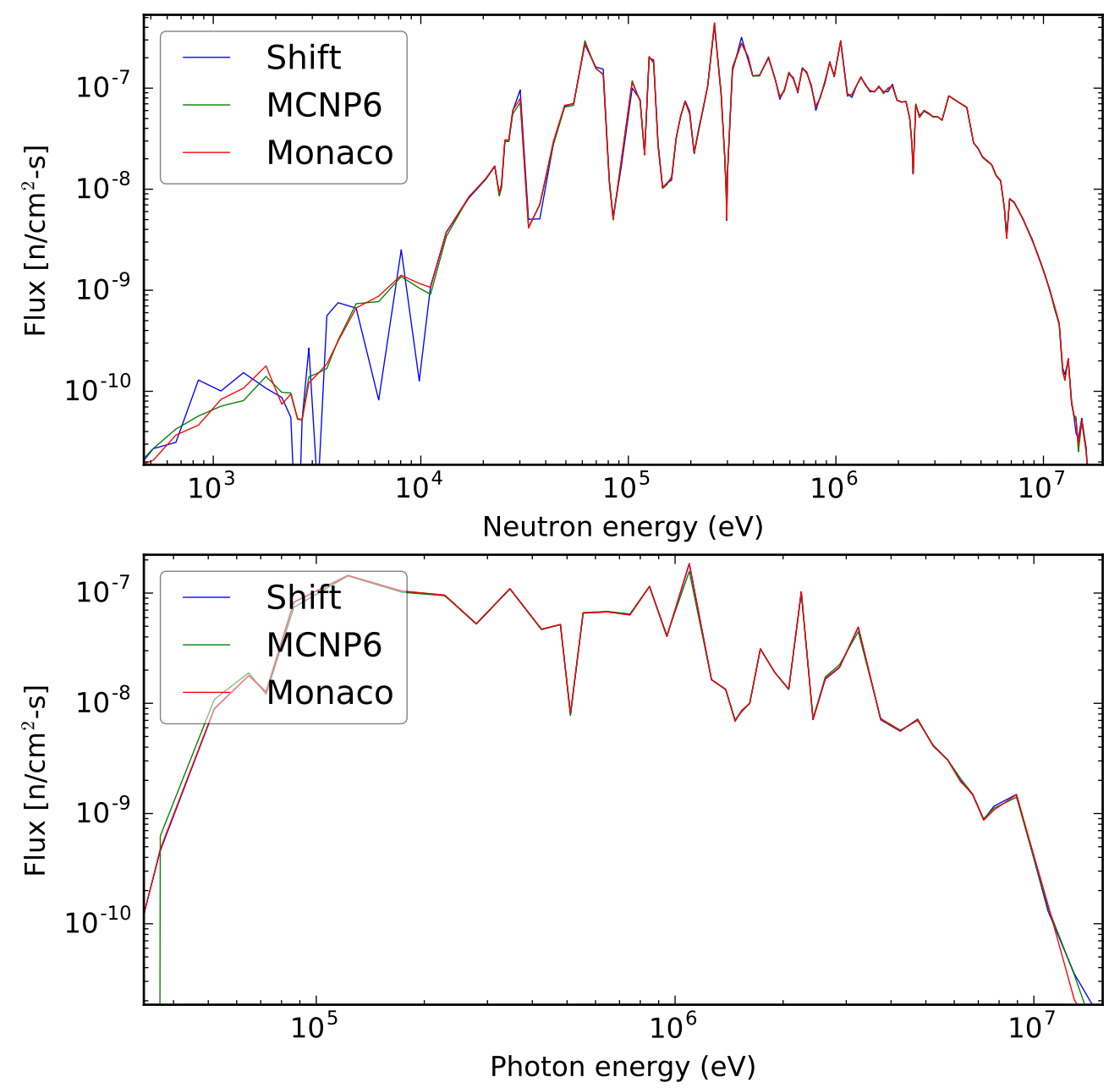

(a) Flux 

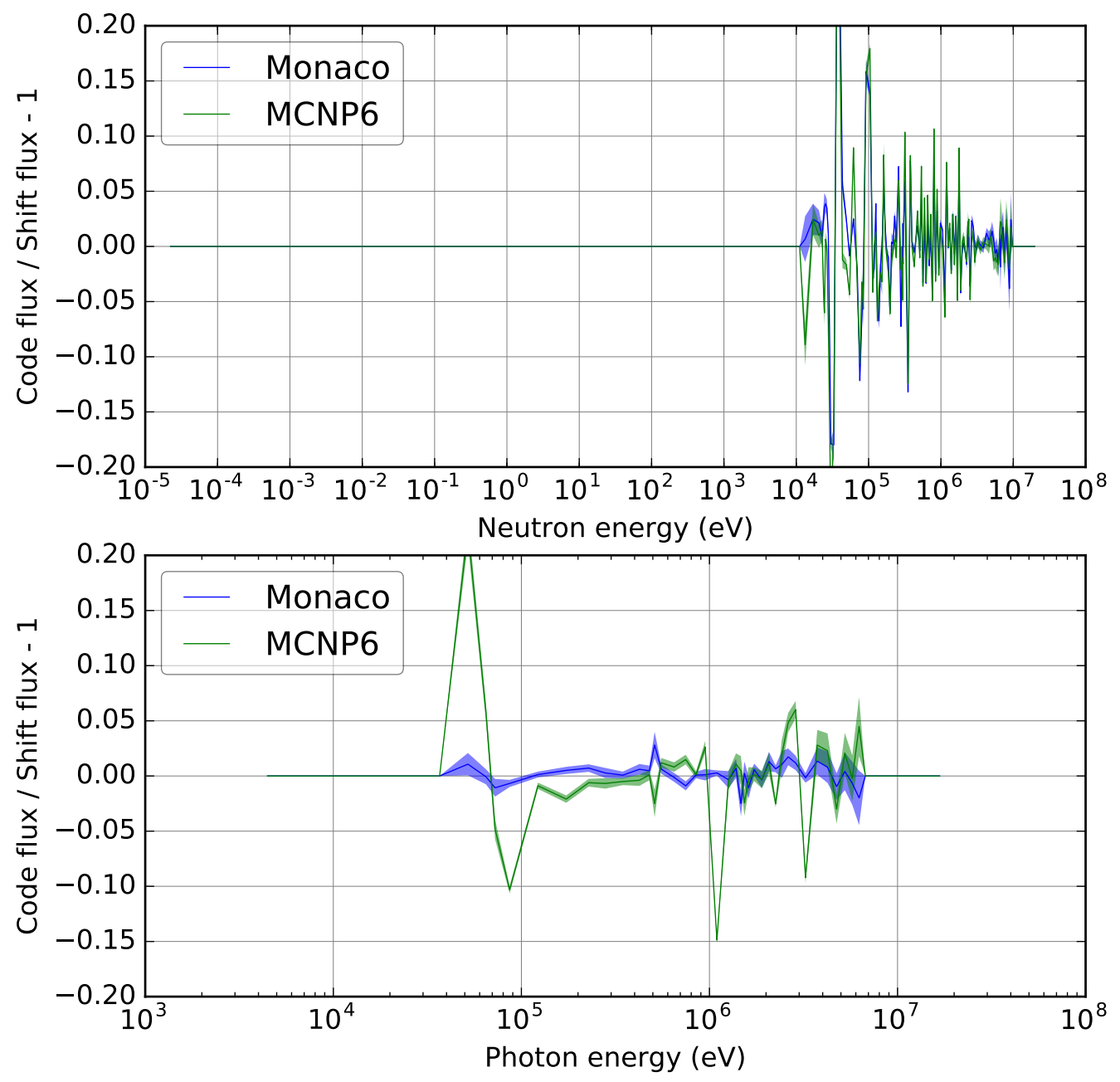

(b) Relative difference in flux

Figure 33. Calculated leakage using MG physics from ${ }^{27} \mathrm{Al}$ spherical shell. 

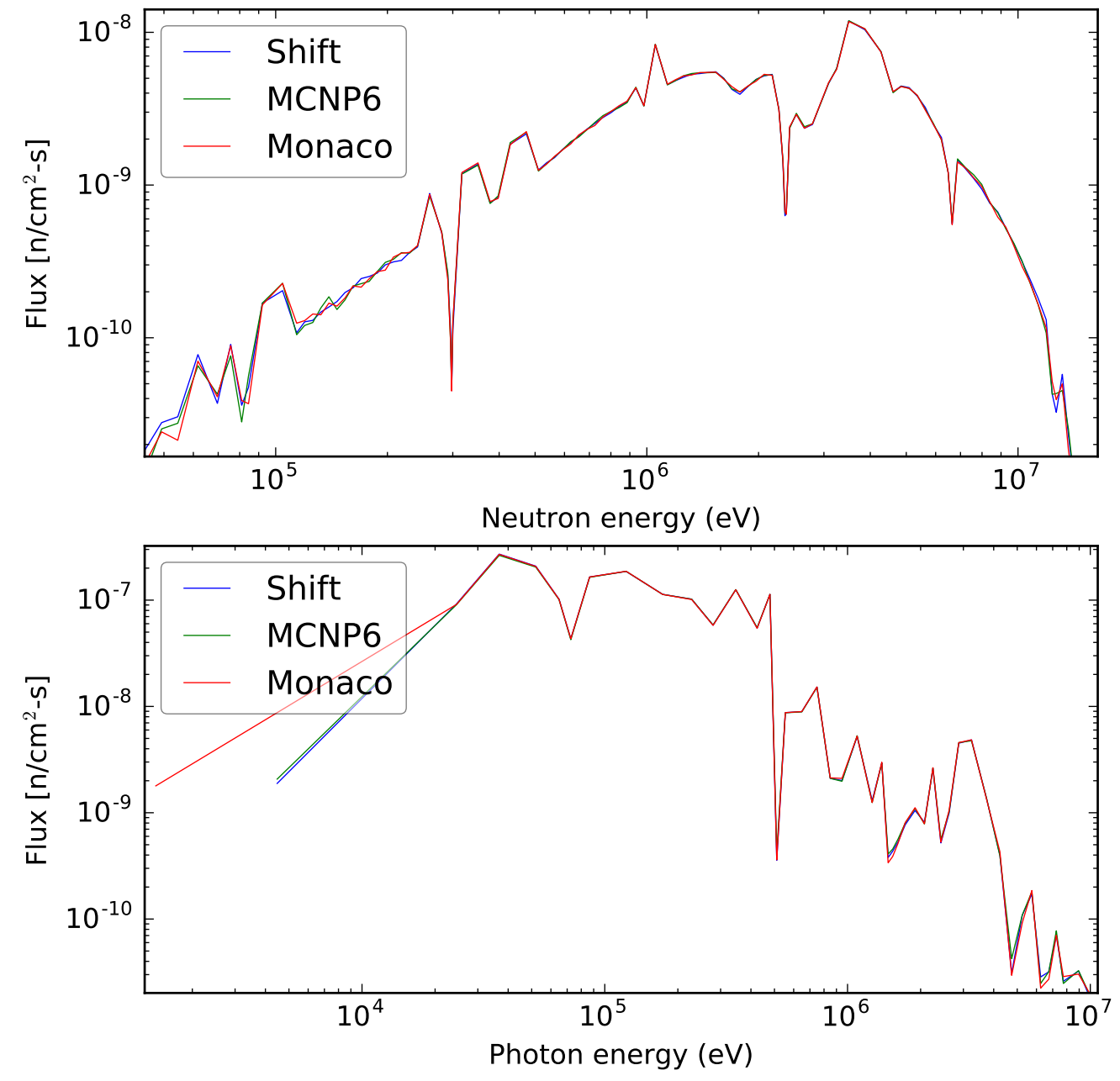

(a) Flux 

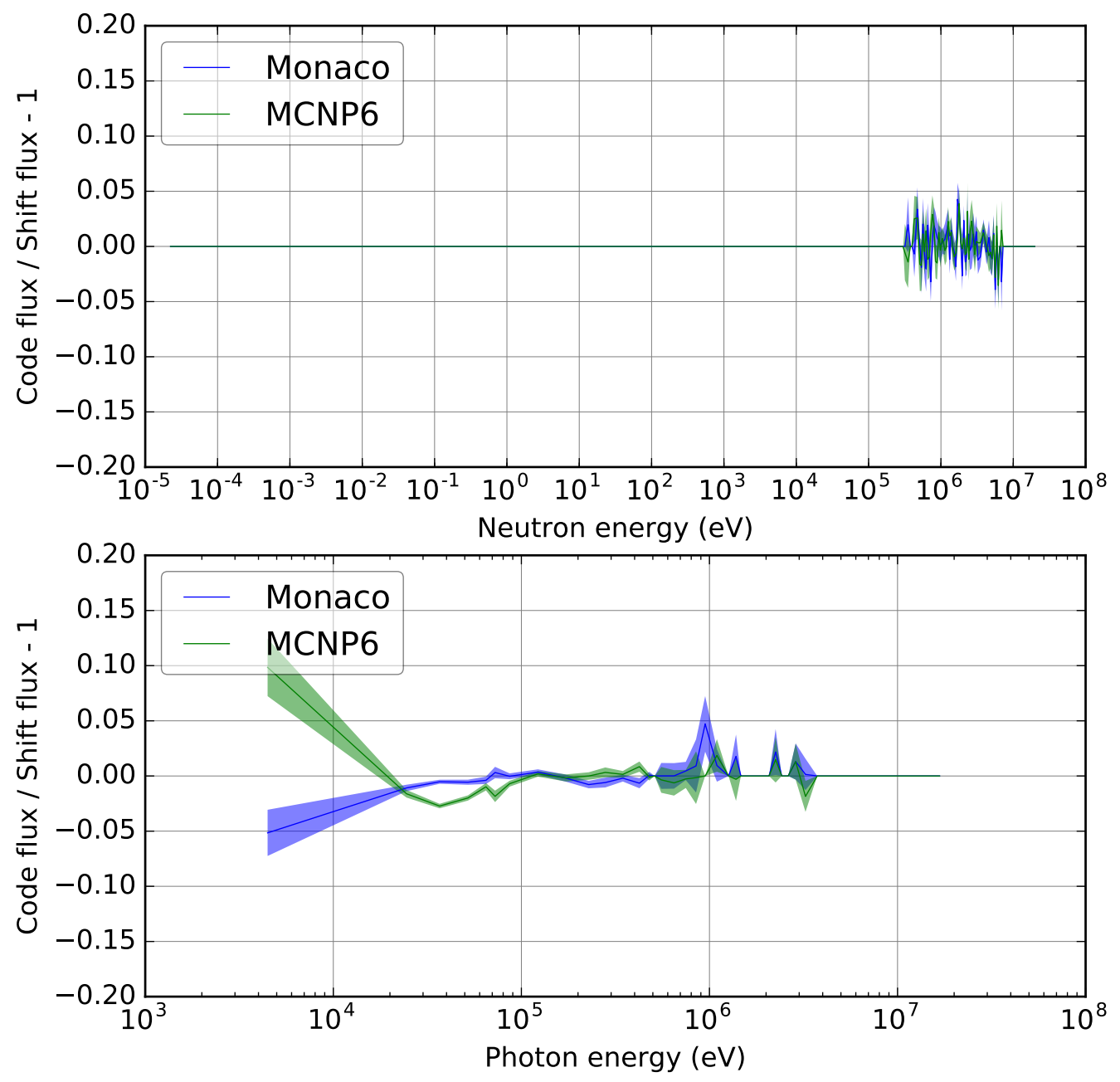

(b) Relative difference in flux

Figure 34. Calculated leakage using CE physics from ${ }^{10} \mathrm{~B}$ spherical shell. 

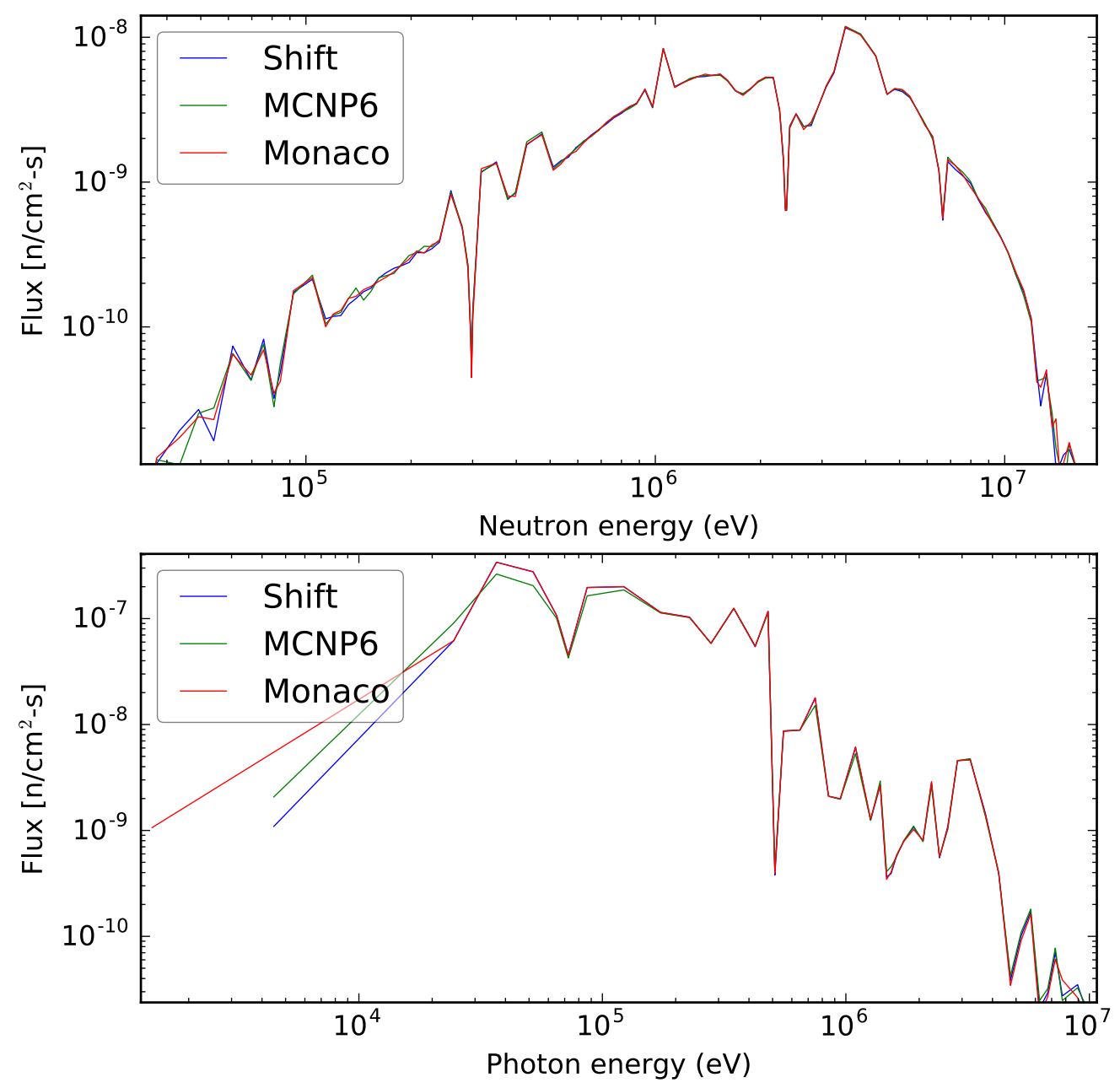

(a) Flux 

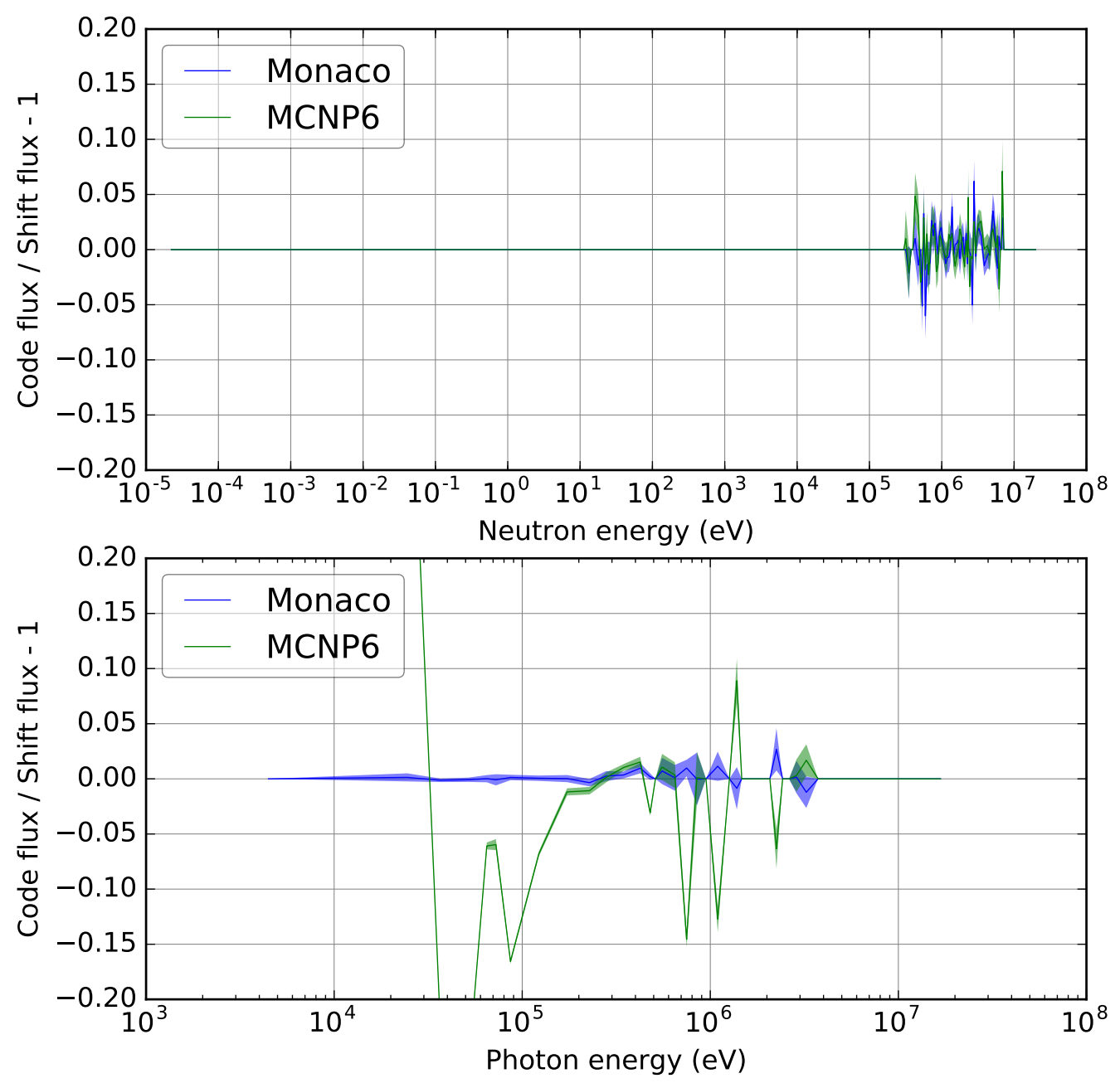

(b) Relative difference in flux

Figure 35. Calculated leakage using MG physics from ${ }^{10} \mathrm{~B}$ spherical shell. 

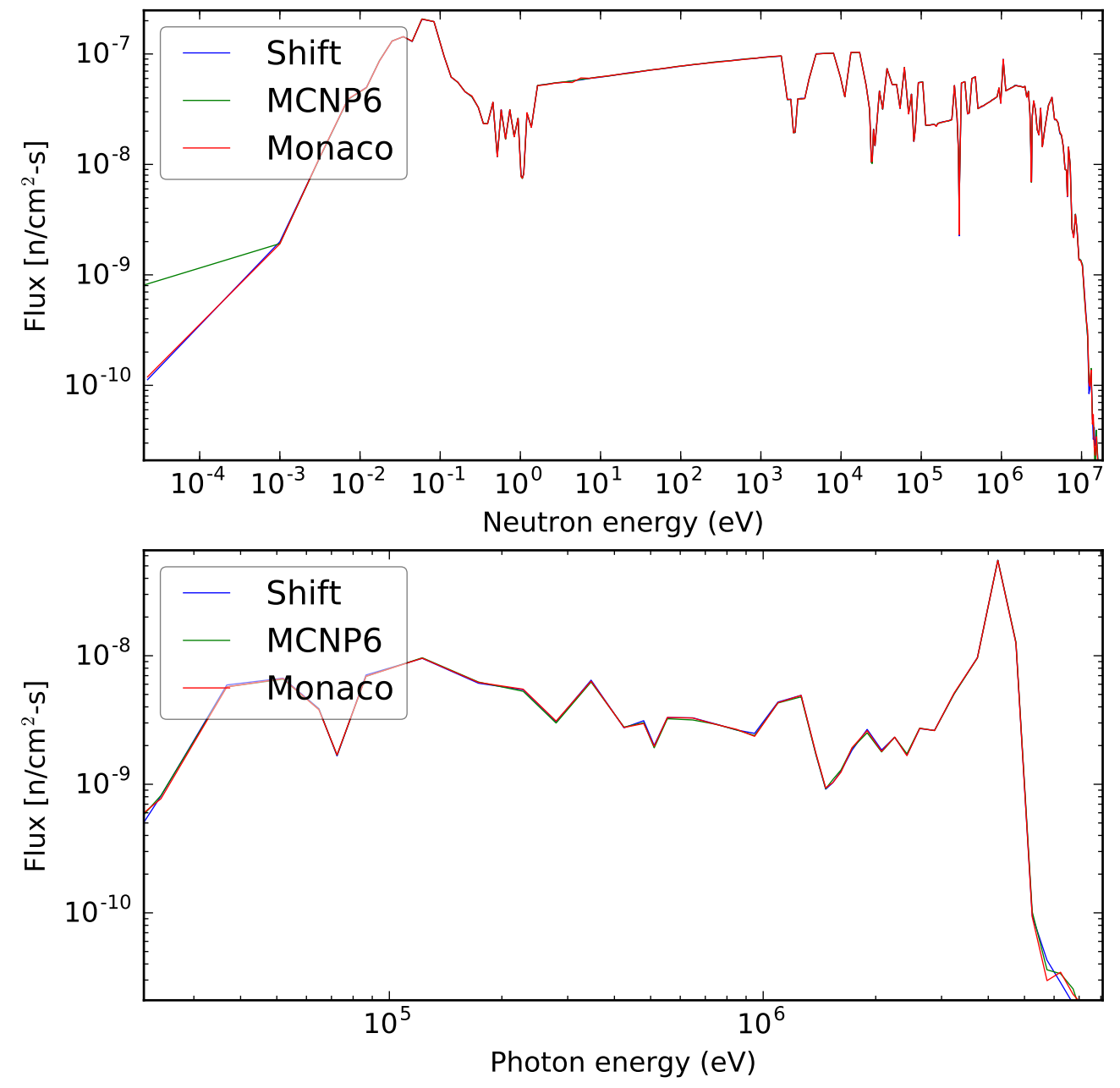

(a) Flux 

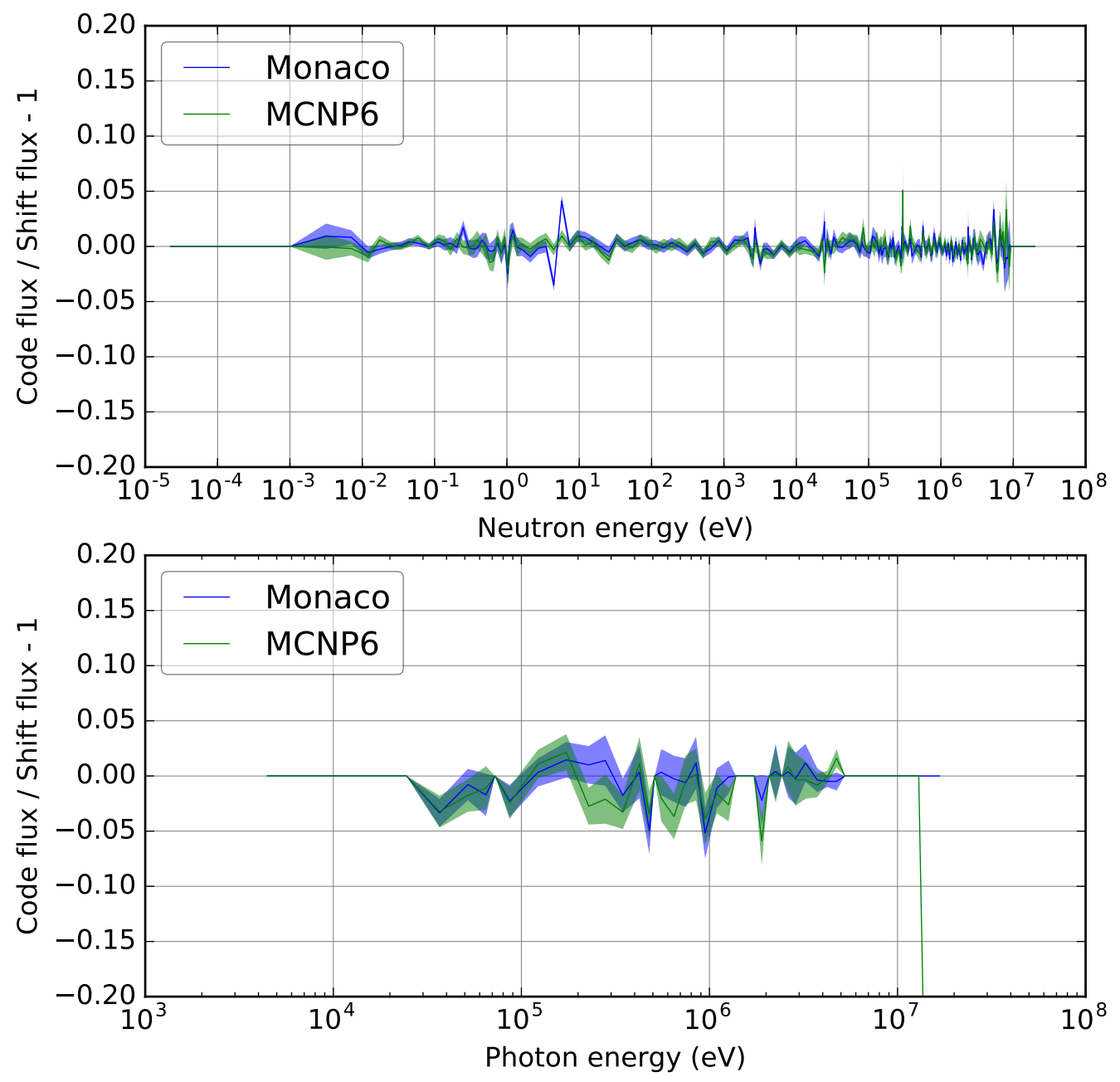

(b) Relative difference in flux

Figure 36. Calculated leakage using CE physics from Carbon spherical shell. 

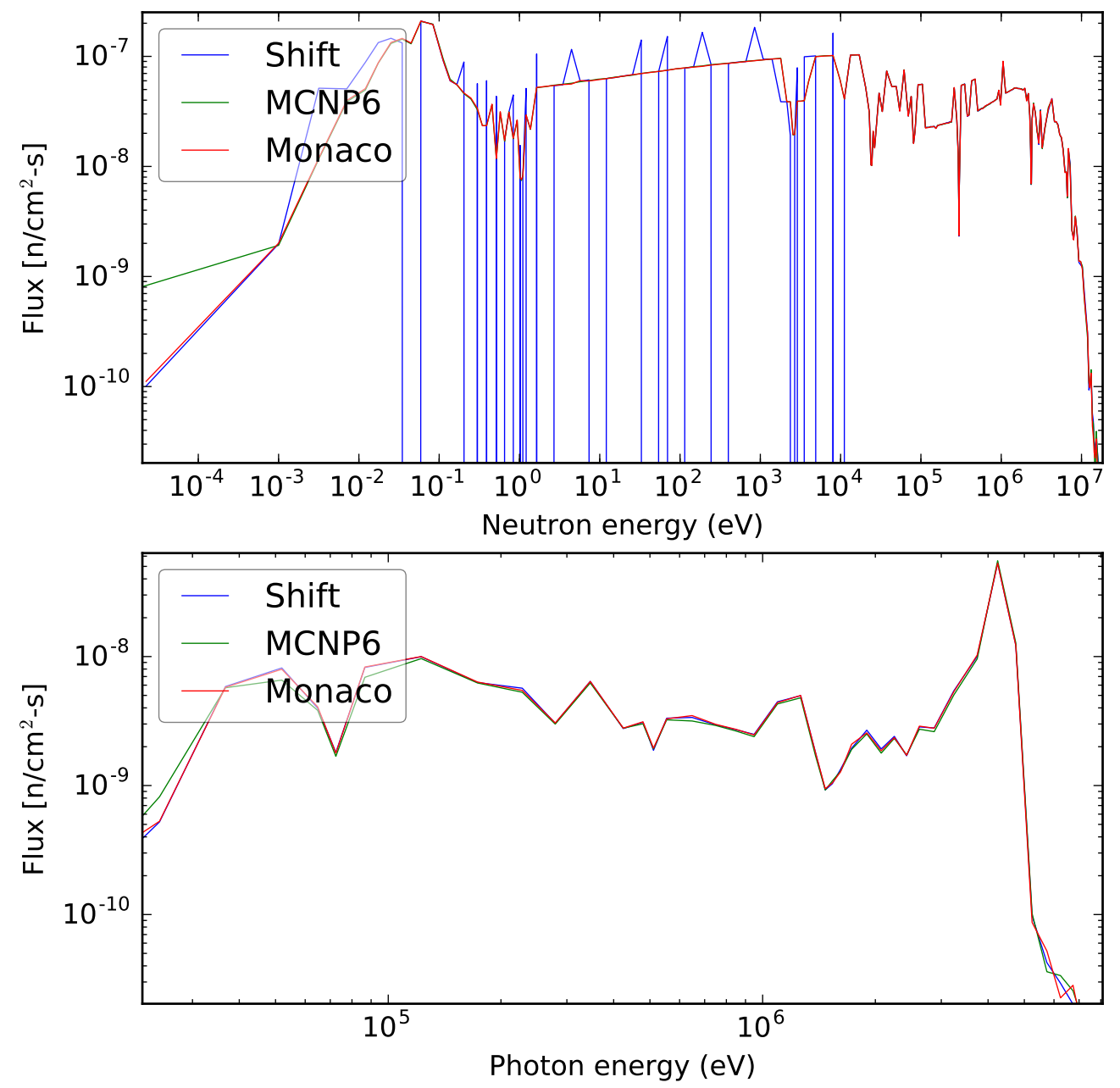

(a) Flux 

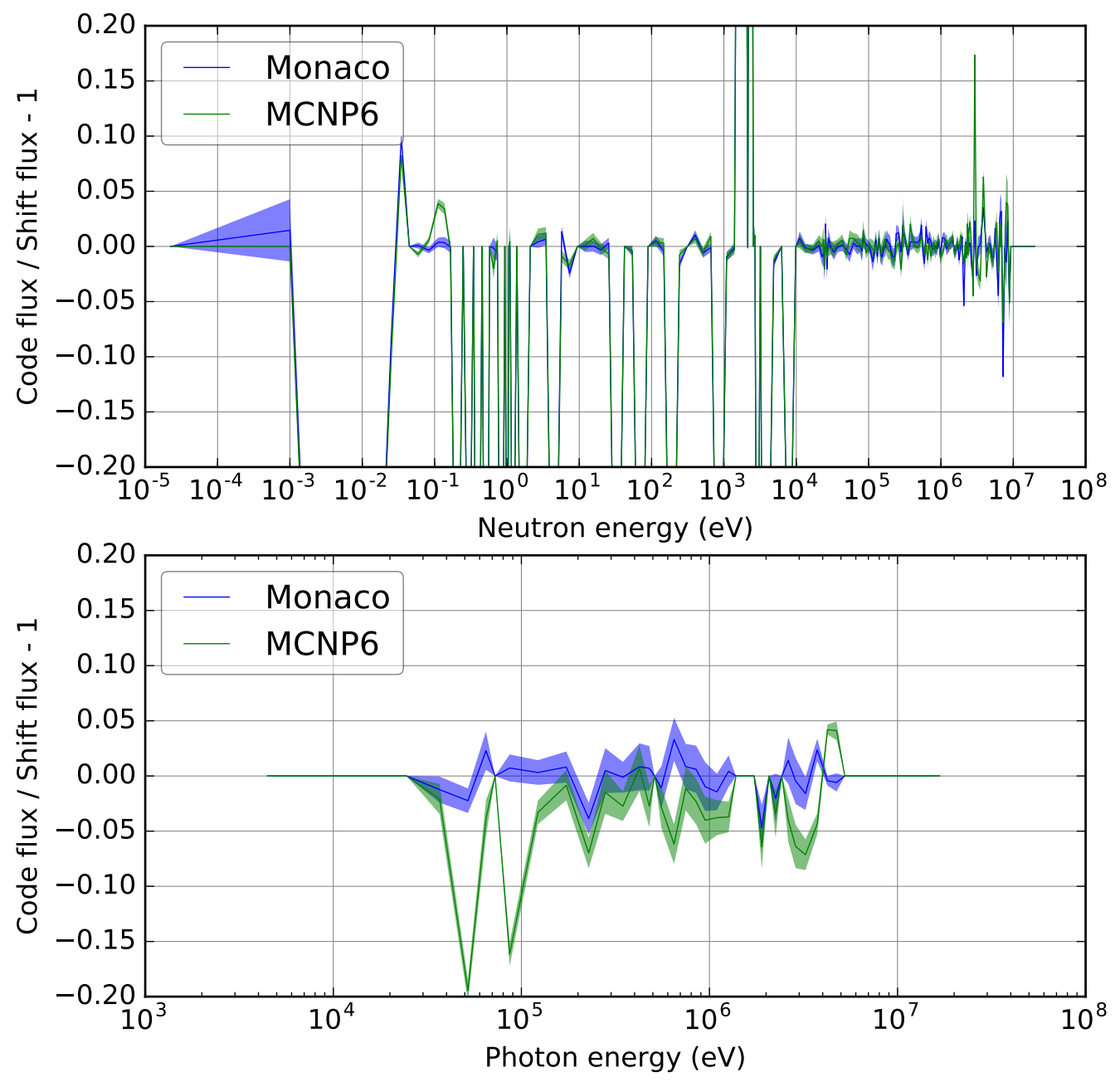

(b) Relative difference in flux

Figure 37. Calculated leakage using MG physics from Carbon spherical shell. 

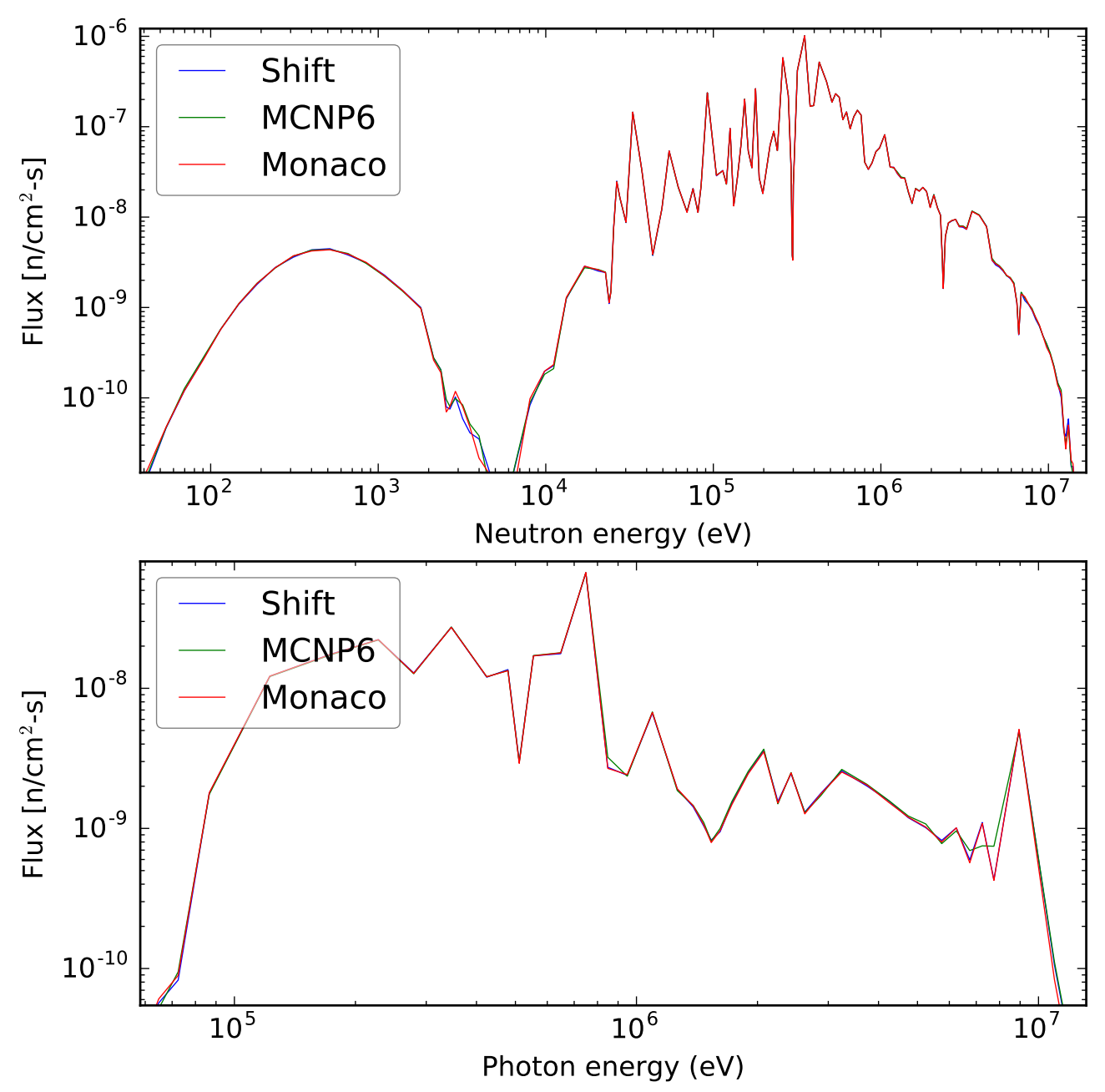

(a) Flux 

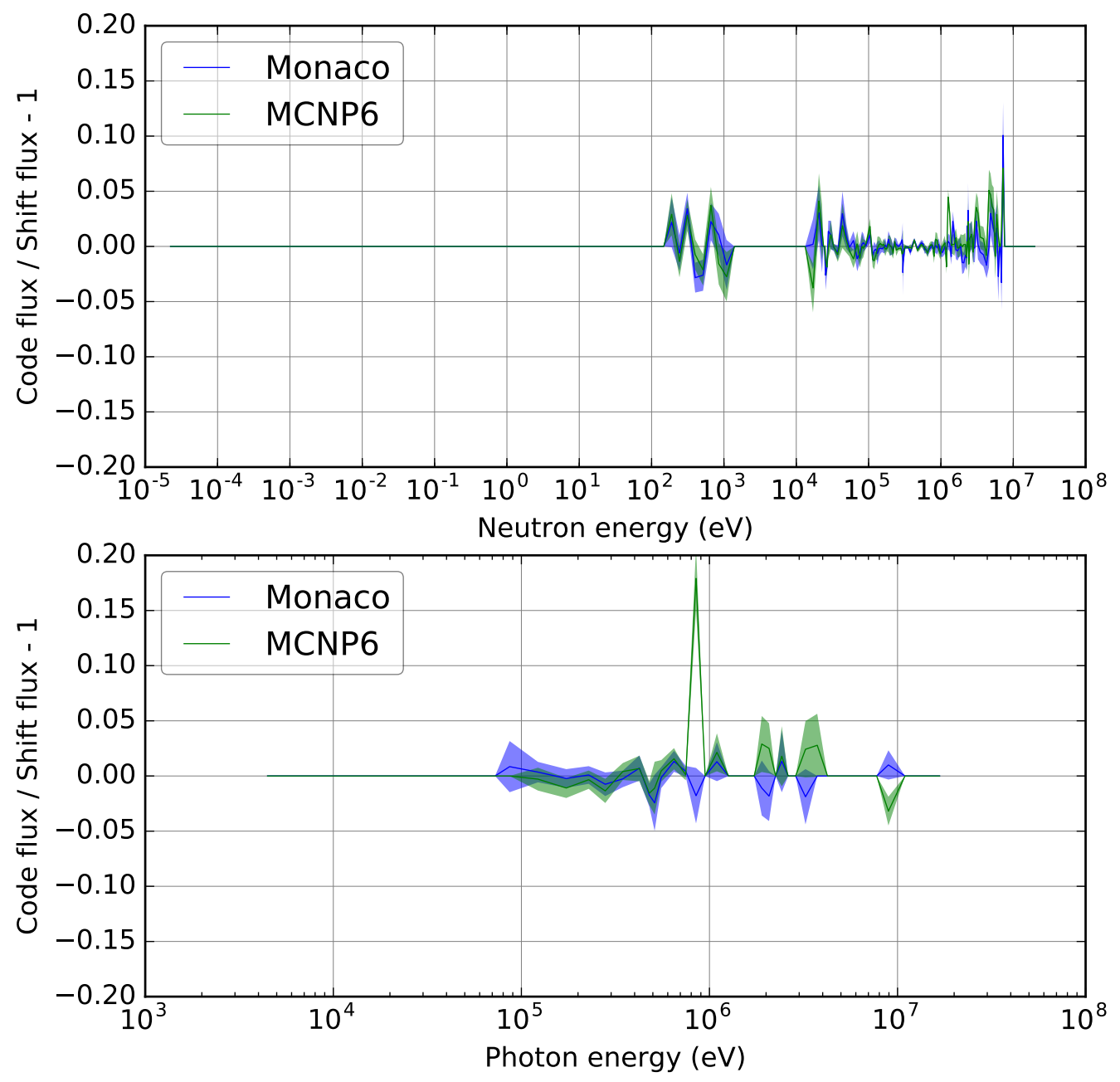

(b) Relative difference in flux

Figure 38. Calculated leakage using CE physics from ${ }^{50} \mathrm{Cr}$ spherical shell. 

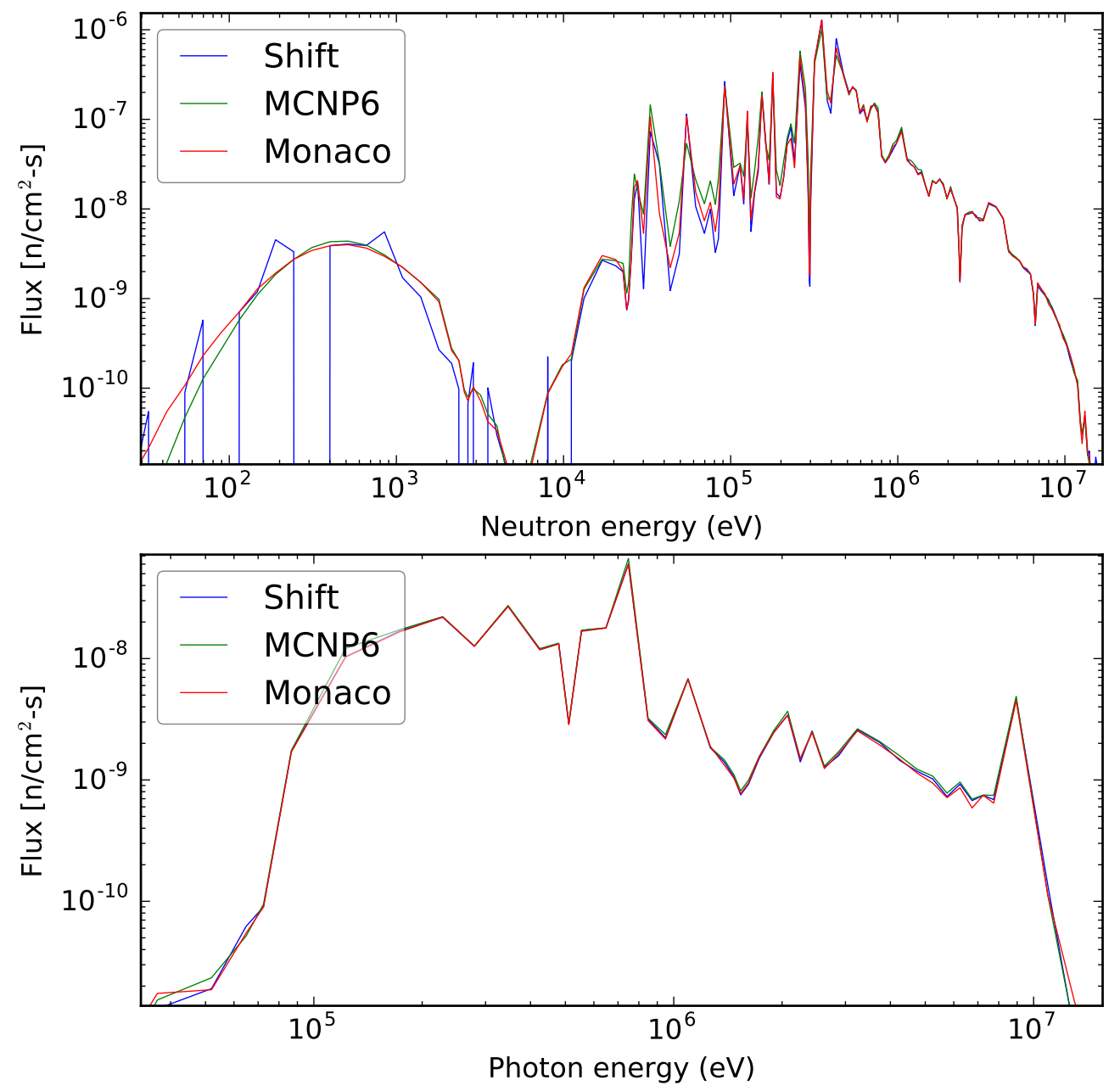

(a) Flux 

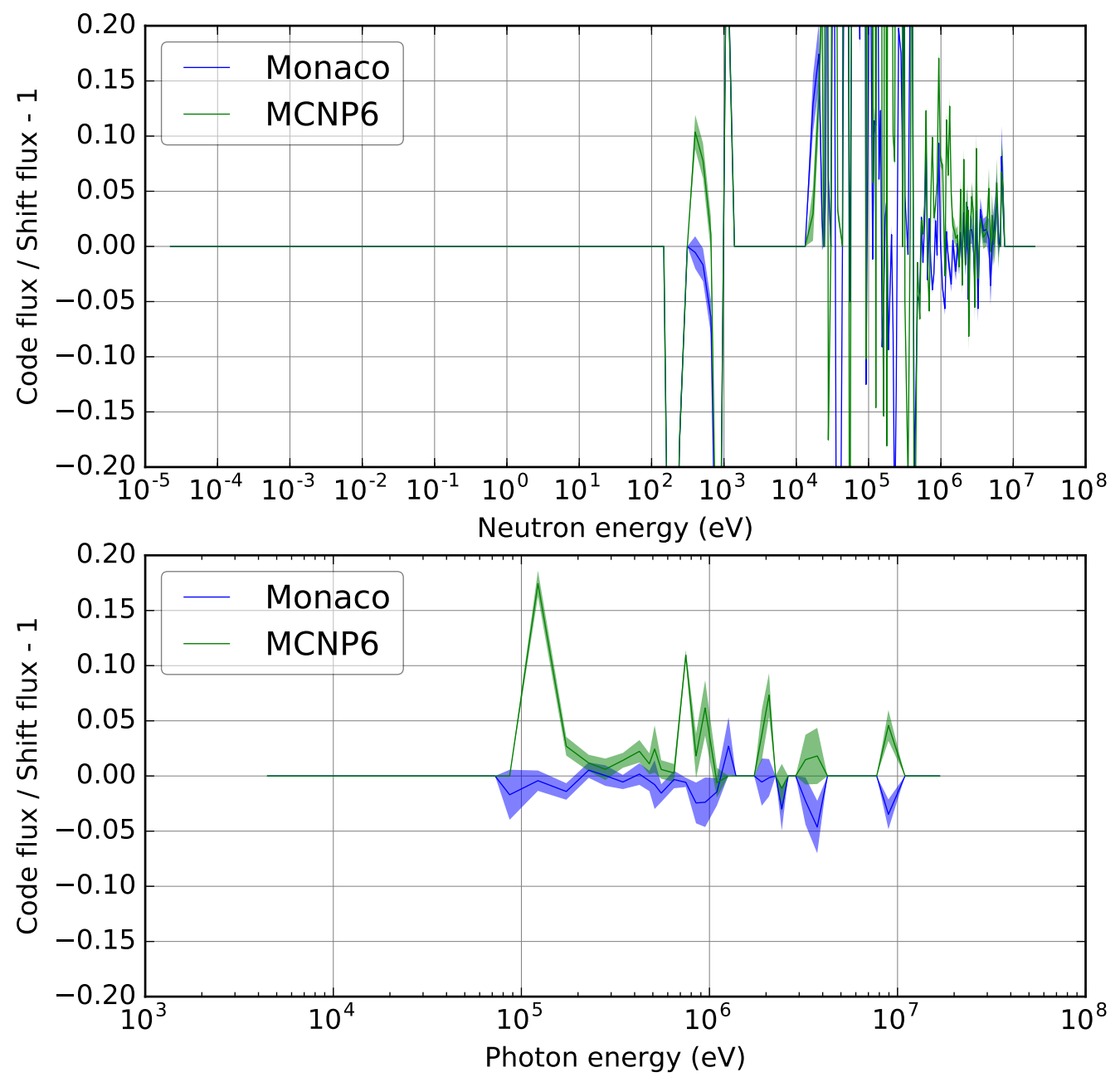

(b) Relative difference in flux

Figure 39. Calculated leakage using MG physics from ${ }^{50} \mathrm{Cr}$ spherical shell. 

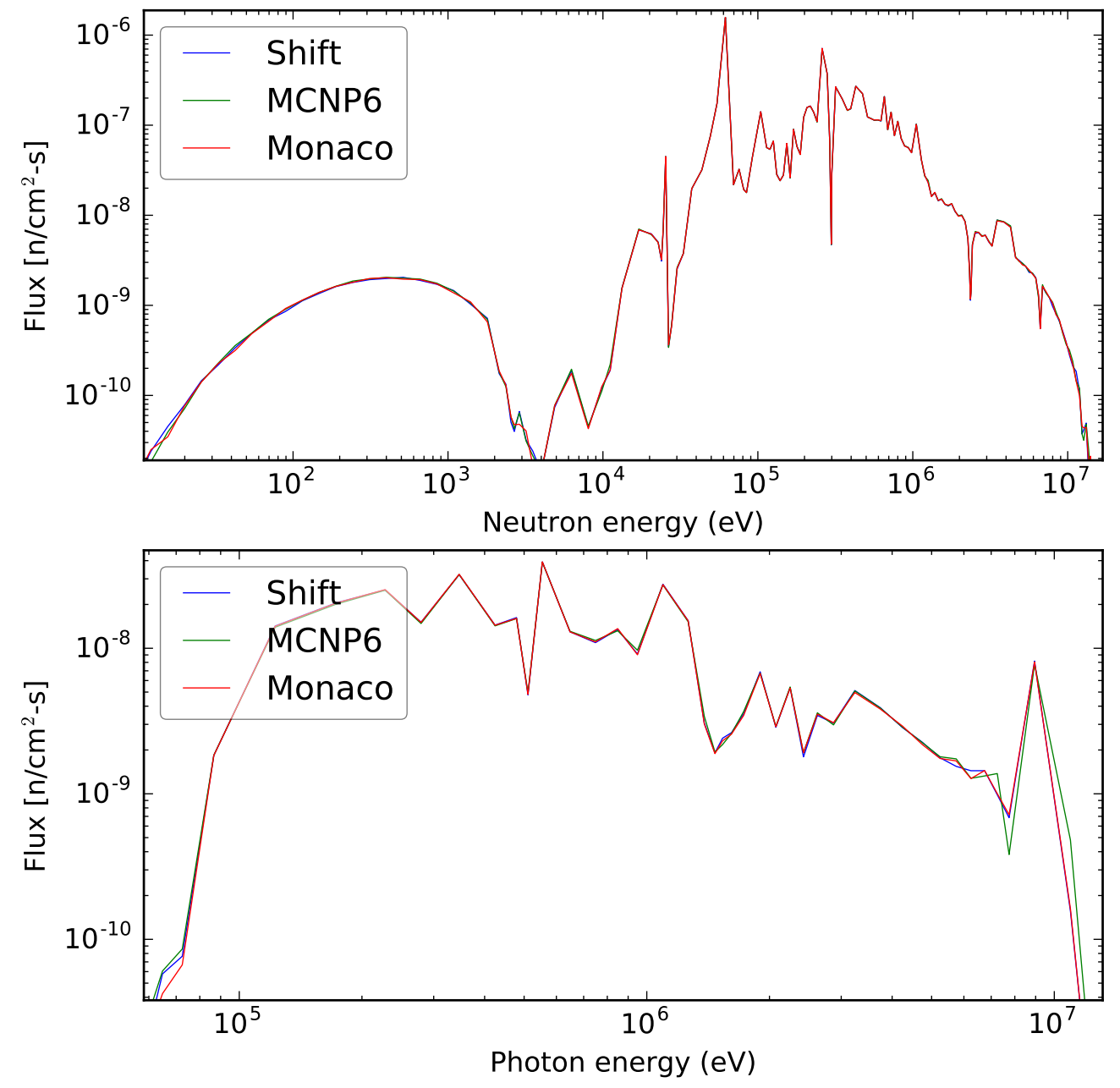

(a) Flux 

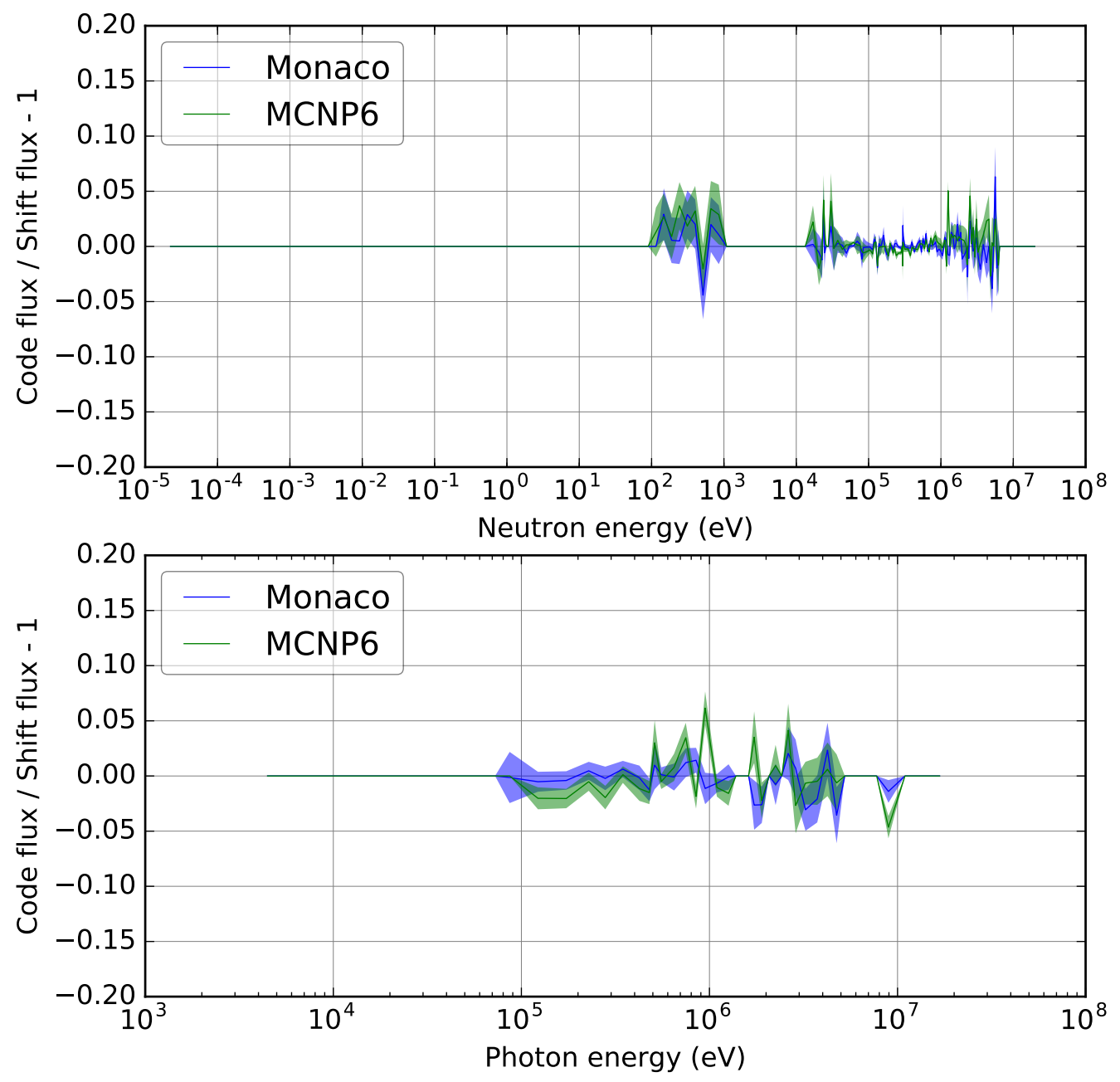

(b) Relative difference in flux

Figure 40. Calculated leakage using CE physics from ${ }^{53} \mathrm{Cr}$ spherical shell. 

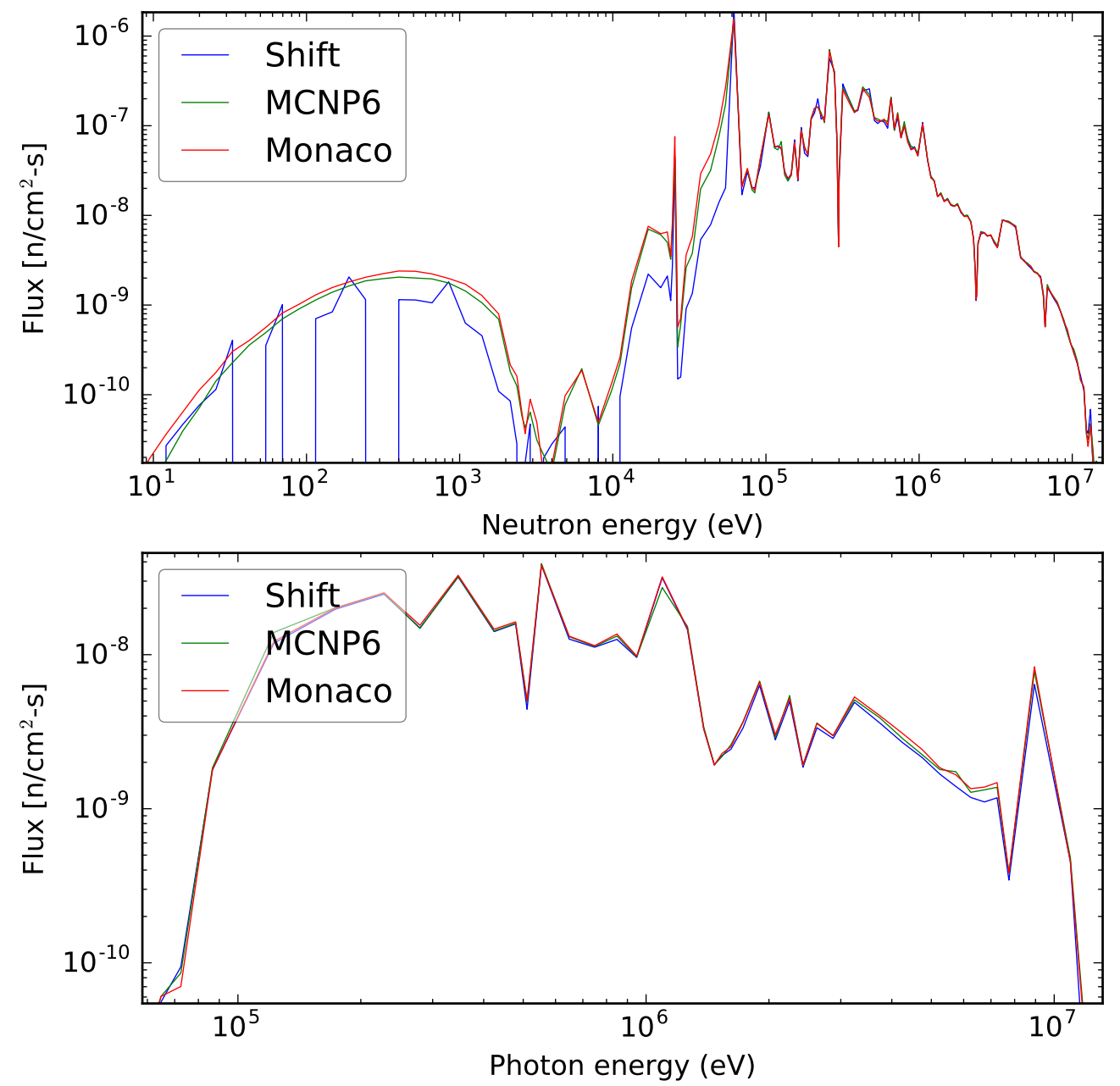

(a) Flux 

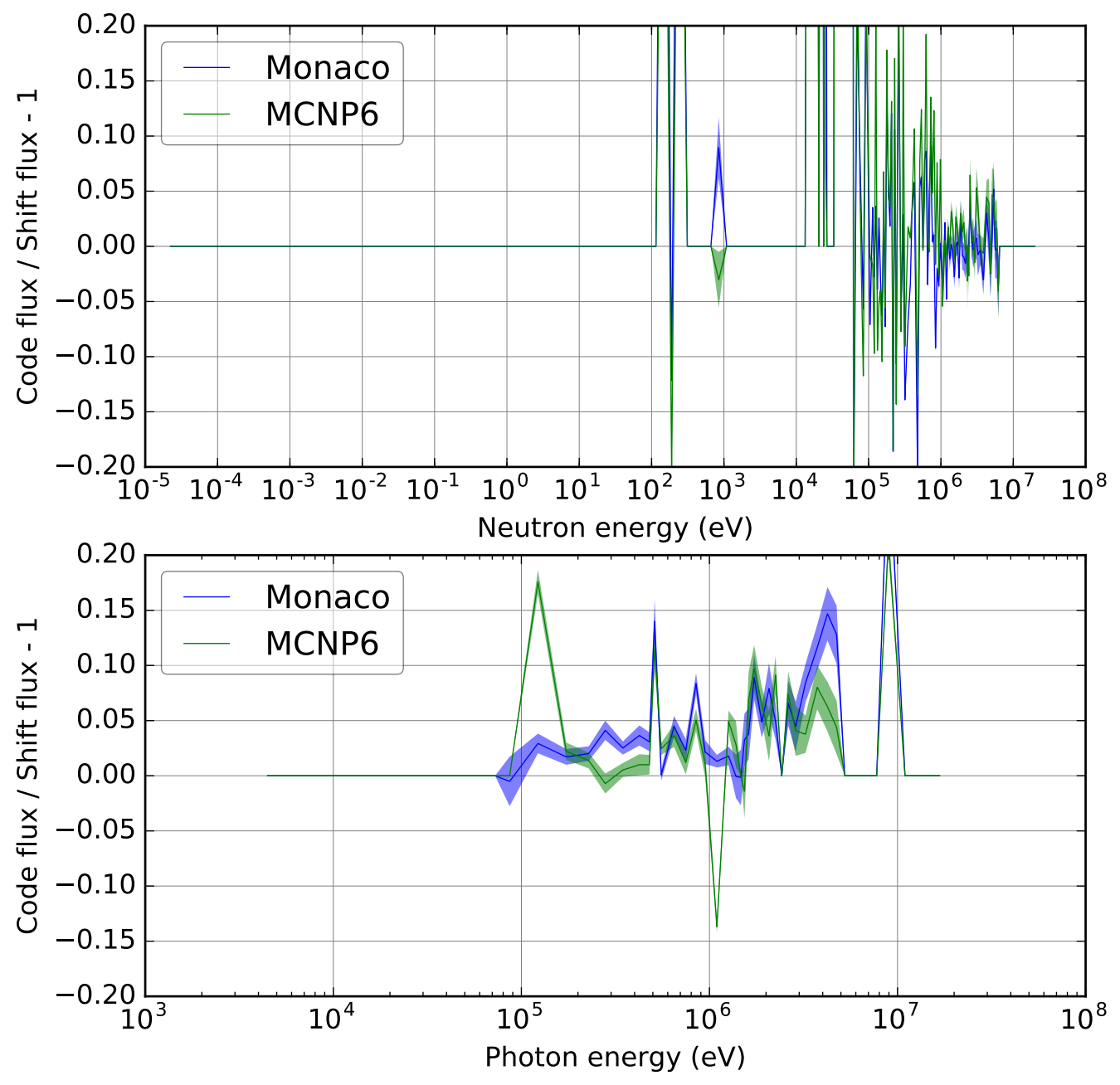

(b) Relative difference in flux

Figure 41. Calculated leakage using MG physics from ${ }^{53} \mathrm{Cr}$ spherical shell. 

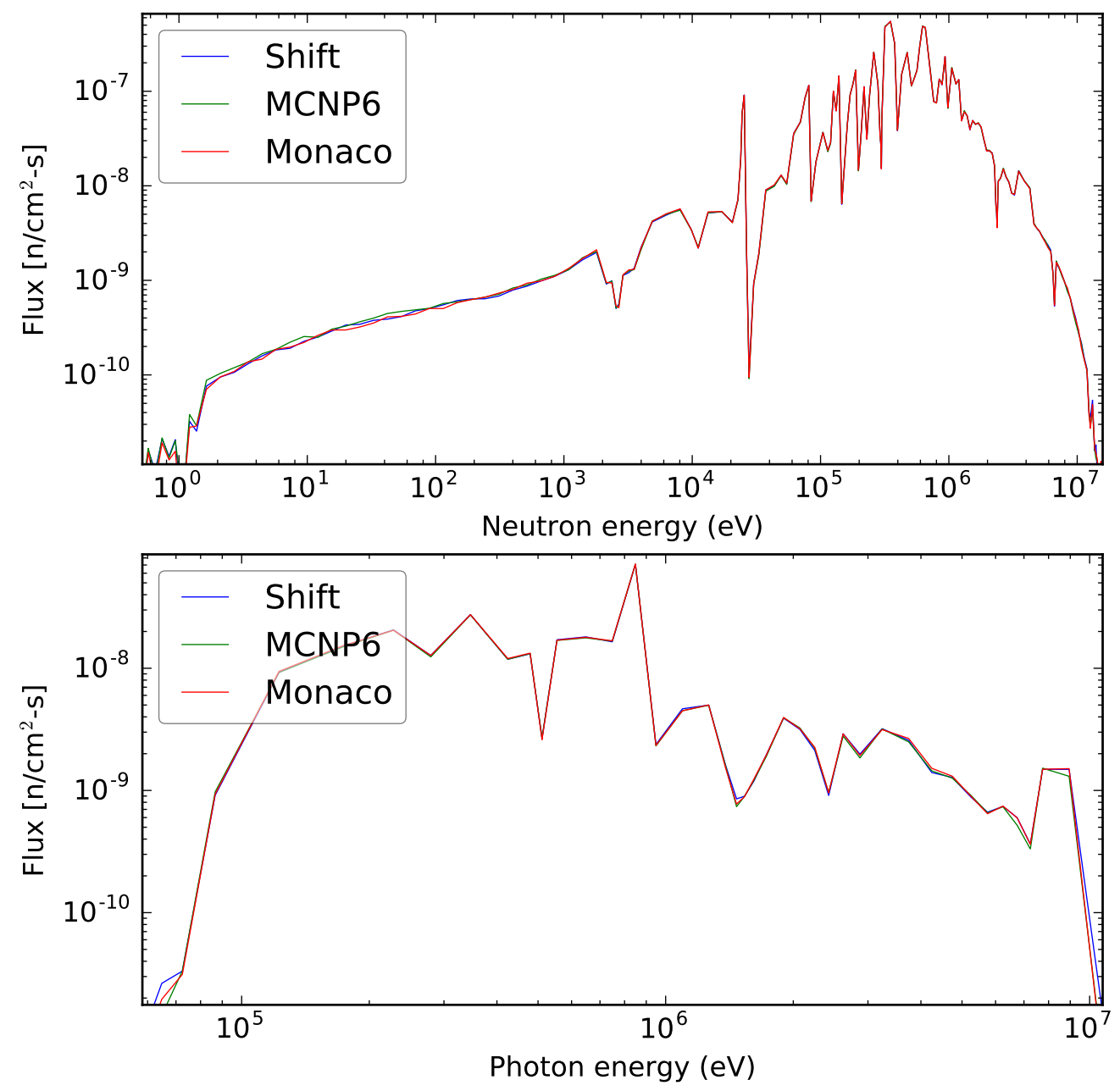

(a) Flux 

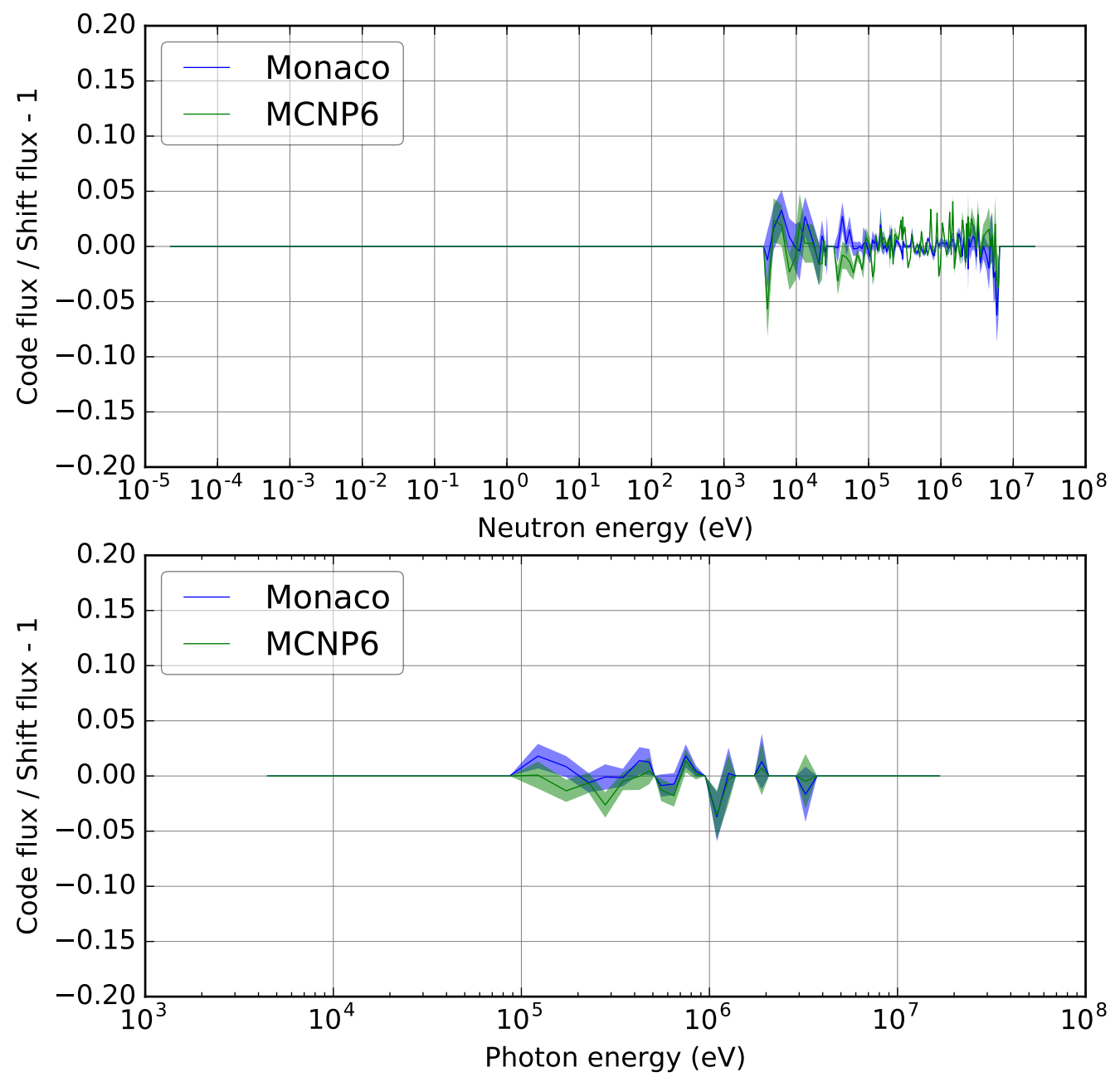

(b) Relative difference in flux

Figure 42. Calculated leakage using CE physics from ${ }^{56}$ Fe spherical shell. 

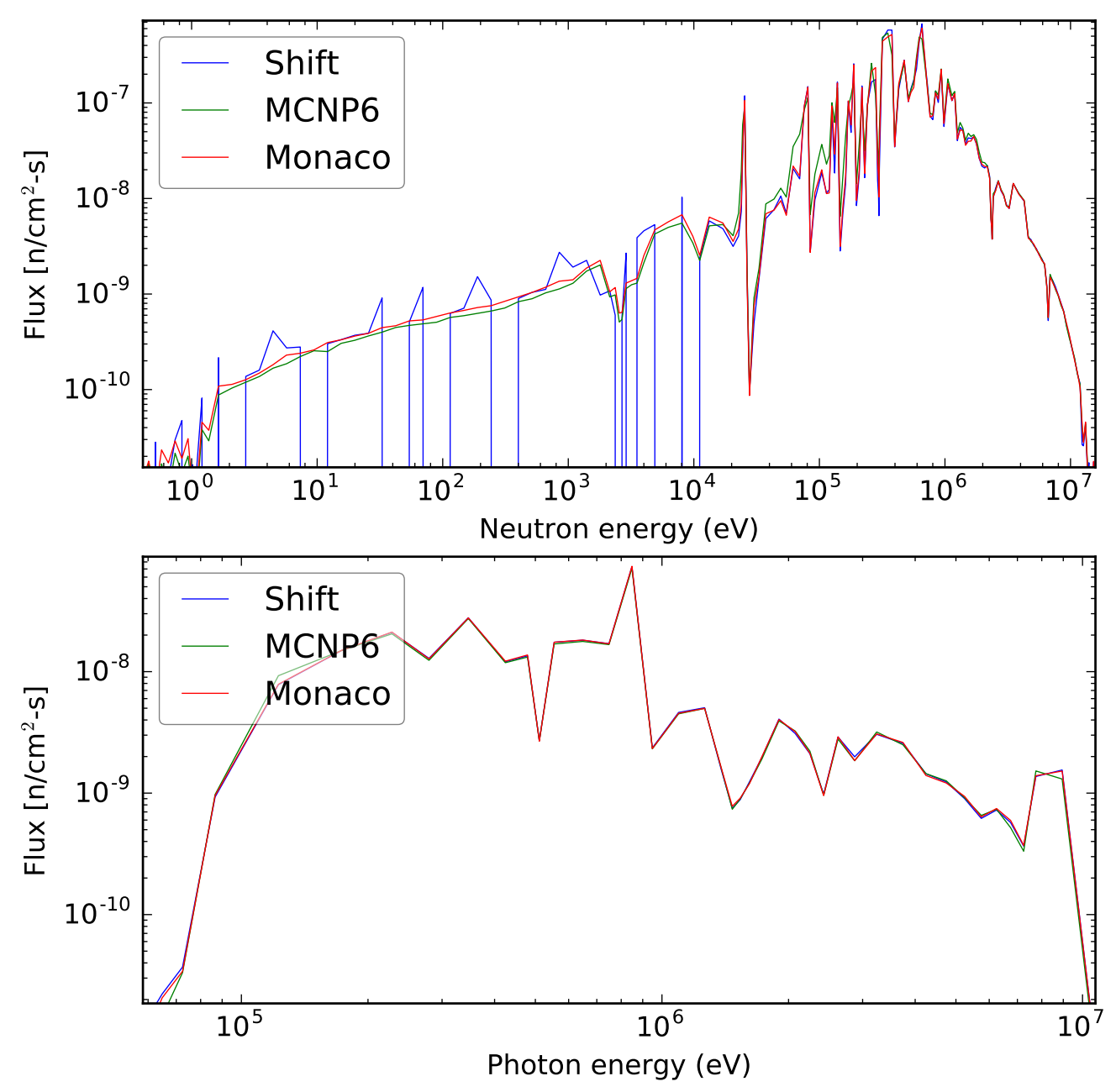

(a) Flux 

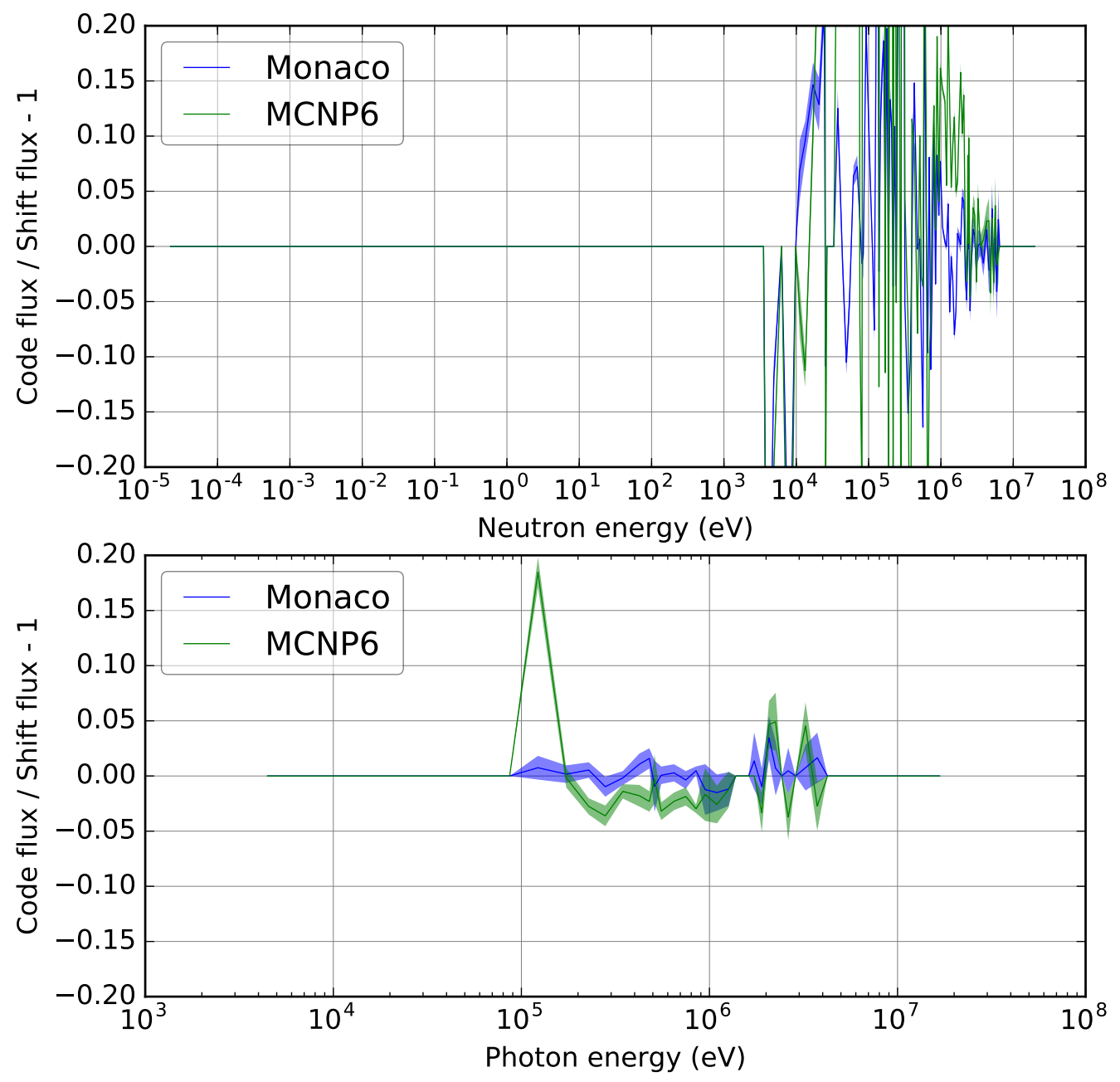

(b) Relative difference in flux

Figure 43. Calculated leakage using MG physics from ${ }^{56}$ Fe spherical shell. 

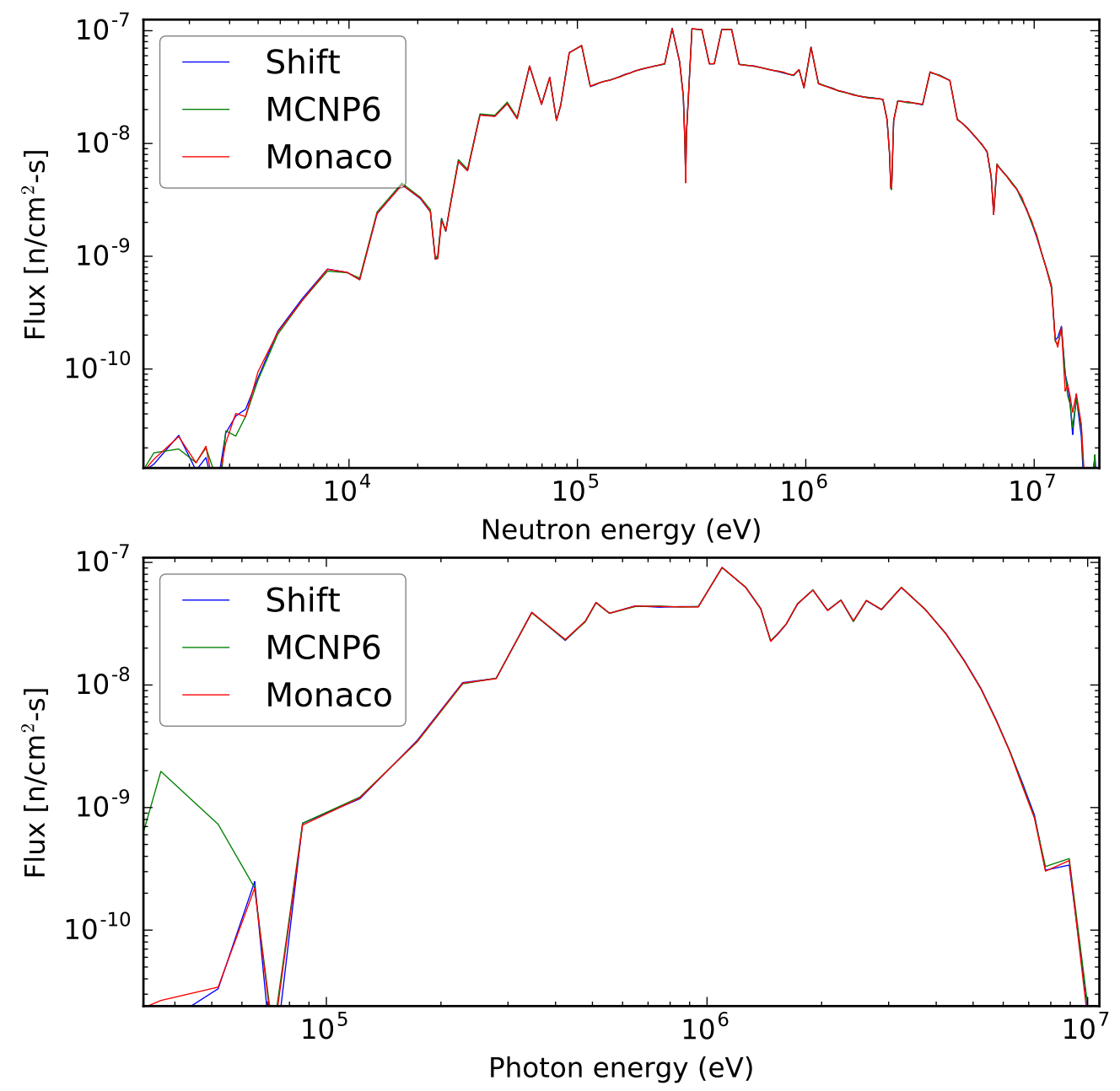

(a) Flux 

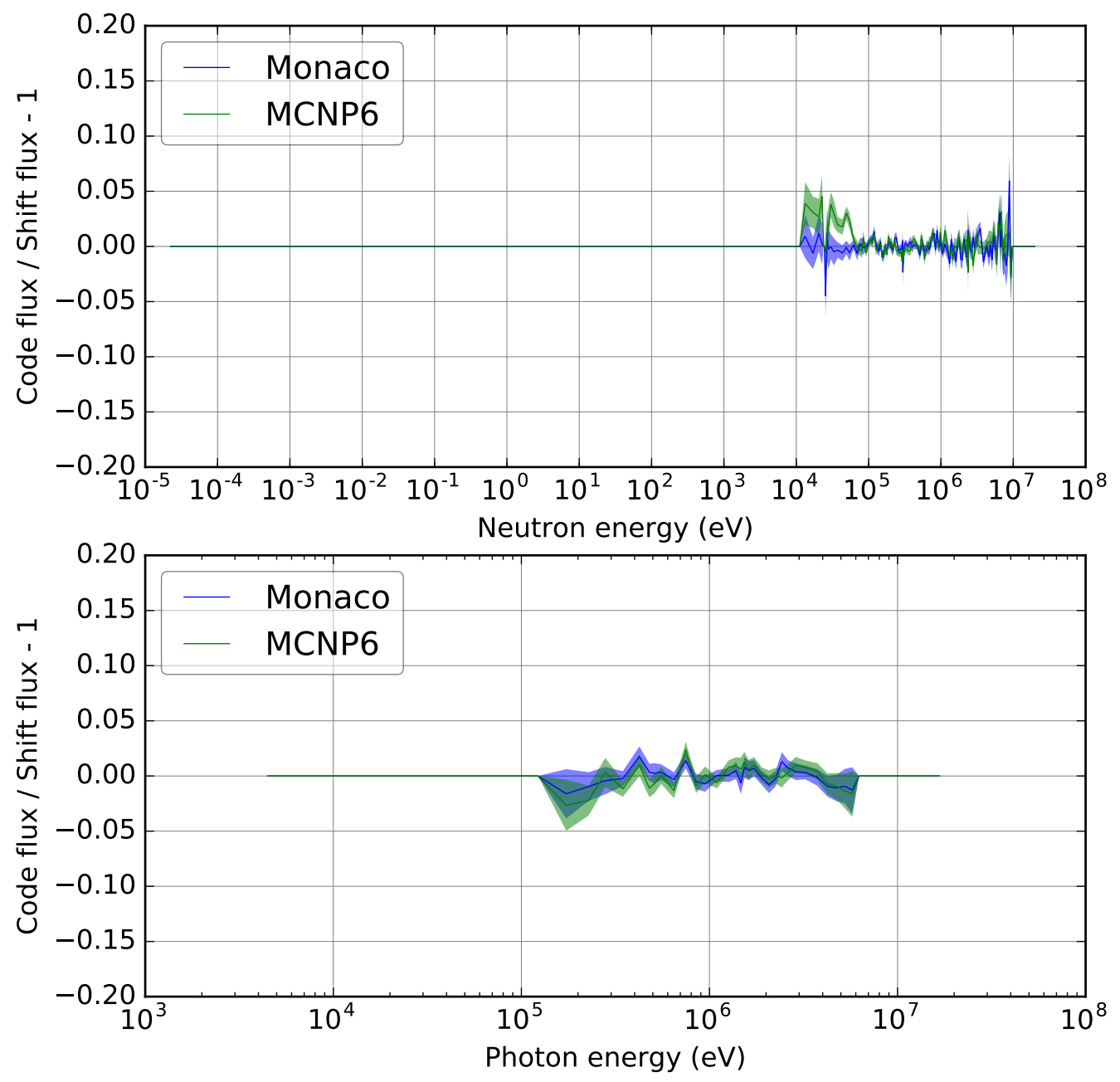

(b) Relative difference in flux

Figure 44. Calculated leakage using CE physics from ${ }^{155} \mathrm{Gd}$ spherical shell. 

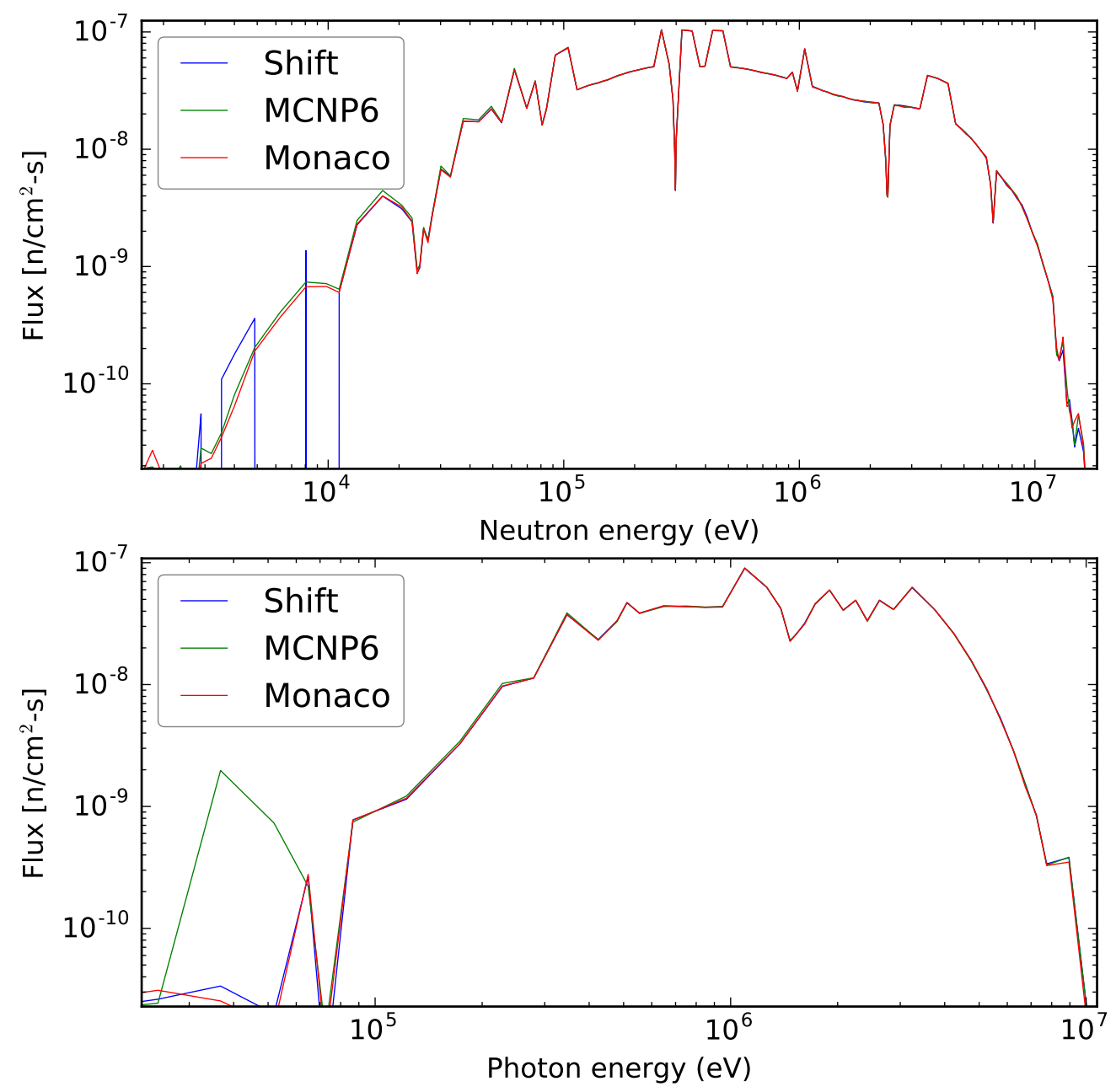

(a) Flux 

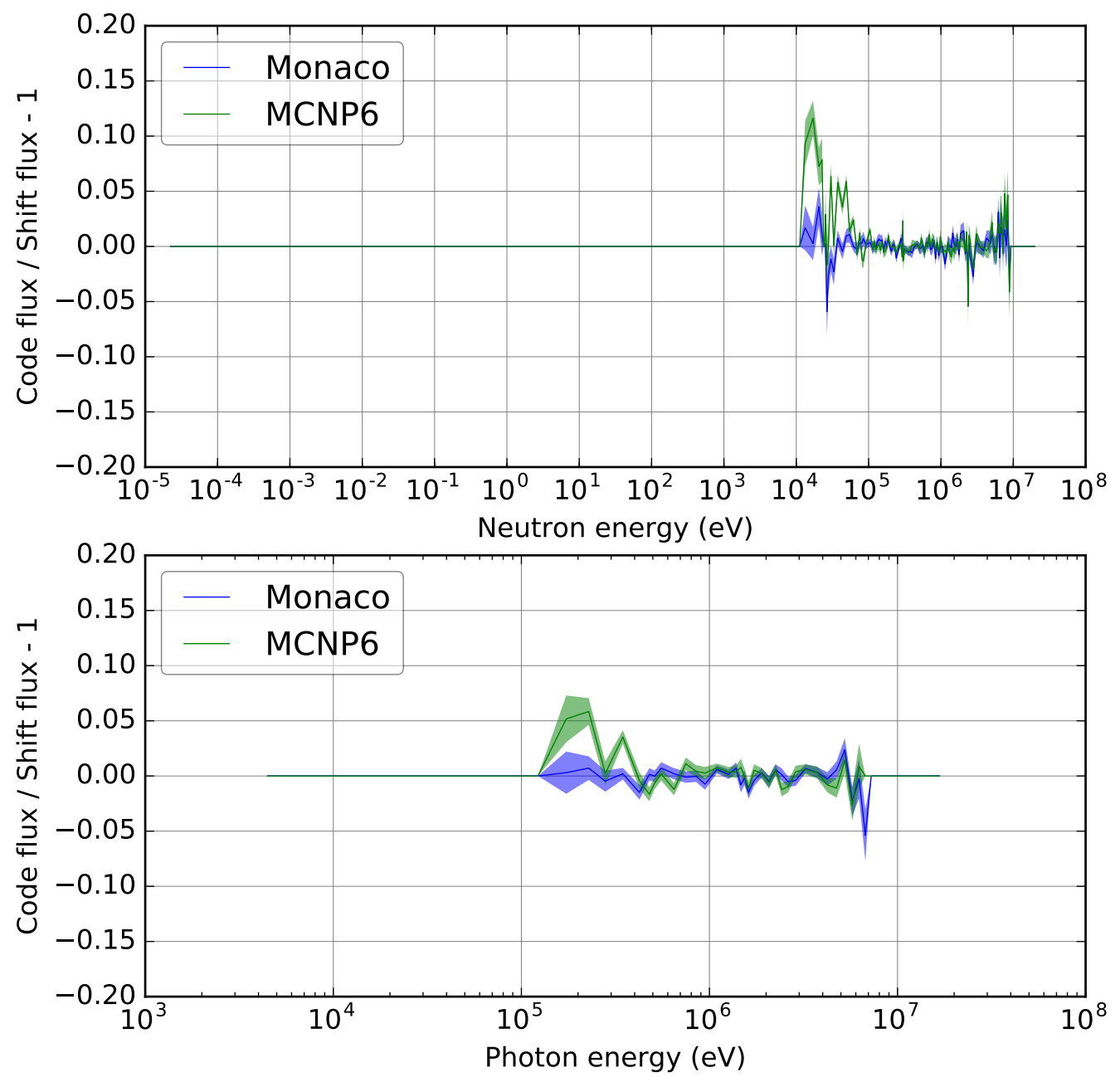

(b) Relative difference in flux

Figure 45. Calculated leakage using MG physics from ${ }^{155}$ Gd spherical shell. 

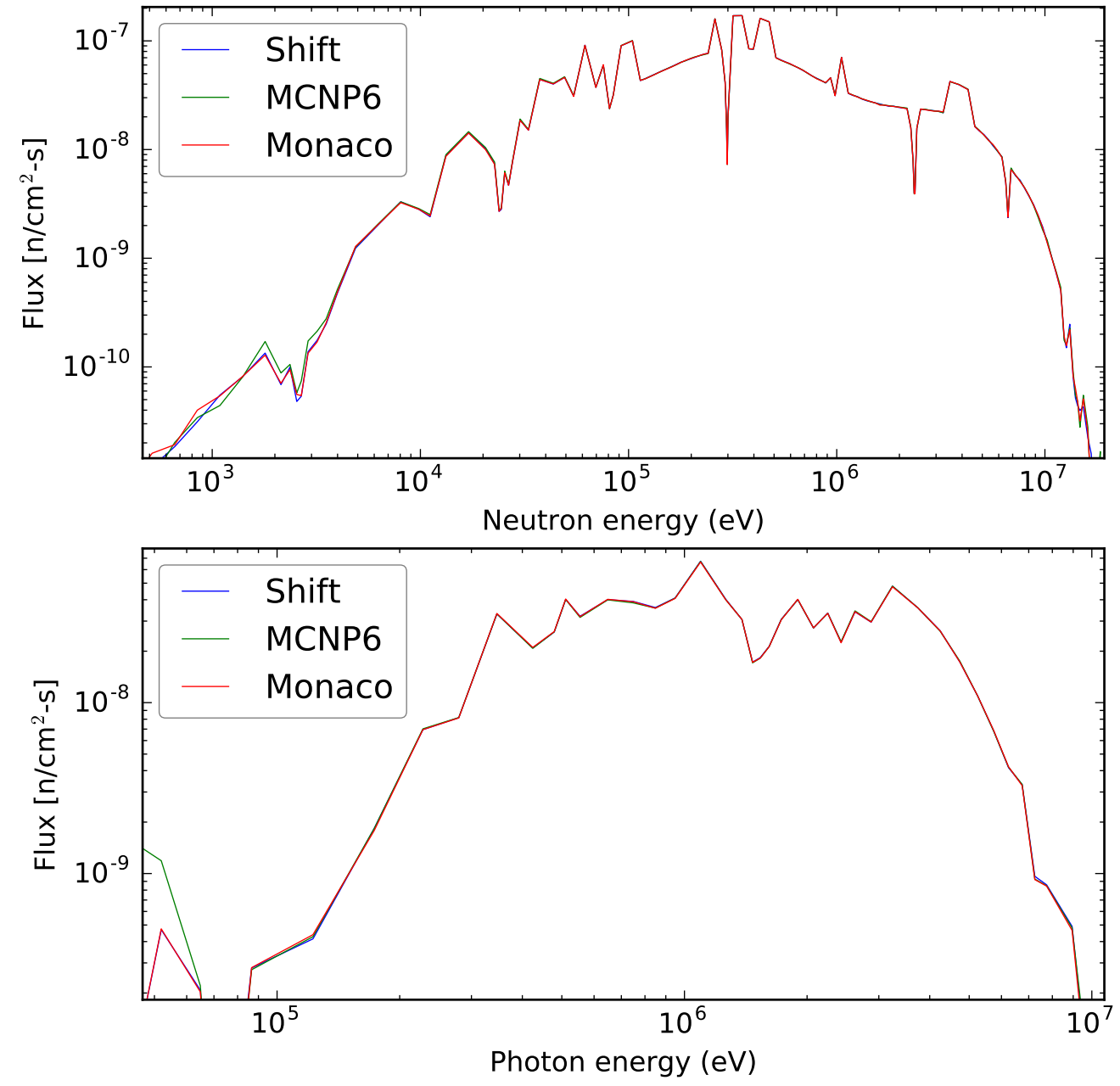

(a) Flux 

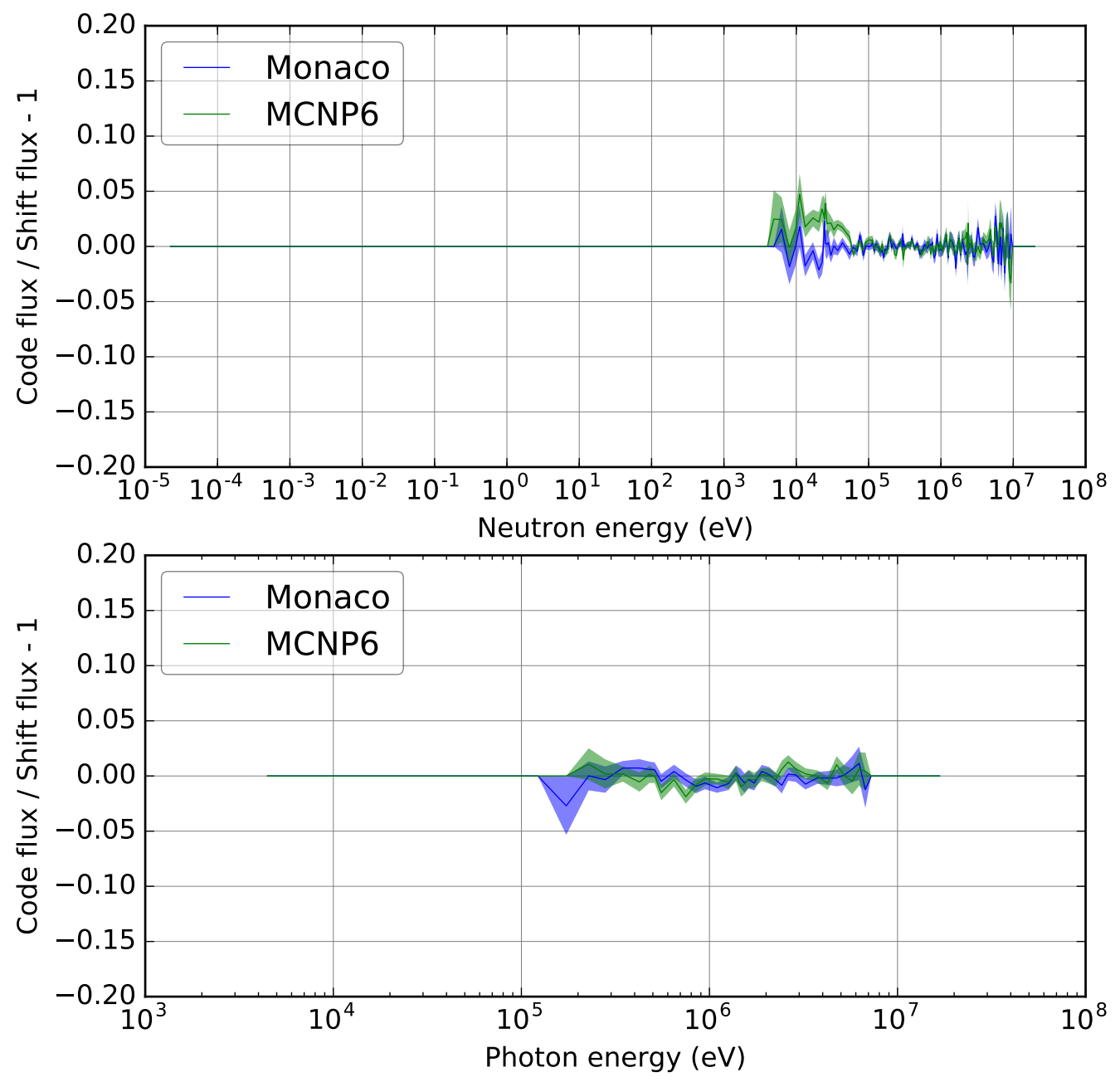

(b) Relative difference in flux

Figure 46. Calculated leakage using CE physics from ${ }^{157}$ Gd spherical shell. 

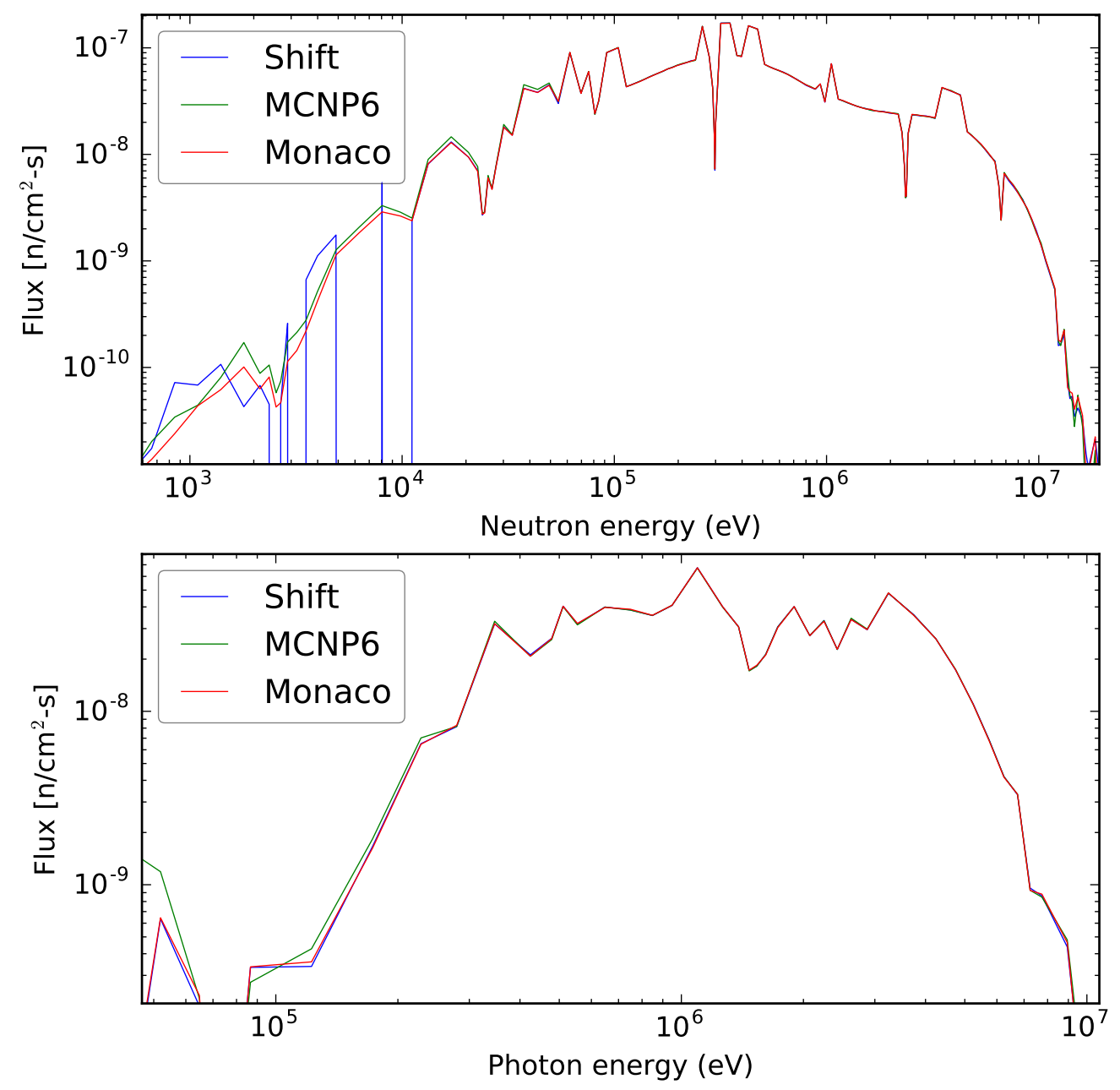

(a) Flux 

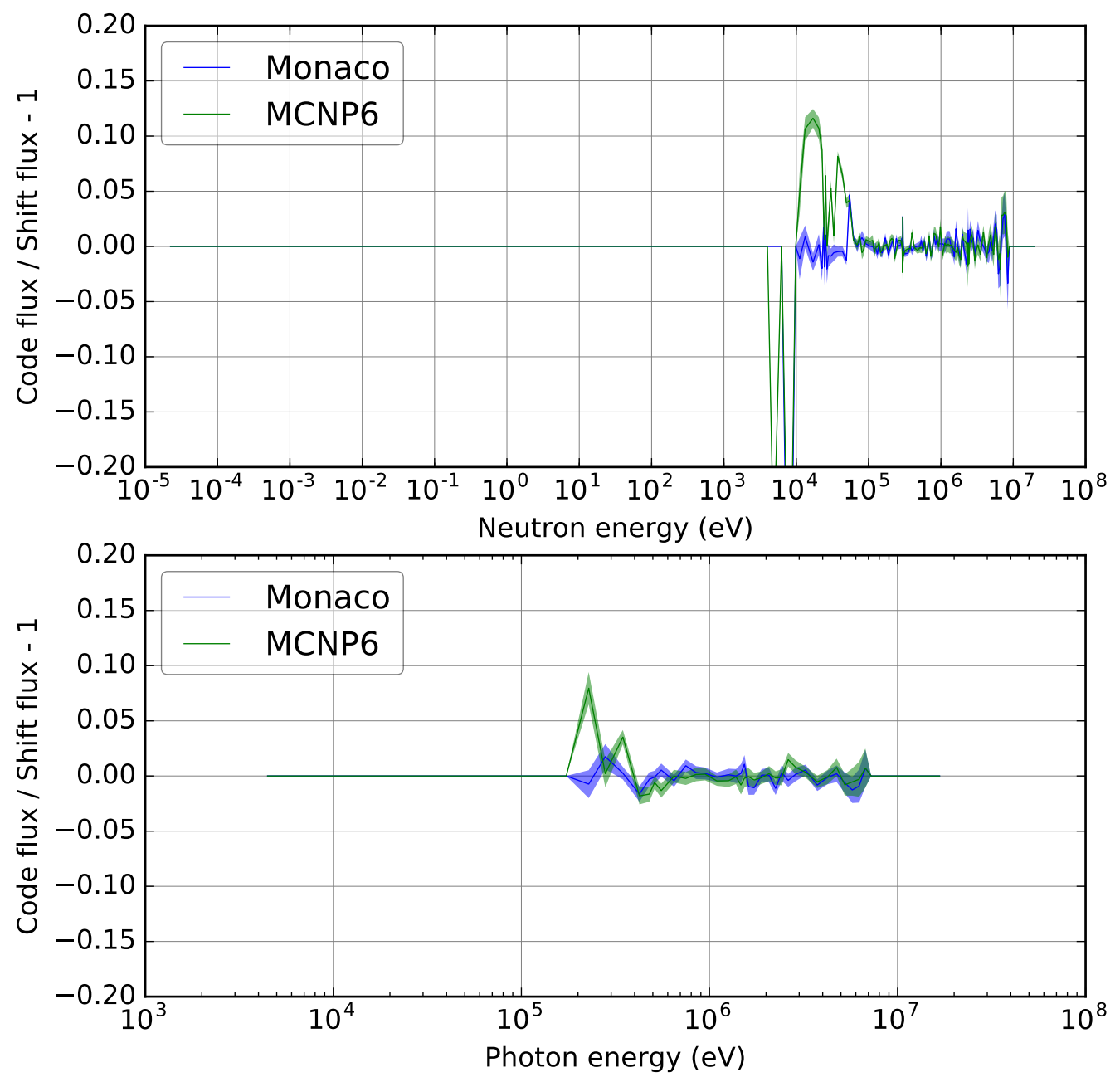

(b) Relative difference in flux

Figure 47. Calculated leakage using MG physics from ${ }^{157}$ Gd spherical shell. 

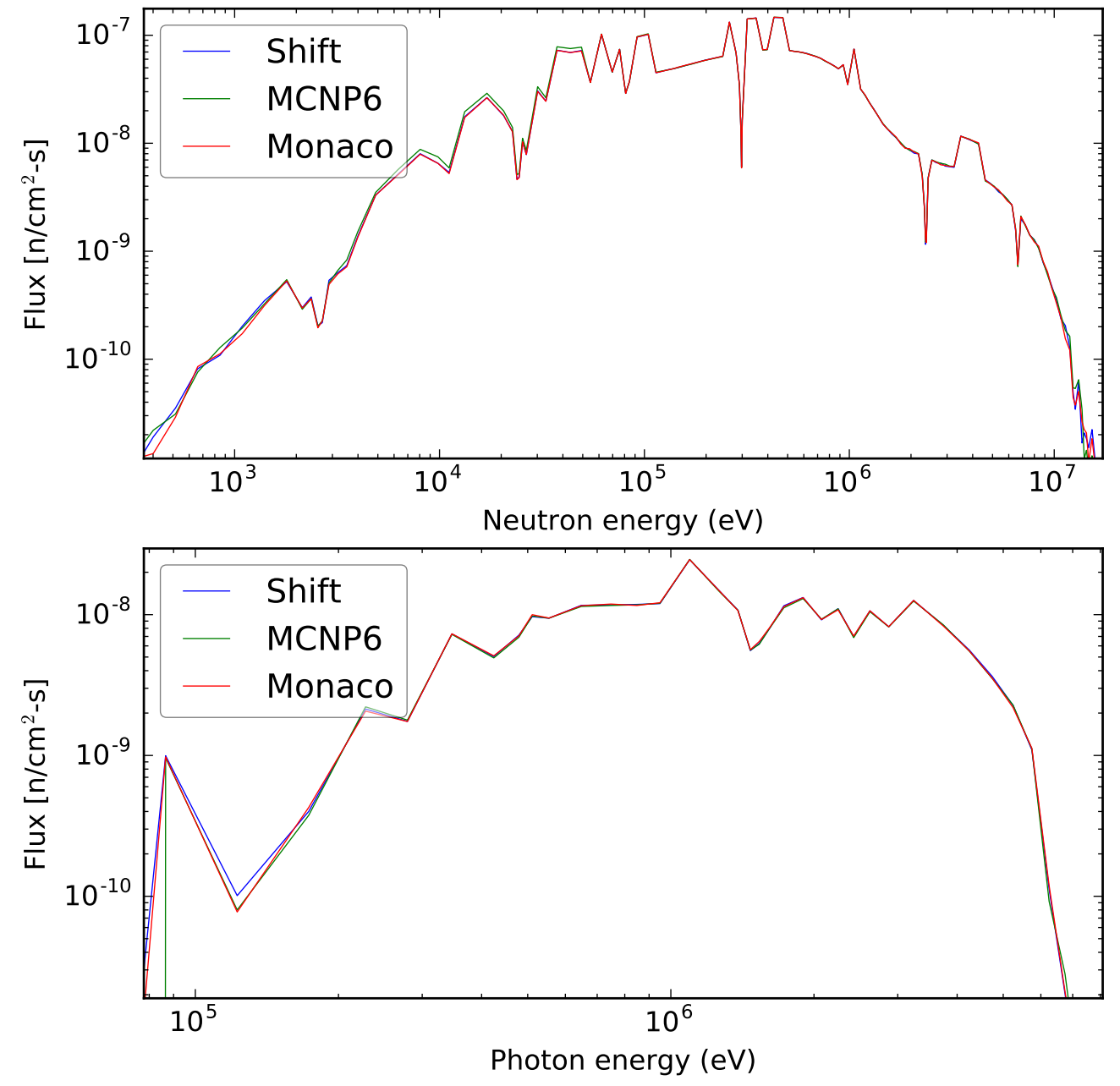

(a) Flux 

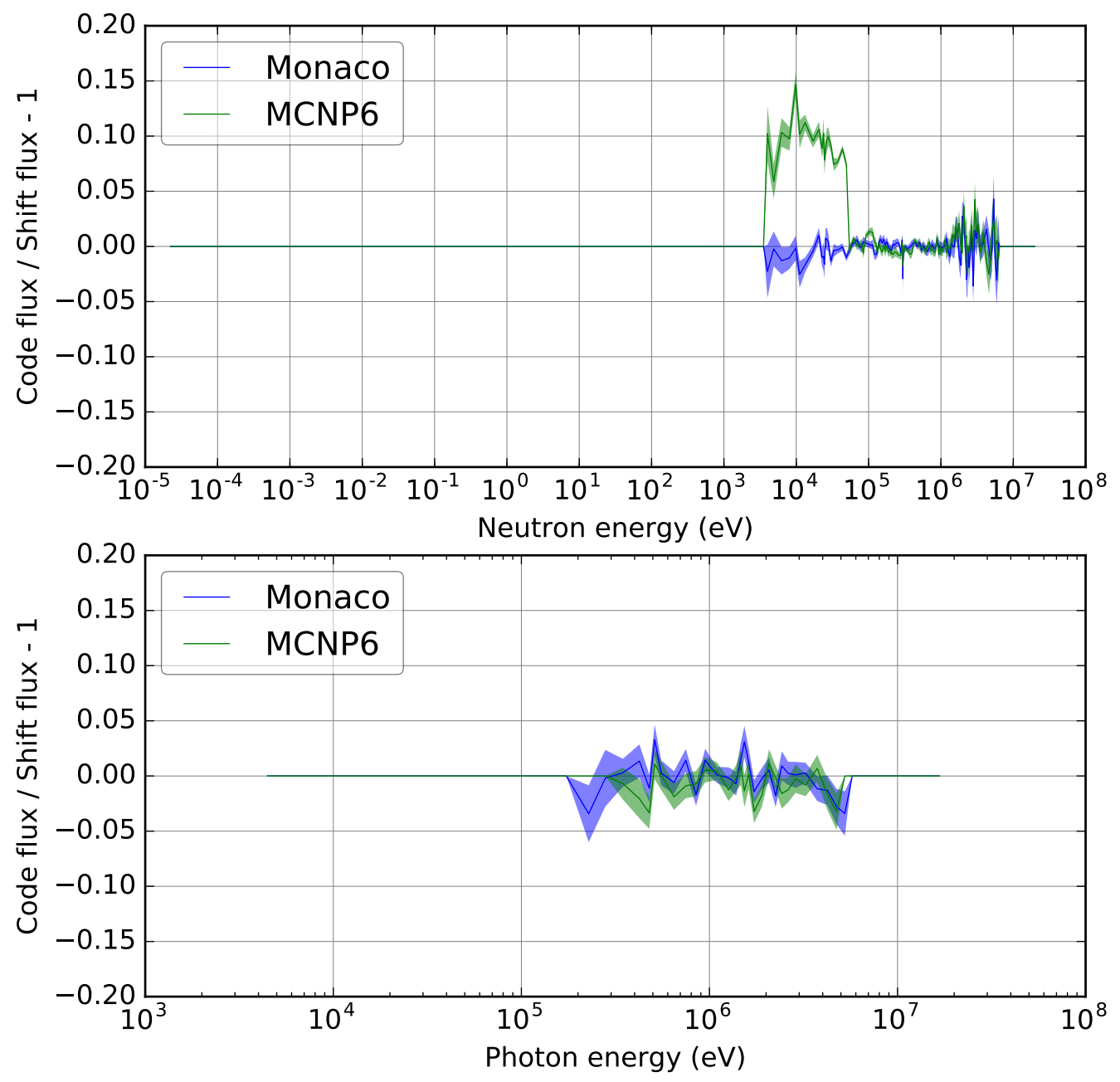

(b) Relative difference in flux

Figure 48. Calculated leakage using CE physics from ${ }^{176} \mathrm{Hf}$ spherical shell. 

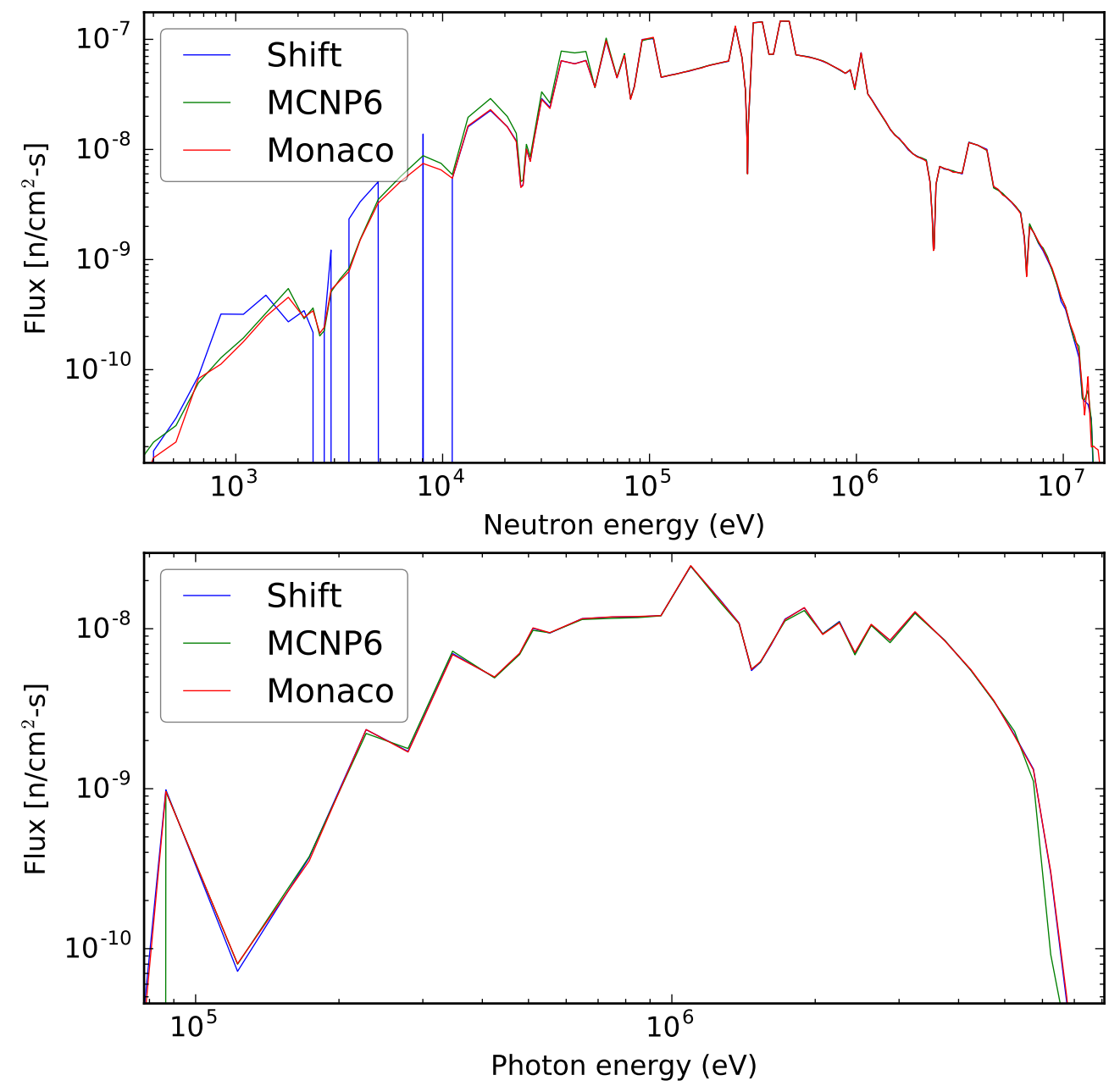

(a) Flux 

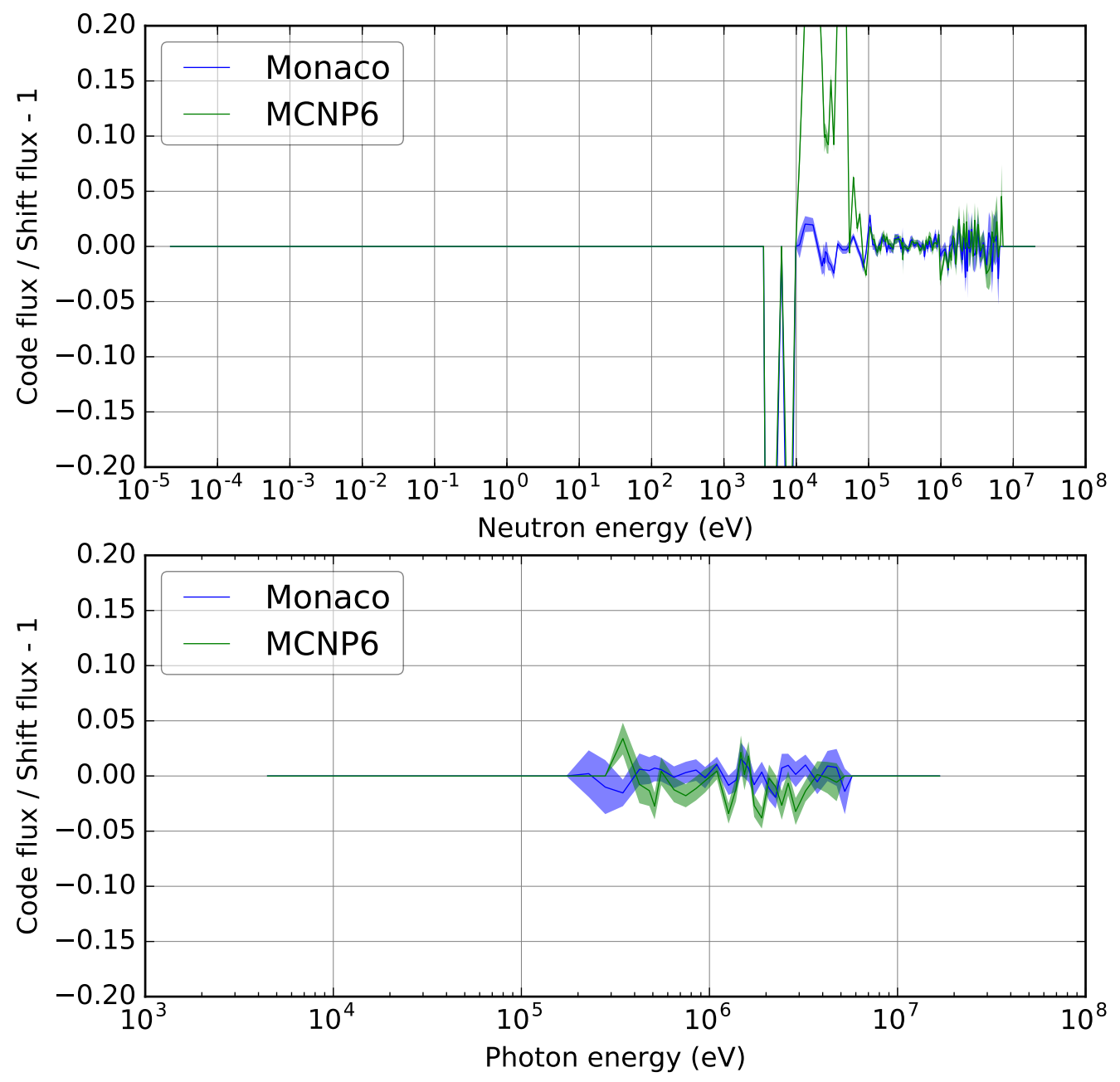

(b) Relative difference in flux

Figure 49. Calculated leakage using MG physics from ${ }^{176} \mathrm{Hf}$ spherical shell. 

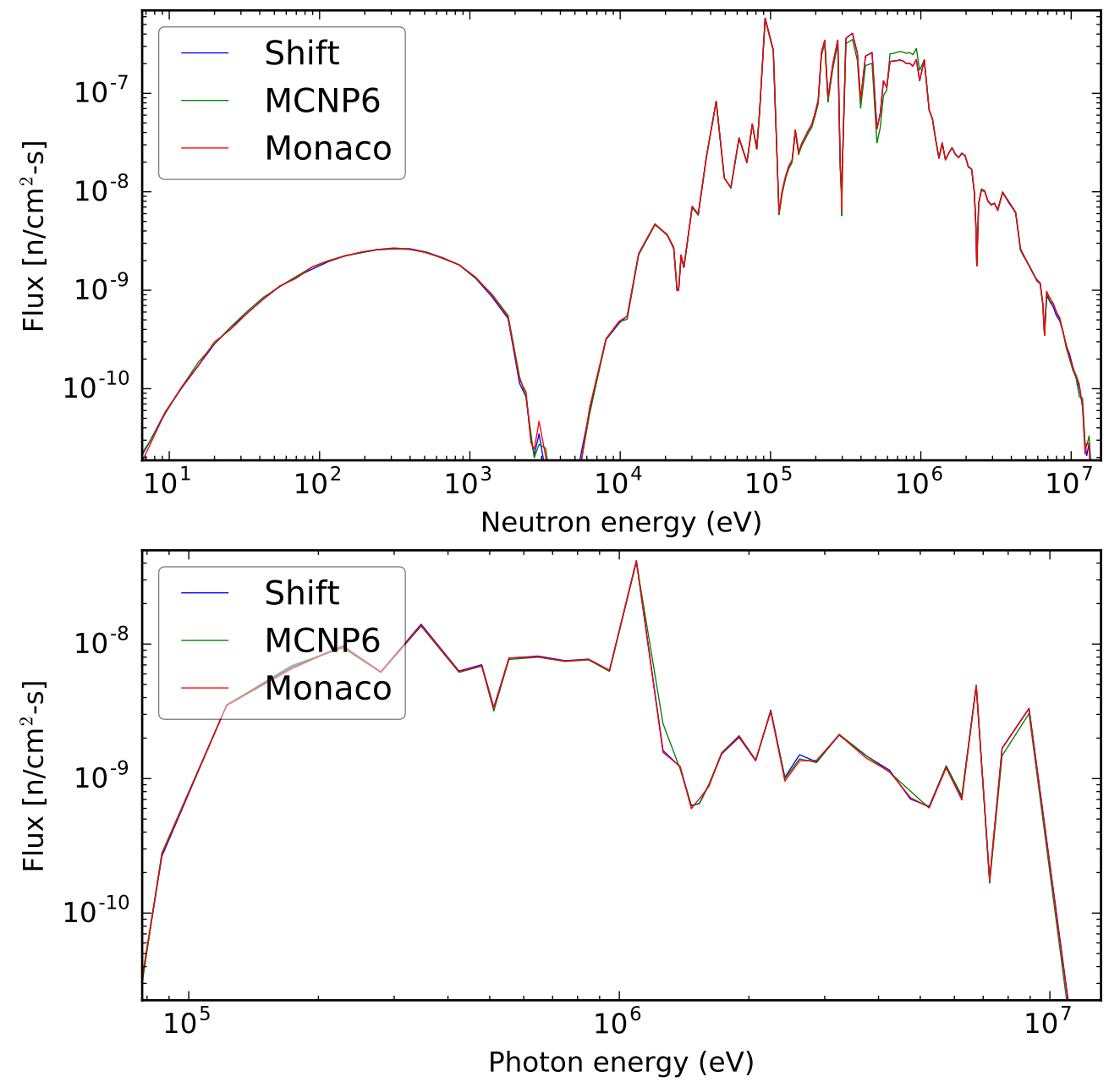

(a) Flux 

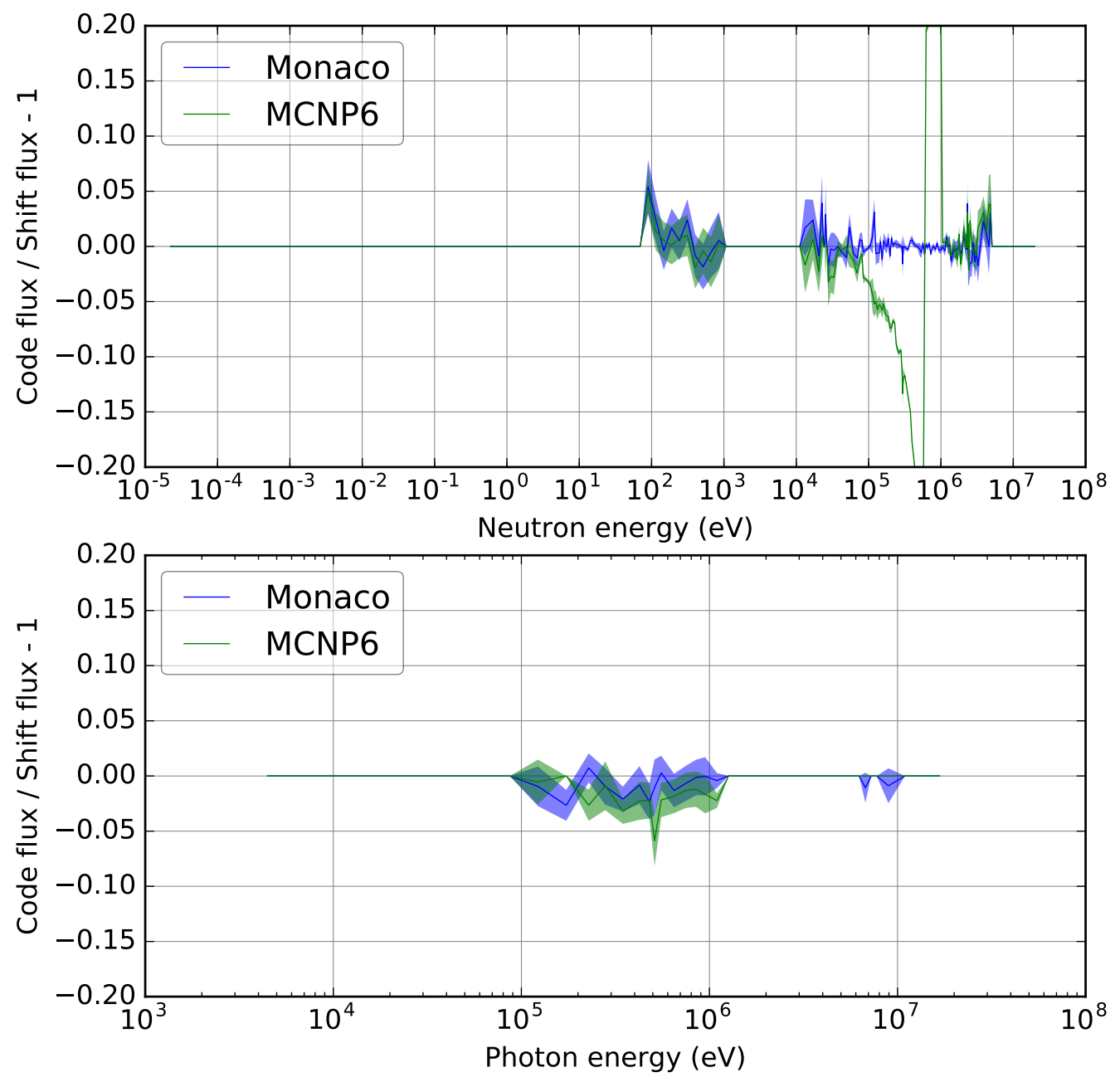

(b) Relative difference in flux

Figure 50. Calculated leakage using CE physics from ${ }^{62} \mathrm{Ni}$ spherical shell. 

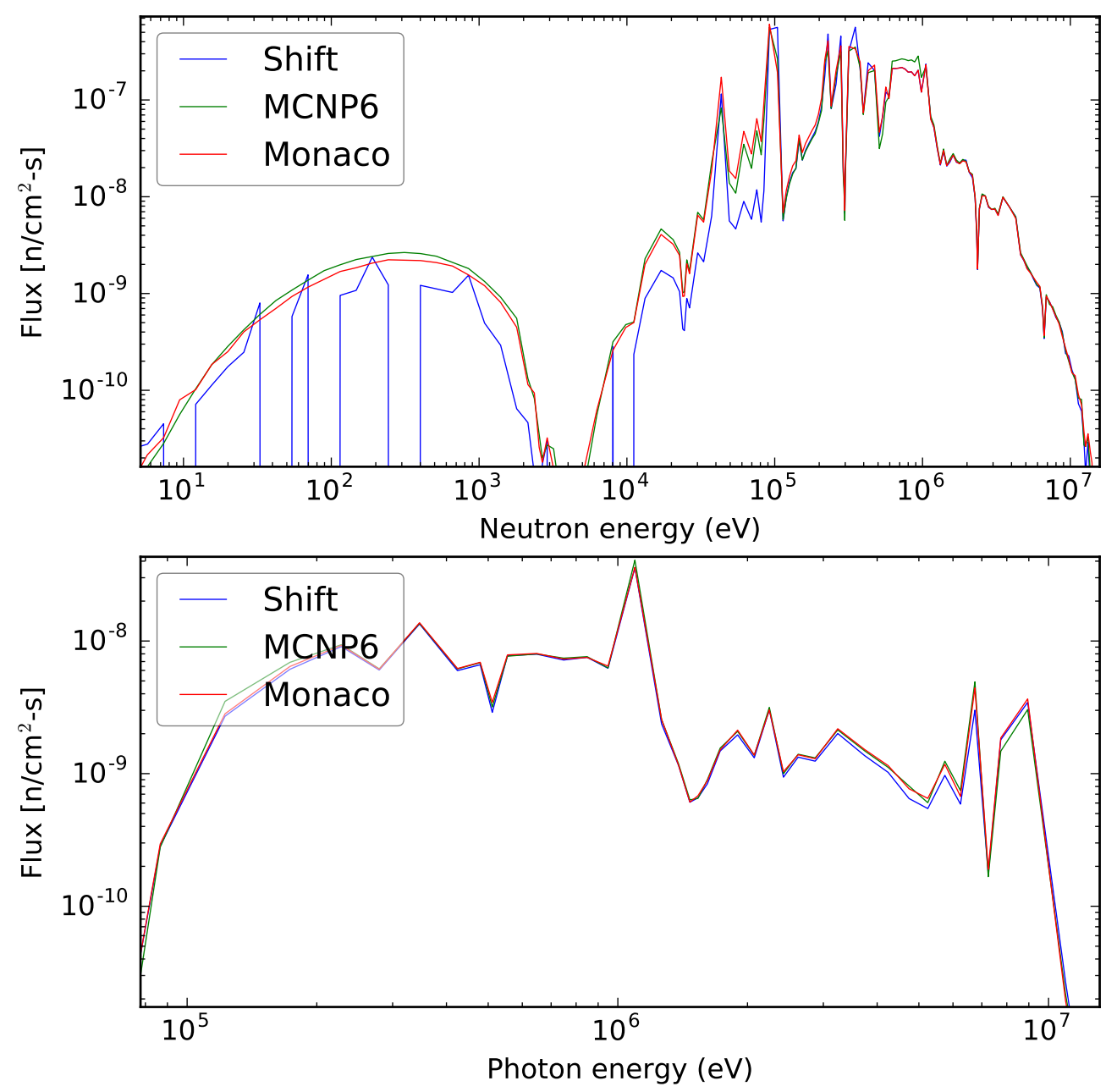

(a) Flux 

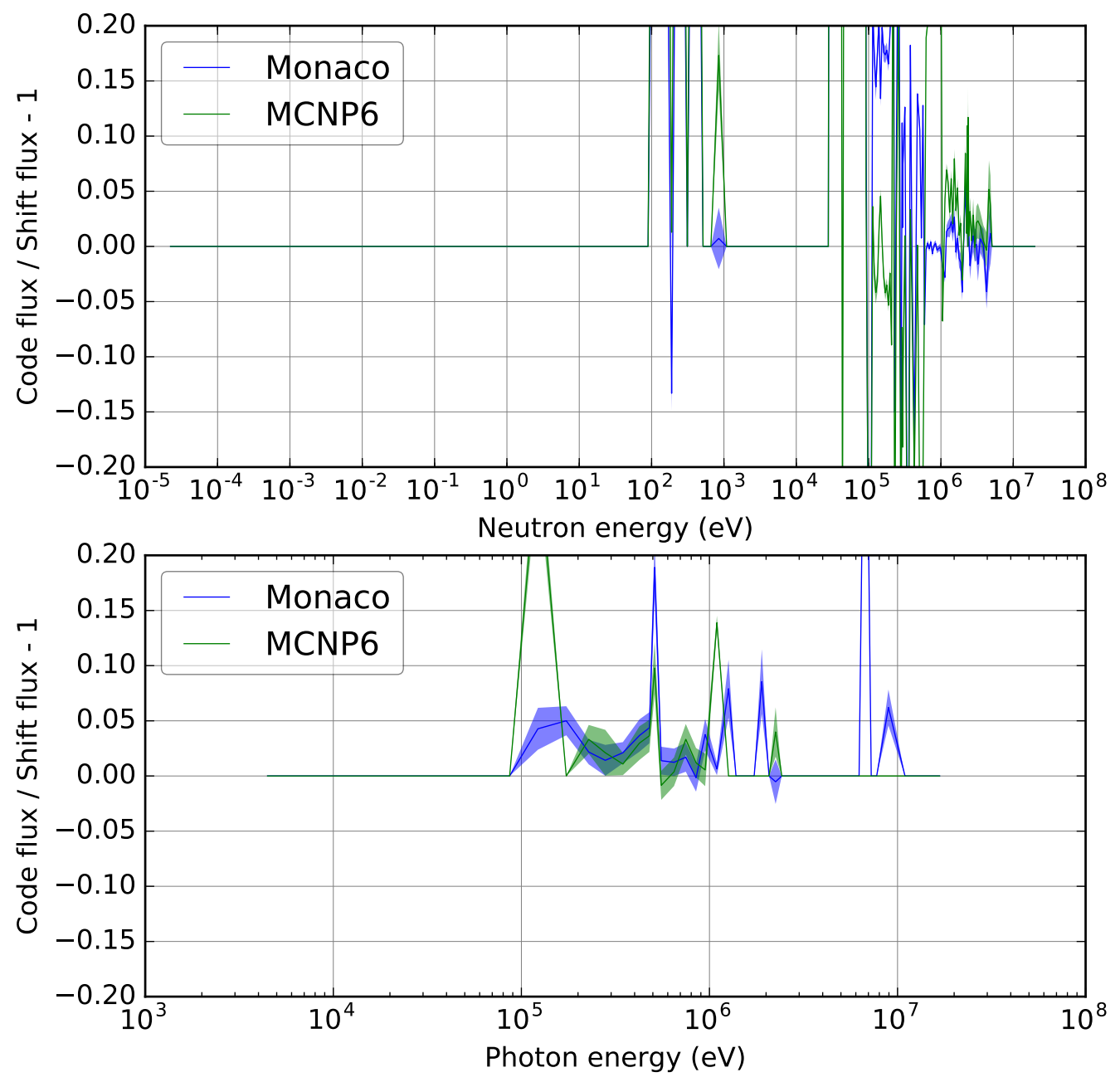

(b) Relative difference in flux

Figure 51. Calculated leakage using MG physics from ${ }^{62} \mathrm{Ni}$ spherical shell. 

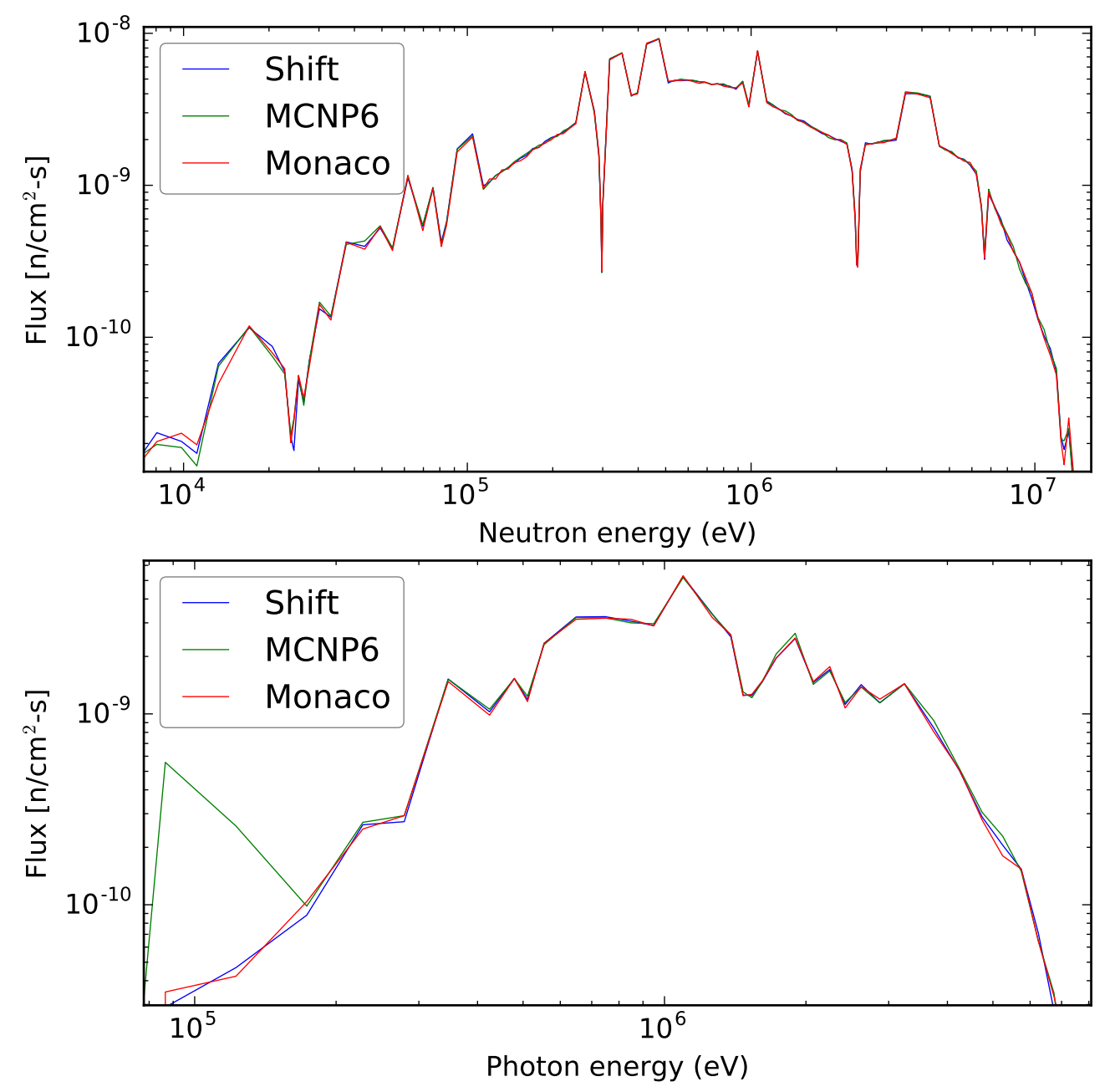

(a) Flux 

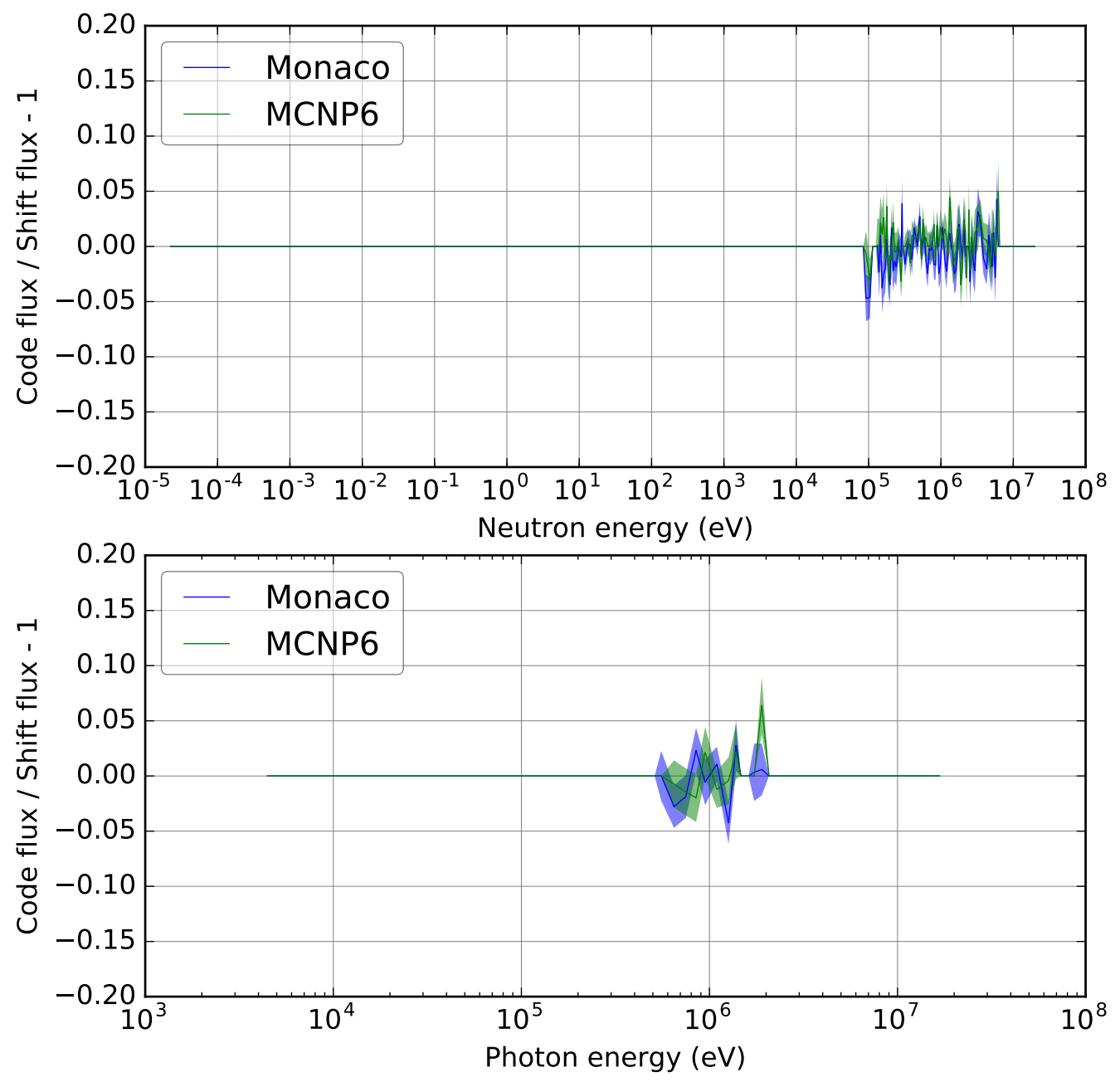

(b) Relative difference in flux

Figure 52. Calculated leakage using CE physics from ${ }^{235} \mathrm{U}$ spherical shell. 

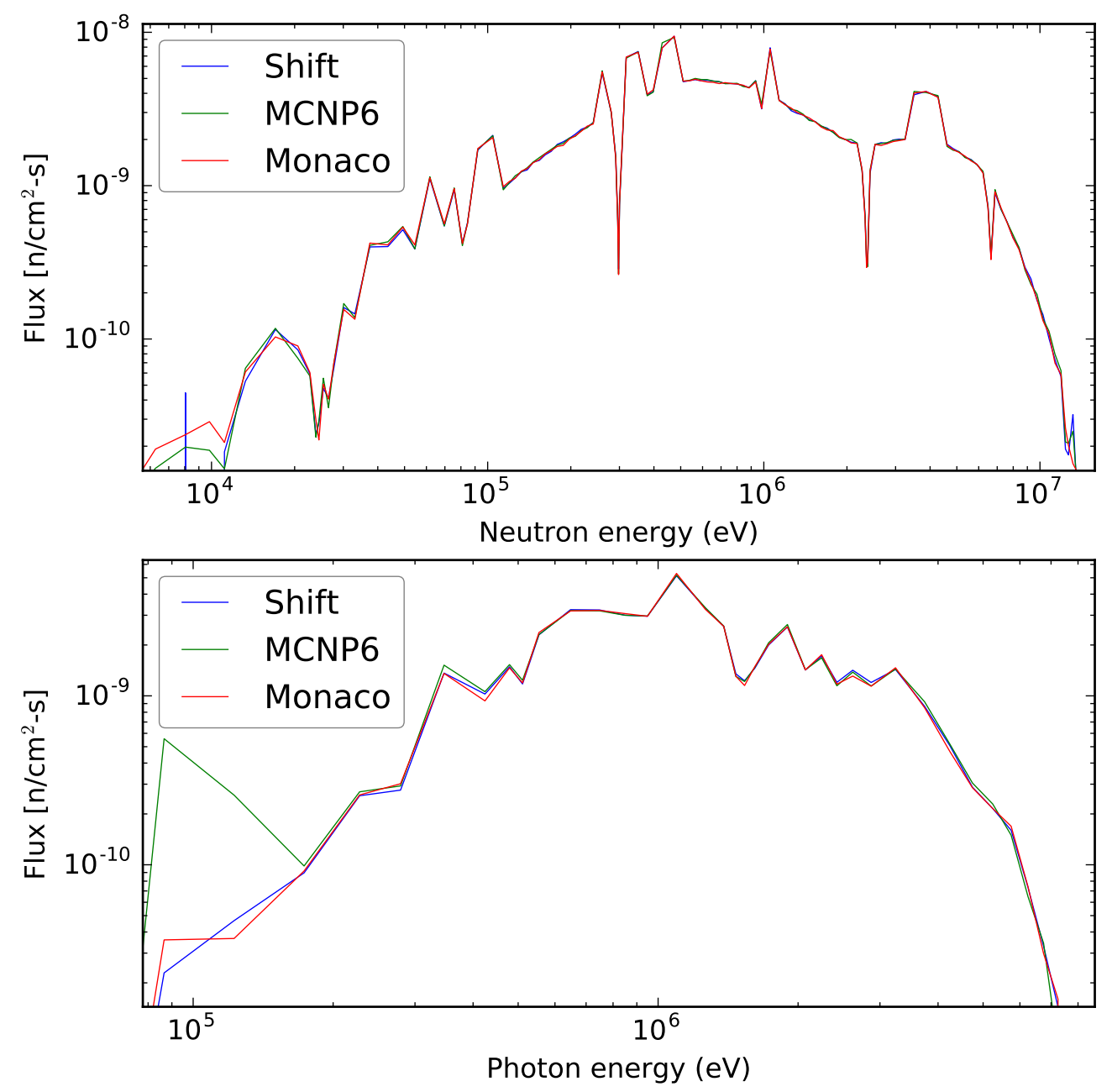

(a) Flux 

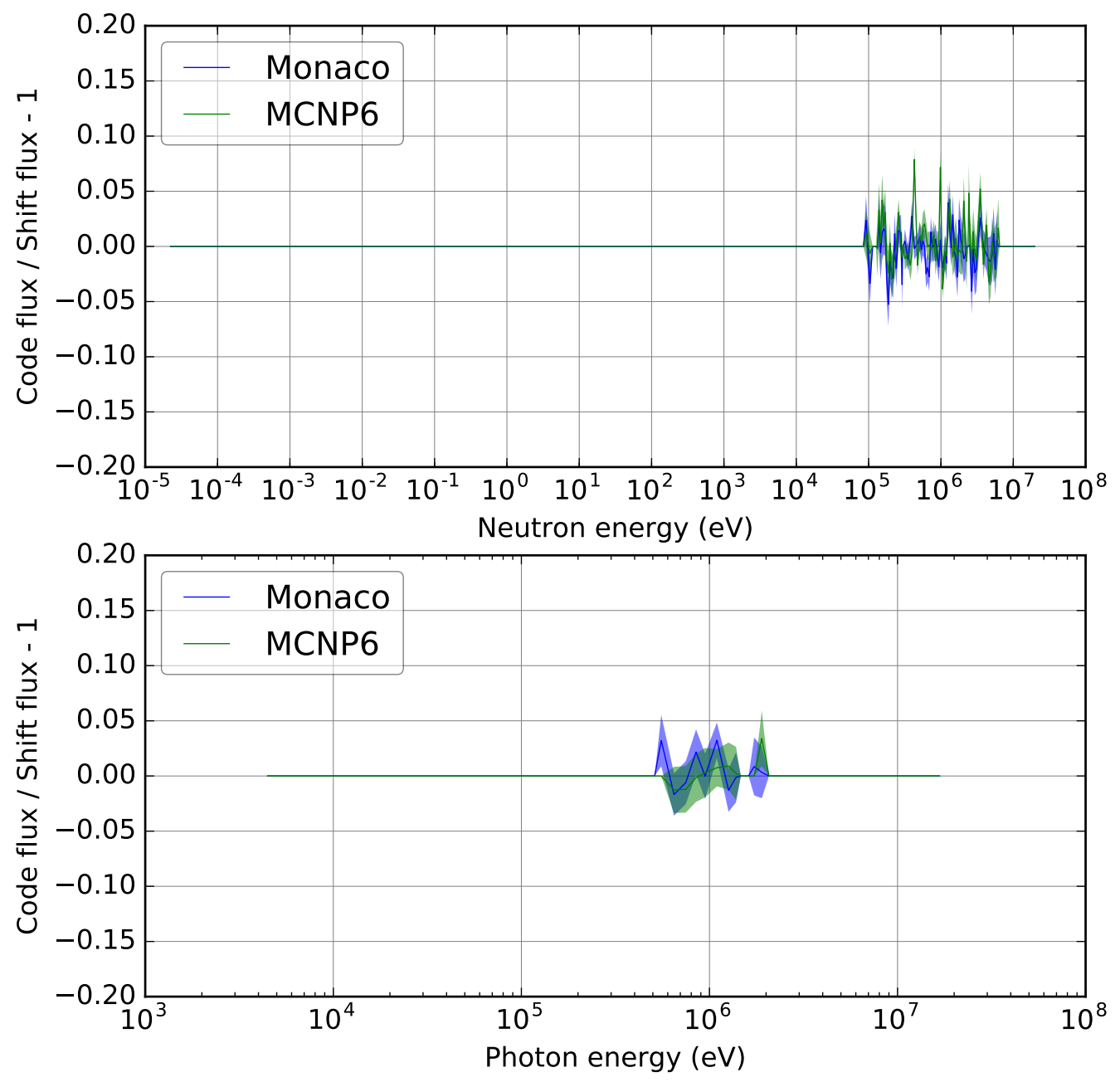

(b) Relative difference in flux

Figure 53. Calculated leakage using MG physics from ${ }^{235} \mathbf{U}$ spherical shell. 

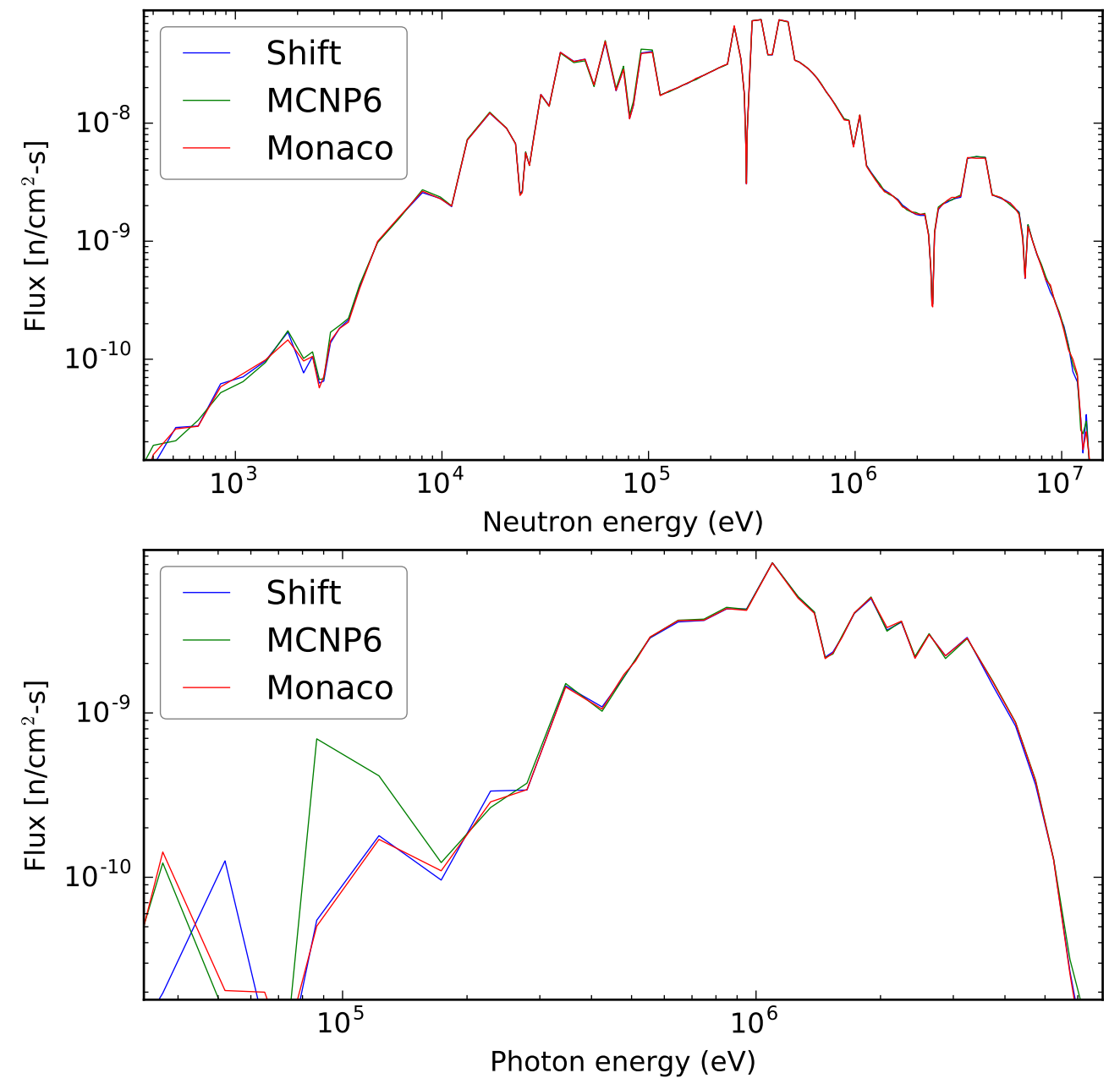

(a) Flux 

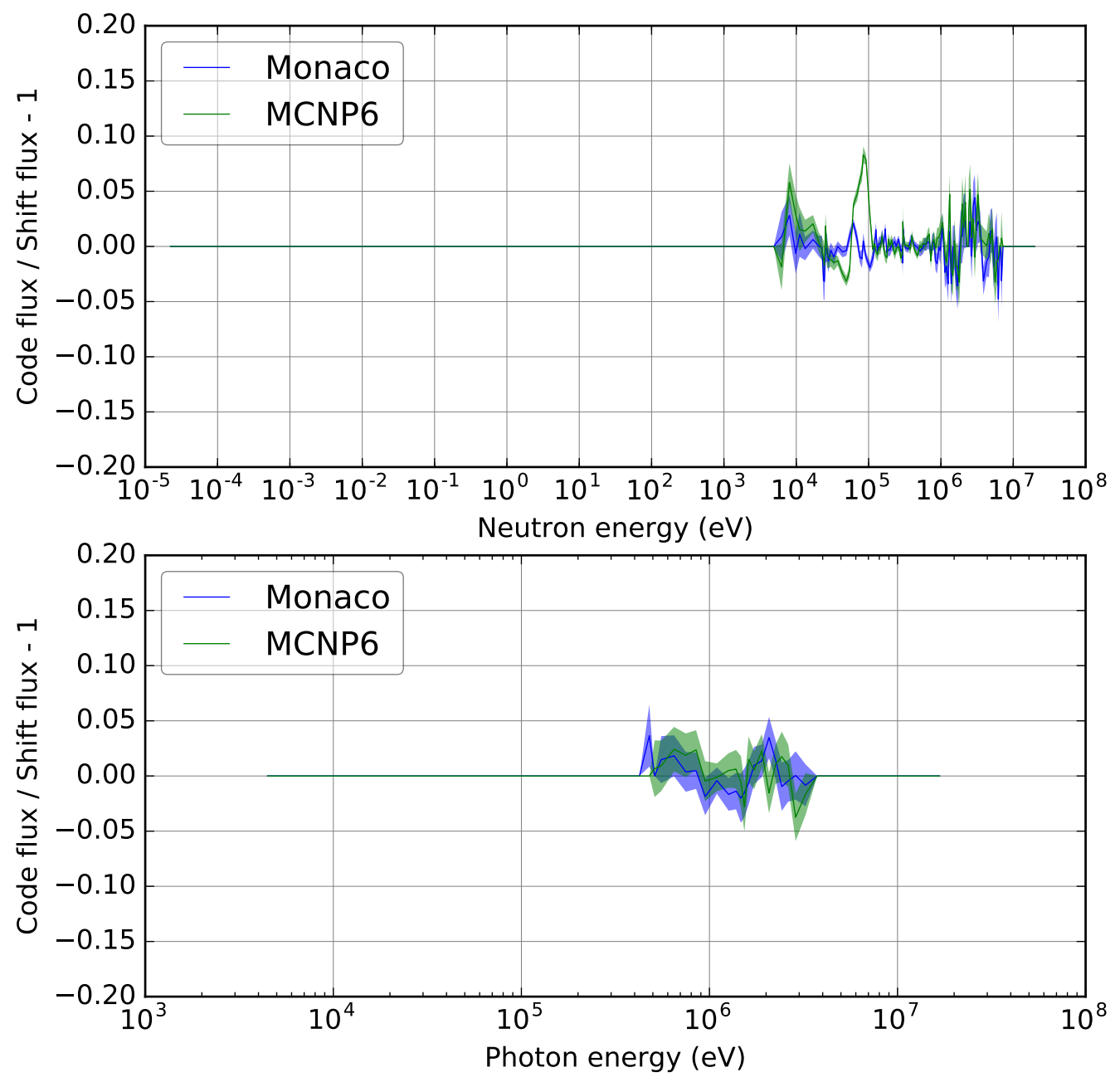

(b) Relative difference in flux

Figure 54. Calculated leakage using CE physics from ${ }^{236} \mathrm{U}$ spherical shell. 

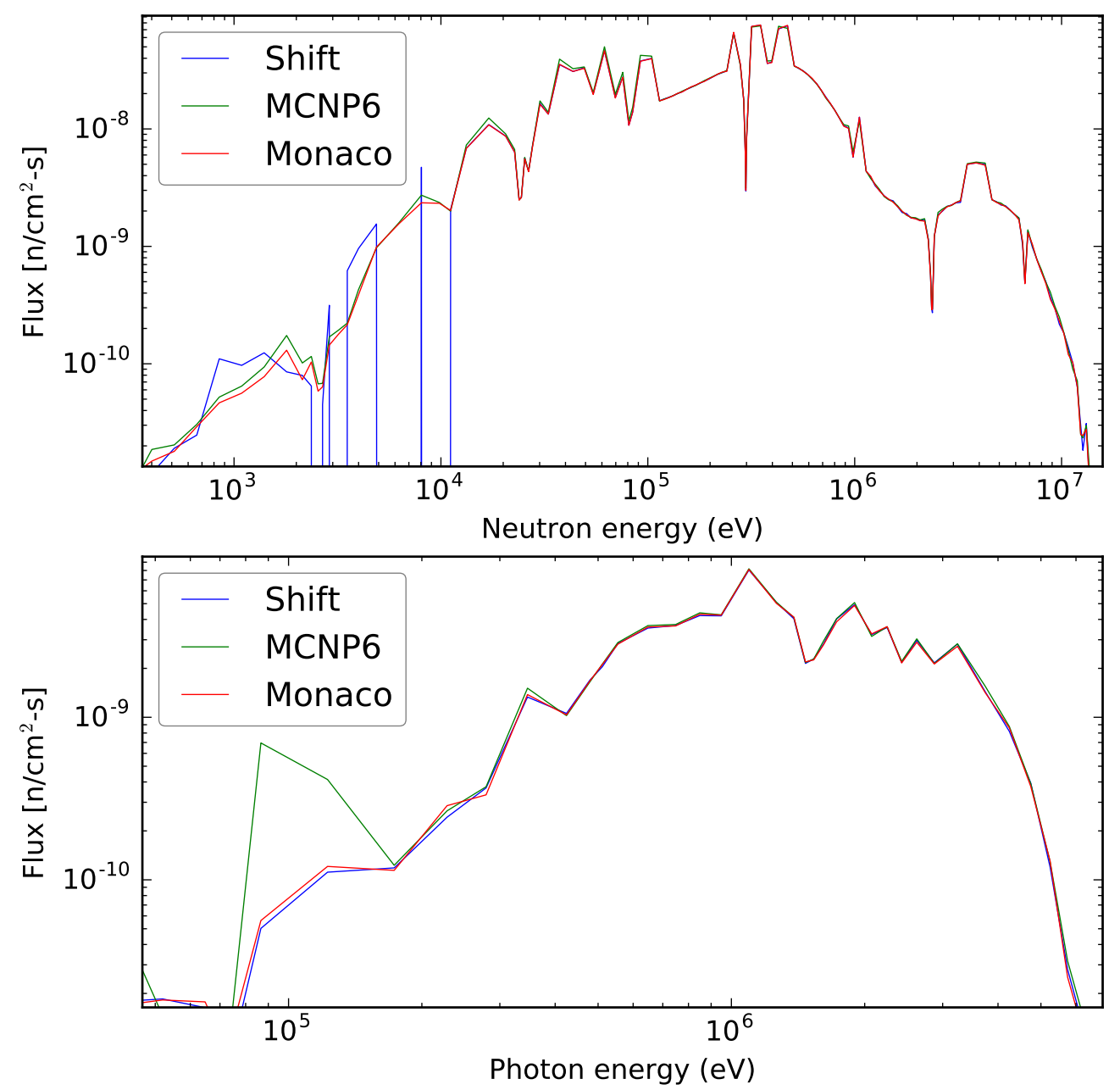

(a) Flux 

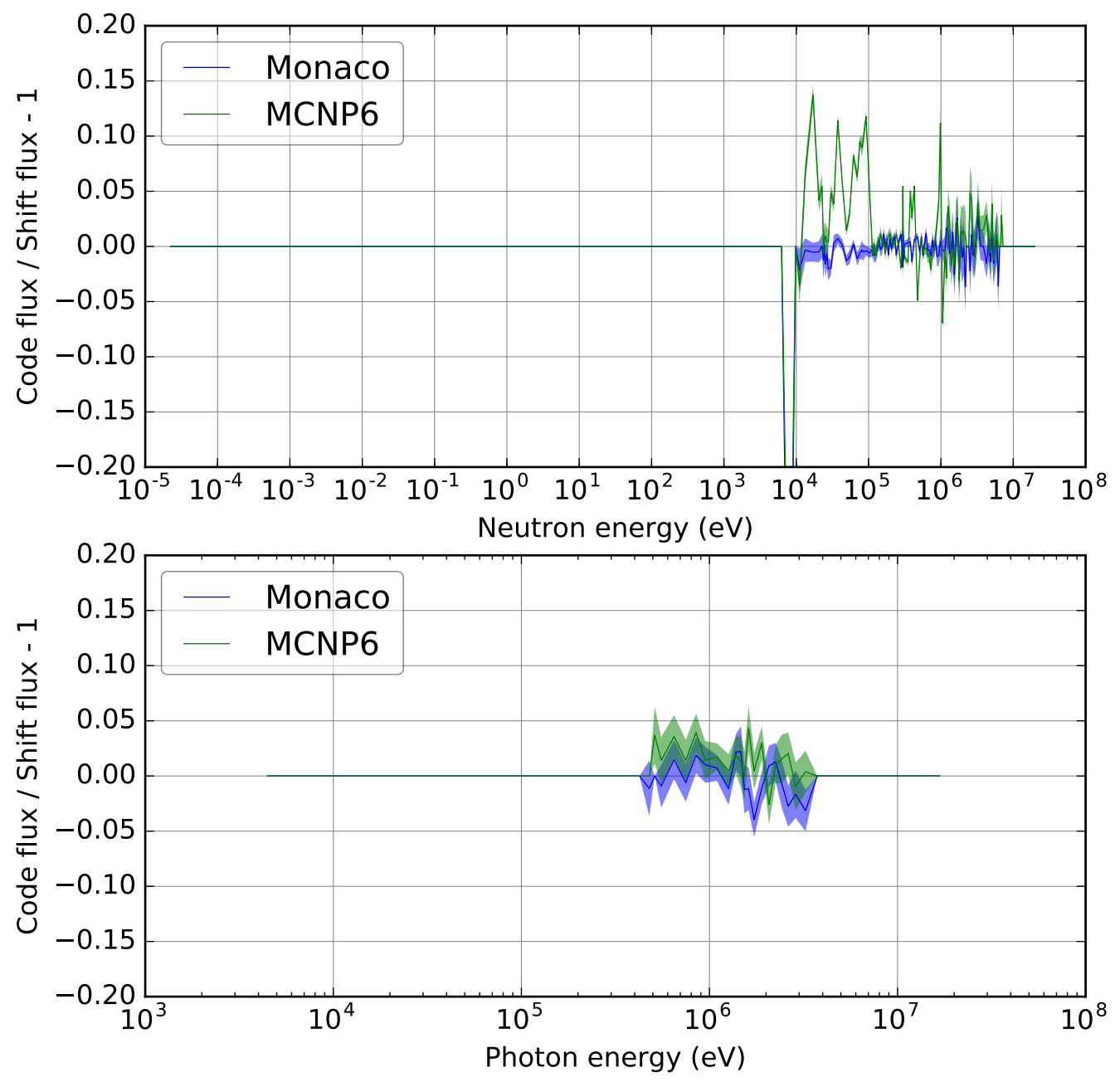

(b) Relative difference in flux

Figure 55. Calculated leakage using MG physics from ${ }^{236} \mathbf{U}$ spherical shell. 

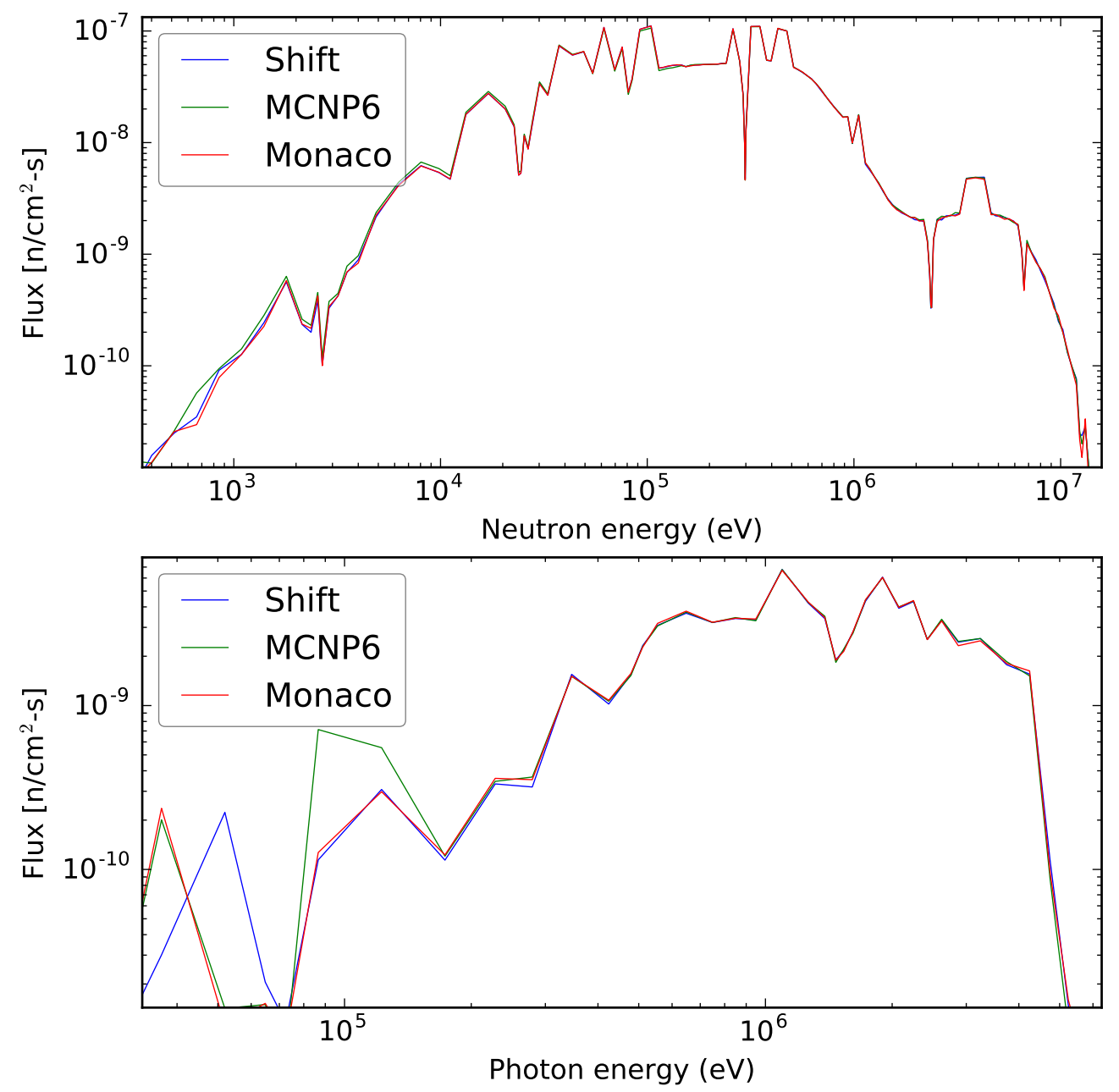

(a) Flux 

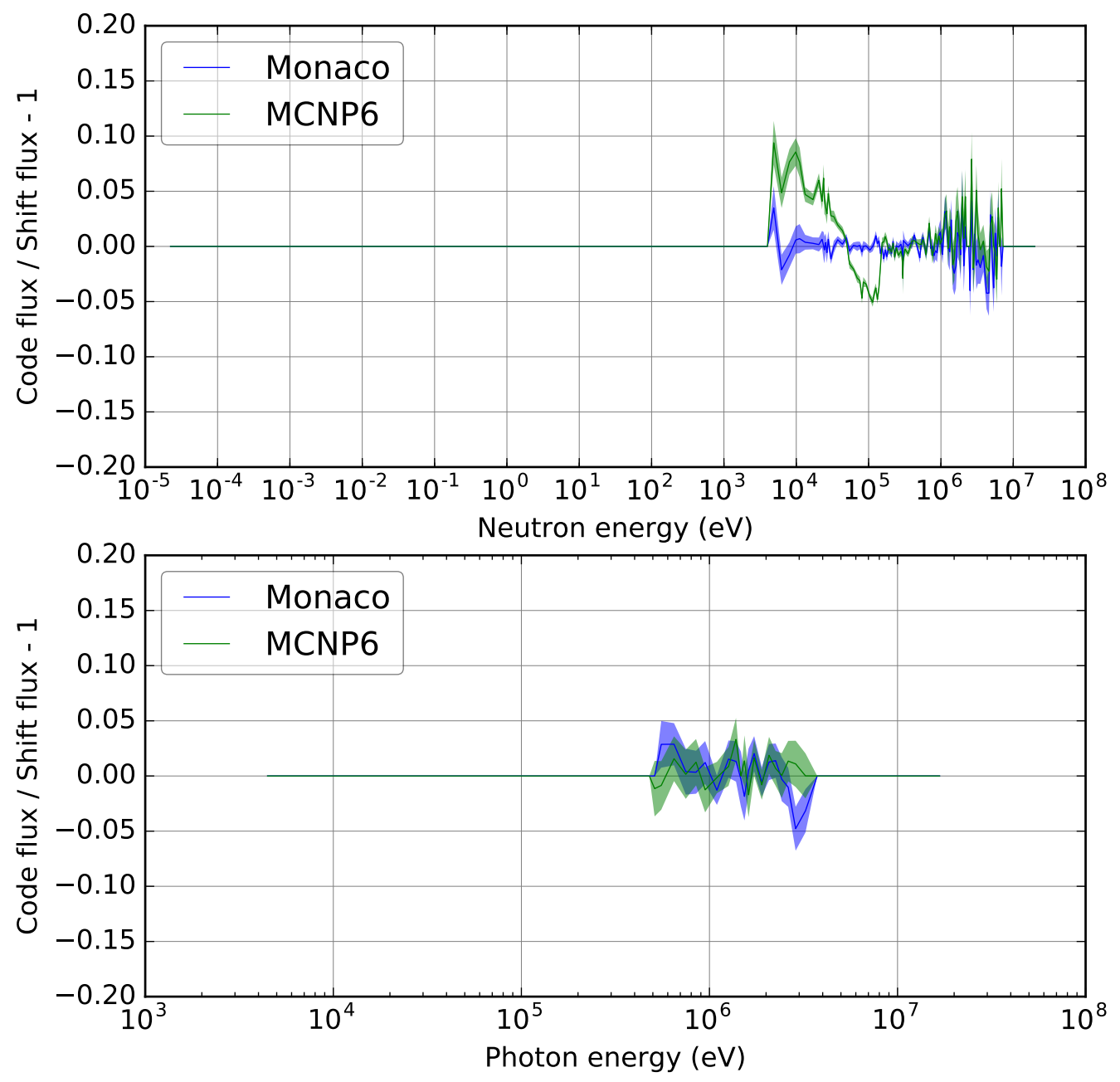

(b) Relative difference in flux

Figure 56. Calculated leakage using CE physics from ${ }^{238} \mathrm{U}$ spherical shell. 

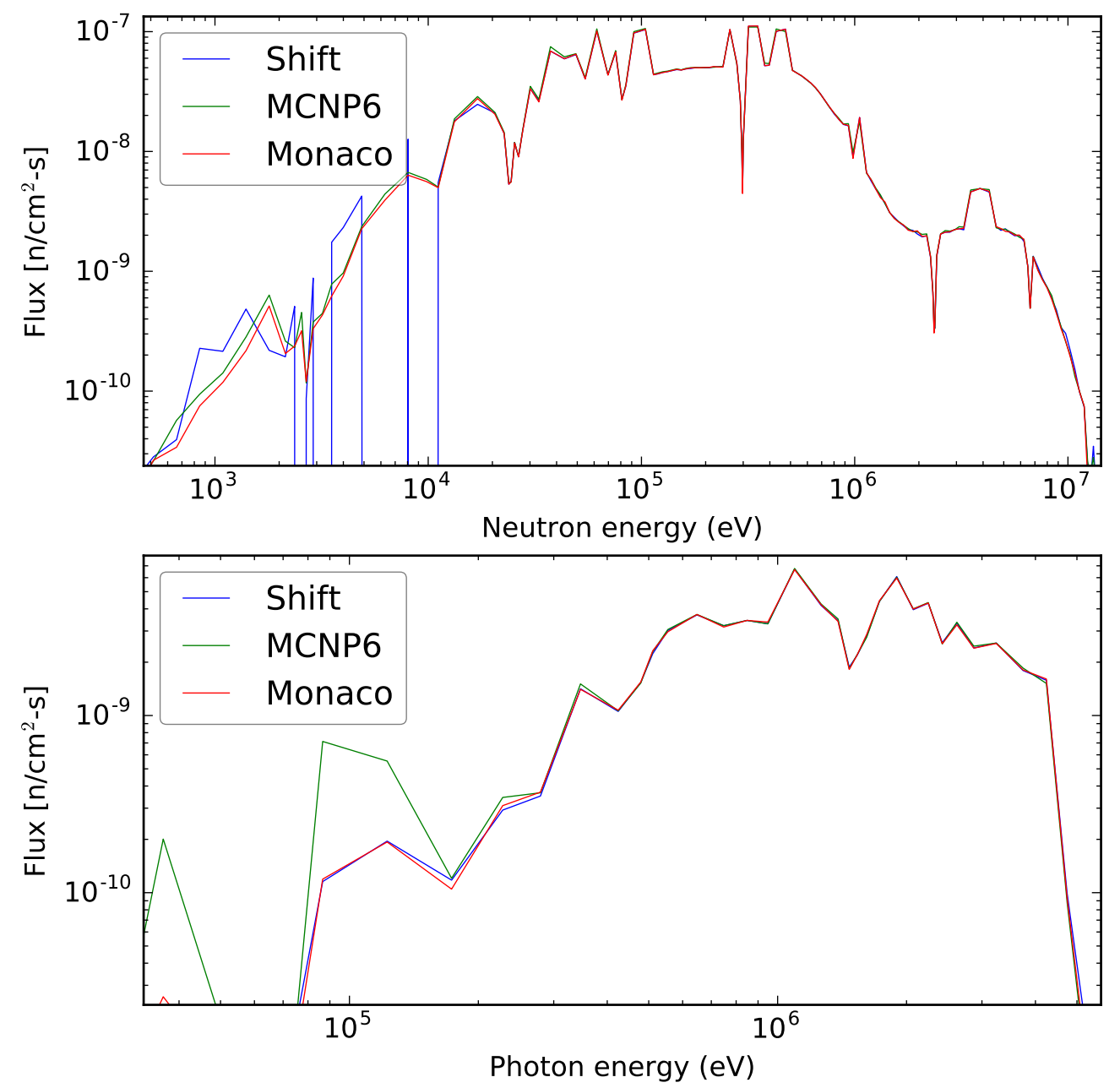

(a) Flux 

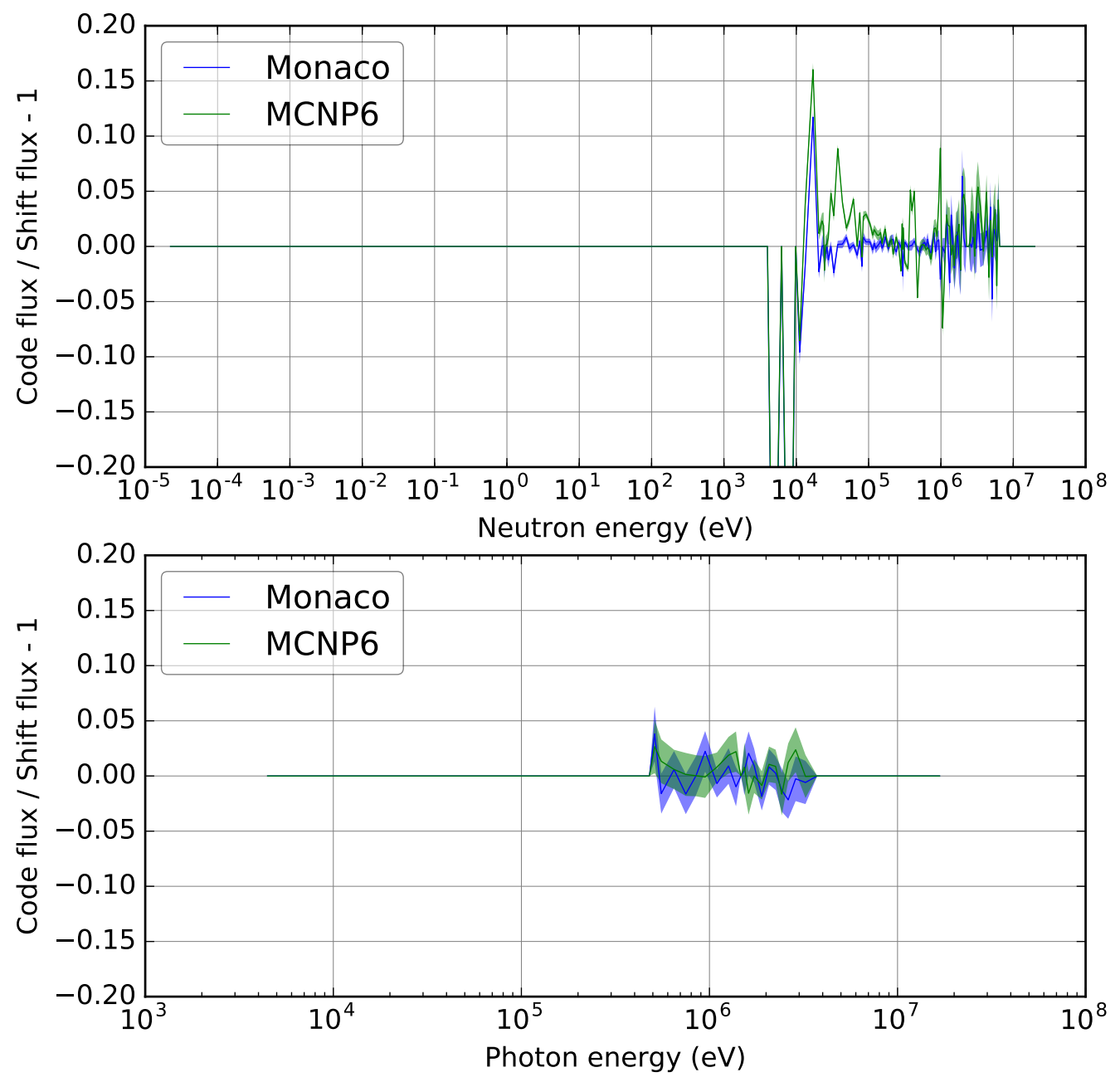

(b) Relative difference in flux

Figure 57. Calculated leakage using MG physics from ${ }^{238} \mathbf{U}$ spherical shell. 

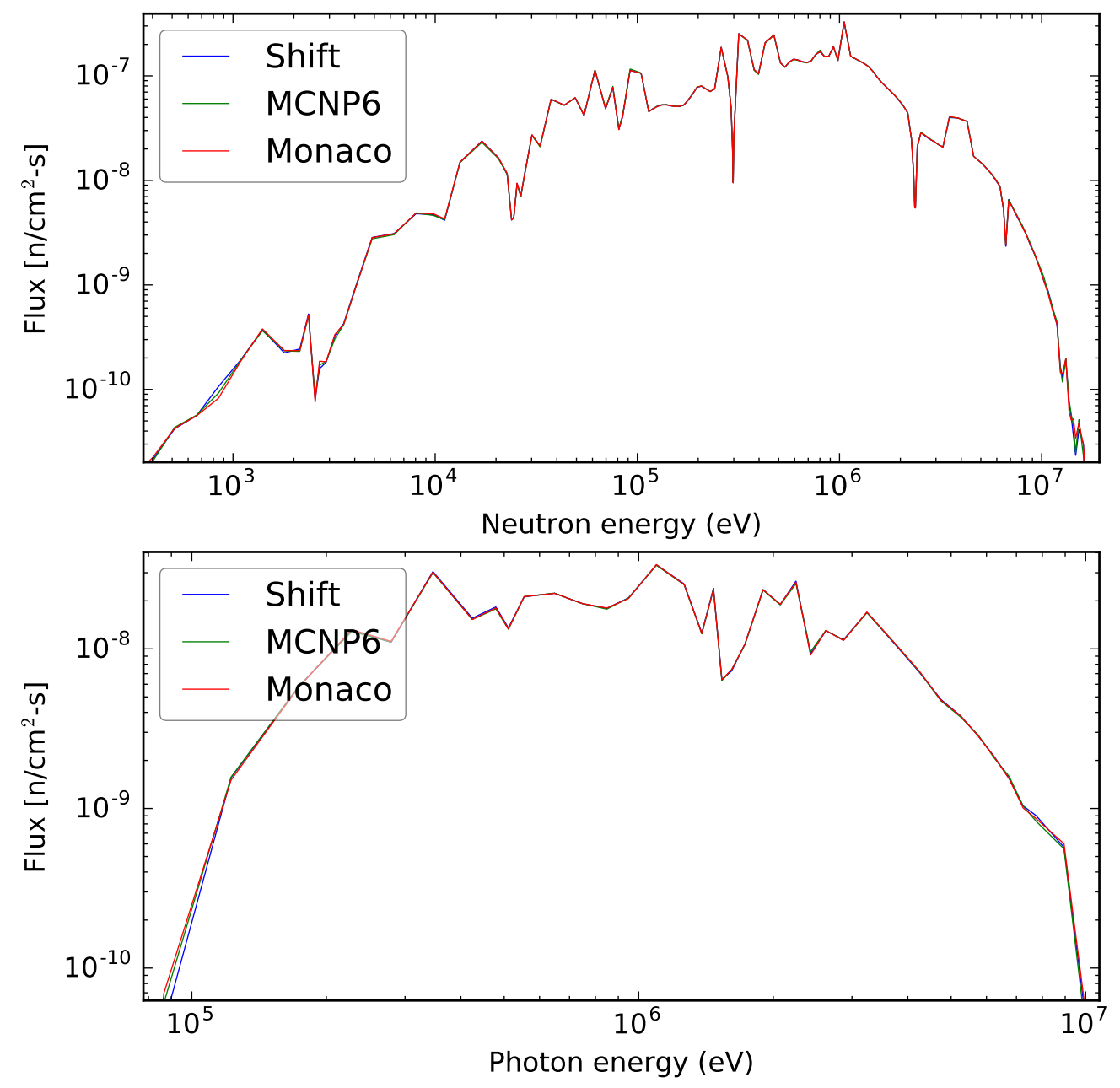

(a) Flux 

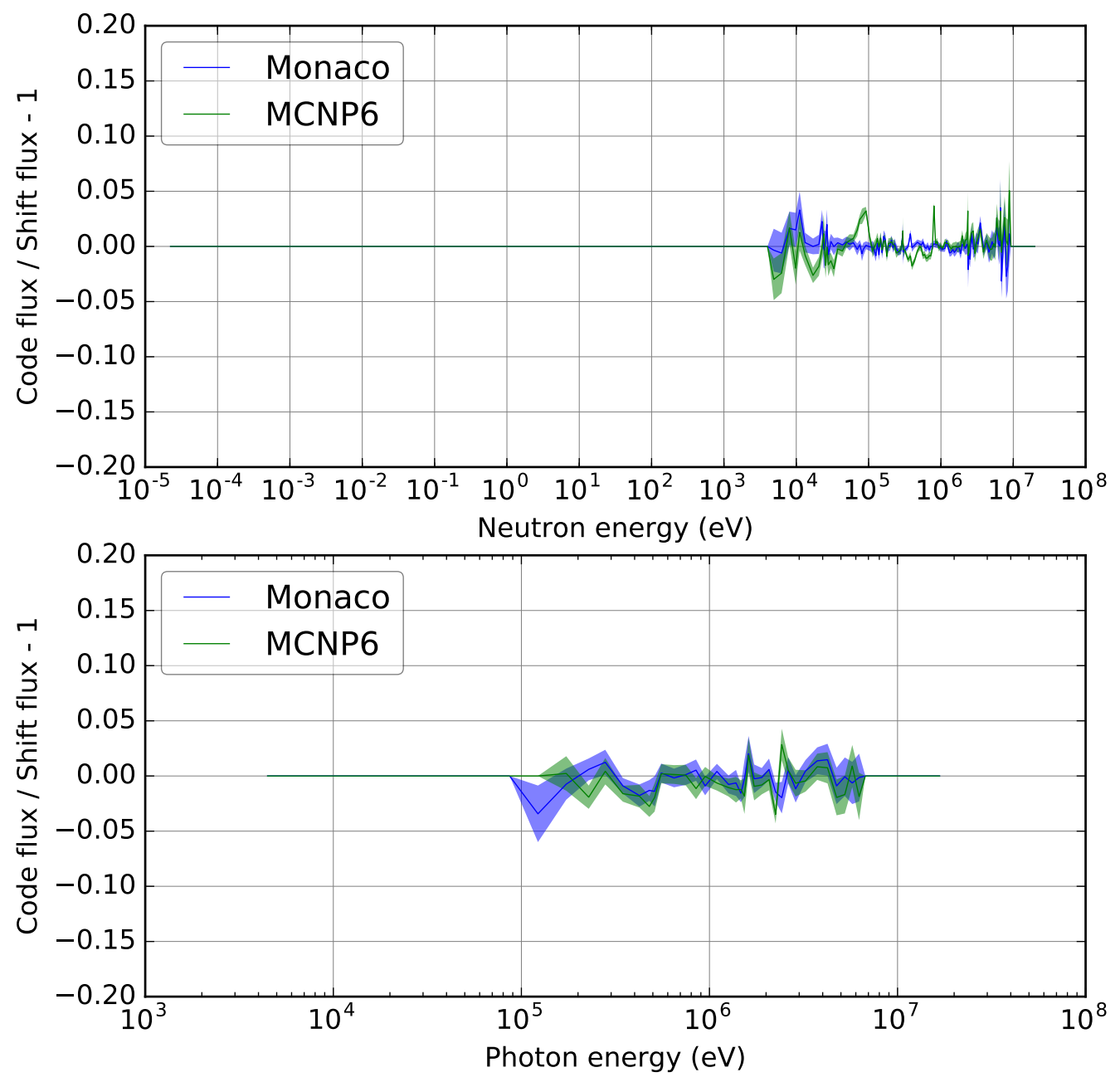

(b) Relative difference in flux

Figure 58. Calculated leakage using CE physics from ${ }^{91} \mathrm{Zr}$ spherical shell. 

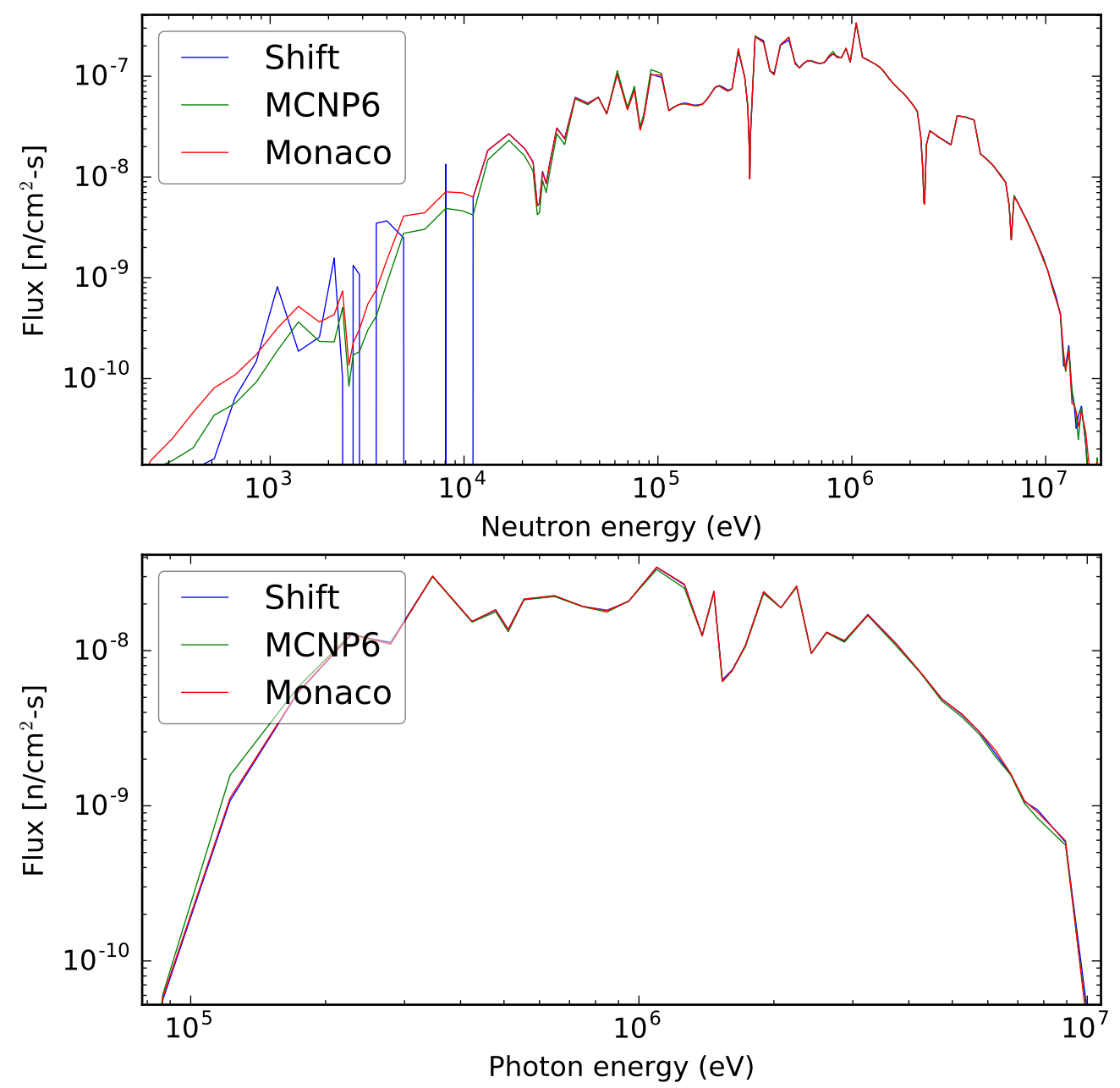

(a) Flux 

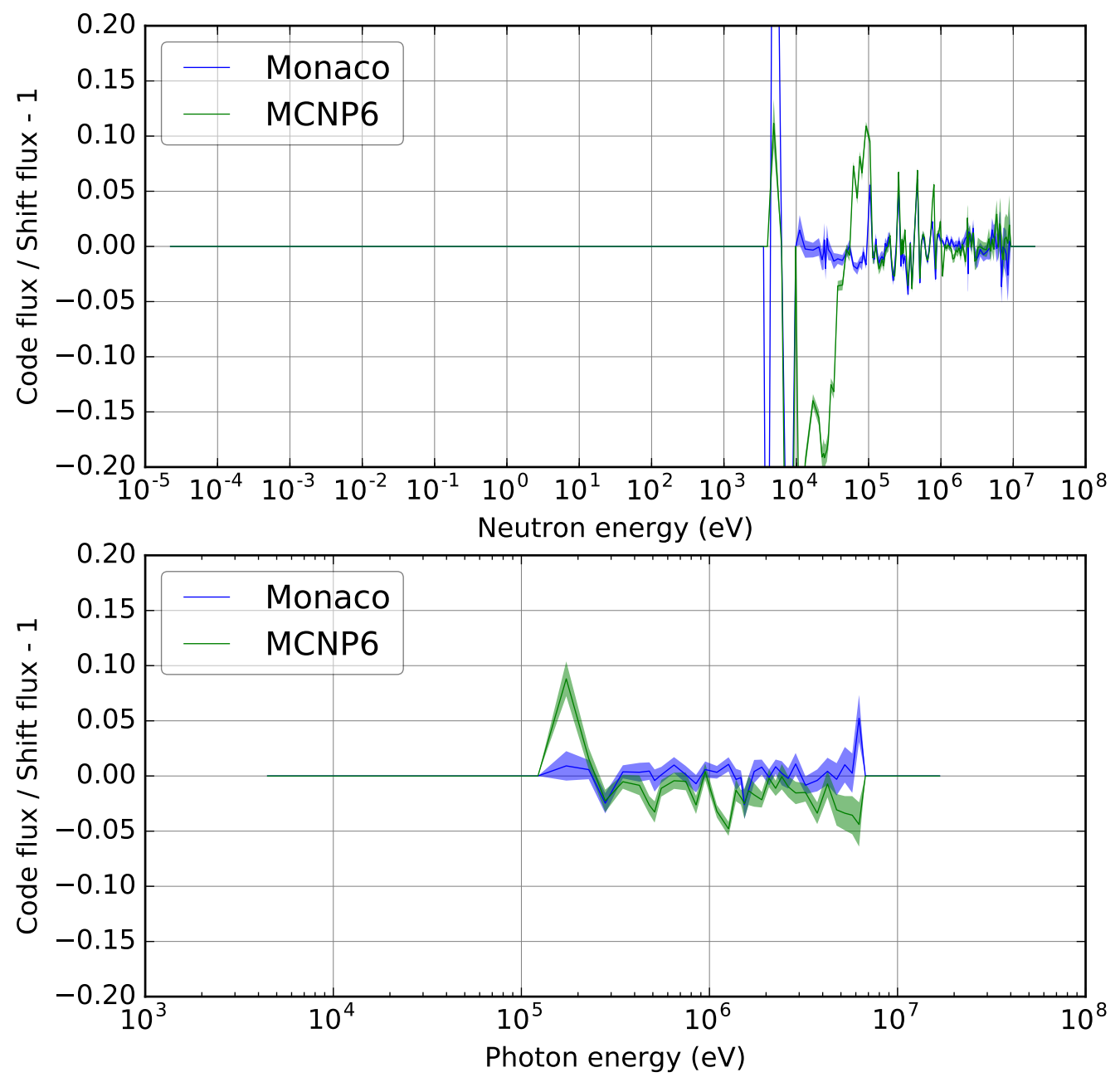

(b) Relative difference in flux

Figure 59. Calculated leakage using MG physics from ${ }^{91} \mathrm{Zr}$ spherical shell. 

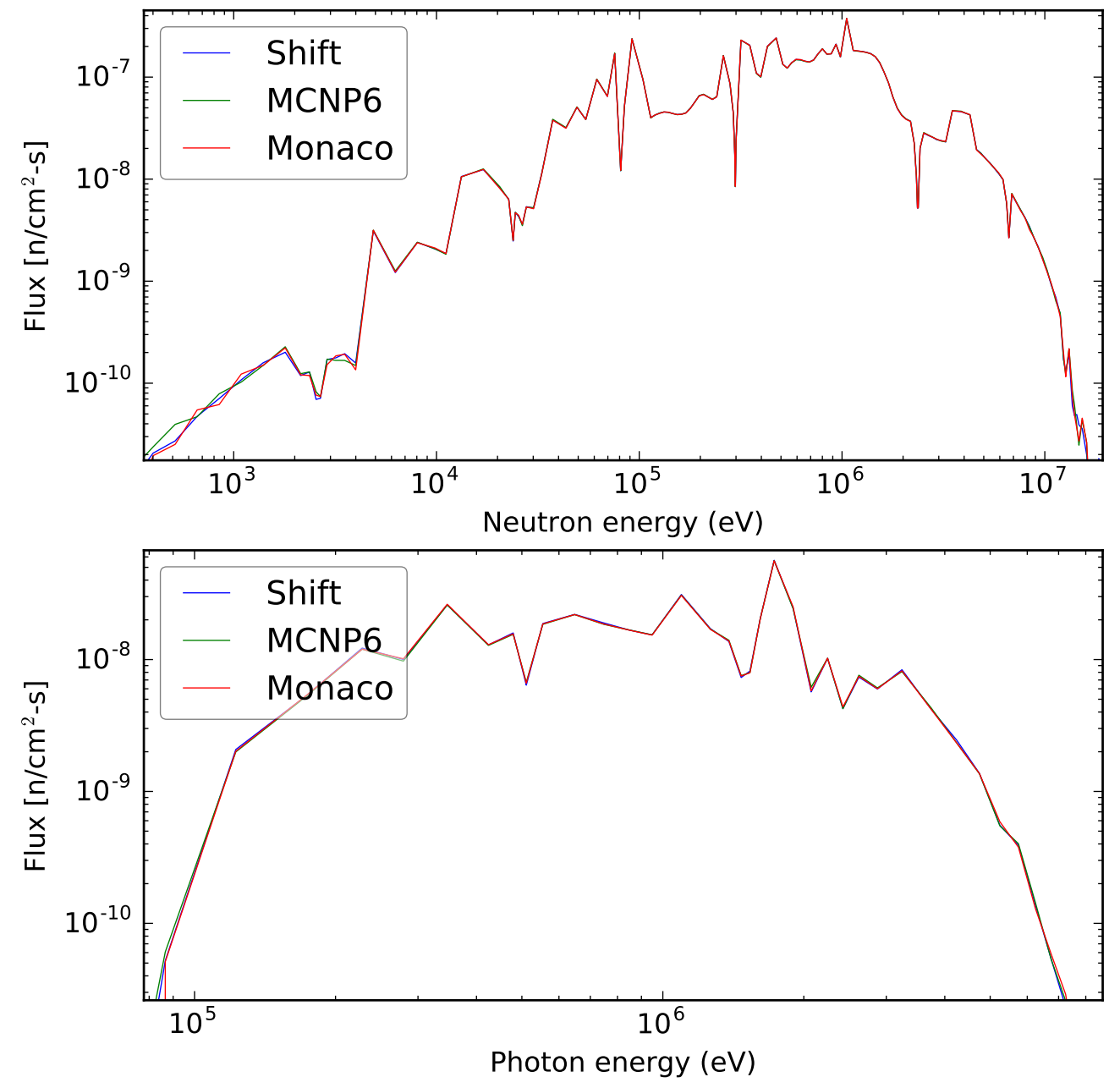

(a) Flux 

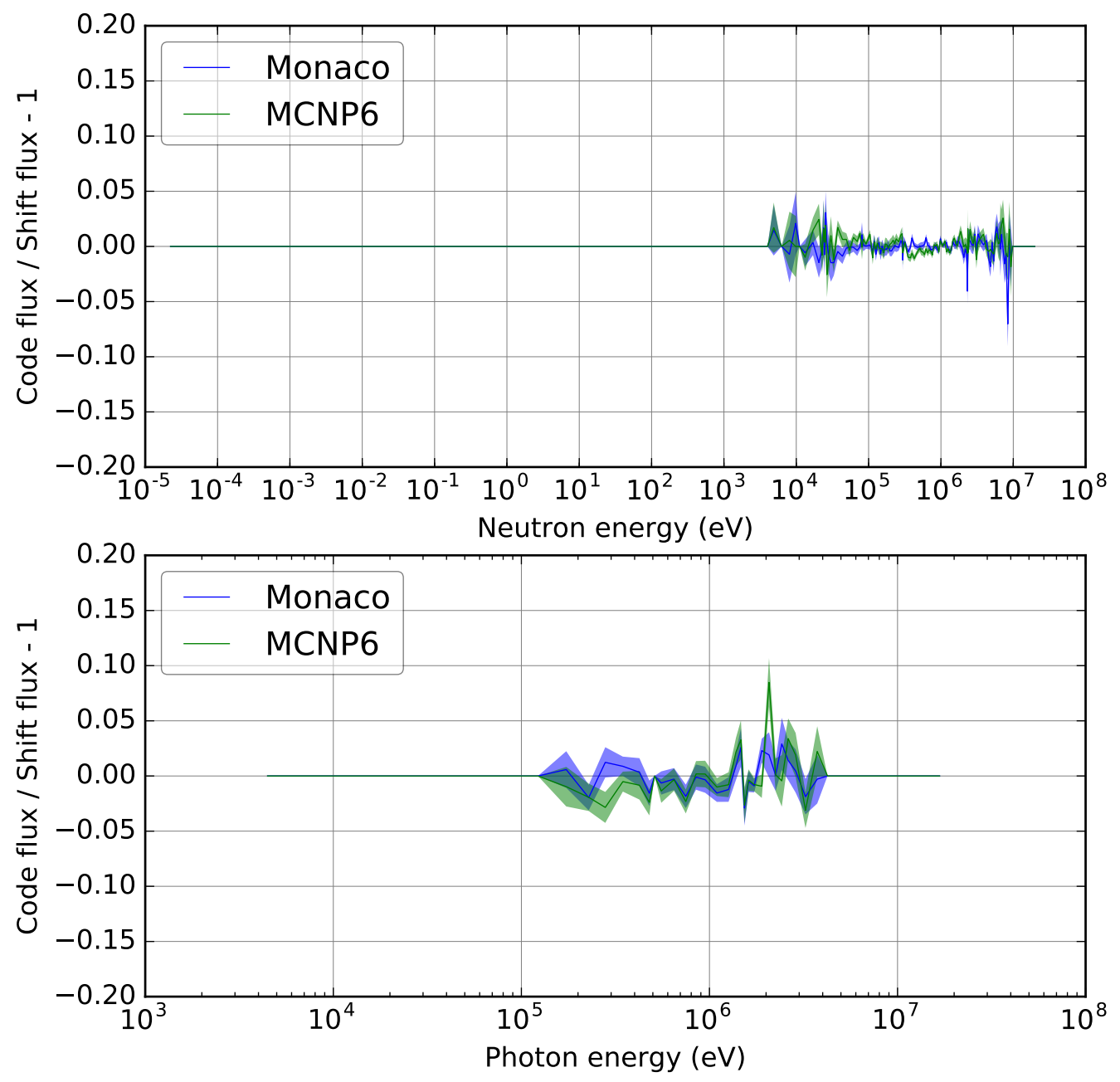

(b) Relative difference in flux

Figure 60. Calculated leakage using CE physics from ${ }^{96} \mathrm{Zr}$ spherical shell. 

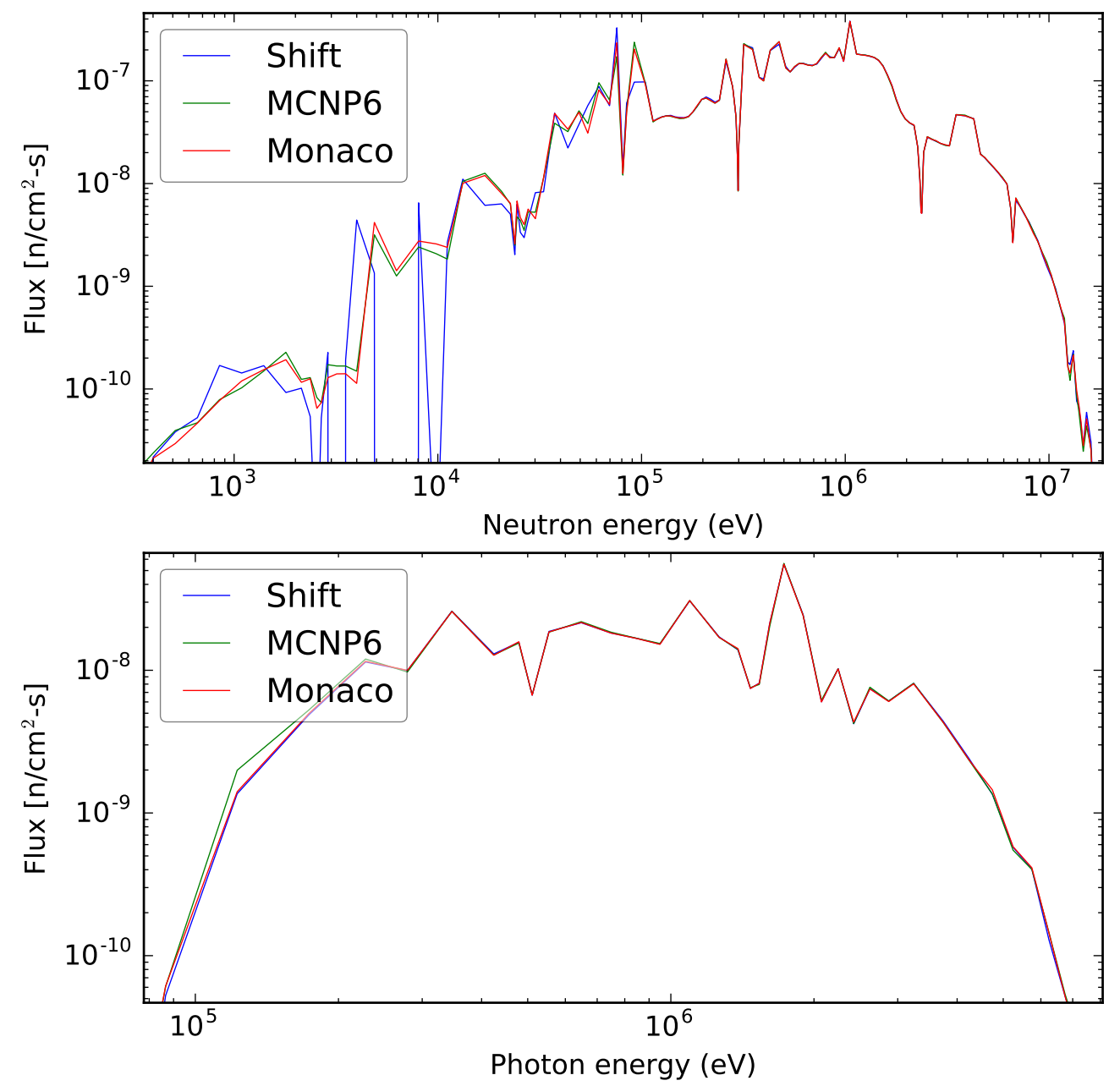

(a) Flux 

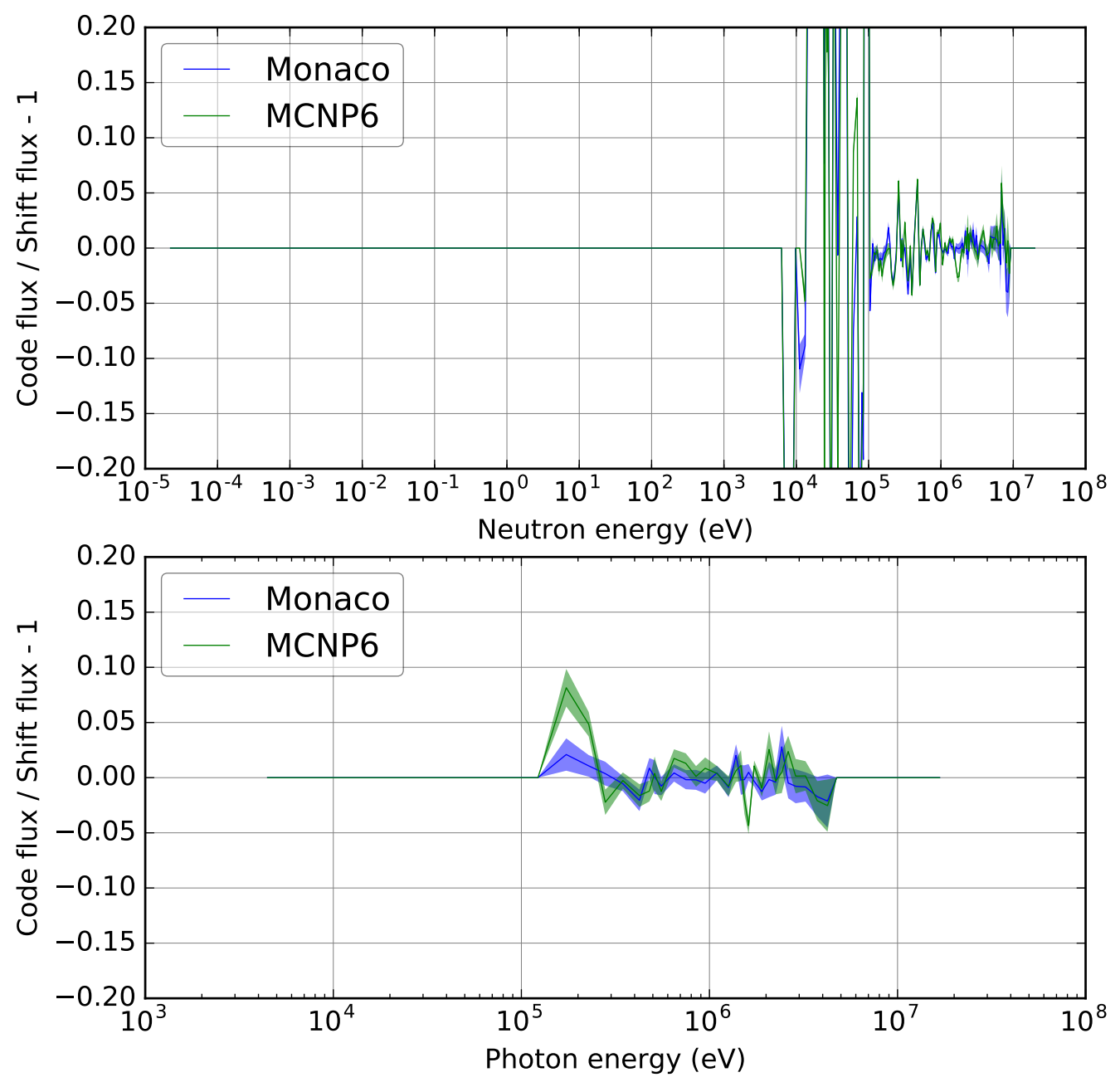

(b) Relative difference in flux

Figure 61. Calculated leakage using MG physics from ${ }^{96} \mathrm{Zr}$ spherical shell. 


\subsection{EXPERIMENTS FROM SINBAD}

Validation of Shift on the two selected Shielding INtegral Benchmark Archive Database (SINBAD) problems is ongoing and will be reported soon. 


\section{DEPLETION BENCHMARKS}

In this section we present the validation of Shift depletion capabilities. Shift uses ORIGEN-6.2 as its burnup package [21]. Details of this coupling can be found in a previously published conference paper (reference [23]). Most of these problems have not been run through Shift as there are still a few features that need to be added to enable Shift to run them properly.

\subsection{CASL DEPLETION VERIFICATION TEST SUITE}

Shift has been run on most of the depletion pincell problems in this CASL test suite. The analysis and validation against other code results is still being performed and will be reported soon.

\subsection{OECD TAKAHAMA-3 17 × 17 PWR POST-IRRADIATION EXPERIMENT (PIE)}

In this section we present the validation of Shift using a modified version of the Takahama-3 $17 \times 17$ post-irradiation experiment (PIE). These results have been previously published in a conference paper; please see [23] for further details.

For the regular fuel rods, we treat the entire fuel region as a single depletion region, whereas we divide the gadolinium rods into 10 equal-volume concentric rings. The results shown here use the Linear Extrapolation/Quadratic Interpolation (LE/QI) transport-depletion coupling method, with no power renormalization during the substeps, because Serpent does not renormalize during each substep. Both codes ran 32 depletion steps, to a total burn time of 1600 days, a burnup of $61,760 \mathrm{MWd} / \mathrm{MT}$, and at a power of $38.6 \mathrm{~W} / \mathrm{g}$ of initial heavy metal. The burnup lengths and number of depletion steps for each length are given in Table 11.

Figure 62 shows the difference in the calculated $k_{\text {eff }}$ between Shift and Serpent for this problem. As shown, this difference is less than $100 \mathrm{pcm}$ throughout the cycle. Figure 63 shows the relative difference in lattice-averaged number density between Shift and Serpent versus burnup for several select actinides. We see that, except for very short burnup times, most of these nuclide inventories are within $1 \%$, except for ${ }^{235} \mathrm{U}$ at high burnup. However, in Figure $64 \mathrm{a}$, we see that by the end of the burn, about $90 \%$ of the mass of the ${ }^{235} \mathrm{U}$ is depleted, and in Figure $64 \mathrm{~b}$ we see that the difference in the depletion percentage between Shift and Serpent is very small. Therefore, the increase in the relative difference in ${ }^{235} \mathrm{U}$ between Shift and Serpent is due to the low amount of uranium left in the problem by the end of the simulation.

Finally, Figure 65 shows the relative difference in lattice-averaged concentrations between Shift and Serpent for several select light nuclides. We see that Shift and Serpent agree within $1 \%$ for all burnups, except near the start of the problem when the concentrations of those nuclides are very low. Overall, we see very good agreement between Shift and Serpent for this depletion problem. 
Table 11. Takahama-3 PIE burnup lengths and number of depletion steps per burnup length.

\begin{tabular}{rrr}
\hline $\begin{array}{r}\text { Burnup length } \\
(\mathrm{MWd} / \mathrm{MT})\end{array}$ & $\begin{array}{r}\text { Number of depletion } \\
\text { steps }\end{array}$ & $\begin{array}{r}\text { Length of each step } \\
(\mathrm{MWd} / \mathrm{MT})\end{array}$ \\
\hline 38.6 & 1 & 38.6 \\
77.2 & 1 & 77.2 \\
154.4 & 1 & 154.4 \\
270.2 & 1 & 270.2 \\
540.4 & 1 & 540.4 \\
13896 & 15 & 926.4 \\
1524.7 & 1 & 1524.7 \\
2084.4 & 1 & 2084.4 \\
2875.7 & 1 & 2875.7 \\
3242.4 & 1 & 3242.4 \\
37056.0 & 8 & 4632.0 \\
\hline
\end{tabular}

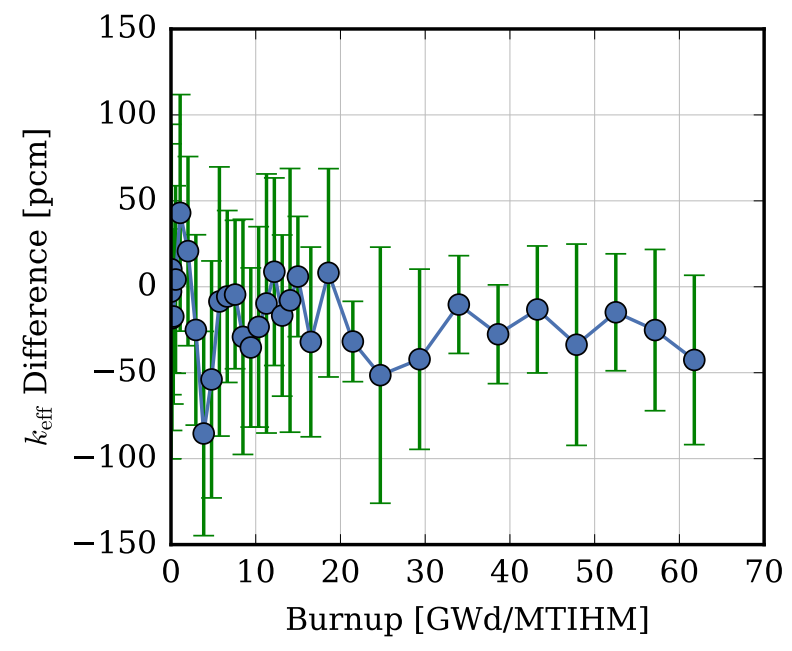

Figure 62. Takahama-3 PIE $k_{\text {eff }}$ comparison. 


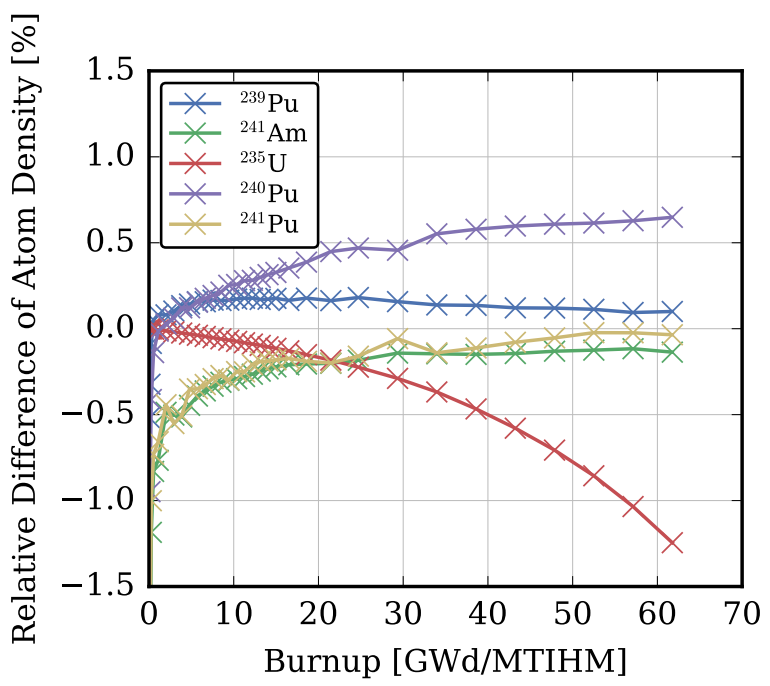

Figure 63. Takahama-3 PIE relative percent difference in latticeaveraged atom density for select actinides.

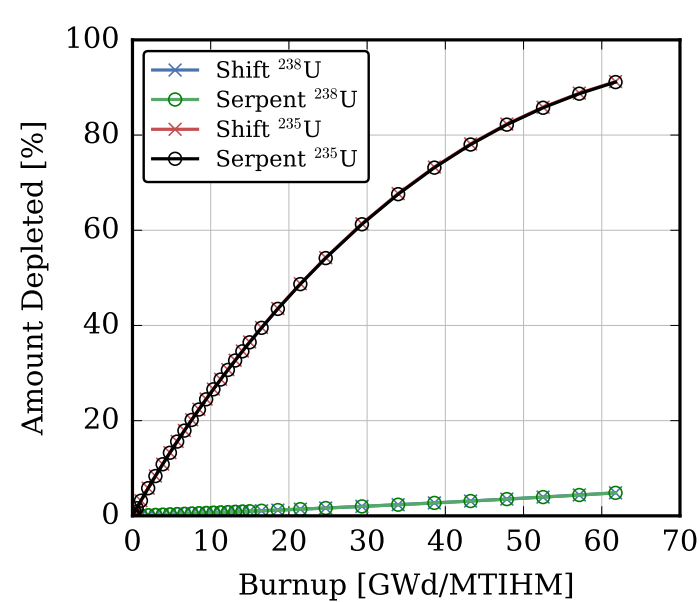

(a) Percentage of ${ }^{235} U$ and ${ }^{238} U$ depleted

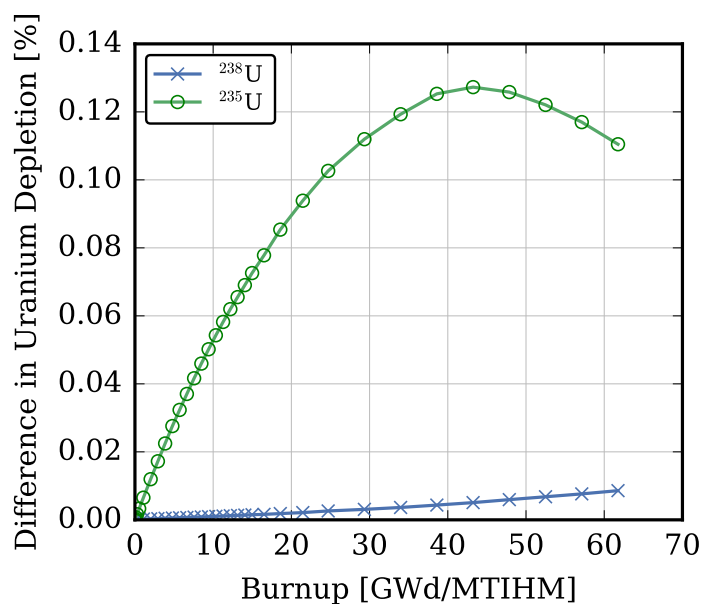

(b) Difference (Shift-Serpent) in ${ }^{235} U$ and ${ }^{238} U$ depletion

Figure 64. Takahama-3 PIE uranium depletion comparison. 


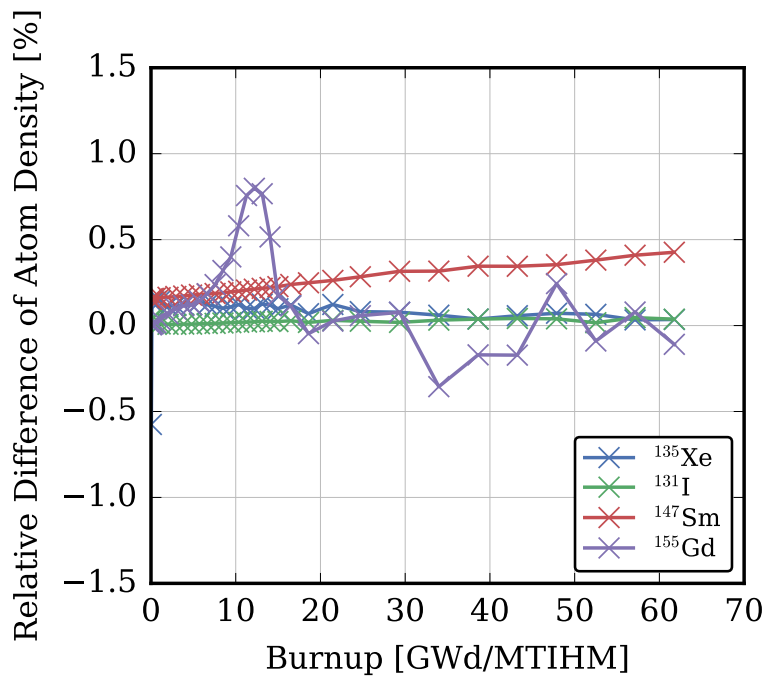

Figure 65. Takahama-3 PIE relative percent difference in latticeaveraged atom density for select fission products.

\subsection{ORNL HIGH FLUX ISOTOPE REACTOR (HFIR) CYCLE 400}

In this section we present a validation of Shift as applied to the HFIR Cycle 400 [24]. Shift results are compared to VESTA results because VESTA is the accepted analysis code for HFIR design work [25]. These results have been previously published in a conference paper; please see [23] for more details.

First, we present results for a homogenized model of HFIR, which homogenizes the fuel region of the core. Shift and VESTA both simulated the full cycle 400. The control element positions were set to the critical positions predicted by VESTA based on a $200 \mathrm{pcm}$ reactivity swing for each day of the cycle. Figure 66 shows the calculated $k_{\text {eff }}$ comparison between Shift and VESTA. As shown, we see very good agreement between Shift and VESTA in the prediction of $k_{\text {eff }}$ for this model for the full cycle and good agreement in the prediction of the operating critical condition. Figures 67 and 68 show the relative difference in total mass of the selected actinides and fission products between Shift and VESTA using the homogeneous HFIR cycle 400 model. These masses calculated over the cycle are in very good agreement between these two codes, with most showing less than $1.5 \%$ difference between the two codes. Note that the large difference at low burnup is due to the low concentrations of the nuclides at this early time. The $2 \%$ difference for ${ }^{149} \mathrm{Sm}$ can be attributed to a difference in data between Shift and VESTA. Figure 69 shows the difference in total mass of ${ }^{149} \mathrm{Sm}$ over cycle 400 ; it clearly shows a lower mass predicted by Shift which is most likely due to the difference in yields between Shift and VESTA.

Second, we present results for the detailed model of HFIR run through Shift and VESTA for the full cycle 400. The control element positions were again set to the critical positions predicted by VESTA based on a 200 pcm reactivity swing for each day of the cycle. Figure 70 shows the calculated $k_{\text {eff }}$ comparison between Shift and VESTA for the detailed HFIR cycle 400 simulation. Again, for this detailed model we see very good agreement between Shift and VESTA in the 


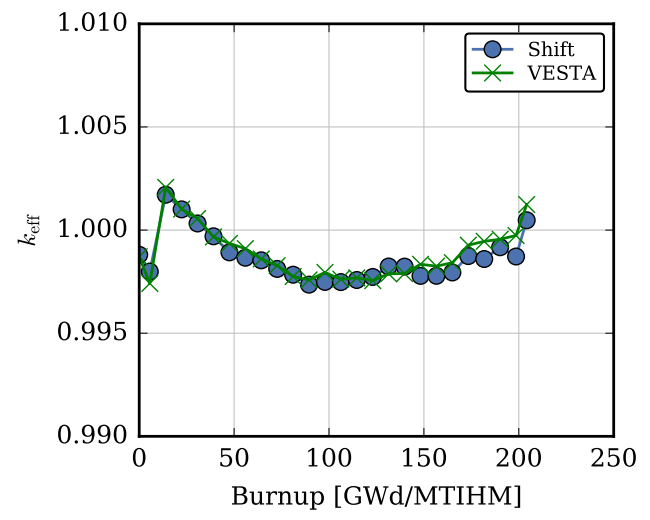

(a) $k_{\text {eff }}$

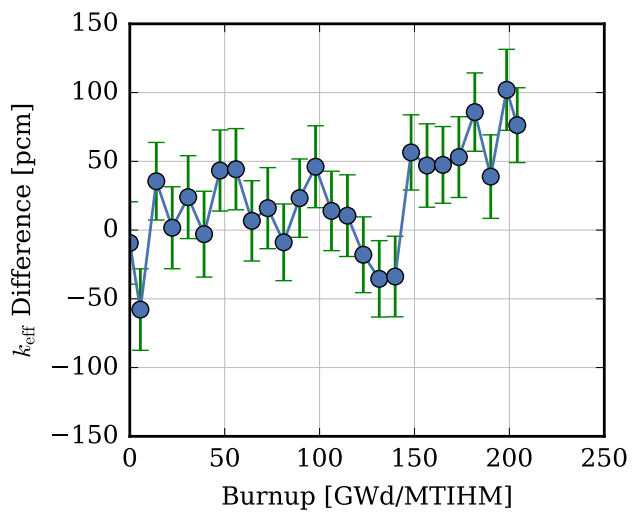

(b) Difference

Figure 66. Homogenized HFIR cycle $400 k_{\text {eff }}$ comparison.

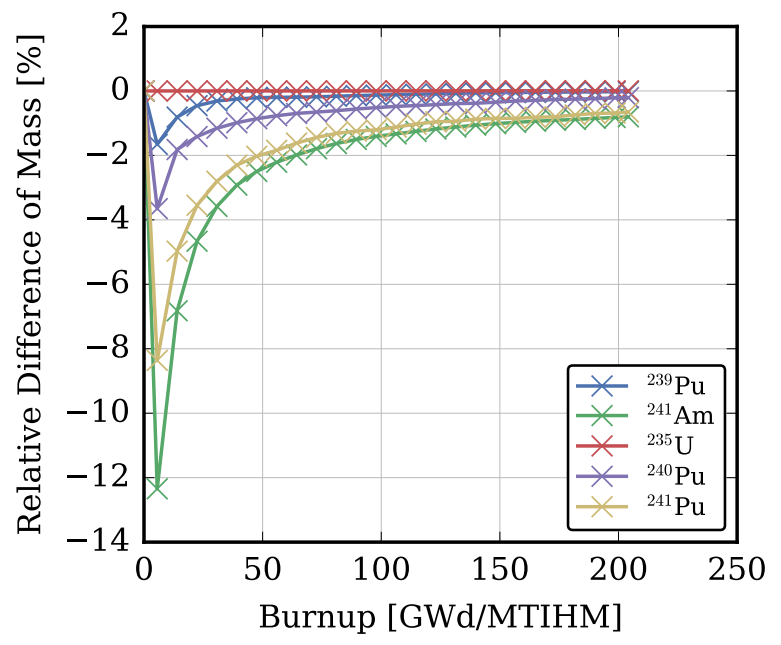

Figure 67. Homogenized HFIR cycle 400 actinide mass comparison. 


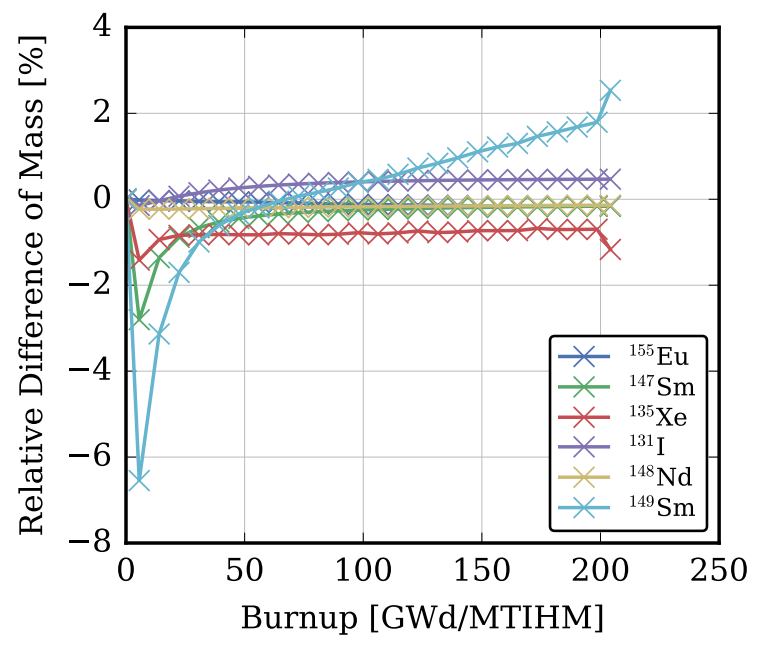

Figure 68. Homogenized HFIR cycle 400 fission product mass comparison.

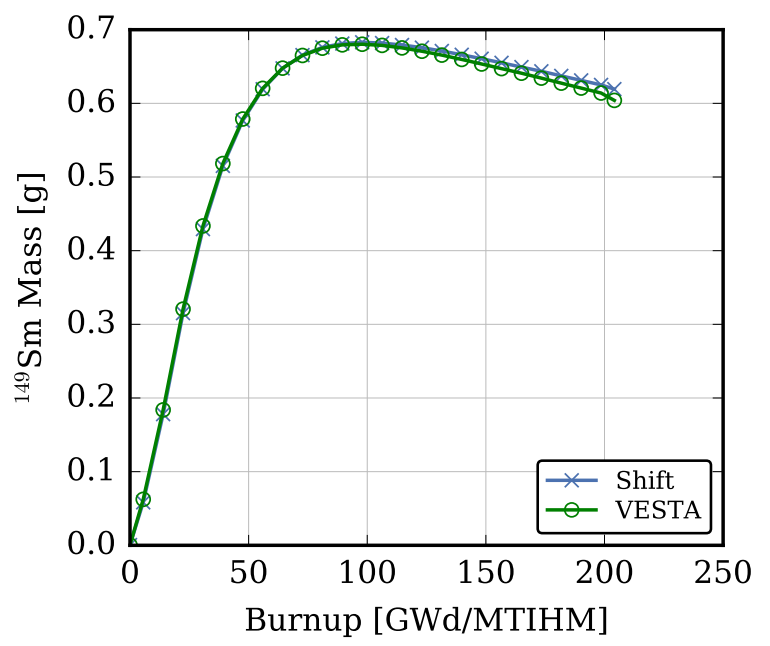

Figure 69. Homogenized HFIR cycle $400{ }^{149} \mathrm{Sm}$ mass comparison. 


\section{Shift Verification and Validation}

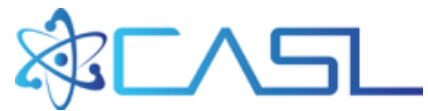

prediction of $k_{\text {eff }}$ for the full cycle and prediction of the operating critical condition. Figures 71 and 72 show the relative difference in total mass of selected actinides and fission products between Shift and VESTA using the detailed HFIR cycle 400 model. Again, these calculated masses over the cycle are in very good agreement between these two codes for this model, with all showing less than $2 \%$ difference between codes. As with the homogeneous model, the larger mass difference over the cycle for ${ }^{149} \mathrm{Sm}$ is due to data differences between Shift and VESTA; a comparison of these masses using the detailed model is shown in Figure 73.

Overall, we have validated Shift against accepted results for the HFIR cycle 400.

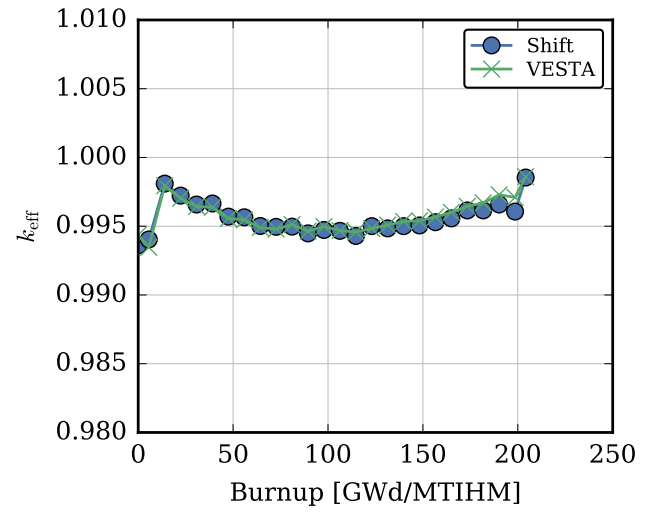

(a) $k_{\text {eff }}$

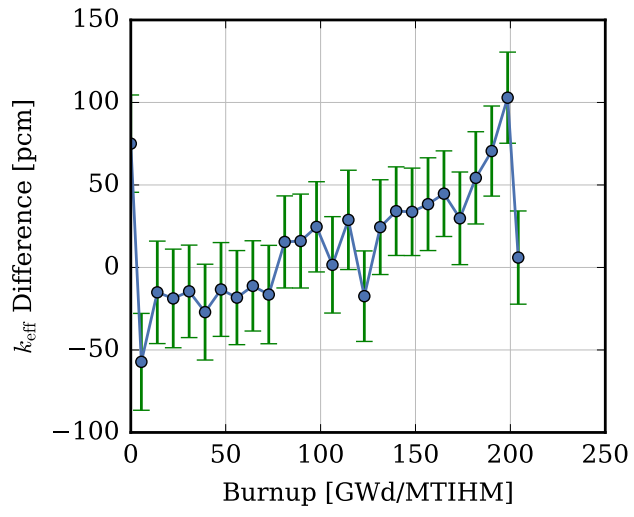

(b) Difference

Figure 70. Detailed HFIR cycle $400 k_{\text {eff }}$ comparison.

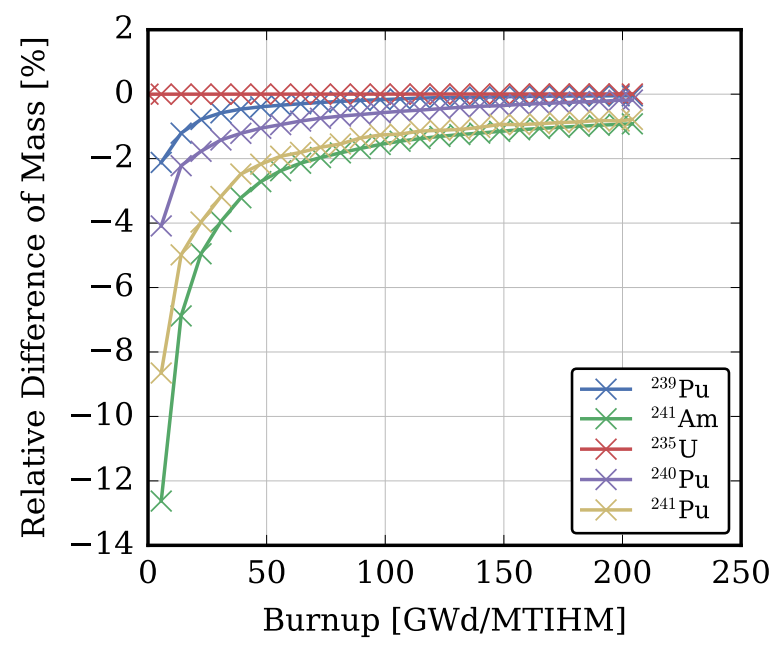

Figure 71. Detailed HFIR cycle 400 actinide mass comparison. 


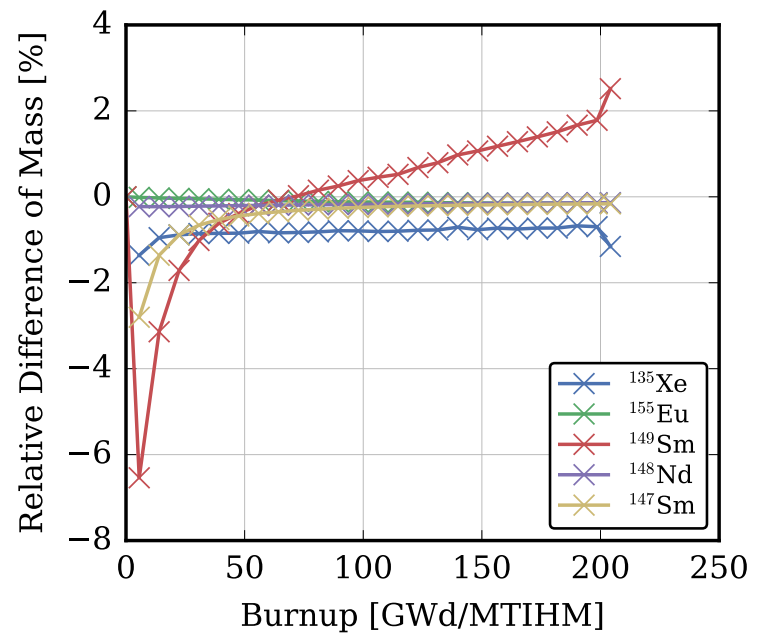

Figure 72. Detailed HFIR cycle 400 fission product mass comparison.

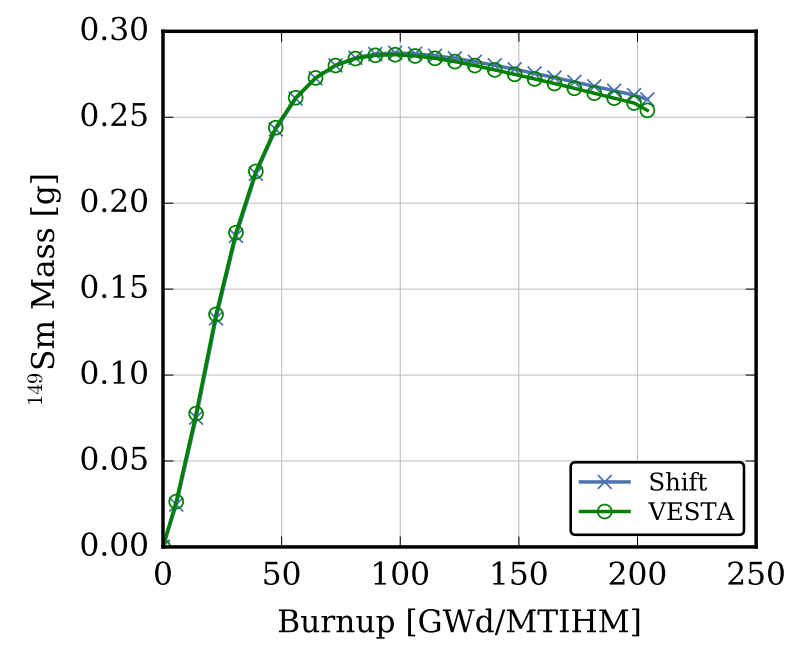

Figure 73. Detailed HFIR cycle $400{ }^{149}$ Sm mass comparison. 


\subsection{BEAVRS}

The full BEAVRS cycle 1 and cycle 2 will be run with Shift in the near future, and validation against the benchmark data for power history, boron letdown curves, control rod bank worths, and fission reaction rates for each cycle will be reported.

\subsection{WATTS BAR UNIT 1 CYCLE 1}

Shift results for WBN1 cycle 1 will be produced soon and will be included in this report with validation against the measured data.

\subsection{WESTINGHOUSE AP1000 ${ }^{\circledR}$ FIRST CORE AT HOT FULL POWER}

The set of seven representative lattice problems for the different regions in the AP $1000^{\circledR}$ core are currently being run with Shift. These results and their validation against Serpent will be reported soon. 


\section{PERFORMANCE BENCHMARKS}

Here we present Shift performance as applied to two reactor benchmarks. These results are taken from a recently published journal article about Shift [1].

\subsection{NEA MC FULL-CORE REACTOR POWER DENSITY PERFORMANCE BENCHMARK}

The full details of the Nuclear Energy Agency MC performance benchmark for detailed power density calculation in a full size reactor core can be found in the original benchmark [26]. For this problem, Shift simulated a total of $1 \times 10^{9}$ particles histories per generation for a total of $1 \times 10^{3}$ generations, with the number of inactive generations set to 300 to ensure fission source convergence.

A single run of this problem using Shift on Titan [14] tallied power across the reactor core with approximately $1.13 \times 10^{7}$ mesh cells which included the power densities requested by the benchmark. This run used $1 \times 10^{5}$ processors split across 12,500 nodes (using 8 processors per node) and ran for a total walltime of 3.43 hours. Shift calculated power densities with less than $1 \%$ relative error in $98 \%$ of all mesh cells tallied, with all power densities having less than $3 \%$ relative error. This timing compares very well to results reported for this benchmark from other codes and machines.

Aside from this timing, a strong scaling study of this benchmark using Shift was performed on Titan. This study used full domain replication of the problem geometry with a fixed number of particle histories per generation of $1 \times 10^{7}$. Figure 74 shows the excellent scaling that Shift attains for this benchmark along with the solve times for the transport solve of these runs. An efficiency of $91 \%$ to $100 \%$ is achieved. The number of particle histories per generation per processor reaches a minimum of approximately 300 for this study; therefore a slight degradation in parallel efficiency due to more dominant communication costs is seen in Figure 74.

These results have shown that Shift achieves excellent scaling on leadership-class machines for a full reactor simulation, and can achieve answers with minimal statistical uncertainty in a short timeframe.

\subsection{WESTINGHOUSE AP1000 ${ }^{\circledR}$ PWR STARTUP}

We also performed a strong scaling of Shift on Titan using problem 1 of the AP1000 ${ }^{\circledR}$ PWR Startup problem discussed in \$3.1. Again, this study used full domain replication of the problem geometry with a fixed number of particle histories per generation of $5 \times 10^{8}$. Figure 75 shows the excellent parallel efficiency Shift attains on Titan, from $97 \%$ to $100 \%$ up to hundreds of thousands of cores. For comparison, the solve times for these runs are also shown in Figure 75. This problems achieves better parallel efficiency than the previous because there is more work to do per processor (more particle histories per generation). 
Overall, these two performance studies have shown that Shift can achieve excellent scaling for full-reactor calculation on a leadership-class high performance computing (HPC) machine such as Titan. 


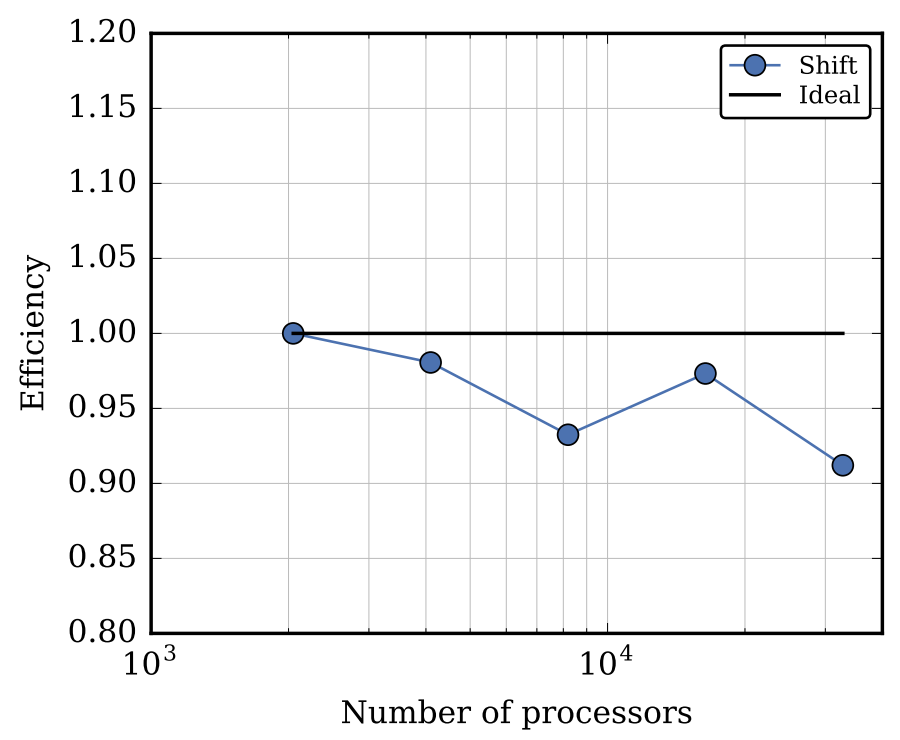

(a) Efficiency

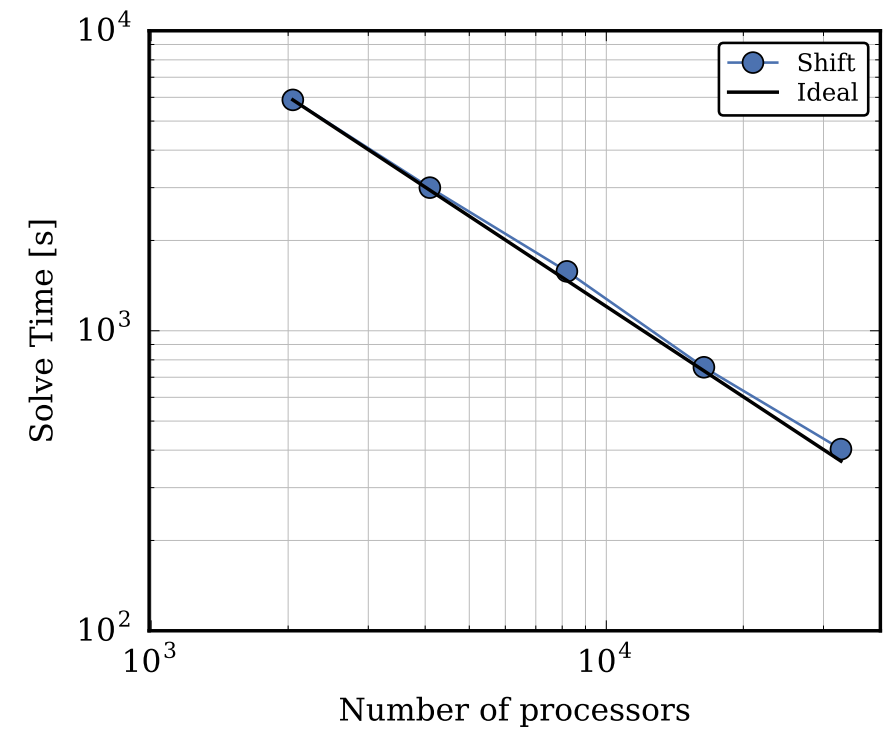

(b) Solve Time

Figure 74. Shift strong scaling results for the NEA MC performance benchmark for reactor calculations run on Titan. 


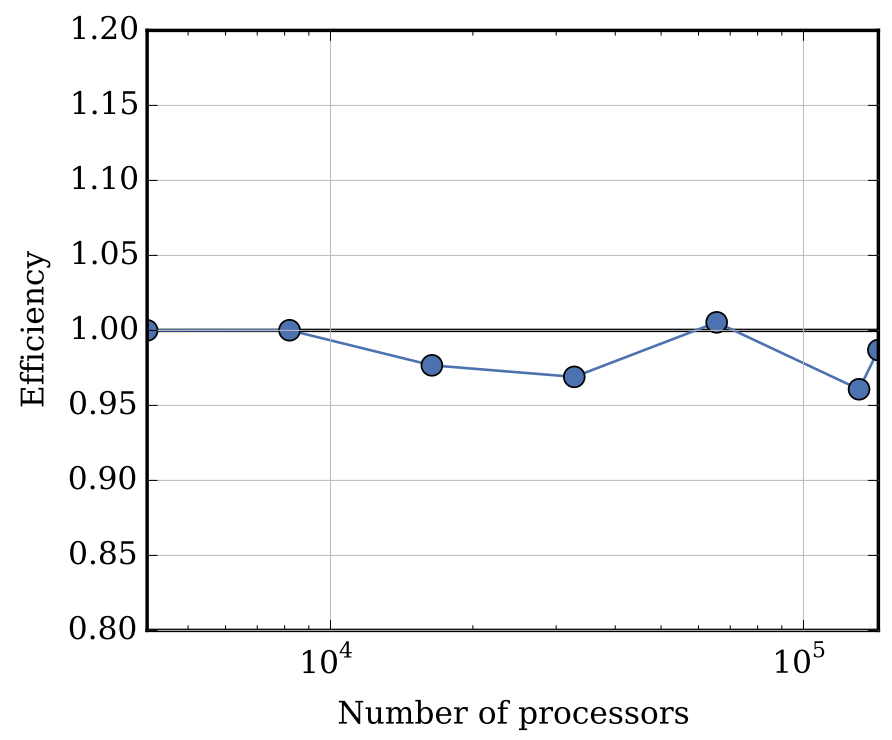

(a) Efficiency

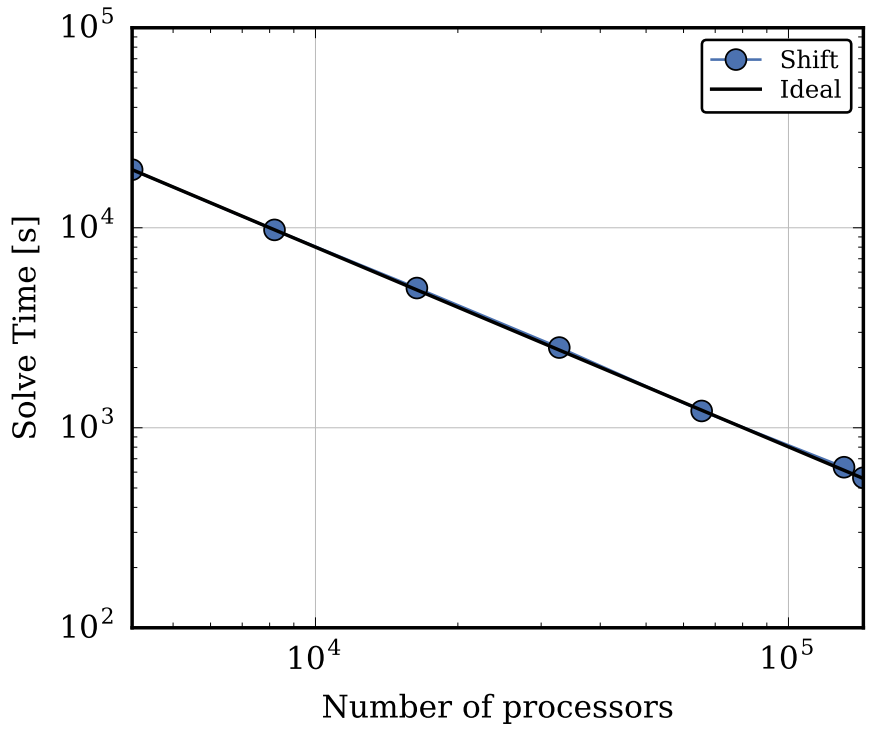

(b) Solve Time

Figure 75. Shift strong scaling results for AP1000 ${ }^{\circledR}$ problem 1 run on Titan. 


\section{SUMMARY}

We verified and validated Shift as applied to a variety of problems of interest to CASL; these were broken down into small criticality problems, full-core reactor benchmarks for light water reactors, fixed source coupled neutron-photon dosimetry benchmarks, depletion/burnup benchmarks, and full-core reactor performance benchmarks. As part of this thorough V\&V, we compared Shift results for quantities of interest such as the critical eigenvalue, radial and axial pin power distributions, rod worth, leakage spectra, and nuclide inventories over a burn cycle. Shift simulated results were compared against measured values, report benchmark values, as well as other Monte Carlo radiation transport code simulation results.

For all of the problems simulated, results showed very good agreement between Shift calculated values and measured values as well as other simulated code results. We found Shift can predict the reactivity of a critical system to within approximately $200 \mathrm{pcm}$ if the model accurately represents reality, power distributions to within $8 \%$, and nuclide inventories to within $2 \%$ for selected nuclides. We also showed that Shift attains parallel efficiencies from $95 \%$ to $100 \%$ up to using the full Titan machine at ORNL. Details of these comparisons can be found in the respective sections of this report.

There are several minor issues still under investigation that are most likely due to the modeling inconsistencies compared to benchmarks. In future versions of this report we plan to include the results of the validation problems currently in progress. Overall, the results of this validation have given us confidence in utilizing Shift to provide reference results for CASL benchmarking.

\section{REFERENCES}

[1] Tara M. Pandya, Seth R. Johnson, Thomas M. Evans, Gregory G. Davidson, Steven P. Hamilton, and Andrew T. Godfrey. Implementation, capabilities, and benchmarking of Shift, a massively parallel Monte Carlo radiation transport code. Journal of Computational Physics, 308:239-272, 2016.

[2] Tara M. Pandya, Seth R. Johnson, Thomas M. Evans, Gregory G. Davidson, and Steven P. Hamilton. A Massively Parallel Monte Carlo Radiation Transport Package. In Joint International Conference on Mathematics an Computation, Supercomputing in Nuclear Applications and the Monte Carlo Method, April 2015.

[3] Tara M. Pandya, Gregory G. Davidson, Thomas M. Evans, and Seth R. Johnson. Shift validation plan for CASL. Technical report, Oak Ridge National Laboratory, April 2016.

[4] R. Montgomery. VERA tools and workflows. Technical Report CASL-U-2014-0054-001, Oak Ridge National Laboratory, March 2014.

[5] M. N. Baldwin, G. S. Hoovler, R. L. Eng, and F. G. Welfare. Critical Experiments Supporting Close Proximity Water Storage of Power Reactor Fuel. Technical Report BAW-1484-7, Babcock and Wilcox Co., Lynchburg, VA, 1979. 
[6] L. W. Newman, W. A. Wittkopf, W. G. Pettus, M. N. Baldwin, H. A. Hassan, V. O. Uotinen, J. D. Connell, and P. S. Campbell. Urania-Gadolinia: Nuclear Model Development and Critical Experiment Benchmark. Technical Report DOE/ET/34212-41 BAW-1810, Babcock and Wilcox Co., Lynchburg, VA, April 1984.

[7] W. J. Marshall and B. T. Rearden. Criticality Safety Validation of Scale 6.1. Technical Report ORNL/TM-2011/450, ORNL, November 2011.

[8] Andrew T. Godfrey. VERA-CS Validation Plan. Technical Report CASL-U-2014-0185-000, Oak Ridge National Laboratory, October 2014.

[9] Benchmark on Deterministic Transport Calculations Without Spatial Homogenisation: A 2-D/3-D MOX Fuel Assembly Benchmark. Technical Report NEA/NSC/DOC(2003)16, OECD/NEA, 2003.

[10] Benchmark on Deterministic Transport Calculations Without Spatial Homogenisation: MOX Fuel Assembly 3-D Extension Case. Technical Report NEA/NSC/DOC(2005)16, OECD/NEA, 2005.

[11] F. Franceschini, A. T. Godfrey, and J. C. Gehin. AP1000® PWR Reactor Physics Analysis with VERA-CS and KENO-VI - Part I: Zero Power Physics Tests. In PHYSOR 2014. American Nuclear Society, September 28 - October 32014.

[12] A. T. Godfrey, F. Franceschini, and J. C. Gehin. AP1000® PWR Reactor Physics Analysis with VERA-CS and KENO-VI - Part II: Power Distribution. In PHYSOR 2014. American Nuclear Society, September 28 - October 32014.

[13] Fausto Franceschini, Andrew T. Godfrey, Joel Kulesza, and Robert Oelrich. Westinghouse VERA Test Stand: Zero Power Physics Test Simulations for the AP1000 PWR. Technical Report CASL-U-2014-0012-000, CASL, March 2014.

[14] Oak Ridge Leadership Computing Facility. Titan Cray XK7, January 2015.

[15] A. T. Godfrey, J. C. Gehin, K. B. Bekar, and C. Celik. Simulation of Watts Bar Initial Startup Tests with Continuous Energy Monte Carlo Methods. In PHYSOR 2014. American Nuclear Society, September 28 - October 32014.

[16] Jess C. Gehin, Andrew T. Godfrey, Fausto Franceschini, Thomas M. Evans, Ben Collins, and Steven Hamilton. Operational Reactor Model Demonstration with VERA: Watts Bar Unit 1 Cycle 1 Zero Power Physics Tests. Technical Report CASL-U-2013-0105-001, CASL, August 2013.

[17] Andrew T. Godfrey. VERA Core Physics Benchmark Progression Problem Specifications. Technical Report CASL-U-2012-0131-004, CASL, August 2014.

[18] Andrew T. Godfrey, Matthew A. Jessee, Shane Stimpson, Ben Collins, Thomas M. Evans, Marjan Kromar, Fausto Franceschini, and David Salazar. VERA Benchmark Results for KRSKO Nuclear Power Plant Cycle 1. In PHYSOR 2016 International Conference. American Nuclear Society, May 2016. 
[19] Scott Palmtag. MPACT Library Verification by Comparison of Pincell Calculations to Monte Carlo Results. Technical Report CASL-U-2015-0281-000, CASL, July 2015.

[20] J. T. Goorley and et. al. Initial MCNP6 Release Overview - MCNP6 Version 1.0. Technical Report LA-UR-13-22934, LANL, 2013.

[21] B. T. Rearden and M. A. Jessee. SCALE Code System. Technical Report ORNL/TM-2005/39, Version 6.2, Oak Ridge National Laboratory, April 2016.

[22] Cross Sections Evaluation Working Group. ENDF-6 Formats Manual: Data Formats and Procedures for the Evaluated Nuclear Data Files ENDF/B-VI and ENDF/B-VII. Brookhaven National Laboratory, 2 edition, December 2011.

[23] Gregory G. Davidson, Tara M. Pandya, Seth R. Johnson, Thomas M. Evans, William A. Wieselquist, and Aarno E. Isotalo. Nuclide Depletion Capabilities in the Shift Monte Carlo Code. In PHYSOR 2016 International Conference. American Nuclear Society, May 2016.

[24] Germina Ilas, David Chandler, Brian Ade, Eva Sunny, Ben Betzler, and Dan Pinkston. Modeling and Simulations for the High Flux Istotope Reactor Cycle 400. Technical Report ORNL/TM-2015/36, Oak Ridge National Laboratory, March 2015.

[25] VESTA User's Manual - Version 2.1.0. Technical Report DSU/SEC/T/2008-331, IRSN, BP 17, 92262 Fontenay-aux-roses, Cedex, France, 2008.

[26] J.E. Hoogenboom, W.R. Martin, and B. Petrovic. Monte Carlo Performance Benchmark for Detailed Power Density Calculation in a Full Size Reactor Core. Benchmark Specifications Revision 1.2, http://www.nea.fr/dbprog/MonteCarloPerformanceBenchmark.htm, 2011. 